\title{
Ice-Ocean Environmental Buoys (IOEB); Technology and Deployment in 1991-1992
}
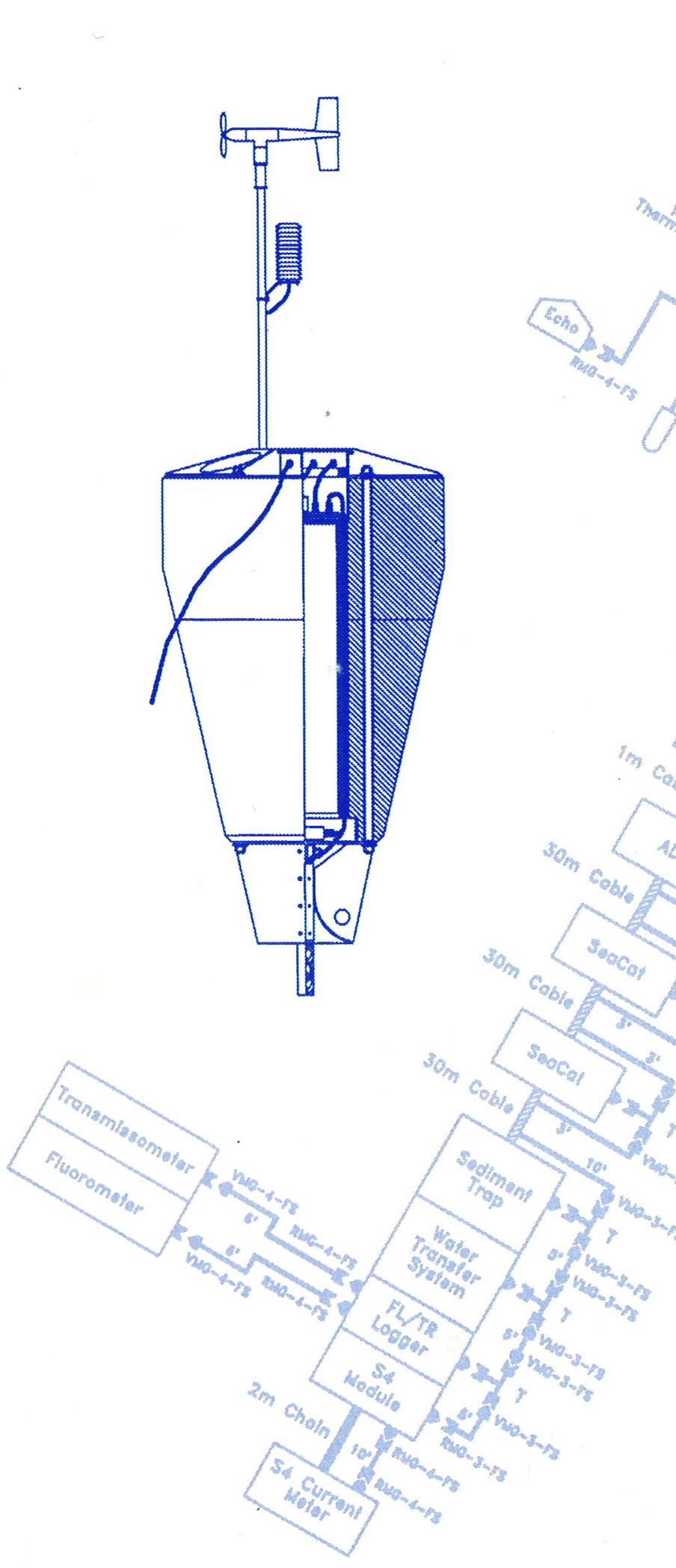

Richard Krishfield Kenneth Doherty Susumu Honjo October 1993 


\title{
WHOI-93-45
}

\section{Ice-Ocean Environmental Buoys (IOEB); \\ Technology and Deployment in $1991-1992$}

by

Richard Krishfield, Kenneth Doherty, Susumu Honjo

\begin{abstract}
Woods Hole Oceanographic Institution
Woods Hole, Massachusetts 02543
\end{abstract}

October 1993

\section{Technical Report}

Funding was provided by the Office of Naval Research, Arlington, Virginia, USA and Japan Marine Science and Technology Center, Yokosuka, Japan

Reproduction in whole or in part is permitted for any purpose of the United States Government. This report should be cited as Woods Hole Oceanog. Inst. Tech. Rept., WHOI-93-45.

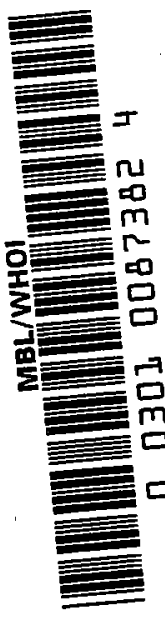

Approved for public release; distribution unlimited.

Approved for Distribution:

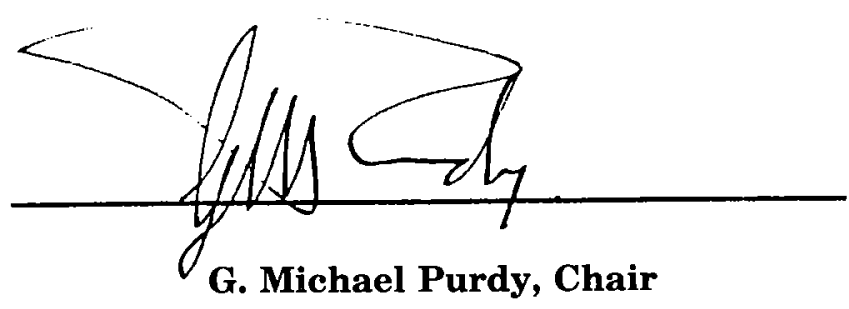

Department of Geology and Geophysics 



\section{ACKNOWLEDGMENTS}

We thank Dr. Thomas Curtin and Dr. Leonard Johnson of ONR for encouragement and advice. We thank Dr. Terry Tucker of CRREL for sharing his expertise with us, and Dr. Shin-ichi Ishii and Dr. Toshiyuki Nakanishi of JAMSTEC for their understanding and support of the concept. We also thank USN SPAWARC (Capt. Greg Dryer) for letting us participate in AREA '92 Program, and ONR for allowing us to deploy the Beaufort IOEB at the LEADEX Camp (Dr. Jamie Morison, University of Wasington, Chief Scientist). John Kemp WHOI, gave us invaluable advice and directed deployment of IOEBs in the spring of 1992 at both Camp Crystal and the LEADEX camp. Our special thanks goes to all of these people. During the development of the IOEB, Dr. Roger Colony, APL, University of Washington, gave us invaluable advice and let us use his unpublished data.

We are in debt to many engineers, scientists, pilots and crew members who unselfishly provided their expertise and ingenuity for the research, development and deployment of the IOEBs during 1991 and 1992. They include, in alphabetical order:

John Billings (WHOI; assistant in quality control of IOEBs)

Bill Bosworth (CRREL; with deep Arctic expertise; participant in the Camp Crystal deployment)

Katherine Brown (WHOI, administration of the project)

Randy Cook (U.S. Navy SPAWARC; Chief Scientist, Camp Crystal)

Tom Danforth (GTE; software development)

Ken Fairhurst (WHOI; engineering development)

Paul Fucile (WHOI; network development)

Kiyoshi Hatakeyama, (JAMSTEC; advice while this report was being compiled)

Andy Heiberg (Administrator of ONR-LEADEX Program at Dead Horse, Alaska)

Comm. Virgil Johnston (C-130 Pilot, New York National Air Guard, who flew us across Greenland)

Steve Manganini (WHOI, valuable advice on mooring design and production)

Dr. Don Perovich (CRREL; valuable advice on ice sensors)

Dr. Al Plueddemann (WHOI; participation in this program with ADCP)

Polar Associates (particularly Jeff Lord, for assistance in deployment of the IOEB at Camp Crystal)

Twin Otter Pilots at Nord, Greenland and Deadhorse, Alaska

U.S. Coast Guard (provision of the opportunity to participate in the USCGC Polar Star cruise the summer of 1991)

Keith Von Der Heydt (WHOI; invaluable advice on air operation in the Arctic environment)

Imants Virsnieks (SPAWARC; chief of operation, AREA-92 program in the Arctic)

Dr. Peter Wadhams and Dave Crane (SPROI-U. Cambridge; valuable advice and support)

This research was supported by Office of Naval Research, Arlington, VA under contract \# N00014-89-J-1288 (to Honjo). Funding to construct the IOEB that was deployed in the Beaufort Sea was provided by Japan Marine Science and Technology Center (JAMSTEC), Yokosuka, JAPAN. 


\section{TABLE OF CONTENTS}

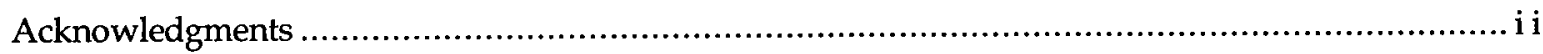

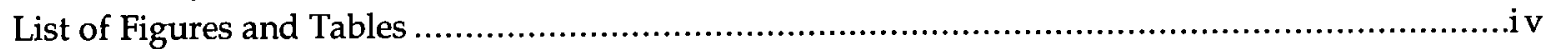

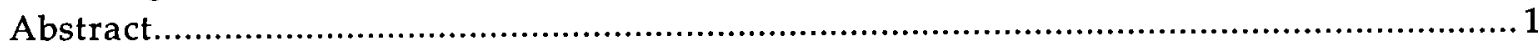

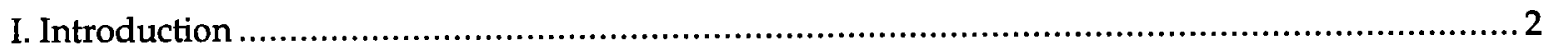

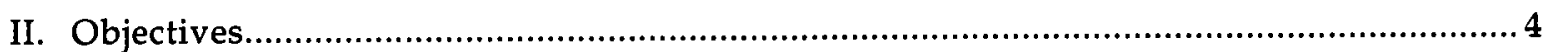

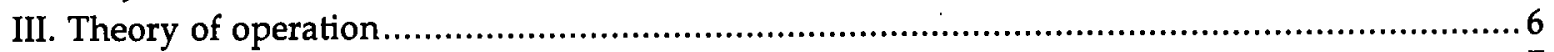

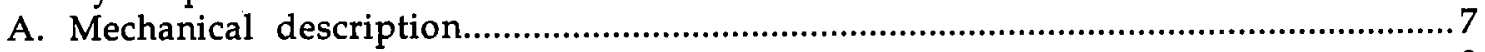

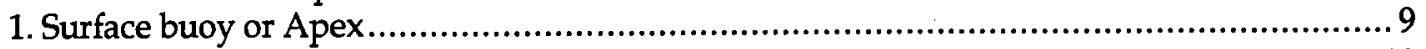

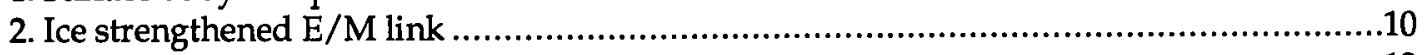

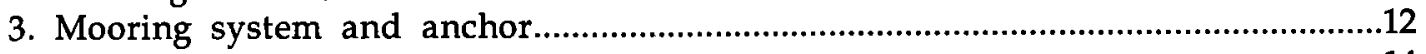

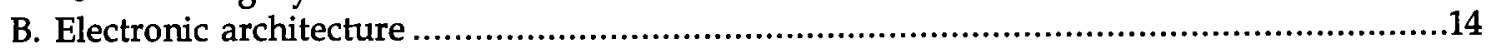

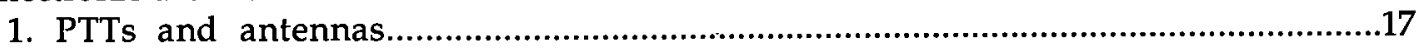

2. Microcontroller Units and MUSSIC.........................................................................18

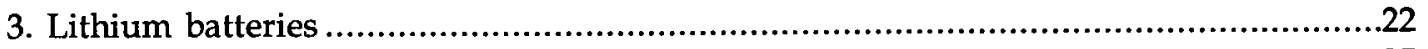

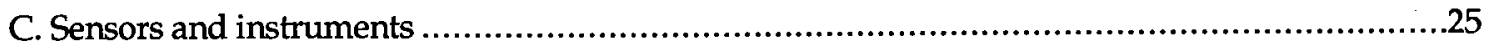

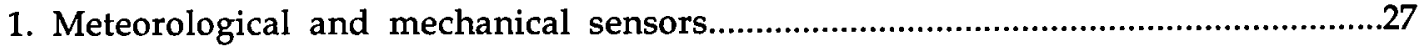

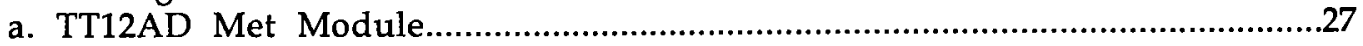

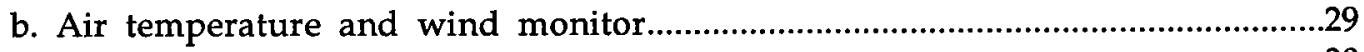

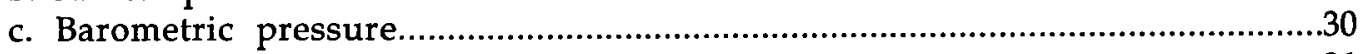

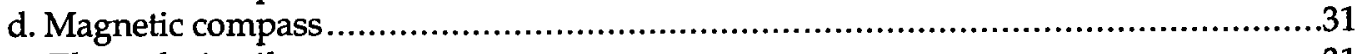

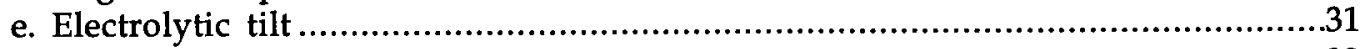

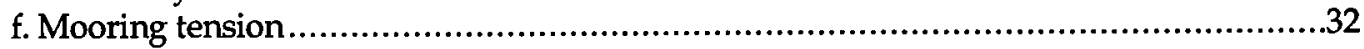

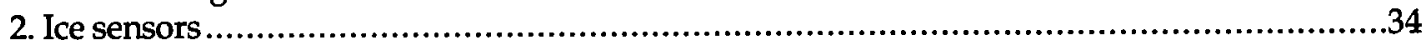

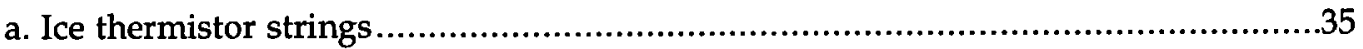

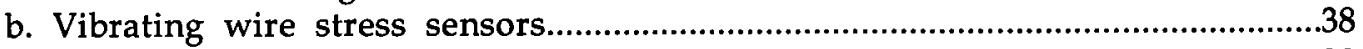

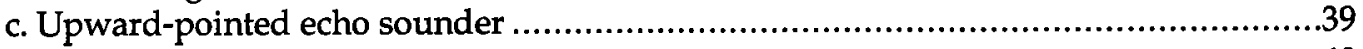

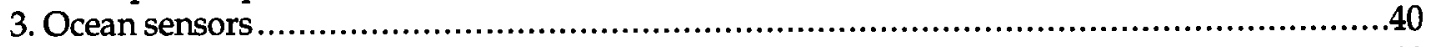

a. ADCP and Data Processing Module ........................................................4

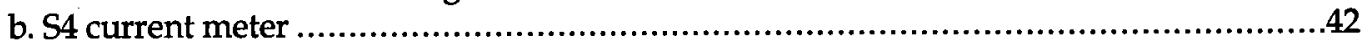

c. Conductivity, temperature and dissolved oxygen....................................................43

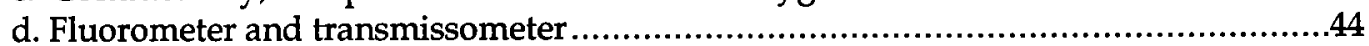

e. Water transfer system................................................................................45

f. Time series sediment trap ....................................................................46

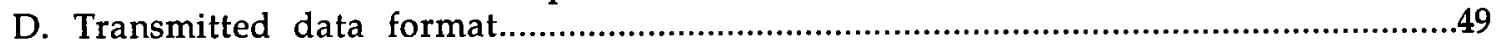

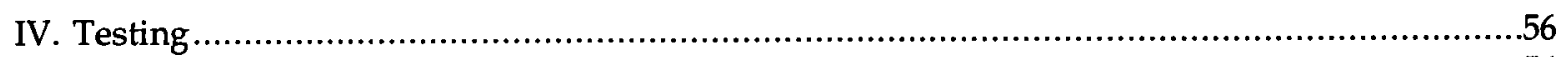

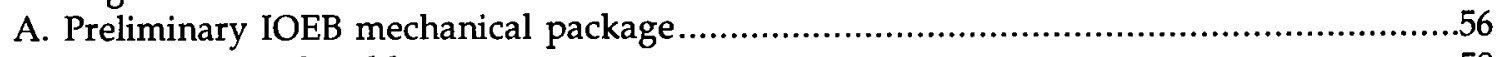

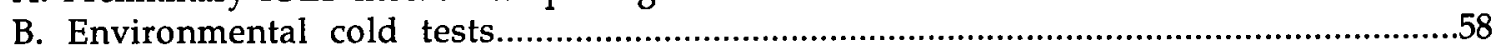

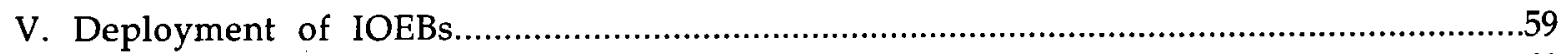

A. Transpolar Drift IOEB deployment at CRYSTAL. ...............................................61

B. Beaufort Gyre IOEB deployment at LEADEX ....................................................61

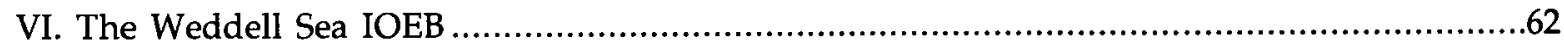

VII. Data acquisition and software

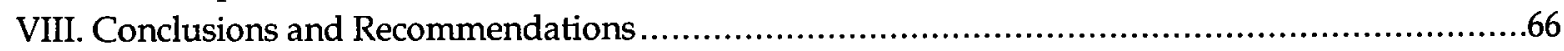

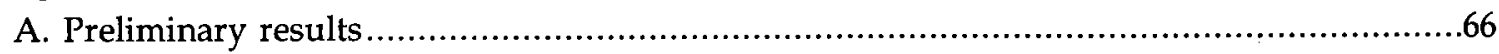

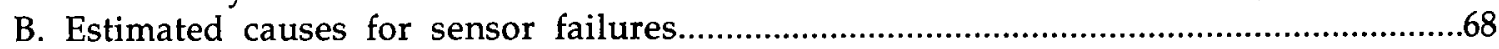

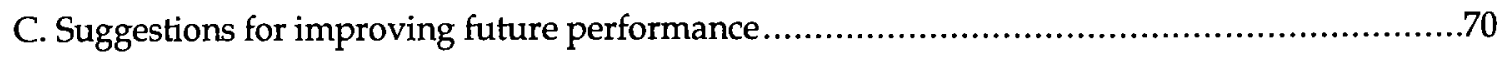

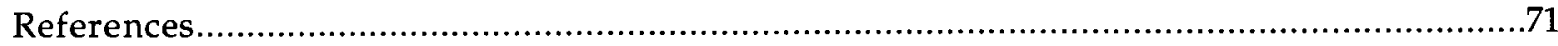


Appendix A

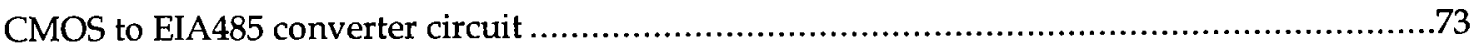

Appendix B

MUSSIC schematics and software.

Appendix C

Ice sensor wiring and software..................................................................................110

Appendix D

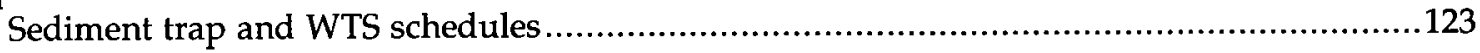

Appendix E

Weddell Sea IOEB architecture

\section{LIST OF FIGURES AND TABLES}

Figure 1: Colony Mean Ice Drift Vector Diagram...................................................................

Figure 2: 1991-92 Ice Ocean Environmental Buoys........................................................5

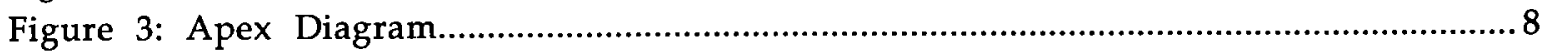

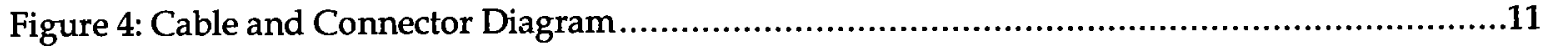

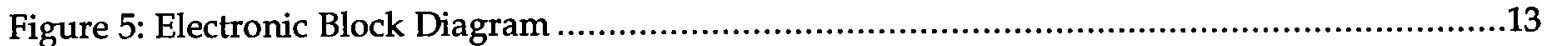

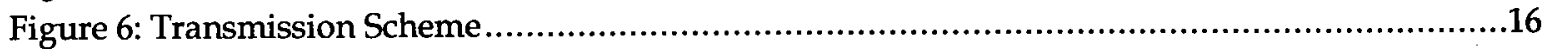

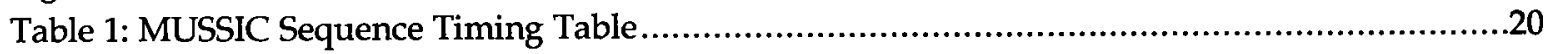

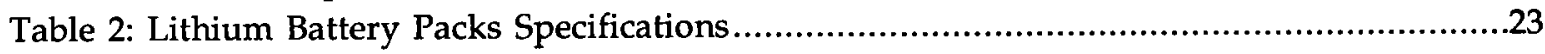

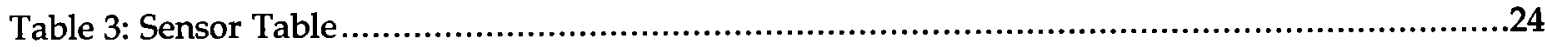

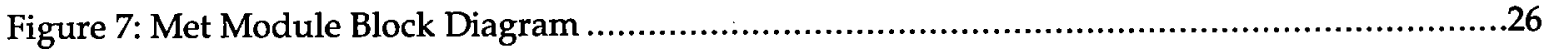

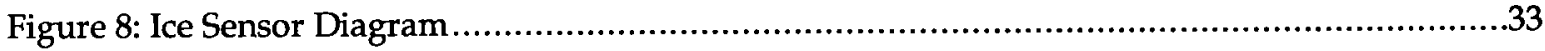

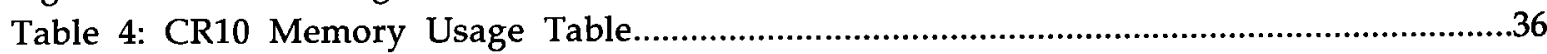

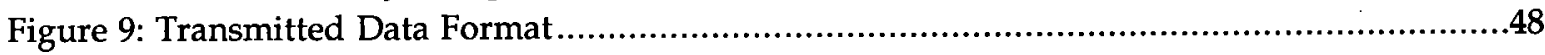

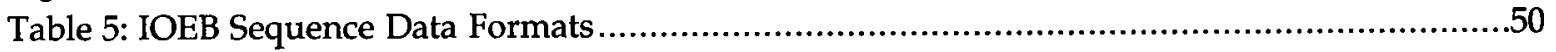

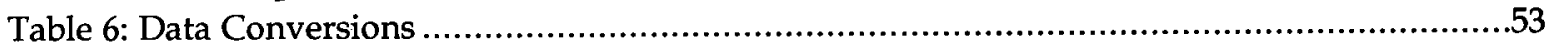

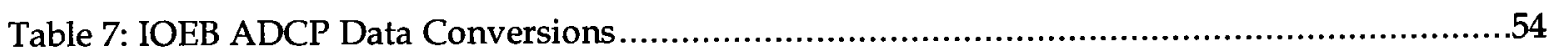

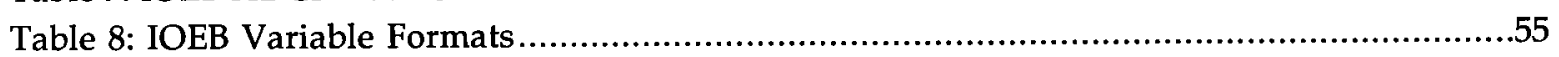

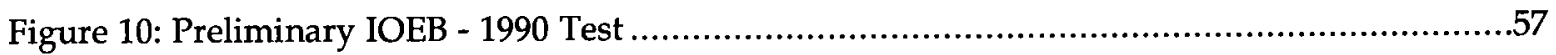

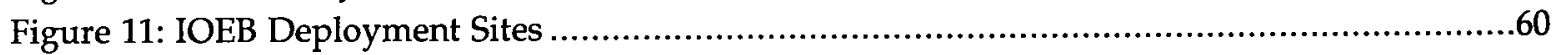

Figure 12: Weddell Sea IOEB - mooring diagram ......................................................63

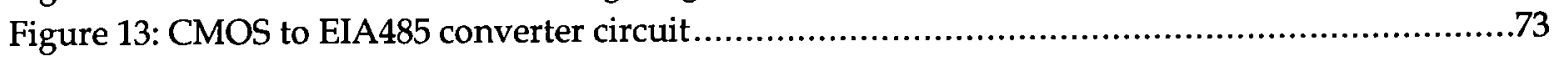

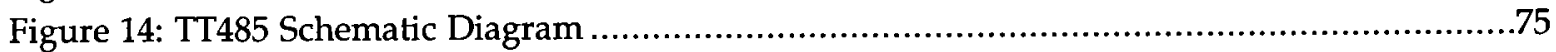

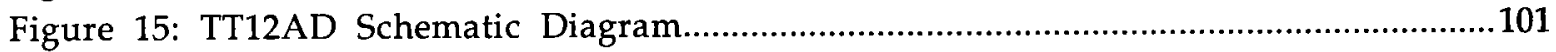

Figure 16: Ice Sensor Wiring Diagram..........................................................................110

Figure 17: Weddell Sea IOEB - Electronic Block Diagram ...........................................125

Figure 18: Weddell Sea IOEB - Transmitted Data Format........................................................126

Table 9: Weddell Sea IOEB - Sequence Data Formats ..................................................127

Table 10: Weddell Sea IOEB - Data Conversions........................................................ 129 


\section{TECHNICAL HIGHLIGHTS OF THE 1991-1992 IOEBS}

- We successfully developed the MUlti-Sensor SIgnal and Control (MUSSIC) scheme for two conductor multipoint mooring cable usage; this scheme significantly furthers the design of the unattended automated Polar ice-ocean research station by providing telemetry of data from air, ice, and ocean sensors.

- Using a surlyn foam rather than a conventional steel surface buoyancy package promotes survivability, as well as reusability of the buoy package.

- The expansion of the number and type of sensors which are employed (versus the prototype Arctic Environmental Drifting Buoy), includes the addition of meteorological sensors as well as new and critical ice monitoring sensors.

- $\quad$ By incorporating a modular system of combining the different electronic sensors, complications in the operation of individual sensors are isolated from interfering with the whole system. However, difficulties with the Platform Transmit Terminals (PTT) have a dramatic effect on the workability of the whole system.

- Related development of Data Processing Module for the compression of Acoustic Doppler Current Profiler data allows telemetering a representative subset of the massive volume of ocean current profiling data.

- We accomplished the deployment of the IOEBs using an air-assisted ice camp method in less time and with greater flexibility of location than by using traditional ice breakers.

- The design of the Satellite Automatic Data Acquisition (SADA) system assures near-real time worldwide access to remote IOEB data. 


\title{
ICE-OCEAN ENVIRONMENTAL BUOYS (IOEB); \\ TECHNOLOGY AND DEPLOYMENT IN 1991 - 1992
}

by

\author{
Richard Krishfield, Kenneth Doherty, Susumu Honjo
}

\author{
Woods Hole Oceanographic Institution \\ Woods Hole, Massachusetts 02543
}

\begin{abstract}
Based upon the 1987-88 Arctic Environmental Drifting Buoy (AEDB), the Ice-Ocean Environmental Buoy (IOEB) was developed to acquire and telemeter in near real-time inter-relatable time-series data on atmospheric, oceanographic and ice physics in ice-covered oceans during all seasons. Two IOEBs were successfully deployed in two Arctic Sea Basin Stations in April, 1992. Since then, although some sensors malfunctioned, for 18 continuous months, they have been sending massive amounts of information. In this report we describe the technology which was developed for the 1991 IOEB. Mechanically, the IOEB consists of an extremely durable surface flotation package and an underwater mooring line of instruments and sensors. The apex contains data loggers for air, ice and engineering measurements, microcontroller modules for accumulating the data from all the instruments, and ARGOS platform transmit terminals (PTTs) for broadcasting the data. Extending above the surface float, a mast supports a wind monitor and air temperature probe, which along with a barometer provides meteorological data. Thermistor strings, vibrating wire stress sensors, and a thickness gauge are installed in the ice surrounding the buoy, and are interrogated by the modules inside the apex. In the ocean, $110 \mathrm{~m}$ of conducting strength cable passes the data from conductivity/temperature recorders, an Acoustic Doppler Current Profiler and data compression module, a dissolved oxygen sensor, a transmissometer and fluorometers to the PTT microcontrollers. Furthermore, a suspended particle collector and sediment trap transmit status information along the two-wire multidrop network cable. Because the IOEB differs from the AEDB by telemetering the majority of the scientific data, a complicated compression scheme is incorporated to broadcast the data from the 103 variables within the allowable 256-bit ARGOS data stream. Via Service ARGOS, this data currently becomes available to scientists in several countries within eight hours of transmission.

In April 1992, two IOEBs were deployed at separate ice camps in the Arctic Ocean with battery power adequate to sustain the systems for over two years. One was deployed 115 miles from the North Pole in the center of the Transpolar Drift sea-ice current, and the other off of the coast of Alaska along the edge of the Beaufort Gyre. Airplanes capable of landing on ice were used for the transportation of the systems to their final destination. Simultaneously, a third, reduced version of the IOEB was deployed in the Weddell Sea by the Scott Polar Research Institute.
\end{abstract}




\section{INTRODUCTION}

Currently, greater attention is being focused on understanding the interrelationships among the Arctic atmosphere, sea-ice and ocean for the purposes of studying climatic change in the present and during the most recent glacial period. The seawater is insulated from the frigid atmosphere above by the relatively thin and mobile sea-ice, which causes a relatively unstable atmospheric heat balance to exist. The behavior of ice which covers the Arctic Basin is the best cursor of global change.

The ice-cover of the Arctic Ocean is divided into two regions with regard to the origin, process and fate of the sea ice. One is the Transpolar Drift with its main source area in Laptev Sea and extending southward to the Denmark Strait through the Fram Strait. It is the gigantic and dynamic transporter of energy to the Atlantic Ocean and resides in the basin for only a few years (Östlund et al. 1987). The other region is called the Beaufort Gyre (or Canada Gyre), and is the major contributor in forming the Arctic air-mass. It occupies a vast area of the Arctic between the Alaska/Canadian coasts, northern Chukchi Sea, and the Alpha Ridge area west of the North Pole, and forms, by relatively slow motion, an ice gyre which contains ice floes for periods of much greater longevity than those of the Transpolar Drift (Aagaard and Carmark, 1989).

To study the characteristics of these regions, what is primarily needed is an inter-relatable set of time-series data on atmospheric, oceanographic and ice physics, all measured at a higher frequency throughout all seasons, particularly during the boreal winter when the temperature contrast between the air and sea reaches maximum and forms a giant heat pump. However, because of the Arctic's extremely severe conditions and life-threatening dangers, it would be very difficult, expensive and inefficient to maintain scientists and experts continuously on the many ice stations necessary to develop such a suite of high quality information.

One of the best solutions is to deploy an array of unattended, automated, telemetered stations in the Arctic. Since the physics, chemistry and biology of the upper ocean are so closely linked with the ice behavior and functions, we wanted to deploy critical under-water sensors along a surface-tethered mooring. Because more low-power, reliable and long-term environmental sensors are now available, in situ measurements can be independently made with greater accuracy and reliability than in the past. Data transmitted from critical sensors mounted on an automated station could reach international laboratories in real time via satellite; thus the information could be evaluated, compared and utilized instantaneously among researchers. All of the raw data could also be stored by the station and retrieved at the time of recovery for redundancy. Some progress has been made by participants in the Arctic Ocean Buoy Program in the sharing of in situ data. However, none of these existing platforms fully combines the diverse sensors required for a complete interdisciplinary study of the ice-covered ocean. 
For these reasons, we deployed an Ice-Ocean Environmental Buoy (IOEB) in both regions in the Arctic Ocean; one in the stable Beaufort Gyre and the other in the dynamic Transpolar Drift. For comparison, an abbreviated version of the IOEB was also deployed in the Weddell Sea at about the same time as the Arctic IOEBs were deployed.

We have already acquired a large volume of inter-related data transmitted for 1991-1992 IOEBs. The analysis of data and interpretations of results are ongoing. Scientific papers will be published elsewhere by many authors.

Arctic Basin

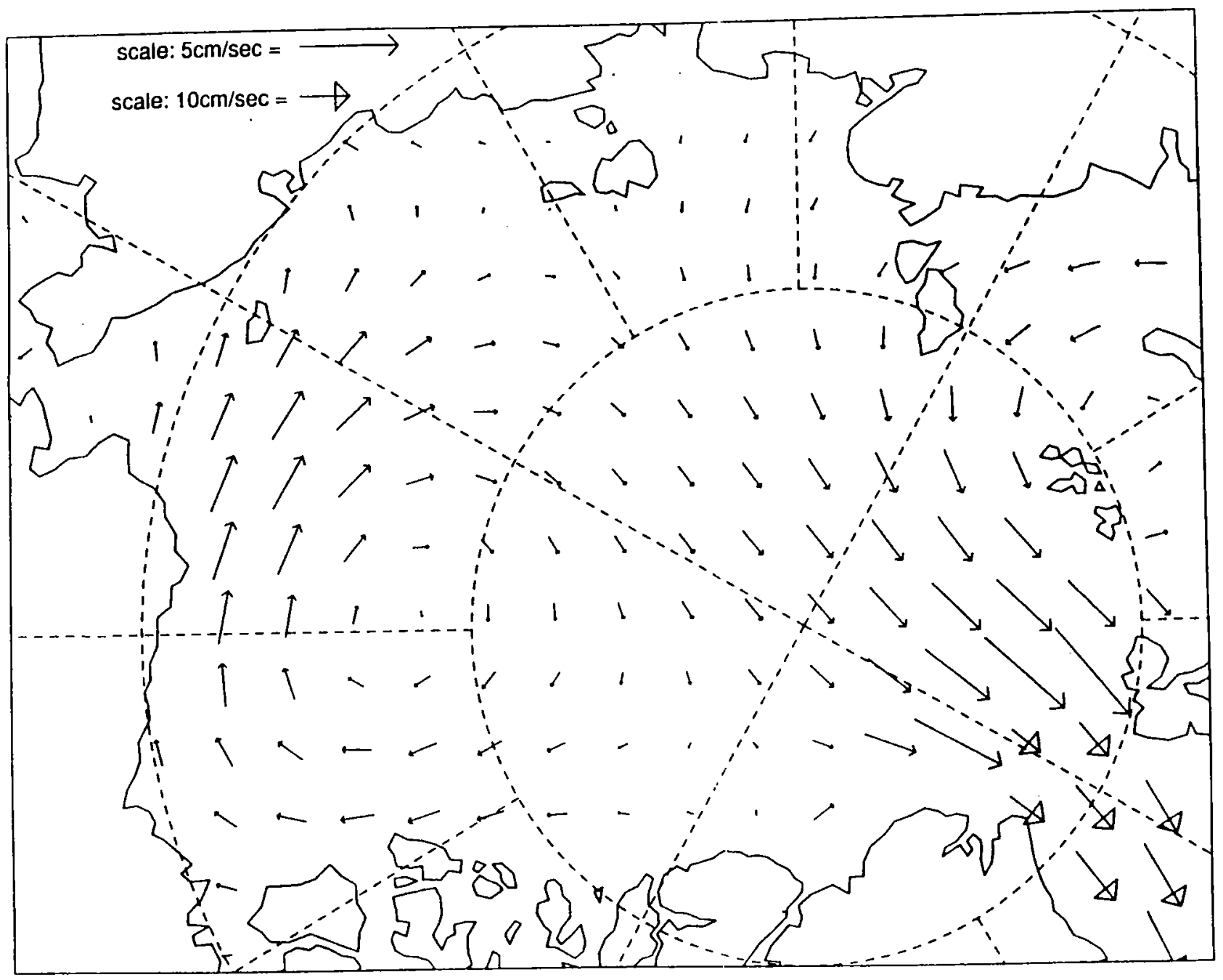

Figure 1: Colony et al. (1990) Mean Ice Drift Vector Diagram 


\section{OBJECTIVES}

The long-term scientific objective of this research program is to clarify the global role of the sea ice that moves through the Arctic Basin and overflows into the northern Atlantic Ocean by depicting the physical, energetic, and biogeochemical characteristics of the ice, ocean, and surface atmosphere; particularly in the southern Transpolar Drift where the melting process is more significant than new ice formation. This information will improve our understanding of how the weather system in the Northern Hemisphere evolves and, by comparison, clarify the global impact of sea ice in the Southern Ocean. Scientific observation of sea ice provides us with the first signs of long-range climatic change caused by anthropogenetic forcing, such as the greenhouse effect and the reduction of reverine discharge in the Arctic Basin. In addition, understanding those oceanic processes which produce the highly characteristic particle flux (Honjo, 1990) which is also a very useful tracer of the Arctic environment, will improve our knowledge of the global carbon cycle and further the sensible utilization of oceanic food stocks in the northern Atlantic Ocean.

The functional objective of an IOEB is to provide the opportunity to understand the short (hourly and daily), seasonal and inter-annual rates of change in sea-ice and their relationship to local and regional meteorology, upper ocean physics, primary production and, finally, to the process and the rate of biogeochemical cycles in the Polar ocean. In order to be useful to all disciplines of the international scientific community, the gathered data needs to be transmitted in real time.

Consequently, specific tasks are required to accomplish the development of such stations and these include the choice, development, and/or implementation of:

1. Appropriate air, in-ice and underwater sensors to fulfill the scientific objectives.

2. Electronic networking between sensors and satellite transmitters which are energy efficient and reliable under cryogenic conditions.

3. An extremely rugged buoy and suspension system which is able to withstand the pressure of ice and low temperature, and has the ability to survive when drifting in a mixed-ice zone or the open sea.

4. Technology to deploy such a station at a remote location in the ice-covered Polar ocean.

5. A long-term energy supply which can sustain all of the above in the extreme low Arctic temperatures.

6. Comprehensive software to access and to monitor the flow of satellite data from one or many distributed automated stations. 


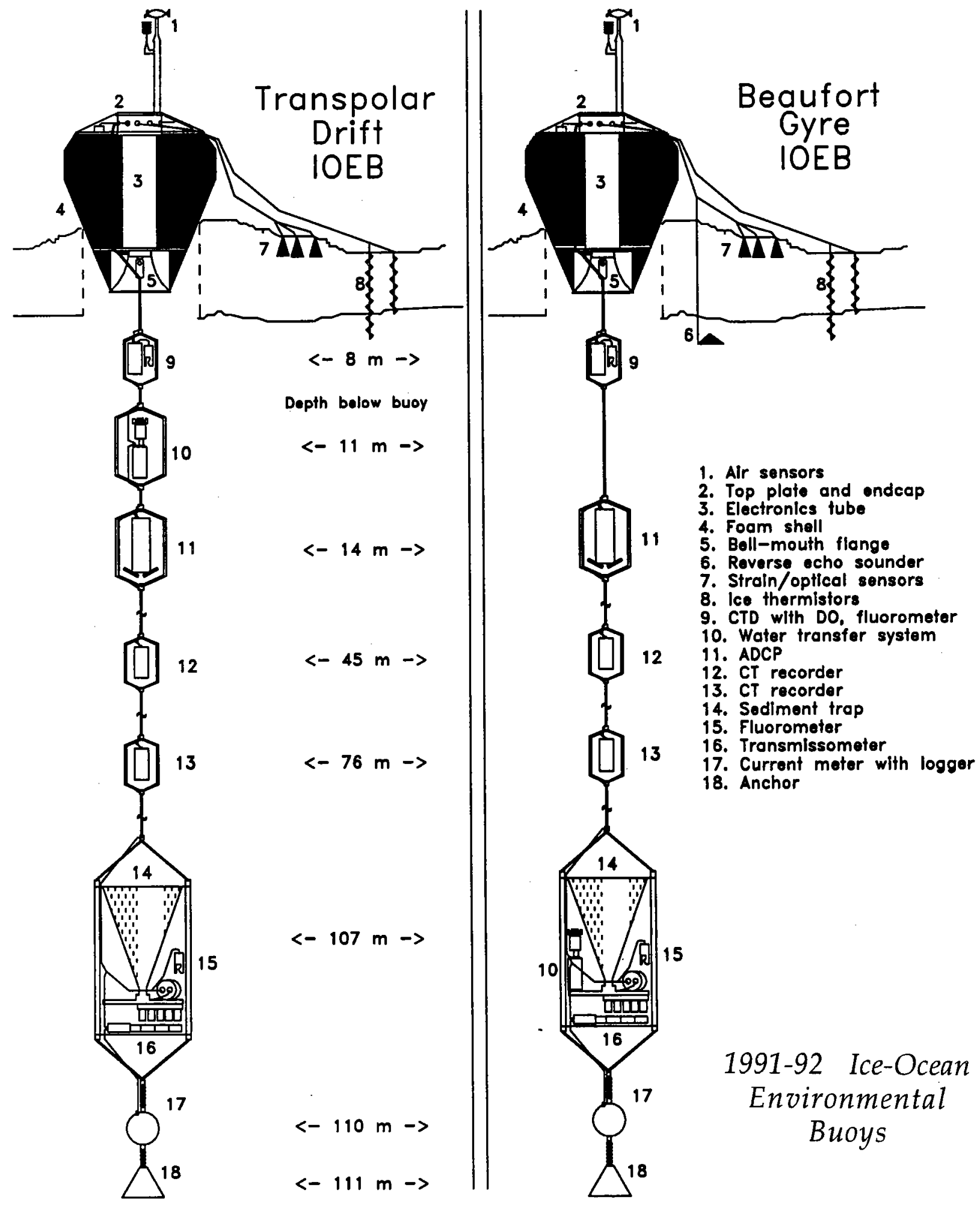

Figure 2: 1991-92 Ice Ocean Environmental Buoys 


\section{THEORY OF OPERATION}

The IOEB was designed and constructed based upon the experience gained from the successful Arctic Environmental Drifting Buoy (AEDB) experiment (Honjo et al., 1990). The AEDB drifted southward from $86^{\circ} \mathrm{N}, 22^{\circ} \mathrm{E}$ with the transpolar ice drift current for eight months between August 1987 and April 1988 covering $3,900 \mathrm{~km}$, while constantly transmitting its position and valuable engineering data via ARGOS. The information retrieved from the recovered instruments has been very useful to our understanding of the sea and ice processes occurring in the Arctic Ocean. Among the scientific results, data collected by ice thermistor chains were used to determine oceanic heat flux (Perovich et al., 1989), while continuous Acoustic Doppler Current Profiler (ADCP) observations provided information for understanding diurnal tidal currents underneath the Arctic sea-ice, especially near the Yermak Plateau (Padman et al., 1992 and Plueddemann, 1992). The IOEB is more sophisticated than the AEDB because of several technological improvements that have been made to this comprehensive Polar measuring device.

The ability of the AEDB to survive the harsh Arctic climate indicated to us that structurally the IOEB should resemble the AEDB. Specifically, the following features were retained:

1. isolation of the electronics package inside of the sphere from moisture with an internal watertight chamber.

2. interfacing of the electronics to the outside sensors via Brantner pressure resistant bulkheads.

3. use of redundant ARGOS Platform Transmit Terminals for near real-time determination of the buoy's location.

4. use of the flat patch antennas for transmitting the ARGOS signal.

5. incorporation of a mooring line of instruments hanging below the sphere in the seawater, terminated by a hanging weight.

6. use of lithium batteries as mandated by temperature or power requirements.

The major improvement of the IOEB over the AEDB is the telemetry of most of the scientific data in near real-time. While retrieval of the mooring is still a requirement, telemetering the data insures that a large portion of the acquired information is relayed back to the laboratory, even if the system is unfortunately destroyed in the sea-ice.

Other differences from or improvements over the AEDB include:

1. use of an ionomer foam shell for protection of the surface flotation package and to provide buoyancy for the mooring system.

2. use of electromechanical cable and terminations between the surface float 
and segments of the mooring line.

3. addition of meteorological sensors.

4. addition of tilt sensors to surface float, and tension monitor to mooring cable.

5. addition of an upward looking depth sounder, ice stress sensors and dissolved oxygen sensors below the ice.

Construction of the two IOEBs started in November 1991 and was completed in March 1992. They were essentially identical in terms of sensor arrangement except for different locations of the water transfer system along the mooring system.

\section{A. Mechanical description}

In the mechanical design of the IOEB, strength and flexibility are combined in an effort to sustain the buoy through the harshness of an Arctic winter and the severe forces encountered in Marginal Ice Zone (MIZ) conditions. The main physical components are the surface flotation package and the mooring system.

The predominant mechanical feature of the IOEB is the apex which protectively houses the electronic controller, satellite communication system and battery array, and supplies buoyancy for the drifting mooring. Meteorological sensors are mounted on a mast protruding from the top, and a bell-mouth flange secures the underwater section of the mooring to the bottom.

The IOEB mooring systems extend down to a depth of $111 \mathrm{~m}$ below the bottom of the apex, as limited by the shelf depth of the Arctic Ocean. The first segment of the IOEB mooring system is the strengthened electromechanical (E/M) link which penetrates the several meters of ice and electrically and mechanically connects the apex to the underwater mooring instrumentation. The underwater mooring segments are all constructed from jacketed steel armored three-conductor cables. Each end of the cable is fitted with an E/M termination and a unique underwater T-splice connector for electrical access to the MUSSIC network. 


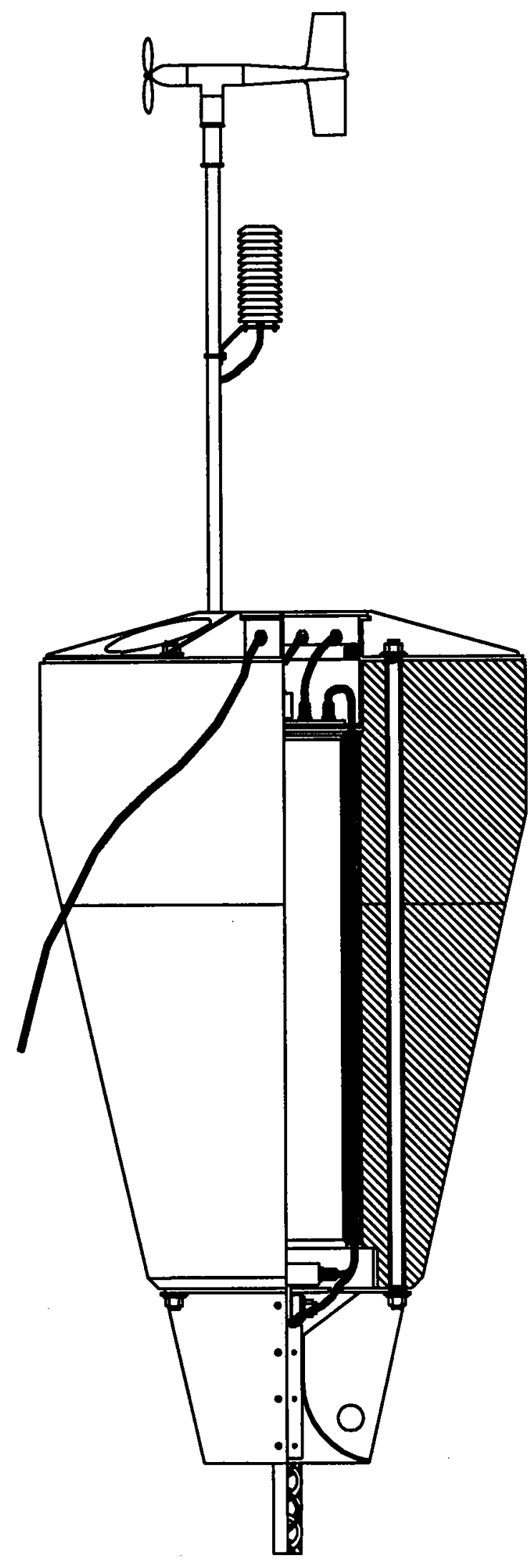

\section{1-92 Ice-Ocean \\ Environmental Buoy}

Apex Diagram

Figure 3: Apex Diagram 


\section{Surface buoy or Apex}

The surface flotation package, or apex, is the single most important structure of the IOEB. More than just a float, it consists of a foam flotation collar surrounding an internal electronics pressure housing, which together are sandwiched between an aluminum top plate and a bell-mouth mooring cable strain relief. One inch titanium tie-rods secure the assembly together. The apex is engineered to protect the electronic devices contained internally, as well as provide buoyancy for the entire buoy system. It is also the platform to which the air and ice sensors are either mounted or connected.

The semi-conical flotation collar is made of Dupont Surlyn 9720 Ionomer Resin and provides nearly twice the buoyancy required to sustain the $1800 \mathrm{lbs}$. of surface package and mooring system. This laminated polymer was chosen as the outside shell of the surface buoy due to its excellent sub zero temperature characteristics, toughness and abrasion resistance, and ability to be formed into nearly any desirable shape. In fact, the foam element remains flexible and resists cracking at temperatures below $-100^{\circ} \mathrm{C}$. To increase abrasion resistance, the foam density is 10 PCF, which is double what is commonly used for open ocean floats. The outer skin is further densified by heat and pressure to form an extremely tough outer skin. The buoyancy volume, initial profile and elasticity of the IOEB apex were developed to enable it to withstand great lateral pressure and impact of sea-ice. Furthermore, it protects the electronics and communication package while floating or submerged in a mixed-ice zone.

Machined from 6061-T6 aluminum and hardcoat anodized, a 10" I.D. electronics pressure housing is centrally located in the surface buoy. The top end cap accommodates 11 pressure resistant electrical penetrators through which sensor information is conveyed into the tube, and subsequently routed out to the antennas. Inside the tube, all of the surface electronic devices and internal sensors are firmly secured to the endcap by an aluminum chassis. Two PTTs, two microcontrollers, three data logger systems and mechanical sensors are all incorporated into a framework that measures only $18^{\prime \prime}$ in length. The remainder of the $49^{\prime \prime}$ tube is occupied by the lithium battery packs which add 70 to $100 \mathrm{lbs}$ of weight to the surface package, and are secured to the bottom of the tube using a 1" dia. threaded rod through the middle of individual packs. Each pack is comprised of a hexagonal 10" dia. plastic boot which contains the wired batteries and protection diodes. All of the battery wires are fed through a fuse block before they connect to the individual devices.

Covering the pressure housing and flotation package, an aluminum top plate protects the cables attached to the penetrators on the pressure housing, provides a platform for mounting the transmitting antennas and meteorological mast assembly, and transmits the mooring line tension through a tie rod assembly. The top plate well is specially constructed so that when the outer sensors are 
pulled from the buoy, the Brantner connectors will not be damaged, and the electronics package remains sealed against moisture. Mounted flush on the surface of the top plate the two flat UHF antennas which are virtually non-destructible by ice chafing or Polar bear attack.

Located at the bottom of the surface buoy, a galvanized steel bell-mouth flange reduces the strain on the armored conducting cable which attaches to the mooring system. The flange radius increases the cable's fatigue resistance by preventing the $\mathrm{E} / \mathrm{M}$ cable from exceeding its minimum bend diameter. Four one-inch titanium tie-rods hold the upper shield and lower plates, sandwiching the Ionomer flotation. To provide engineering data on mooring tension, an inline submersible load cell is mounted on top of the bell mouth.

The apex measures $124 \mathrm{~cm}$ in diameter and $200 \mathrm{~cm}$ in length and supplies $680 \mathrm{~kg}$ of buoyancy in seawater. The entire IOEB system weighs $415 \mathrm{kgs}$ in the air of which $210 \mathrm{~kg}$ is the apex weight. In calm conditions, with a full underwater mooring and a $250 \mathrm{~kg}$ stabilizing anchor, the surface float projects $70 \mathrm{~cm}$ above the surface of the water.

\section{Ice strengthened $E / M$ link}

The $\mathrm{E} / \mathrm{M}$ link connecting the surface buoy to the $\mathrm{E} / \mathrm{M}$ mooring cable, is exposed to two different types of loading. In one case, when the buoy is buried in the ice, the link penetrates several meters of ice and is subjected by the ice to compression and shear forces, as well as abrasion. These forces are especially large during ridge formation. In the other case, when the buoy breaks out into the open sea, the link is exposed to high dynamic tension loads and bending fatigue.

The design of the E/M link for the IOEB was based on the above loading considerations and results from the AEDB. The AEDB link was made from 3/8" trawler chain and survived for 9 months in the ice and ocean without any noticeable damage. The AEDB link, however, was mechanical only, and had to be redesigned for the IOEB which required electrical conductors for data transmission.

This was accomplished by loosely attaching a three conductor polyurethane jacketed cable to the chain links. Each end of this assembly was mechanically terminated with a galvanized steel clevis and electrically terminated with a three conductor pigtail. This assembly is then placed in a cylindrical mold and polyurethane potted to form a semi-rigid, water-tight link $6.35 \mathrm{~cm}$ in diameter and over 7 meters long.

One end of the link is mechanically and electrically attached to the bottom of the apex. A steel bellmouth mounted at this joint limits the bend radius of the link to increase the fatigue life of the link. The other end is mechanically and electrically connected to the uppermost instrument and $\mathrm{E} / \mathrm{M}$ mooring cable segment. 


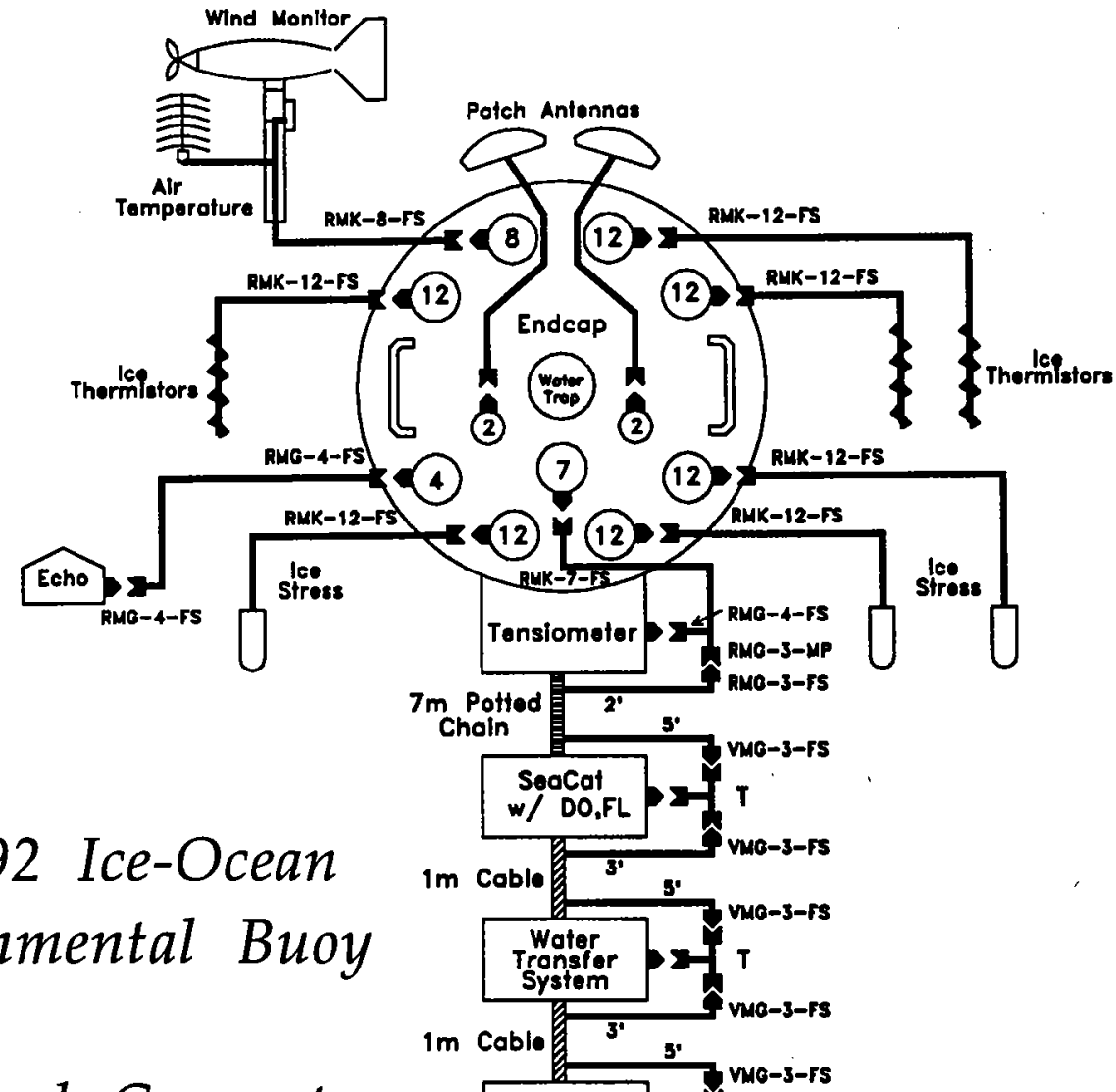

\section{Cable and Connector Diagram}

1991-92 Ice-Ocean Environmental Buoy
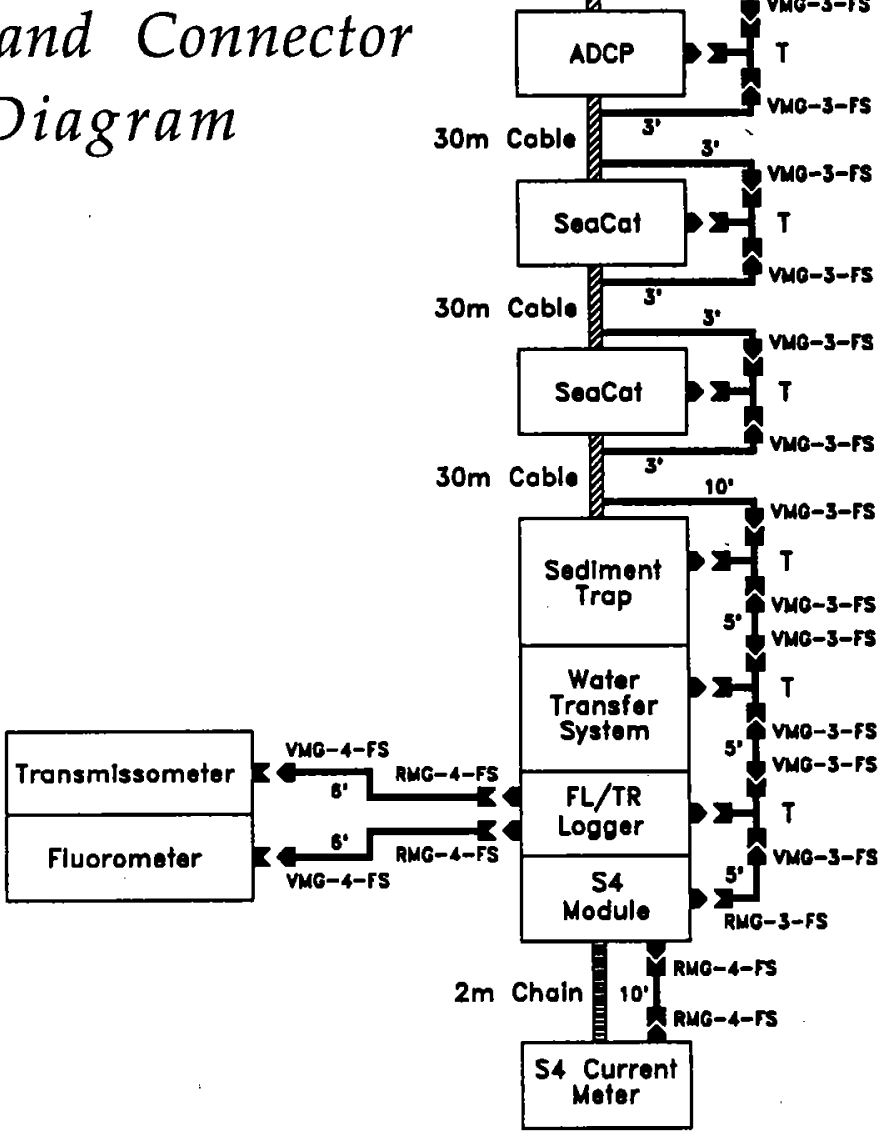

NOTES:

RMK-X-FS mates with XSK-X-BCL bulkheads

RMG-X-FS matos with $X 5 G-x-8 C L$ bulkheads or RMG-X-MP cables

VMG-4-FS mates with VSG-4-BCL bulkhoods

$T=$ VSG-3-THL of rach and with RMG-3-FS in middle

Figure 4: Cable and Connector Diagram 


\section{Mooring system and anchor}

Underneath the sea-ice, the individual instruments of the IOEB mooring system are coupled together mechanically and electrically by mooring cables. These E/M mooring cables are constructed from 5/16" diameter, torque balanced $3 \times 19$ wire rope with three 20 AWG stranded PVC insulated conductors placed in the valleys of the strands. These cable assemblies are wrapped with 1 mil of clear mylar and covered with a $60 \mathrm{mil}$ polyurethane jacket. On each cable, a special oceanographic clevis termination is swaged on each end of the wire rope and an underwater electrical cable connector is soldered to the three conductors. This whole termination assembly is placed in a mold and potted with polyurethane to make a waterproof electrical termination and a mechanical strain relief. The cable assembly has a breaking strength of $4700 \mathrm{~kg}$.

In order to position the individual instruments on the mooring line at a desired depth, three different lengths of mooring cables were manufactured: 1, 4, and $30 \mathrm{~m}$ segments. Depending on the size of the instrument in-line, different lengths of underwater cable connectors were used: 3,5 , and 10' sizes. For every instrument on the mooring, a specially designed underwater T-splice connector interfaces between the cable connectors to feed the electrical conductors to the instrument on the mooring line and through to the next mooring cable segment. On each IOEB, a total of eight T-splices was required.

Between terminations, stainless steel cages contain most of the IOEB instruments; positioning them in-line with the mooring system. The dimensions of each cage vary according to the instrument that it protects, however the end fittings were standardized for attachment to the cable terminations. The cages for the smaller instruments use 3/8" ss rod, while the ADCP frame uses $1 / 2$ " rod to accommodate the heavier unit. All frames were electropolished and isolated from the clevis bolts by plastic sleeves to minimize the effects of corrosion.

To determine the minimum acceptable anchor weight, dynamic mooring analysis was performed. According to the model, the chosen anchor weight of $500 \mathrm{lbs}$. ensures an inclination of less than $12.1^{\circ}$ at the sediment trap package near the end of the mooring for apparent currents of $75 \mathrm{~cm} / \mathrm{s}$. In the case where the IOEB is frozen into the icefloe, the apparent current is the combination of the ocean current and ice drift vectors. The anchors used for the final deployment operations were designed to be easily assembled in the field and therefore were constructed of several lead plates bolted through the center with 2" eye-bolts. Several meters of $1 / 2$ " galvanized chain secure the anchor safely below the deepest instrument on the mooring line. 


\section{1-92 Ice-Ocean Environmental Buoy}

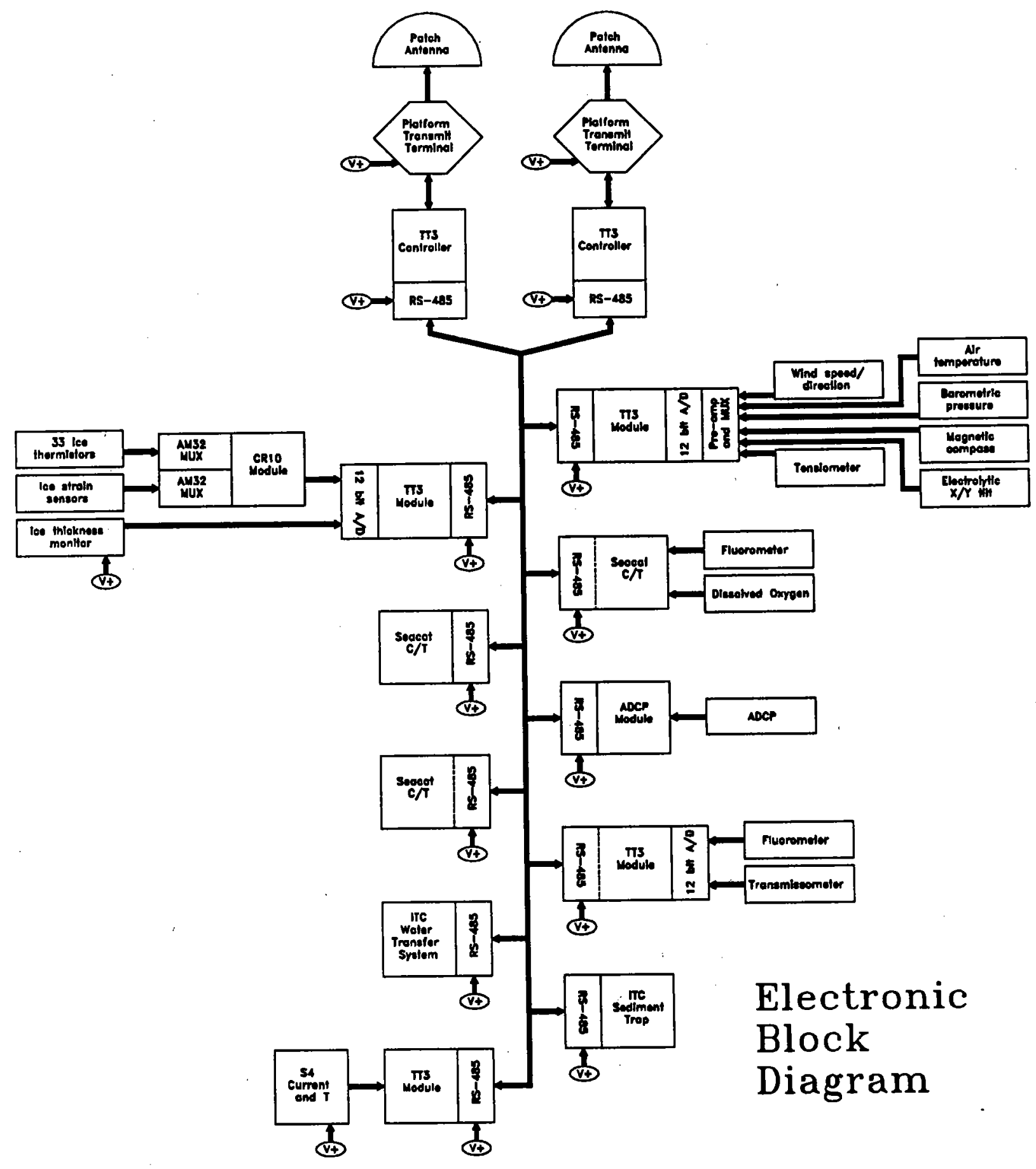

Figure 5: Electronic Block Diagram 


\section{B. Electronic architecture}

Compared to the AEDB, there is a substantial increase in the amount of data that is transmitted via the ARGOS data acquisition and location system by each IOEB. Furthermore, almost all of the data broadcast in the present version is scientific rather than engineering oriented. There are 25 long-term, recurrent sensors; if counting individual sensors, such as each time-series flux sampler or each bin of an acoustic Doppler current profiler, there are over 200 sensors onboard an IOEB. One hundred and three variables are designed to be broadcast via ARGOS in two channels.

The introduction of telemetry into the design of the IOEB requires that units which interrogate sensor data be able to communicate this data to a transmitter, as well as store the information internally, when required. Sensors and instruments above, below, and in the ice must all be coordinated to pass their information systematically to the transmitting devices. This function is most effectively performed under the command of a central controller. But in order to keep local electronic problems from affecting other units on the network, a modular design of independent data acquisition units for each set of sensors was employed to ensure that if a single unit fails, data from the all the remaining units will continue to be broadcast. Consequently, the electronic architecture of the IOEB was designed around a pair of micropower processors each linked both to a transmitting device and to a network of all of the individual data loggers or data buffers acquiring data from the scientific sensors. Redundant antennas, transmitters, and controllers are used, not only to increase data throughput, but also because it is important that the buoy be recovered to retrieve the sediment and filtration samples.

A low power controller which is inexpensive, reliable, and versatile is the Tattletale III Data Logger (TT3) from Onset Computers (1988). The TT3 is suited for the IOEB modular design because it is micropower, electronically versatile, and low cost. Furthermore, it is easily programmable in a form of BASIC which reduces the amount of development time required for applications.

Based on the Hitachi 6303 CMOS 8-bit microprocessor chip, the TT3 has a hardware UART, 14 digital I/O lines, an 8-channel 8-bit analog-to-digital converter, EPROM, and $96 \mathrm{k}$-byte of RAM (including EPROM) for program and datafile. Measuring only $3 "$ x 5", this model has a real-time clock which is useful for putting the unit into two software controllable low power (typically less than $100 \mu \mathrm{A})$ modes. Throughout the IOEB electronic architecture, TT3s are used to acquire data from sensors, to communicate over the sensor network, for sampling and temporarily storing data from another acquisition device, or for communicating a complete data stream to the satellite transmitter.

A complete data acquisition and telemetry system for the IOEB thus begins with several TT3 data loggers directly obtaining data from various thermistors, 
fluorometers, transmissometers, etc. As indicated earlier, eight 8-bit A/D channels are available to each TT3 for low resolution data acquisition. For implementation on the IOEB, we developed an eight channel 12-bit A/D circuit board to increase the resolution of the logger. The limiting factor in using the model 3 Tattletale as a data logger is the $64 \mathrm{k}$-byte limit of memory available for the data file. High resolution data will require two bytes for each stored value while low resolution will require only a single byte. In 11.5 months are the equivalent of 8192 (or 8 kbytes) hours. This means that only 4 high resolution sensors fill the memory of a TT3 in one year, given an hourly sampling rate, and ignoring housekeeping data.

For the surface meteorological, ice, and biosensors which do not have their own data loggers, TT3s are used as data loggers and telemetry buffers with added circuit boards to acquire the data, process and temporarily hold that information, and finally convey the result to each controller, when signaled. Furthermore, another type of data buffer is required to obtain serial data from an external acquisition unit (i.e. InterOceans S4 Current Meter) and feed the information to the central controller. The TT3 has an auxiliary software UART which can be programmed to reliably receive an ASCII string at a rate of 4800 baud. Due to the difficulty with which TT3s handle interrupts, it is necessary to wake-up the buffer unit at repeated preprogrammed intervals, and provide a window in time for the TT3 to expect the incoming signal. In this instance, the model III will act only as a buffer, and will only temporarily store the information before feeding it to the network. To retain modularity, only one external device may be monitored by a single TT3 independent of its data logging responsibilities.

Each ARGOS transmitter has a single microprocessor controller based on the TT3, which assembles the data from the various modules, and conveys that information to the transmitter in the proper format over its CMOS serial port. Communications occur over an EIA485 (1983) standard network with the common oceanographic SAIL software protocol. This allows numerous devices to be accessed over only 2 conductive wires. All of the instruments on the IOEB network are configured to communicate with the surface electronics in this fashion, and we call this system MUlti Sensor SIgnal and Control (MUSSIC).

By sequential addressing, each controller allows only one of the data buffers to be active on the network at any time. Each microprocessor can access all of the devices, so that information from every sensor unit is available to each controller/transmitter pair, should the other network fail. Through its auxiliary CMOS UART, it passes a time-coded, fixed length data stream to the transmitter, which contains all of the information collected by all of the devices. The ARGOS transmitter accepts the fixed-length data stream from the controller at the proper time and then transmits the information to the satellite in the appropriate format.

According to the modular design, each individual data logger, data buffer, 
controller, and transmitter module is provided with separate battery power supply to ensure isolation from faults passing between units. For surface units, lithium power technology must be used to ensure operation down to below -40 ${ }^{\circ} \mathrm{C}$.

While this particular method of developing and combining the hardware and software to control the flow of the signals through the system was developed especially for the IOEB, this system is fully applicable to other areas of oceanographic data acquisition.

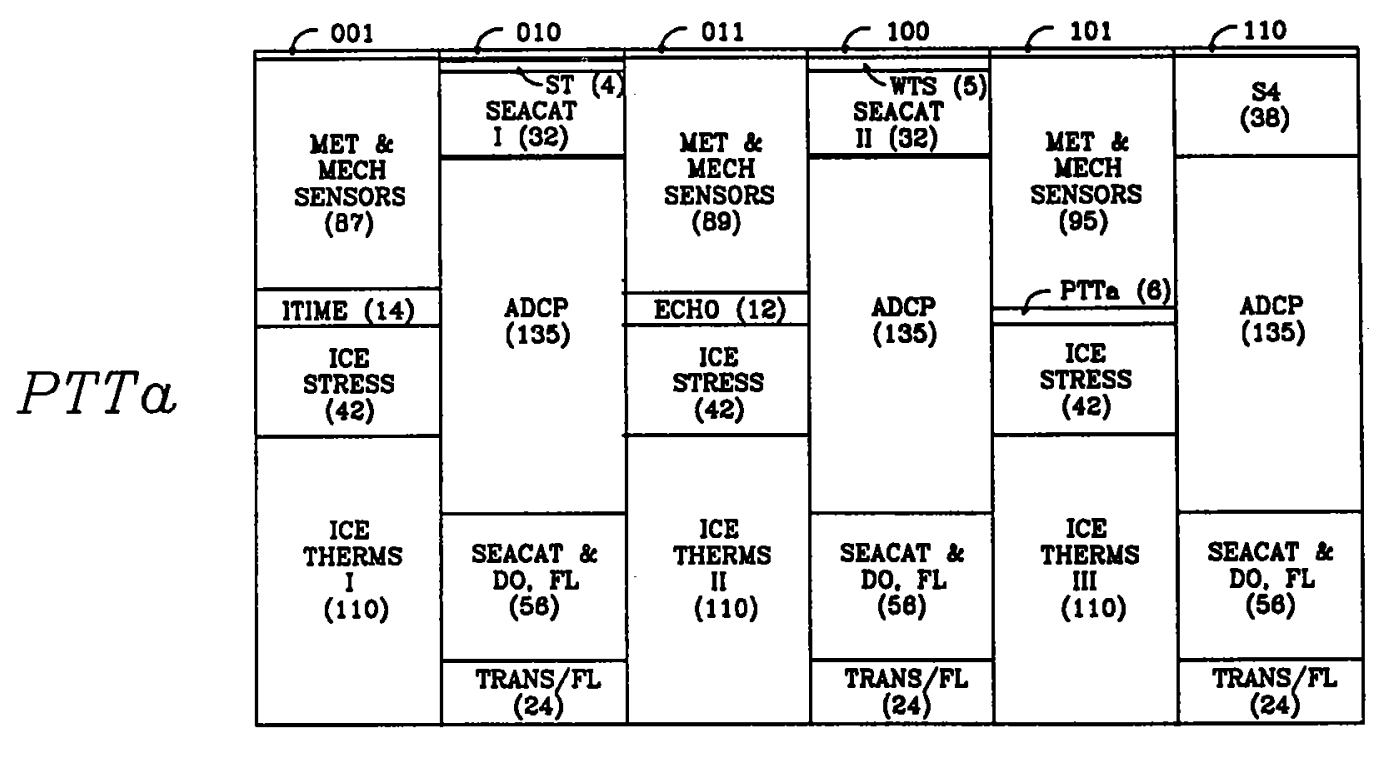

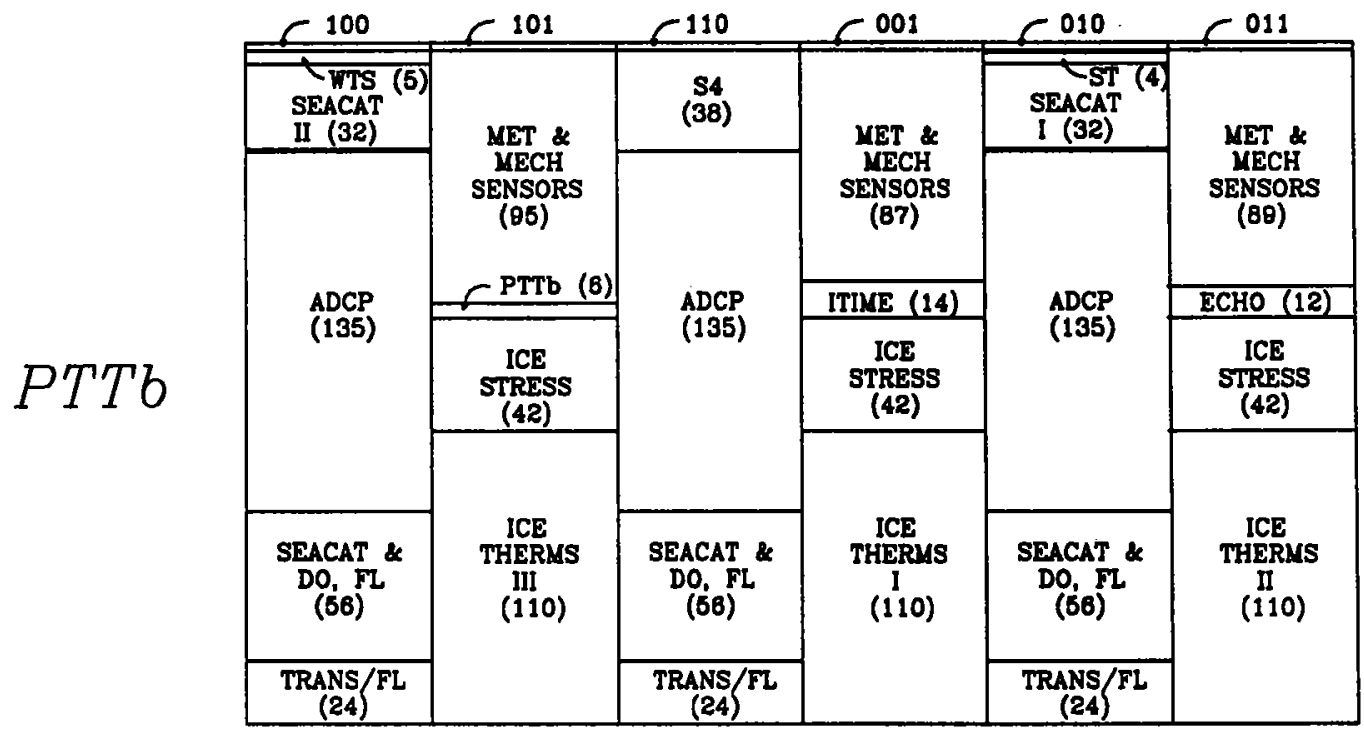

Schedule Hour 1 Hour 2 Hour 3 Hour 4 Hour 5 Hour 6

Figure 6: Transmission Scheme 


\section{PTTs and antennas}

Dual Synergetics 2101A platform transmit terminals (PTTs) are used on the IOEBs to provide the uplink signal to the ARGOS satellite. Because signals from the PTTs are essential to acquire locations for each buoy, the reliability of the PTTs is of primary importance. By minimizing the number of tasks performed by the PTTs, it was desired to avoid problems brought on by complexity. Independently, even if subjected to temporary unscheduled power losses, every PTT should correctly reconfigure itself and continue to broadcast properly.

Our selection was based on power consumption requirements, the stated operating temperature range and features of the transmitter which allowed it to be configured to broadcast independently of its ability to accept serial data from a separate microcontroller unit. The 2101A PTT is easily configured by setting dipswitches to load the platform number, repetition period and number of data bits to broadcast. A solder jumper on the PTT circuit forces the PTT to accept the input of serial data when it is made available.

Service ARGOS provides the hexadecimal code to set the platform number, as well as the repetition period which was 90 seconds for all of the IOEB PTTs. In order to minimize interference between the two PTTs on each IOEB, one was provided with an 89 second interval, and the other with a 91 second interval. Every interval, these transmitters output header information and 256 bits of data to circular patch antennas mounted on the top plate of the sphere. After each transmission, the PTT toggles a hardware line to the microcontroller indicating that it is ready to accept new serial data. If no new data is received after $x$ seconds, then the PTT continues to broadcast the previously stored datastream.

On startup, each PTT reads its dip-switch settings to determine its own configuration, broadcasts the last input data, and goes into low power mode until the next period is reached, and then repeats the same process for as long as appropriate power is applied. Under normal circumstances, to reach the satellite, the PTT must output approximately $1 \mathrm{~W}$ at the ARGOS carrier frequency of $401.650 \mathrm{Mhz}$. Temperature will cause the temperature compensated crystal oscillator (TCXO) onboard the PTT to vary slightly, but it may drift no more than 400 $\mathrm{KHZ}$ away from the ARGOS frequency or it will not be detected by the satellite. Each transmission lasts only 920 milliseconds, during which the PTT draws a maximum of 530 milliamps.

In extreme high latitudes, the ARGOS satellites are within range to receive the signal approximately 24 to 28 times a day, which is subsequently passed along to Service ARGOS in Landover, Maryland. There the location of the IOEB is calculated, and the data from the IOEB assembled, for access over telephone lines.

In keeping with the modular design of the electronic network, each PTT was wired to a separate battery supply to provide power independent of all other 
electronics. Due primarily to the $5 \mathrm{~mA}$ current that each PTT draws in quiescent mode while enabled for serial data input, each unit requires nearly $100 \mathrm{Ah}$ of battery to supply energy for a one year operation.

Flat patch antennas are used to convey the transmission from the PTT to the ARGOS satellite. The shape of this type of an antenna allows it to be mounted flush along the top surface of the buoy to prevent damage, and still provide a nearly 180 degree radiation pattern. Furthermore, these antennas may be submerged to a few meters depth without being harmed. In the AEDB, similar oil-filled patch antennas were successfully used, although the $401.650 \mathrm{Mhz}$ ARGOS carrier frequency would shift if oil leaked from the housing. As a result, on the IOEBs, the radiating and reflecting surfaces are now encased in a hard epoxy mold, with a two-wire coaxial pressure resistant cable protruding out from the underside.

In order to monitor the operation of each PTT, the battery voltage of the instrument is divided through a resistor network and digitized by its corresponding microcontroller. The three bit variable PTT represents this voltage (within $0.5 \mathrm{~V}$ ) and is updated every six hours and broadcast to the ARGOS satellite. However, because of the decay characteristics of lithium batteries, the voltage should change very little throughout most of its life, but will be affected more by changing temperatures.

\section{Microcontroller Units and MUSSIC}

Managing the flow of data between the individual instruments on the network and to the PTTs, are dual microcontroller units (MCUs) which are based on TT3 data loggers. Each IOEB utilizes a modified SAIL communications protocol to obtain data from all other sensors via an ELA485 two-wire electrical network. This combination of hardware and software allows data to be telemetered from all the sensors on the IOEB.

In order to allow the TT3 to interface with the MUSSIC network, a TT485 circuit board was designed specifically for the IOEB to include the EIA485 network circuit and extended auxiliary UART circuitry to enable CMOS data to a PTT. A multifunction board, it also includes a two channel 12-bit A/D converter with power switching for applications other than the MCU.

The EIA485 standard specifies the electrical characteristics of generators and receivers for the interchange of binary signals in multipoint interconnection of digital equipment (EIA485, 1983). Implementing this standard means that multiple instruments may be networked using only two individual conducting cables. This is mechanically advantageous because it eliminates the bulkiness of multi-cable assemblies that would be required using other dedicated single-point standards. On the other hand, complexity in the system is increased, since care must be taken to ensure that only one driver is active at a time, or meaningless 
overlapping communications will occur.

The TT485 circuit used for the IOEB MUSSIC network is based on the LTC485 which is a low power differential bus/line transceiver designed for multipoint data transmission standard EIA485 applications, and also meets the requirements of EIA422. To prevent faults, the CMOS integrated circuit (IC) has an extended common mode range and protection against latchup. The driver and receiver are normally forced into a high impedance state, so that input voltage differences of only $200 \mathrm{mV}$ are detectable. The result is that only two conductors are required to address many instruments along the EIA485 network. Mechanically, the network is implemented on the IOEB by the mooring cable segments and underwater Brantner connections of the three-wire conducting cable. On the three-pin connectors to the MUSSIC network the wire to pin 1 is a spare conductor, the wire to pin 2 is the A terminal of the LTC485, and the wire to pin 3 is the B terminal on the same.

Because more than 256 bits of data is being acquired by the IOEB sensors every measurement interval, a complicated transmission scheme (Figure 6) is used to compress all of the information for ARGOS broadcasting. According to the particular sequence, each MCU interrogates a subset of the IOEB instrumentation, compiles the data and then passes it to a PTT via an auxiliary UART circuit. Then, after hibernating in micropower mode for approximately 57.5 minutes, the MCU implements the next sequence and repeats the process. There are a total of six sequences that each MCU utilizes, and for simplicity in the modular design, each MCU exclusively controls the flow of all sensor data to only one PTT.

The Serial ASCII Instrumentation Loop (SAIL) data communications standard (IEEE, 1985) was adapted to define the software protocol on the instrument network. On the IOEBs, the network MCUs begin each sequence by sending the attention character "\#" (hex 23) over the MUSSIC network, which wakens all of the instrument controllers on the mooring system. Each of the devices is individually interrogated serially at 9600 baud, by sending the attention character first, followed by the unique two character address and the character "R" (hex 52). When addressed, an instrument responds by repeating its address and the character "R", followed by ASCII hexadecimal data, and the message terminator character ETX (hex 03). For example, to request the latest acquired data from an IOEB sediment trap, it is necessary to prompt the device with "\#12R", whereupon the sediment trap microcontroller will respond with "12RHE", where " $\mathrm{H}$ represents the hexadecimal character containing the event and status information from the sediment trap, and "E" is the ETX terminator character.

The software programs 40CTRL.BAS and 41CTRL.BAS operate the MCUs on each IOEB. The first program begins the MCU unit on sequence one and interrogates the ADCP DPM module using the address "\#40R", while the other program begins on sequence four and interrogates the DPM with "\#41R". The DPM is the only instrument on the IOEB that discerns between the prompting 
Table 1: MUSSIC Sequence Timing Table

\begin{tabular}{|c|c|c|}
\hline $\begin{array}{l}\text { Data } \\
\#\end{array}$ & $\begin{array}{l}\text { Sequence } 1 \text { : } \\
\text { attention character sent by MCU }\end{array}$ & Time \\
\hline \#20R & sleep 15; prompt Meteorological Module & 15 \\
\hline $20 \mathrm{R}<26 \mathrm{H}>\mathrm{E}$ & receive Met data (26 Hex chars.) & $1-37$ \\
\hline \#21R & sleep 2; prompt Ice Module (I) & \\
\hline $21 \mathrm{R}<42 \mathrm{H}>\mathrm{E}$ & receive Ice data (42 Hex chars.) & $2-38$ \\
\hline \multirow[t]{2}{*}{ \#R\#R\#04R } & $\begin{array}{l}\text { turn off SeaCats } \\
\text { send data to PTT }\end{array}$ & $\frac{2-92}{20-182 \text { secs }}$ \\
\hline & $\begin{array}{l}\text { Sequence } 2 \text { : } \\
\text { attention character sent by MCU }\end{array}$ & \\
\hline \#12R & sleep 20; prompt Sediment Trap & 20 \\
\hline $12 \mathrm{R}<\mathrm{H}>\mathrm{E}$ & receive ST data (1 Hex char.) & $1-52$ \\
\hline \#R\#R\#31R & sleep 1; prompt SeaCat I & \\
\hline $31 \mathrm{R}<8 \mathrm{H}>\mathrm{E}$ & receive SeaCat data (8 Hex chars.) & $1-10$ \\
\hline \#40R & prompt ADCP/DPM (40 or 41$)$ & \\
\hline $40 \mathrm{R}<34 \mathrm{H}>\mathrm{E}$ & receive ADCP data ( 34 Hex chars.) & $1-10$ \\
\hline \#R\#R\#32R & sleep 1; prompt SeaCat DO,FL & \\
\hline $32 \mathrm{R}<18 \mathrm{H}>\mathrm{E}$ & receive SeaCat data ( $18 \mathrm{Hex}$ chars.) & $1-10$ \\
\hline \# & attention character sent by MCU & \\
\hline \#51R & sleep 15; prompt TR,FL & 15 \\
\hline $51 \mathrm{R}<6 \mathrm{H}>\mathrm{E}$ & receive TR,FL data (6 Hex chars.) & $1-37$ \\
\hline \multirow[t]{3}{*}{ \#R\#R\#04R } & turn off SeaCats & \\
\hline & send data to PTT & $\frac{2-92}{42-246 \text { secs }}$ \\
\hline & $\begin{array}{l}\text { Sequence 3: } \\
\text { attention character sent by MCU }\end{array}$ & \\
\hline \#20R & sleep 15; prompt Meteorological Module & 15 \\
\hline $20 \mathrm{R}<26 \mathrm{H}>\mathrm{E}$ & receive Met data (26 Hex chars.) & $1-37$ \\
\hline$\# 22 \mathrm{R}$ & sleep 2; prompt Ice Module (II) & \\
\hline $22 \mathrm{R}<42 \mathrm{H}>\mathrm{E}$ & receive Ice data (42 Hex chars.) & $2-38$ \\
\hline \multirow[t]{2}{*}{ \#R\#R\#04R } & turn off SeaCats & \\
\hline & send data to PTT & $\frac{2-92}{20-182 \operatorname{secs}}$ \\
\hline
\end{tabular}

Notes:

Hibernate period between sequences $=3450$ seconds $(57.5 \mathrm{~min})$

Total cycle time for all six sequences $=5.8$ to 6.1 hours $(20,892$ to 21,954 secs $)$ 
Data

\#

\#13R

$13 \mathrm{R}<2 \mathrm{H}>\mathrm{E}$

\#R\#R\#30R

$30 \mathrm{R}<8 \mathrm{H}>\mathrm{E}$

\#40R

$40 \mathrm{R}<34 \mathrm{H}>\mathrm{E}$

\#R\#R\#32R

$32 \mathrm{R}<18 \mathrm{H}>\mathrm{E}$

\#

\#51R

$51 \mathrm{R}<6 \mathrm{H}>\mathrm{E}$

\#R\#R\#04R

$\#$

\#20R

$20 \mathrm{R}<26 \mathrm{H}>\mathrm{E}$

\#23R

$23 \mathrm{R}<42 \mathrm{H}>\mathrm{E}$

\#R\#R\#04R

\#

\#50R

$50 \mathrm{R}<34 \mathrm{H}>\mathrm{E}$

\#40R

$40 \mathrm{R}<34 \mathrm{H}>\mathrm{E}$

\#R\#R\#32R

$32 \mathrm{R}<18 \mathrm{H}>\mathrm{E}$

\#

\#51R

$51 \mathrm{R}<6 \mathrm{H}>\mathrm{E}$

\#R\#R\#04R
Sequence 4:

attention character sent by MCU

sleep 20; prompt Water Transfer System 20

receive WTS data (2 Hex char.) $1-52$

sleep 1; prompt SeaCat II

receive SeaCat data(8 Hex chars.) $1-10$

prompt ADCP/DPM (40 or 41)

receive ADCP data (34 Hex chars.) 1-10

sleep 1; prompt SeaCat DO,FL

receive SeaCat data (18 Hex chars.)

attention character sent by MCU

sleep 15; prompt TR,FL

receive TR,FL data (6 Hex chars.)

turn off SeaCats

send data to PTT

Time

$-52$

$1-10$

15

$1-37$

$2-92$

$42-246$ secs

Sequence 5:

attention character sent by MCU

sleep 15; prompt Meteorological Module

15

receive Met data (26 Hex chars.)

$1-37$

sleep 10; convert PTT and CON data

12

sleep 2; prompt Ice Module (III)

receive Ice data (42 Hex chars.)

$2-38$

turn off SeaCats

send data to PTT

$\underline{2-92}$

32-194 secs

Sequence 6:

attention character sent by $\mathrm{MCU}$

sleep 15; prompt S4 Current Meter

15

receive S4 data (34 Hex char.) 1-37

sleep 1; prompt ADCP/DPM (40 or 41)

receive ADCP data (34 Hex chars.) 1-10

sleep 1; prompt SeaCat DO,FL

receive SeaCat data (18 Hex chars.) 1-10

attention character sent by $\mathrm{MCU}$

sleep 15; prompt TR,FL

15

receive TR,FL data (6 Hex chars.) 1-37

turn off SeaCats

send data to PTT $\underline{2-92}$

$36-216$ secs

Minimum duration of a single sequence cycle $\sim 58 \mathrm{~min}$ (3470 secs) Maximum duration of a single sequence cycle $\sim 62 \mathrm{~min}$ (3696 secs) 
MCUs. Each program is configured to begin operation on powerup, and is also coded to restart at the beginning if it momentarily loses power, or encounters a software error. At the beginning of every sequence, each MCU checks the EIA485 network for other communications before it begins addressing the other network sensor modules. If the unit detects signals on the network, it sleeps for 1 minute and checks again; repeating this process until it finds an opening to communicate. This feature is incorporated to prevent the two microcontrollers from talking simultaneously, which would only provide noise on the line and jam communications. The drawback to the "waiting" method is that any instrument on the network can indefinitely jam the network by creating unwanted noise. Ordinarily, however, the MCU addresses an instrument and expects a response within 2 seconds. If there is no response, only noise, or if the answer does not include the proper interrogation address, the MCU will attempt to readdress the instrument. Depending on the particular instrument being addressed, the MCU may wait up to 17 seconds between reprompts. If the MCU does not receive an appropriate answer in three consecutive attempts, then it proceeds to the next instrument in the sequence. Normally the period of a complete sequence (including $57.5 \mathrm{~min}$ of hibernate) is between 58 and $62 \mathrm{~min}$, which is dependent on temperature effects on the clock oscillator on the TT3, and on the amount of network communications required each sequence to retrieve appropriate responses from the instruments. Table 1 lists the MUSSIC address sequencing of the instrumentation according to the MCU programs.

After completing the acquisition of the instrument data for a sequence, the MCU sends the characters "\#R\#R\#04R" over the MUSSIC network in order to send the SeaCats into low power mode. The initial "\#R" prompts are added to clear the buffers of the SeaCats in order to ensure recognition of the "\#04R" command. Internally, the MCU reverses the order of the compiled datastream in memory to ensure that it is broadcast inorder when received by the PTT. The data is passed to the PTT when it notifies the MCU it will accept new data by setting a CTS hardware line high and then low. The PTT toggles this line every 90 seconds just prior to broadcasting the data already stored in its memory.

The EIA485 converter typically draws only $300 \mu \mathrm{A}$ of current quiescently. When added to the 60 to $80 \mu \mathrm{A}$ that a TT3 typically draws in hibernate mode, the sleep current of the combination is between 350 and $400 \mu \mathrm{A}$. That requires less than $3 \mathrm{Ah}$ to power for one year, which is the equivalent capacity of two "AA" batteries at room temperature. In operation, each TT3 MCU draws approximately $30 \mathrm{~mA}$ during each awake period which normally lasts more than $30 \mathrm{sec}-$ onds but less than 3.5 minutes.

\section{Lithium batteries}

Power for the electronics in the surface package of the IOEB was provided by fused and diode protected packs of lithium oxyhalide batteries assembled in 
plastic molds. Four battery slices with a total of 120 cells were used to power the Transpolar Drift IOEB for 1.5 years of data collection and 2 years of PTT transmission, while 192 cells in six slices were used for the Beaufort Gyre IOEB to maintain the sensor electronics for 2 years and the PTTs for 3 years.

Electrochem "DD" batteries are cased in stainless steel, internally fused at 4 Amps, and sealed against hydrogen leakage to ensure safe operation. Furthermore, they have a high energy density and reliable performance at cold temperatures; providing up to $30 \mathrm{Ah}$ of energy apiece at room temperature and nearly two-thirds of that at $-40{ }^{\circ} \mathrm{C}$.

The batteries were assembled into 10" diameter battery slices by Battery Assemblers Inc. Sixteen and 20 gauge Teflon coated wire were used between cells and coming out from the pack. Protection diodes were sealed with the batteries inside of the 5" high plastic molds, and all of the outputs from the various slices were wired to a separate fuse panel, which was wrapped and sealed in the electronics tube prior to deployment. Standard $3 \mathrm{amp}$ fuses protect the battery slices from external short circuits during operation.

The Transpolar battery pack was 20 inches long and weighed $30 \mathrm{~kg}$, while the Beaufort was 30 inches long and weighed nearly $50 \mathrm{~kg}$. All of the buoy electronics was mounted on the endcap of the 10" diameter pressure housing and was 18 inches long. Between the electronics and the Beaufort battery pack, the total length of the 48 " tube was occupied.

Table 2: Lithium Battery Packs Specifications

Transpolar IOEB: 1.5 year minimum lifetime

\begin{tabular}{clccc}
$\#$ & Device & Total batts. & $A h$ & Min. duration \\
\hline 2 & PTT & 64 & 144 & 1.5 years \\
2 & MCU & 24 & 54 & 1.8 \\
1 & Met module & 12 & 54 & 2.3 \\
2 & Ice modules & 12 & 54 & 2.0 \\
1 & Echo sounder & 8 & 18 & 3.0
\end{tabular}

Beaufort IOEB: 3 year minimum lifetime

\begin{tabular}{clccc}
$\#$ & Device & Total batts. & Ah & Min. duration \\
\hline 2 & PTT & 128 & 288 & 3.0 years \\
2 & MCU & 32 & 72 & 2.4 \\
1 & Met module & 12 & 54 & 2.3 \\
2 & Ice modules & 12 & 54 & 2.0 \\
1 & Echo sounder & 8 & 18 & 3.0
\end{tabular}



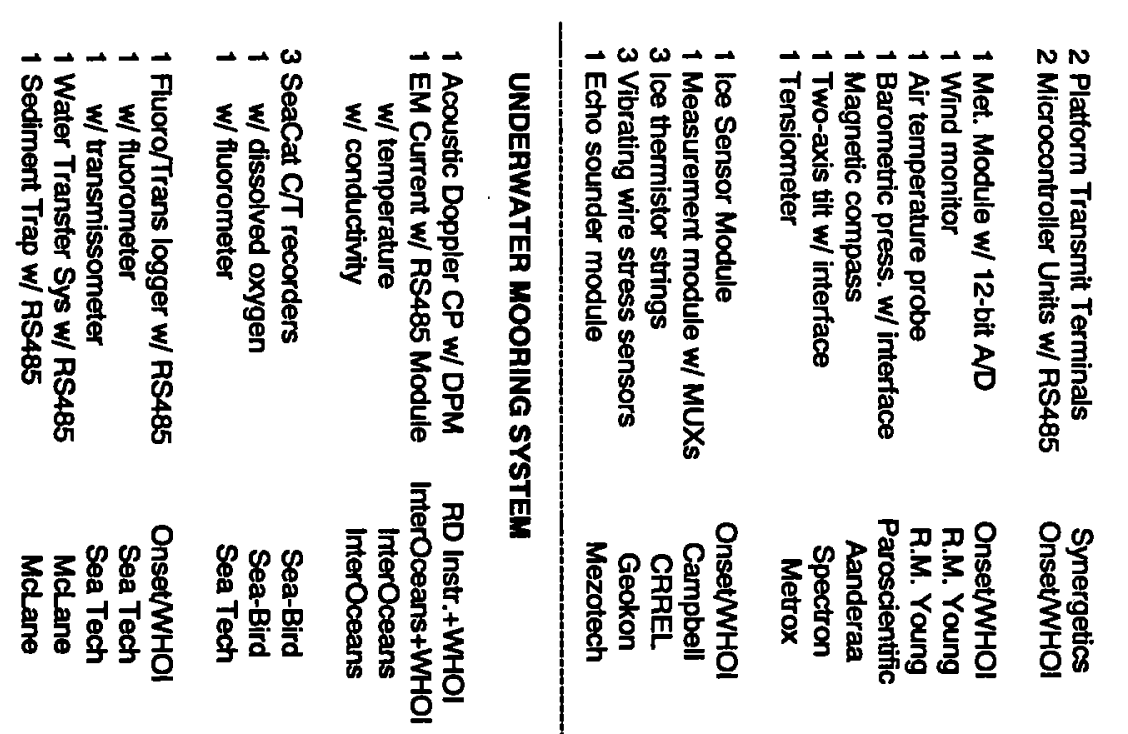

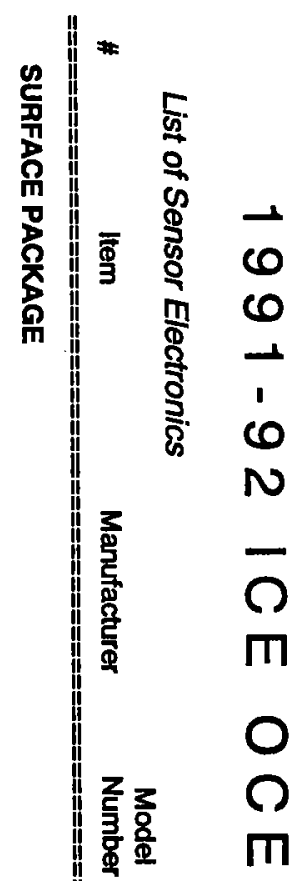

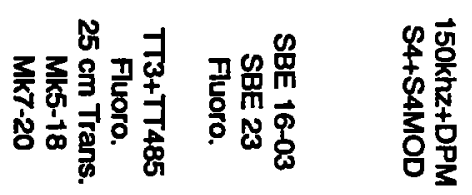
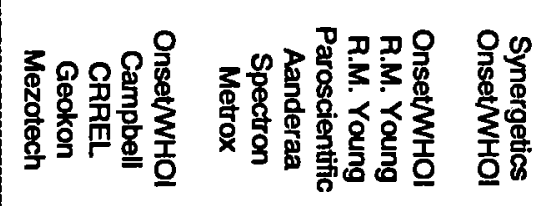

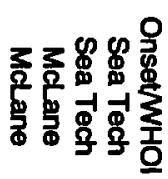

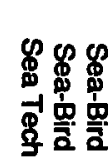

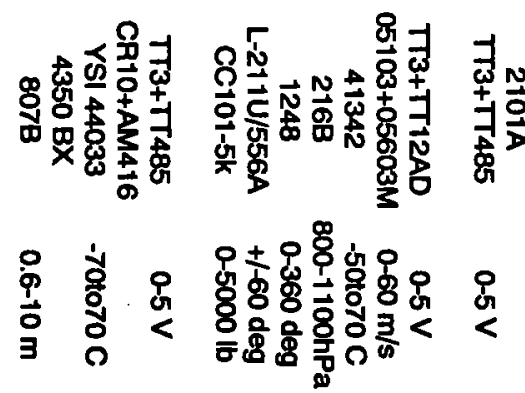

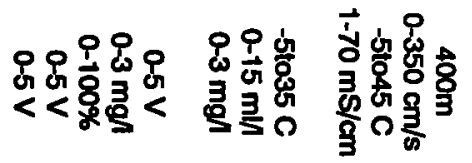

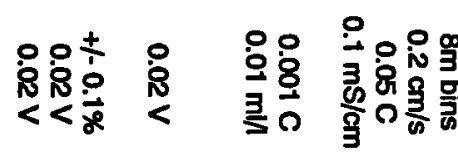

安

キ土去

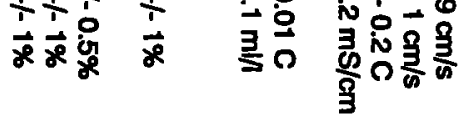

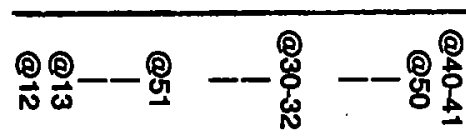

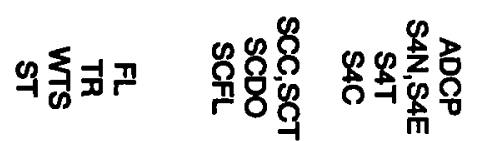

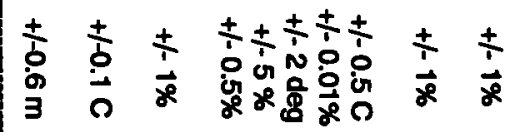

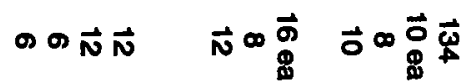

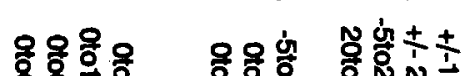

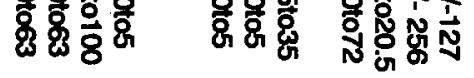

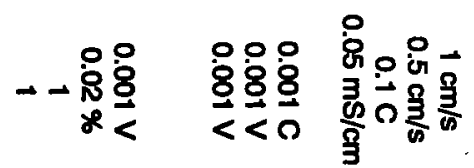

-

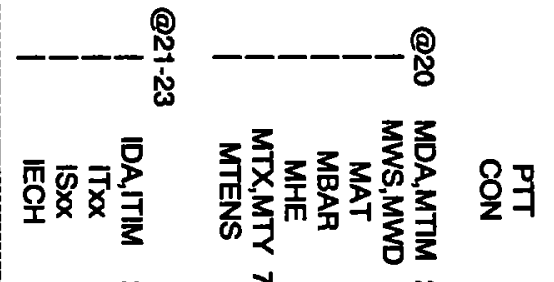

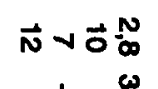

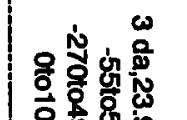

ळळठ大 $\infty$

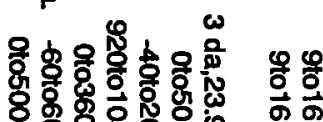

总总幽

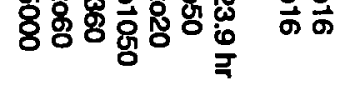

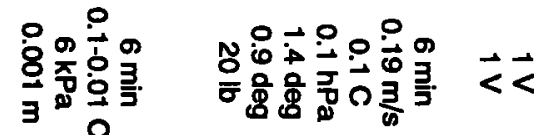

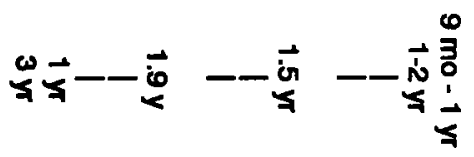

Table 3: Sensor Table 


\section{Sensors and instruments}

The scientific sensors on the IOEB can be divided into three main categories: meteorological sensors, ice sensors, and ocean sensors. Simultaneously, data is acquired by all the sensors throughout the lifetime of the buoy. While individual groups of sensors are included with specific scientific objectives in mind, intercomparison between sensors from different fields may lead to the most innovative results. All sensors that are located in the air, in the ice, or in the surface float are rated to operate to temperatures at least as low $-40{ }^{\circ} \mathrm{C}$, in order to function during the severe cold Arctic winter. Underwater instruments are rated to at least $-5{ }^{\circ} \mathrm{C}$ operation.

Meteorological sensors are essential to monitor the daily and seasonal weather conditions and the passage of storm systems over the ice covered areas in the Arctic. Because of the large effect that winds have on the variance of ice motion, a wind monitor is an essential instrument to determine the wind stress on the momentum budget of the movement of the icefloe. Furthermore, an array of barometric pressure sensors throughout the Arctic would allow the geostrophic winds to be calculated. Along with an air temperature probe, these sensors complete the current meteorological station onboard the IOEB.

Because the ice pack has the single greatest effect on the Arctic environment, IOEBs collect time series data of internal ice stress, profiles of ice temperature, and ice thickness conversions from sensors which are deployed in the ice immediately surrounding the surface flotation package. One objective of these sensors is to measure ice temperatures, determine the thickness of the individual ice floe, and determine oceanic heat fluxes during the drift of the IOEB. By integrating additional sensors, this work more precisely continues research instituted during the AEDB experiment (Perovich, et. al., 1989).

Under the icefloe, ocean instruments are collecting data useful for determining the circulation of water masses, and the biogeochemical composition of the seawater. An ADCP system is incorporated on the IOEB primarily to detect advection of ocean water and the internal wave frequency spectrum from the observed currents as the mooring systems drift over the topography of the Arctic Ocean. Synchronized comparison of internal waves at different locations under the icepack will provide fundamental data for understanding water motion in the Arctic. In addition, bio-sensors, a combination of fluorometer, transmissometer and a multiport microfiltering water transfer system for the collection of phytoplankton and suspended particles, have been deployed in order to clarify the short- and long-term evolution of under-ice standing stock throughout the Arctic seasons. Optimistically, particle flux data from time-series sediment traps in the Beaufort Gyre and Transpolar Drift ice will clarify one of the major missing links in the global carbon cycle. Among the other underwater sensors, conductivity and temperature recorders should indicate the melt-water signal to the Holocline layer. 


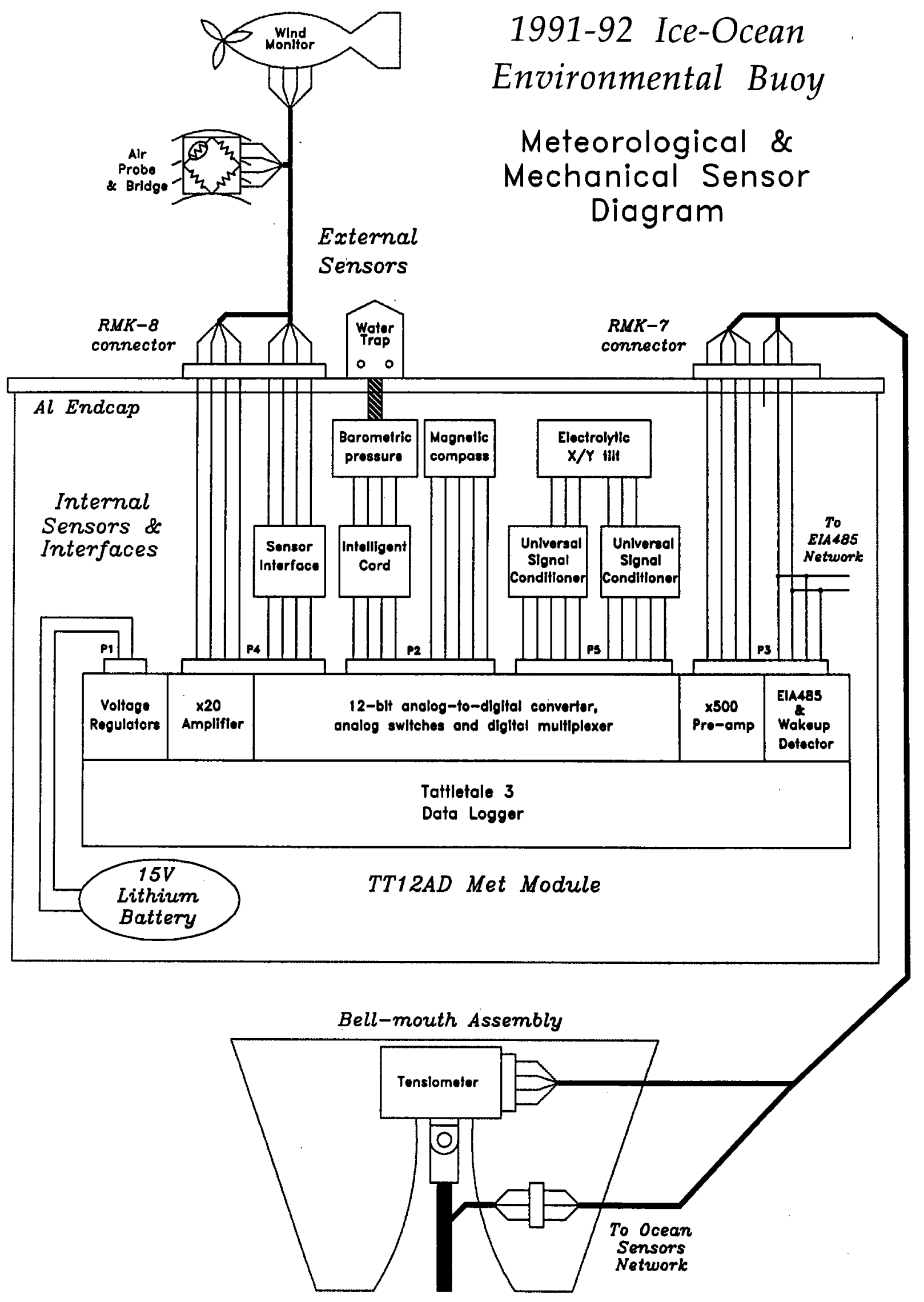

Figure 7: Met Module Block Diagram 


\section{Meteorological and mechanical sensors}

Mounted on a six foot long aluminum mast protruding above the surface float on the IOEB are mounted the wind and temperature sensing devices. Though the mast is securely $\mathrm{u}$-bolted to a strut on the buoy top plate, it has to be considered expendable when an icefloe might fracture around the buoy. Similarly, the Brantner cable connecting the sensors to the electronics endcap is designed to pull out without disturbing the integrity of the sealed electronics.

On the other hand, the barometric pressure sensor is mounted inside of the electronics endcap and open to the outside air through a hole in the endcap to an air pressure port and water trap on the outer side of the endcap. The longevity of a quality barometric pressure signal depends on the length of time that the water trap mechanism prevents the sensor aperture from icing over.

The choice of meteorological sensors incorporated on the IOEB was based on the sensors used during the Winter Weddell Sea Program in 1986 by Hoebert et al. (1987), which demonstrated how a simultaneous array of meteorological buoys in the Polar sea-ice can be used to calculate the sea ice momentum budget over a particular area.

In addition to the purely scientific sensors on board the IOEB, several engineering measurements are broadcast in order to measure the effect of environmental forces on the structure of the IOEB. These other sensors are mounted on the chassis on the electronics endcap in the surface package and are being interrogated every hour with the meteorological sensors for convenience. In addition to a magnetic compass, an $x-y$ tilt sensor, and strain gauge tensiometer on the mooring line are taking measurements inside the surface buoy.

All of these sensors are interrogated synchronously at hourly intervals, and the time-coded results transmitted via the ARGOS platform transmit terminals. This information will not be recorded internally by the data acquisition electronics.

\section{a. TT12AD Met Module}

A single data logger module is used on each IOEB to collect the data from meteorological and mechanical sensors that are incorporated in the surface flotation package. A mast protruding above the apex supports a wind monitor and air temperature sensor, inside the electronics package are a barometric pressure sensor, magnetic compass, and electrolytic tilt sensors, and attached to the top of the mooring cable is a tensiometer.

The data logger engine is another TT3. A 12-bit A/D converter board (TT12AD) was added to interface between the sensors and the TT3, and to provide the MUSSIC network circuitry. Along with the A/D converter and EIA485 
circuitry, this board contains analog switches to provide power to the sensors, signal conditioning circuitry, voltage regulators, and a digital multiplexer. Together the TT12AD and TT3 comprise the meteorological and mechanical sensor module, or met module.

Under normal circumstances, the met module acquires data every hour from the barometric pressure sensor serial interface, a magnetic compass, a twoaxis electrolytic tilt sensor, an air temperature thermistor, and ten minute averages of the wind monitor and tensiometer data. All of the data from the sensors is digitized by an LTC1290 A/D converter IC on the TT12AD board, except for the barometric pressure sensor which uses an interface to pass processed readings serially to the auxiliary UART of the met module TT3. The same 12-bit conversion circuit is used not only on the TT12AD met module board, but also on TT485 boards when used to digitize the echo sounder input by the ice module, and transmissometer and fluorometer data by the TRFL module. The following description of the converter hardware and assembly code applies to both board systems.

The LTC1290 is an 8-channnel, serial I/O, 12-bit A/D converter that uses CMOS switched capacitor technology to minimize power consumption. The input multiplexer can be software configured for single ended or differential inputs in any combination, and either unipolar or bipolar conversions. In order to supply a $1 \mathrm{Mhz}$ clock for the conversion, a modification is made to TT3s which connect to the converter circuit boards. Signal ECLK is made available to the addon board by adding a header pin to the center of the TT3 and wiring it to pin number 44 on the 6303 microprocessor. Because of the capacitive redistribution A/D conversion technique used by the LTC1290, it is susceptible to power supply noise, and software averaging is performed by the met module TT3 on repetitive conversions to smooth the digitized output.

Due to certain limitations of the TTBASIC compiler for the TT3, the code to pass configuration information to the converter chip, do the conversion, and get the results, was written in 6303 assembly. The assembly routine is loaded into TT3 memory (beginning at location $4000 \mathrm{H}$ ) at the start of the met module operation program, and is accessed by using the TTBASIC "CALL" command with the appropriate parameters. The first parameter is the routine's location in memory (\&H4000 in TTBASIC), and the second parameter is the configuration byte for the conversion. The configuration word (also passed in hexadecimal) determines the number of consecutive conversions to be performed ( 255 maximum), and the port configuration for the input to the LTC1290 converter. The results are automatically stored by the assembly code into the @0 to @n variable array of the TT3 (which begins at memory location $7218 \mathrm{H}$ ), where $n$ equals the number of conversions specified.

When prompted over the MUSSIC network The TT12AD met module returns with the latest completely acquired data from the sensors within $30 \mathrm{sec}-$ 
onds. The unit draws between 3 and $100 \mathrm{~mA}$ when operating (depending upon which sensor is being powered) and less than $400 \mu \mathrm{A}$ when sleeping between acquisitions and communications. Consequently, it requires only 12 "DD" lithium cells to power this system for over 2 years.

\section{b. Air temperature and wind monitor}

Data collected on the local winds is important for determining their impact on the short-term drift of the Arctic ice pack. Mounted on the very apex of the meteorological sensor mast the R.M. Young model 05103 Wind Monitor measures horizontal wind speed and azimuth approximately 10 feet above the surface of the icefloe. Just below the wind monitor are a R.M. Young Platinum Temperature Probe (RTD) protected by a Gill Multi-plate Radiation Shield. A single Y-cable feeds the signals from both these instruments to a single bulkhead connector on the electronics endcap.

With a sensitivity of $0.6 \mathrm{~m} / \mathrm{s}$, the Young wind monitor measures wind speed over the range of 0 to $60 \mathrm{~m} / \mathrm{s}$, and can survive gusts up to $80 \mathrm{~m} / \mathrm{s}$. The vane threshold is $0.9 \mathrm{~m} / \mathrm{s}$ at 10 degrees. Though noted for its reliability and accuracy, in the Arctic environment this apparatus is subject to the effects of icing and rimming which could cause a change in the calibration when severe weather conditions are encountered. However, since this is an expendable sensor on the IOEB, power hungry preventive measures were not employed to reduce these effects.

Through a bulkhead penetrator on the electronics package endcap, information from the wind monitor is conducted to the appropriate acquisition circuitry. Inside the surface electronics package of the IOEB, a Young 05603 Sensor interface circuit card provides the excitation for the wind monitor and receives the raw output signals. Ten times during the first ten minutes of every hour the TT12AD met module powers the sensor interface, and receives calibrated voltages representing the wind speed and azimuth. These data are averaged, digitized to 8 bits and stored in memory. As a result, wind speeds between 0 and 50 $\mathrm{m} / \mathrm{s}$ are telemetered with a resolution of $0.2 \mathrm{~m} / \mathrm{s}$, and azimuth measurements are resolved to 1.4 degree.

On the other hand, the air temperature data is not averaged for $10 \mathrm{~min}$ utes, but rather a single interrogation of this data is made and stored at the top of the hour. To determine air temperature, a Young 41342 platinum temperature probe (RTD) is used with a 41002 radiation shield. The temperature sensor is accurate to $\pm 0.5^{\circ} \mathrm{C}$, but was calibrated to within $0.1^{\circ} \mathrm{C}$.

A full Wheatstone bridge using Vishay resistor elements was added to the air thermistor assembly on the met mast to preamplify the output signal and reduce temperature effects on the measurement. Furthermore, the radiation shield surrounding the temperature probe ensures that radiation error on the 
temperature measurement will be less than $0.4{ }^{\circ} \mathrm{C}$ for winds exceeding $3 \mathrm{~m} / \mathrm{s}$. The TT12AD met module feeds the output from the bridge into an instrumentation amplifier and to the A/D converter where the air data is digitized, converted to temperature units, redigitized and stored with 10-bit resolution between the range of -40 to $20^{\circ} \mathrm{C}$.

When interrogated over the MUSSIC network, the met module responds with the latest meteorological and mechanical data, including the air temperature and wind speed and direction. If the timing is such that the 10 minute averaging of the wind data is interrupted, zeros are returned for the wind variables and the averaging begun anew. With the exception of the tensiometer data, the other met module sensor variables are unaffected by the interruption.

\section{c. Barometric pressure}

The barometric pressure sensor on the IOEB is a Paroscientific model 216B101 quartz crystal pressure sensor with temperature. Mated with an Intelligent Transmitter (also from Paroscientific), the device is highly accurate $(0.01 \%$ full scale) down to $-54{ }^{\circ} \mathrm{C}$ because it makes the temperature correction and provides the information on a RS-232 bus. In addition, the unit is specified for up to 18 PSIA of overpressure before failure, which means that the surface electronics package could be submerged over $10 \mathrm{~m}$ deep before danger of a leak through the barometer would occur.

The Digiquartz pressure transducer detects pressure-induced stress by measuring changes in the oscillating frequency of a crystalline-quartz resonator (Busse, 1987). Relatively insensitive to temperature, residual thermal effects are compensated for (down to $-54^{\circ} \mathrm{C}$ ), by an internal quartz-crystal temperature sensor. Special mountings in the design of the sensor assembly isolate the detected signals from extraneous vibrations, and allow the device to be accurate to $0.01 \%$ of the reading, with calibration.

Every hour the met module powers the pressure sensor and interface and then prompts the Intelligent Transmitter for the corrected barometric pressure using the commands "*0100P1", "*0100Q1", and "*0100P3", which cause the sensor to sample and send one pressure sensor period, one temperature sensor period, and finally one compensated pressure value. It is important to configure the Intelligent Transmitter before connection to the met module, for the proper address, baud rate, integration period, and output units. On the IOEB, the address of the unit is always 1 , the baud rate is set for 4800 , the integration time is 1.3 seconds (which provides a resolution of $0.5 \mathrm{ppm}$ in the pressure reading), and

the output is in hPa. The output is compressed by the met module to provide a 10 bit representation of the barometric pressure in the range of 920 to $1050 \mathrm{hPa}$.

The water trap was purchased from Simtronix in Norway, and was chosen because it was implemented successfully on Nordrift Polar Research Data Buoys 
by Dr. H. Hoebert during his Weddell Sea Drifting buoy program. The water trap removes water droplets by mechanically guiding the air through a labyrinth and then filtering. It requires no power to operate, and should be invisible to the acquired results.

\section{d. Magnetic compass}

An Aanderaa 1248 magnetic compass is provided to fix the heading of the surface package as it drifts with the sea-ice. During the period when the buoy is secured in the ice, the compass heading indicates icefloe rotation; although in marginal ice zones (MIZs) this connection cannot necessarily be made. More importantly, the magnetic compass variable is used to convert the wind azimuth to earth magnetic coordinates. Further correction will need to be performed during post processing to produce true wind vectors from the magnetic data at different locations due to the nearness of the Earth's geomagnetic pole. In addition, comparison of this data with the flux gate compass on the ADCP below the ice will also indicate twist along the mooring cable, which could be significant in terms of future engineering considerations.

This magnetic compass is the same reliable component that is used on the Aanderaa recording current meters. When taking a reading, current must first be applied to an axially wound coil which clamps the magnetic assembly to a potentiometric ring. The direction is then determined by applying a voltage to the effective half-bridge circuit and measuring the output voltage ratiometrically with the 8-bit A/D converter on the met module TT3. The resultant heading measurement resolves $1.4^{\circ}$ with a stated accuracy of $\pm 2^{\circ}$ within the operating temperature range of -40 to $60^{\circ} \mathrm{C}$.

\section{e. Electrolytic tilt}

Two perpendicular Spectron L-211U electrolytic tilt sensors mounted in a holder are wired to separate Universal Signal Conditioners (MUPI-2) and are stored as separate $x$ and $y$ axis tilt data in the met module. These sensors indicate the vertical orientation of the surface package up to $60^{\circ}$ from the vertical. Furthermore, because the Aanderaa magnetic compass has an allowable tilt of less than $12^{\circ}$, indications of excessive tilt will determine the accuracy of the calculated wind vectors.

Each axis of tilt is a separate sensor which takes an electrolytic measurement of the resistance of a conductive fluid in a glass vial, relative to the physical pitch of the device. Designed for use in aircraft, these sensors are small, accurate, and operate at temperatures down to $-40{ }^{\circ} \mathrm{C}$. The electronic sensing circuit perceives each tilt axis as a liquid potentiometer. Small universal signal conditioning circuits are controlled by the TT 3 met module to produce a voltage between -5 and +5 corresponding to the tilt of each axis. Though the sensor is sensitive to a few minutes of arc, only 7-bit resolution (or approximately half a degree) is re- 
tained for transmission after scaling, in order to reduce the total amount of ARGOS data.

\section{f. Mooring tension}

The Metrox load cell tensiometer is positioned in the protective bellmouth flange, hanging directly in the mooring line. By the way that the unit is positioned in the bell-mouth, a potted strain gauge responds to compression on the load cell caused by the tension of the mooring system at the joint between the surface float and the ice strengthened E/M link. The acquisition circuit for this sensor is inside the electronics pressure tube, accessed through a bulkhead penetrator on the upper endcap.

The load cell has a rated capacity of $5000 \mathrm{lbs}$, but can be overloaded by $300 \%$ without failure. Under normal static circumstances, the tension detected by the load cell is around $1000 \mathrm{lbs}$, but varies when the buoy is subject to dynamic conditions. As controlled by the met module, when a voltage is applied to the load cell, the output from the strain gauge bridge is amplified on the TT12AD circuit board and digitized.

In order to estimate the dynamic stresses working on the ice strengthened link and the rest of the mooring system, ten measurements from the tensiometer are taken during the first 10 minutes of each hour along with the wind data. Not only the average tension is transmitted, but also the maximum and the standard deviation of the tension during the 10 minute time period. Depending on which odd sequence is transmitted, the standard deviation variable may be included in full, only partially, or not at all. Each tension value is expressed with 8 bits during broadcast, for a resolution of approximately $20 \mathrm{lbs}$. for the average and maximum, and $10 \mathrm{lbs}$. for the standard deviation. Along with the data from the wind monitor, zeros may be broadcast for tension data if the unit is interrupted during the 10-minute averaging period. 


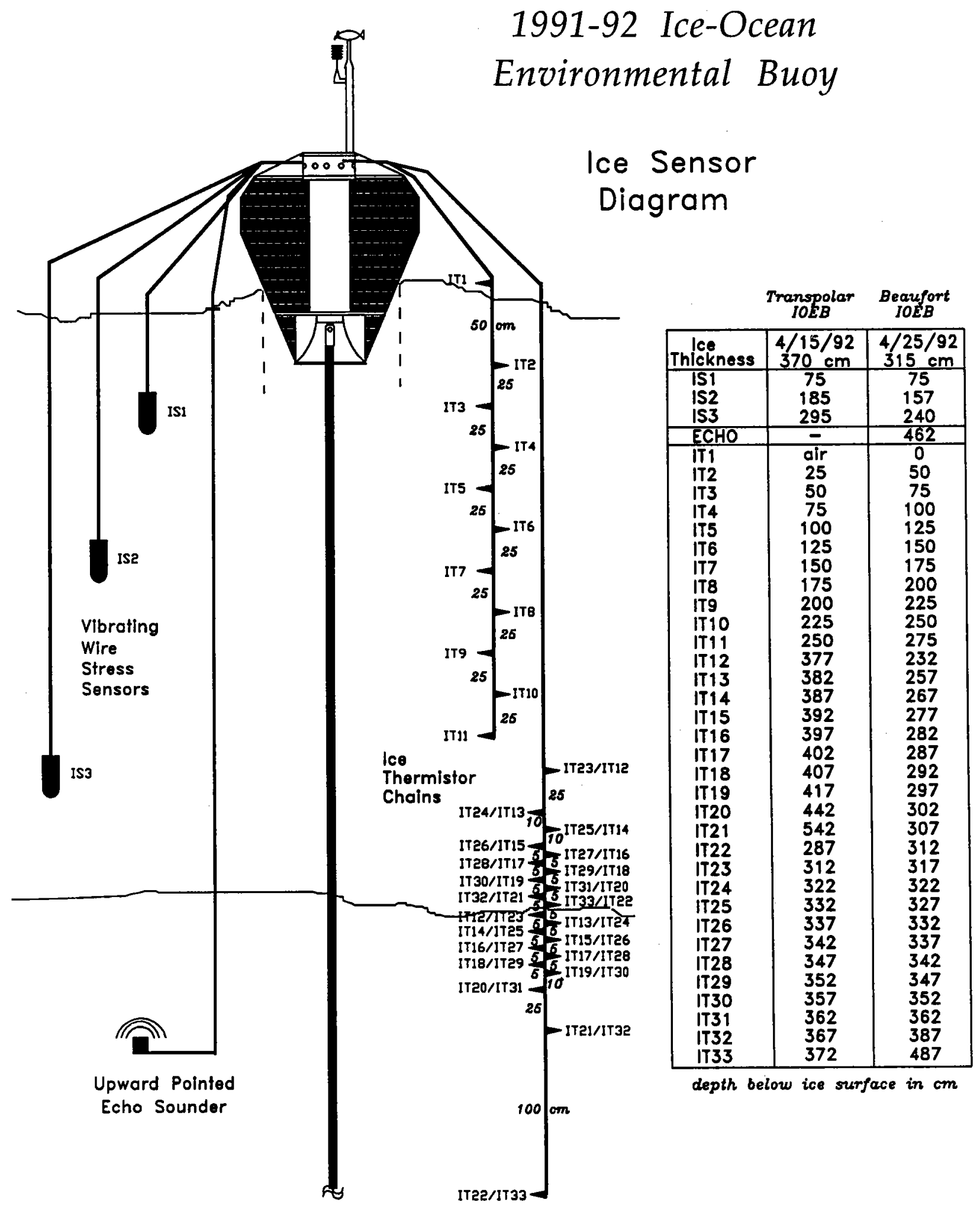

Figure 8: Ice Sensor Diagram 
In the ice surrounding the IOEB are two thermistor strings, three vibrating stress sensors, and an upward-pointed echo sounder for taking physical measurements of the sea-ice. All the sensors are operated by electronic modules in the pressure tube of the surface float; interfaced via bulkhead penetrators on the endcap. Similar to the meteorological sensors, most of the ice data is transmitted, but not stored. Expendable components, all these sensors will be torn away from the surface float when the ice floe breaks apart, but no physical damage to the buoy and no harm to the electronics will occur when this happens

Adhering to the system implemented by the U.S. Cold Regions Research and Engineering Laboratory (CRREL) in Hanover, $\mathrm{NH}$ and which was partially employed on the AEDB, information from the thermistors and stress sensors is multiplexed and collected by a Campbell CR10 data logger with two AM32 (or AM416) multiplexer cards. A TT485 ice module collects these results from the CR10 to pass along the MUSSIC network. Furthermore, the ice module uses its own circuitry to acquire the ice thickness from the upward-pointed echo sounder.

Like the TT3, the CR10 Measurement and Control Modules are loggers also based on the Hitachi 6303 microprocessor. Rugged precision data loggers, those on the IOEBs were specified for an operating temperature range of -55 to 85 ${ }^{\circ} \mathrm{C}$. Programmed by a specific set of instruction commands, simultaneous communication and measurement functions can be made by the module operating system. Voltage measurements are accurate to $0.2 \%$ of F.S., and the CR10 has 32 kbytes of ROM and 64 kbytes of RAM memory available for program and logging. Unlike the TT3, a frequency reference accurate to $\pm 40 \mathrm{ppm}$ enables precise period averaging measurements to be acquired. Programs are entered and monitored by a portable keypad or can be entered via a Campbell storage module. Development software from the manufacturer eases code development by allowing programs to be edited on IBM compatible computers and then downloaded to a storage module with another interface device.

Campbell multiplexers (AM32 or AM416) are used to increase the number of sensors that are interrogated by the CR10. The AM416 is the upgraded version of the obsolete AM32 with some changes. Whereas the AM32 has 32 sets of double contact relays, the AM416 has 16 groups of four contacts. One the Transpolar IOEB, AM32 multiplexers are used for the ice thermistor and ice stress measurements, while the Beaufort IOEB uses AM416 cards. The data in the CR10 Input Storage locations represent the processed data from both the ice thermistors and stress sensors; the calculations are made using the high resolution floating-point ability of the logger. During implementation slightly different wiring and programming was required to provide the same outputs from the different multiplexers without a variation in accuracy of the results. Appendix $C$ provides the sensor wiring for both multiplexer versions, and software for the Beaufort IOEB. 
Note that when using the AM416 multiplexer, only five out of the total six sets of stress wires can be interrogated. This fact is reflected in the software, and in Table 4.

The software program which operates the TT485 ice module is named ECHO.BAS, and serves to digitize and store data from the echo sounder module, but also acquires the ice stress and ice temperature data from the CR10, and combines all of the ice data into three datastreams for transmission over the MUSSIC network. The ice module recognizes and responds to three different MUSSIC addresses, so that the ice data can be divided into three subsets which are transmitted separately during every six hour period. Based on the different rates that various ice sensors acquire data, the total amount of updated ice data broadcast by each IOEB is 2376 bits/day.

Every hour, the ice module collects the latest sampling time and the battery voltage of the CR10, along with all of the latest ice stress and ice temperature samples, by employing telecommunications with the logger. The ice module initiates modem communications with the CR10 by raising the hardware line RING high. The CR10 responds by raising the ME (Modem Enable) line high, and determines the baud rate ( 9600 on IOEB) of communications from initial carriage returns (CR) sent to it via a 9-pin CMOS serial input/output connection. The CR10 indicates that it is ready for a command by prompting with a '*', and will terminate communications if more than 40 seconds elapses between telecommunications commands. Using the command "<loc. no. $>$ I", the CR10 is sequentially interrogated by the ice module for the calculated data in 48 Input Storage locations. The "E" command ends the call, and puts the CR10 logger back into low power mode.

Between acquisition periods and telecommunications, the CR10 low power mode draws about $500 \mathrm{uA}$ quiescently. Acquiring and processing the data from both the ice thermistors and stress sensors takes about 30 seconds, while drawing less than $100 \mathrm{~mA}$ for a power requirement of only $28 \mathrm{Ah} /$ year. Since the echo sounder module is supplied with its own separate battery supply switched by the ice module, the power requirements for the TT485 ice module are even less, and consequently are derived from the CR10 power supply. On the IOEB, 12 lithium "DD" cells are used to power the ice module CR10 combination for a minimum of 2 years.

\section{a. Ice thermistor strings}

In order to make indirect measurements of the oceanic heat flux through the Arctic sea-ice, two strings comprising a total of 33 ice temperature thermistors were provided by CRREL and are installed in the icefloe surrounding each IOEB. This information is fed to the inner electronics package of the surface float by three 12-pin Brantner cables, requiring that every eleven thermistors be wired to a separate cable. Though the strings are mounted in the ice quite close to the 


\title{
Table 4: CR10 Memory Usage Table
}

\author{
Ice Stress Memory Usage \\ CR10 Program Table 1 (JAMSIOEB.PDF)
}

Program instruction numbers:

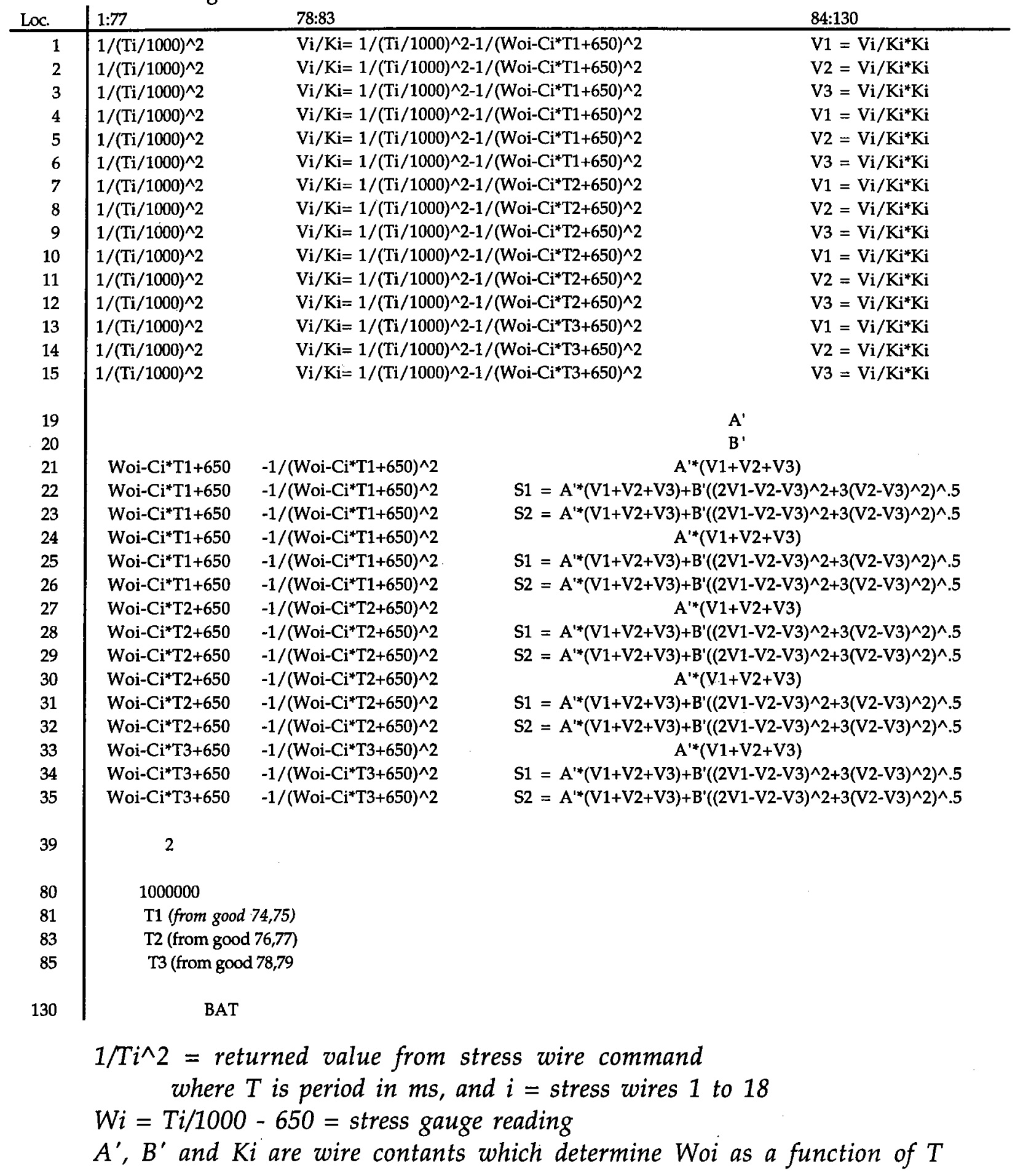




\section{CR10 Memory Usage Table}

Thermistor Memory Usage

CR10 Subroutine Table 3 (JAMSIOEB.PDF)

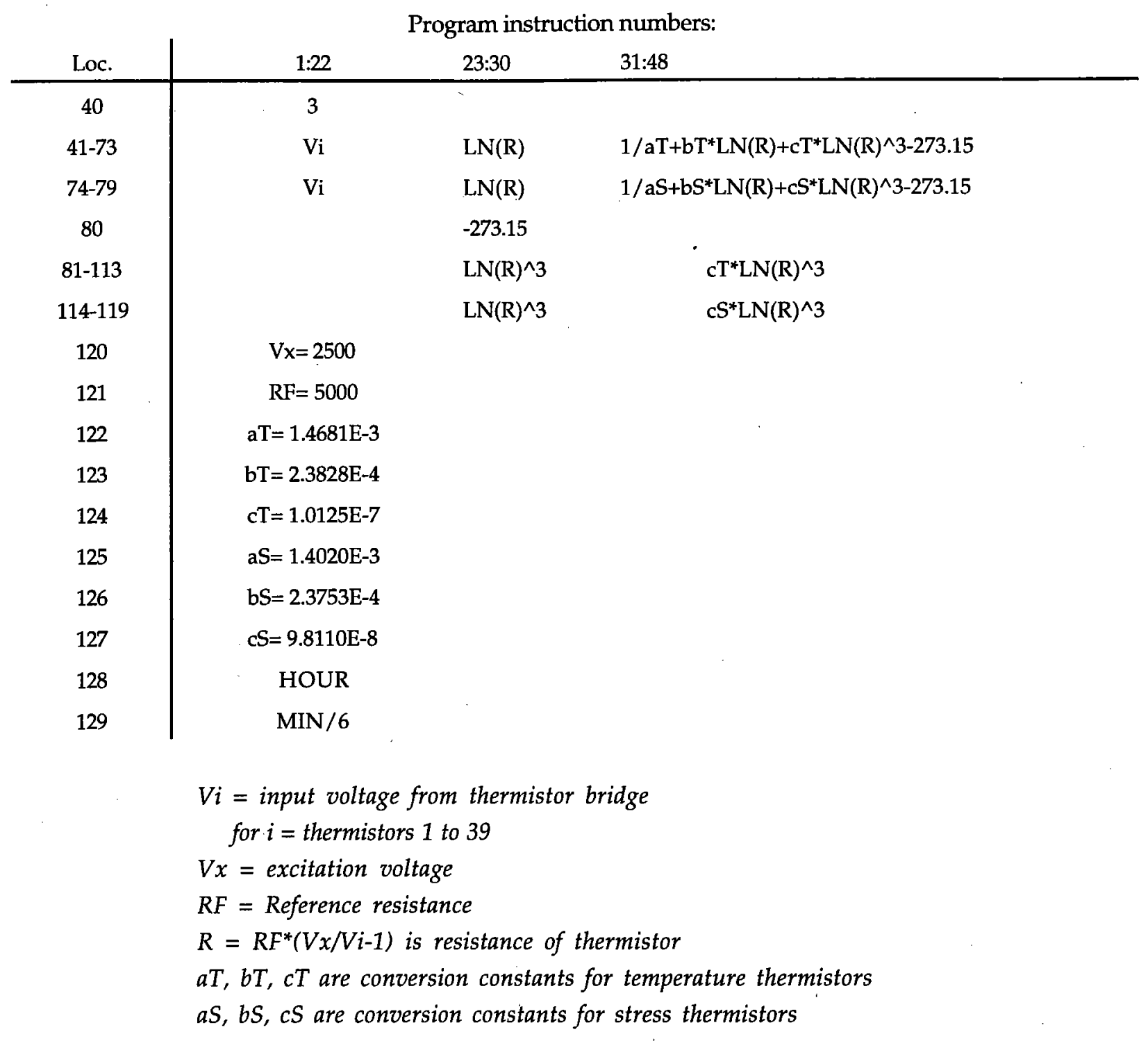

buoy, each cable has 30 feet of leader which is loosely spread between the sensors and the float, with the hope of keeping the strings attached to the buoy for as long as possible.

One thermistor string extends from above the surface of the icefloe, contains 11 relatively widely spaced thermistors and is $2.75 \mathrm{~m}$ long. The other string is centered at the ice-ocean interface, contains 22 more closely space thermistors and is $2.55 \mathrm{~m}$ long. Combined, these strings overlap to create a temperature profile from the surface down to over a meter below the icefloe.

At CRREL, each chain is manufactured by potting YSI44033 thermistors on 
a PVC channel at increments, and running the wires up to a Brantner watertight/pressure resistant cable. Afterwards, each chain is calibrated in order to detect differences between sensors, although this information is not incorporated into the CR10 measurements, but may be added to the transmitted data in post processing, as required.

The thermistor outputs and their common ground wire are fed to a Campbell AM multiplexer and through a half-bridge circuit, where the CR10 sequentially interrogates each of the 33 sensors in only a few seconds. The voltage inputs are immediately converted to temperatures using the Steinhart and Hart equation that relates the resistance to temperature of a negative temperature coefficient thermistor, and are subsequently stored. Every six hours, the CR10 updates and stores new ice temperature data. These interrogations do not require much power, but more frequent readings would only be spurious.

Although the thermistor data is unchanged for six hours at a stretch, the TT485 ice module collects all the data from the CR10 hourly. The ice module converts the ASCII values from the CR10 into 10-bit representations of the ice temperature from -55 to $+5{ }^{\circ} \mathrm{C}$. During the digitizing, two separate temperature conversion equations are used to divide the data into two ranges. From -55 to -5 ${ }^{\circ} \mathrm{C}$, the ice module resolves $0.1{ }^{\circ} \mathrm{C}$, but increases resolution to $0.01{ }^{\circ} \mathrm{C}$ for temperatures between -5 and $+5{ }^{\circ} \mathrm{C}$. Consequently, for each ice thermistor word, the MSB indicates which conversion equation to apply to the remaining 9 bits which are the value.

Because of ARGOS limitations on the amount of data that can be transmitted during a single broadcast, the total 330 bits of ice thermistor data are transmitted by the IOEB PTTs in three separate groups of 110 bits. To accomplish this, the ice module stores the data from each set of 11 thermistors in a different block along with other appropriate ice data. A unique MUSSIC network address (@21, @22, or @23) is associated with each block by the ice module. When one of the three recognizable addresses is detected, the data from the applicable block is communicated to the MCU. The result is that data from each thermistor is broadcast only once every six hours per PTT.

\section{b. Vibrating wire stress sensors}

One of the least understood coefficients in the ice momentum budget is the effect of internal ice stress over an extended period of time. Geokon vibrating wire stress sensors are installed in the ice near the IOEB surface float in order to detect horizontal variations in ice stress at three depths.

The sensor consists of a thick walled steel cylinder containing two sets of three vibrating wire strain transducers that measure the radial deformation of the cylinder. Using theoretically derived equations, the associated stress measurements are determined. Furthermore, vibrating wire temperature transduc- 
ers in the sensor allow correction for the effects of temperature.

All of the wires from the stress sensors are routed through bulkhead connectors on the endcap of the apex electronics package to one of the Campbell AM multiplexer circuit cards located inside the tube. At acquisition time, the CR10 selects and excites each set of wires in turn, and stores the results in memory. As programmed for the IOEB, the vibrating wire measurement function of the CR10 excites each wire with a swept frequency from 1000 to $1800 \mathrm{hz}$, then measures the period of the response over 500 cycles and calculates $1 / \mathrm{T}^{2}$, where $\mathrm{T}$ is the period in msec. Subsequent instructions inside the CR10 perform a series of calculations on the acquired values to transform the period measurements into deformations, including the zero-temperature calibrations of $K$ and $\omega_{o}$ for all of the individual wires in the each of the stress sensors. Each set of three-wire deformations is further converted into $\sigma_{1}$ and $\sigma_{2}$ stress measurements, using constants $(A$ and $B)$ derived from the material properties of ice and the steel gauges. Table 4 shows the equations that are stored in the Input Storage locations of the CR10 at several stages of the calculations. The transmitted 7-bit values resolve 6 $\mathrm{kPa}$ increments of stress between the range of -270 and $498 \mathrm{kPa}$. These data are passed to the TT485 ice module along with the ice thermistor data every hour, as described previously.

Ice stress measurements are nominally acquired every hour, but on the Transpolar IOEB, the ice stress sensor data is acquired every ten minutes and stored in a Campbell SM716 solid-state storage module for greater resolution of the forces in time, upon retrieval. The CR10 software program includes several commands for the storage function, but otherwise this storage capability is invisible to the rest of the data acquisition electronics.

\section{c. Upward-pointed echo sounder}

Determining the position of the ice bottom is the largest source of error in calculating the oceanic heat flux, so an echo sounder was deployed underneath the icefloe containing the IOEB on a mount so that it would point upward and take readings of the distance between the sea-ice bottom and its sensor head.

The echo sounder module that was selected for the IOEB is a Simrad Mesotech Model 807-12 with a distance range of 0.6 to $10 \mathrm{~m}$. The unit operates at $2.25 \mathrm{Mhz}$ and produces an output voltage proportional to the detected range with a resolution of $1 \mathrm{~mm}$. To operate, at least 22 VDC and approximately $250 \mathrm{~mA}$ are required. In order to accommodate these extended power requirements, a separate $30 \mathrm{~V}$ battery pack is furnished on the IOEB solely for the echo sounder.

The TT485 ice module collects hourly data from the echo sounder by switching power to the echo sounder and dividing and digitizing the echo voltage output. This information is stored as a 12-bit measurement that is transferred to the MCU every hour, along with the current ice stress readings and the 
second block of ice thermistor data.

Physically, the echo sounder is mounted on an aluminum framework which is attached to the surface of the ice floe and extends down $4.62 \mathrm{~m}$. At the bottom of the framework, is an aluminum platform with a flotation collar which maintains the sounder vertically when submersed in the seawater.

\section{Ocean sensors}

Below the surface icefloes in the relatively warm Arctic Ocean a mooring line of oceanographic instruments collect physical and biogeochemical data down to a depth of approximately $111 \mathrm{~m}$. A deeper depth would be desirable for sedimentology, but the underwater topology of the Arctic limits the length. Hanging from, and electrically coupled to, a conductive strength cable, these units communicate their information to the electronic modules in the surface float, where that information is telemetered via the transmitters. In addition, all of these units internally record their results, as a backup in the event that the conductive wires in the mooring cable fail during the experiment.

In general, there are two groups of ocean sensing instruments: physical oceanographic and biogeochemical sensors. The seawater currents and CTD data are determined with the high precision required for oceanography, while the transmissometry and fluorometry data are more significant for detecting variations rather than absolute values for biogeochemical studies.

SeaBird SeaCat conductivity and temperature recorders are used at 3 locations along the mooring line to provide points above, below, and in the holocline. One unit is outfitted with a dissolved oxygen probe and a fluorometer specifically to detect pimary productivity. SeaBird Electronics cooperated extensively by modifying both the firmware and communications hardware to converse with the data acquisition electronics in the surface buoy, using the appropriate protocol. A second Sea Tech fluorometer, paired with a Sea Tech transmissometer, have a separate TT485 data logger for acquiring data and communicating with the surface electronics.

Two units on the mooring line measure currents. One unit is an InterOceans S4 current meter which determines current electromagnetically. In order to communicate with the surface electronics, a separate underwater data buffer module is required to interface between the units. Outfitting the IOEB S4s with a temperature probe and an inductive conductivity sensor (on one), also provides a deep watermass data point along the IOEB mooring line.

The second current measuring device is an RD Instruments ADCP which collects ocean current data in a profile underneath the sea-ice. Using the Doppler principle, the ADCP determines currents in a series of depth bins below its sensor faces, and collects temperature, heading and tilt information at the device's depth. In order to broadcast via the ARGOS system, this data is compressed by a 
module external to the ADCP for communication by the surface electronics.

McLane Research water transfer systems with 18 Nucleopore filters, are deployed at different locations on the separate IOEB mooring lines. One water transfer system is independently located at a shallow depth, while at the very bottom of the conducting cable, the other pumping system is paired with a McLane Research 21-sample sediment trap, providing information on both suspended and falling particles at that depth. Although the McLane units were specially modified to directly communicate status information to the ARGOS transmitting electronics, because these units are sample collecting devices, they must be retrieved at the end of the deployment in order to remove their specimens for laboratory analysis.

\section{a. ADCP and Data Processing Module}

At $14 \mathrm{~m}$ below the apex on each IOEB, an RD Instruments $150 \mathrm{KHZ}$ ADCP (1991) and a Data Processing Module (DPM) are mounted in a single in-line mooring cage. By pointing the ADCP downward, a profile of ocean currents down to a depth of about $340 \mathrm{~m}$ below the instrument is obtained. The ADCP produces large amounts of data with each transmission cycle which are recorded internally. The DPM serves as an interface between the ADCP and the buoy telemetry system by processing and reducing the information so that a representative subset of the data can be broadcast via the ARGOS system.

The ADCP transmits acoustic pulses from four transducers along four beams separated by $90^{\circ}$ in azimuth and pointed downward at $60^{\circ}$ from the horizontal. The received backscattered echoes from plankton and small particles riding the water currents allows estimation of the fluid velocity from the Doppler shift. Vertical profiles of horizontal velocities are determined from the 4 radial velocities determined at 40 locations called depth bins. So called "vertical" velocities are also measured, but this data is really only an error check. On the IOEBs, the ADCP precisely measures current between 26 and $338 \mathrm{~m}$, with a bin resolution of $8 \mathrm{~m}$. With the additional flux-gate compass heading and two-axis pendulum tilt sensors, the ADCP transforms velocity data from instrument referenced coordinates to earth referenced coordinates. Furthermore, a thermistor provides a time-series of water temperature at the instrument depth.

As configured for the IOEB, the ADCP takes measurements every $15 \mathrm{~min}$ for a period of 270 days, which is limited by both the storage memory and battery capacity of the instrument. Every measurement interval it generates 719 bytes of data which is stored in $20 \mathrm{Mbyte}$ internal solid-state memory. The large signal generating capacity of the ADCP precludes simultaneous ARGOS transmission of all files.

To deal with this difficulty, the DPM was developed (Plueddemann et al., 1992) to allow transmission of a representative subset of the data via ARGOS; 
primarily for implementation on the IOEB. Due to the maximum allowable data rate through ARGOS, the ADCP data is reduced by about a factor of 170 by the IOEB DPMs. Although previous efforts to telemeter data from ADCPs have achieved some notable results (McPhaden et al., 1990), the design of the DPM as a self-contained, addressable ADCP data compression module is unique.

The DPM receives the ADCP data bytes, performs unpacking routines, averages 2 hours of current data, and buffers the data for transmission to the MCU telemetry controllers. The full DPM output array is split into separate sets of odd and even bins, so that either set represents the current profile. In the averaging step, the leader or status data is time averaged, along with the heading and tilt data. The status data includes the time, number of ADCP bins, ensemble number, BIT status, $x$-axis tilt, $y$-axis tilt, heading, temperature, high voltage level, transmit current level, low voltage level, and the standard deviations of tilts and headings. The heading and tilt are used to transform currents into earth coordinates which are then depth averaged across 3 bins. The resulting DPM profiles are composed of ten $24 \mathrm{~m}$ bins of earth referenced currents. On the IOEB, the even bins are centered at the depths of $34,82,130,178$, and $226 \mathrm{~m}$, and the odd bins at $58,106,154,202$, and $250 \mathrm{~m}$. To compress the data even further down to the 135 bit limit required for IOEB transmission, all the velocity data is scaled and resolved to $1 \mathrm{~m} / \mathrm{s}$.

When interrogated by one MCU with the MUSSIC address \#40R, the DPM responds with the data set that includes the even bins. The other MCU interrogates the same DPM with address \#41R, and receives the data set with odd bins. A counter and even/odd bin flag assist combining both data halves together to restore the complete current profile. The velocity measured by the ADCP includes the actual fluid velocity and velocity of the IOEB mooring through the water. In post-processing, removing the depth-averaged drift velocity from the velocity profile provides an approximate drift correction without introducing satellite-induced velocity errors at short time scales (Plueddemann, 1992).

The DPM has its own battery pack and anodized electronics pressure tube and is mounted with, and connected to, the ADCP in the electropolished stainless-steel mooring cage. The battery of the DPM is sufficient for the unit to operate for over 9 months, which should equal the capacity of the ADCP to generate data. Upon recovery, the raw 15-minute current ensembles can be downloaded from the ADCP to provide greater resolution of the profiles that were telemetered by the IOEBs.

\section{b. S4 current meter}

In addition to the massive Doppler current profiler, each IOEB is equipped with an InterOceans S4 electromagnetic current meter positioned near the end of the mooring system to determine the horizontal currents near the sediment trap. Furthermore, this current meter will verify the results of the ADCP for a single 
depth bin.

The S4 produces earth referenced currents by electromagnetically sensing the movement of particles in the water surrounding its spherical case. On the IOEBs, both S4s average the current sample for two minutes every hour, or every other hour to produce a precision of $0.2 \mathrm{~cm} / \mathrm{s}$. Temperature and conductivity (when included) are also sampled and stored in the solid state memory of the current meter, along with other operational data. On the Transpolar IOEB the memory of the S4 will be filled in 360 days, whereas the Beaufort S4 samples only half as frequently, providing the capacity to collect data for over 2 years. This raw data can be retrieved from the instrument when recovered.

Because the S4 could not be factory modified to compensate for the MUSSIC protocol, an S4 Module was created with a TT3 and TT485 converter circuit with software to allow it to interface between the current meter and the sensor data network. On the IOEB, the S4 Module is a passive device that listens to the data from the S4 and converts the data to the MUSSIC format for ARGOS transmission. Because the currents that the $S 4$ detects are superimposed on the drift track of the buoy, excessive velocities can be seen by the mooring instrumentation hanging from the IOEBs. To account for this, the S4 Module operating software scales each velocity vector into 7 bits between the range of \pm 127 $\mathrm{cm} / \mathrm{sec}$ with a $0.5 \mathrm{~m} / \mathrm{s}$ resolution. The S4 Module responds to the MUSSIC address \#50R with a 38 bit data stream including conductivity, or a 28 bit data stream without.

The S4 has its own mounting rod which positions the instrument in-line with the rest of the mooring system. So that the network EM cable would not have to be conveyed around the S4 package (and possibly influence the EM readings), this meter was placed at the end of the mooring cable at $110 \mathrm{~m}$ depth.

\section{c. Conductivity, temperature and dissolved oxygen}

To determine the basic oceanographic characteristics of the seawater: salinity and temperature, a total of three SeaBird SBE-16 SeaCats are positioned on each mooring system. The SeaCats are established instruments for acquiring accurate measurements of conductivity and temperature, from which other variables such as seawater salinity and density can be calculated. However, in order to be compatible with the IOEB data transfer protocol, these units were altered by SeaBird to include EIA485 circuitry, and the firmware accordingly modified. .

While the other two units provide only hourly conductivity and temperature data at depths of 45 (SCI) and $76 \mathrm{~m}$ (SCII), the shallowest SeaCat (SCDO) was outfitted with circuitry to include data from a SensorMedics dissolved oxygen (DO) sensor and a SeaTech fluorometer, and is located $8 \mathrm{~m}$ below the surface float. To prevent oxygen depletion of the seawater sample during measurement, this SeaCat is equipped with a pump to flush the sample past the sensor while 
taking a reading. Eventhough this configuration reduces biofouling, SensorMedics DO sensors have a variable operational life of only about $1+$ years and are subject to calibration drifts. The stated accuracy of $0.1 \mathrm{ml} / 1$ is only achievable with frequent field calibrations. The assembled instrument package is positioned as near the underside as the sea-ice as seemed reasonable without putting the instrument in danger of possible damage by colliding icefloes.

All of the SeaCats transmit 16-bit numbers for both temperature and conductivity frequencies, while the voltage of the fluorometer channel is described in 12 bits. For the dissolved oxygen sensor, 12-bit measurements of both the current and internal temperature of the oxygen sensor are internally recorded and transmitted over the IOEB network, but only the oxygen current value is relayed to the ARGOS satellite. Consequently, the temperature frequency data is employed in the calculation of the oxygen value from the transmitted data. Dipswitches set the MUSSIC network address (@30 to @3F are possible) inside each of the SeaCat units. The firmware includes a special EIA485 mode where each unit responds to interrogations from the MCU with its last acquired data, within 0.5 seconds after receiving its address.

The electronics for each SeaCat are encased in a plastic pressure housing which protects the instrument at depths down to $600 \mathrm{~m}$. Because of the added sensors, the shallow unit is outfitted with a lithium battery pack which should provide power for this instrument for 1.5 years. The others are powered with standard alkaline batteries that should still allow the acquisition of data for over 2 years, even with the addition of the MUSSIC network circuitry.

All of the sensors on the SeaCats were calibrated at SeaBird before the deployment of the IOEBs. The temperature sensors have a stated accuracy of 0.01 ${ }^{\circ} \mathrm{C} / 6$ months, but can resolve a millidegree. The vertical conductivity cell is stated accurate to $0.001 \mathrm{~S} / \mathrm{m} /$ months and can resolve 10 times that. Anti-fouling cylinders provided by SeaBird are used on all the units to discourage biofouling of the cells. The lowermost ice thermistors, the ADCP, and the S4 also take temperature readings at their respective depths, but with a lower resolution and accuracy than the SeaCats. Furthermore, on one IOEB, the S4 is additionally equipped with a inductive conductivity sensor.

\section{d. Fluorometer and transmissometer}

Because of the fundamental role that primary productivity assumes in the biogeochemical processes of the ocean, two fluorometers and a transmissometer are included on each IOEB to detect the presence of particles and/or plankton in the seawater under the Arctic ice-floes. As indicated above, one Sea Tech Fluorometer is mated with the shallowest SeaCat recorder at $8 \mathrm{~m}$, and has its data acquired and transmitted by that instrument. Near the bottom of the mooring, at $110 \mathrm{~m}$ depth, a TRFL module composed of a TT3 with a TT485 circuit board collects and transmits the data from another Sea Tech Fluorometer and a Sea Tech 
Transmissometer.

The fluorometers are optically tuned to detect chlorophyll $a$ in the seawater by sensing the fluorescence at $425 \mathrm{~nm}$ (red) wavelengths after exciting the sample with a $685 \mathrm{~nm}$ (blue) lamp. The sensitivity adjustments for both instruments on the IOEB are set on high, with an approximate full scale value of 3 $\mu \mathrm{g} / \mathrm{L}$. Every hour, power is applied to the fluorometer for 15 seconds by the SeaCat, which subsequently takes a reading.

The transmissometer detects the attenuation of light in a $25 \mathrm{~cm}$ path through the seawater using a modulated light emitting diode (LED) and synchronous detector. Every hour, the TRFL Module powers the transmissometer for 3 seconds, allows the output to stabilize, and averages 32 samples. The resulting resolution is 0.01 percent. Subsequently the module powers the fluorometer for 15 seconds, and averages 32 readings with the same resolution as the transmissometer.

The TRFL module may store the hourly results for 681 days of operation before the memory is completely filled. However, due mainly to the large operating current of the fluorometer, lithium battery power to the logger will be exhausted in just over 1.5 years. The module electronics and battery are mounted inside of a standard 4" diameter aluminum pressure case and connected to the external devices via Brantner bulkhead connectors and cables. Each IOEB TRFL system is physically located inside of the sediment trap frame for protection, and for comparison with the other biogeochemical data when it is recovered and analyzed.

\section{e. Water transfer system}

The McLane Mark 5-18 Water Transfer System (WTS) consists of eighteen separate Nucleopore filters with a 0.4 micron pore size in holders connected to a single multi-port valve and pump mechanism. Based upon settings furnished by the user, a TT3 based microcomputer called an Instrument Timer and Controller (ITC) steps the valve between filters and controls the speed of the pump while precisely measuring the flow of seawater through the selected filter.

The valve assembly is manufactured out of an inert engineering plastic which ensures that water absorption by the valve is negligible for several years in a deep ocean environment. To prevent contaminating the filtering apparatus and the samples, the precision gear pump is positioned after the valve and the Nucleopore filter holders are sealed using one-way valves. The selection of each port is made by a high torque bipolar stepping motor, while the pump is driven by a DC servomotor whose speed is controlled by the ITC computer using readings obtained from a Hall-effect sensor in the driver circuit. The flow rate is calculated from the number of revolutions made by the motor over time.

The ITC combines an Onset Computers TT3 single-board data logger with 
two McLane interface boards and a TT485 circuit board. The McLane interface boards condition the inputs and outputs to the Tattletale while the TT485 board is included only to provide access to the MUSSIC network. The ITC is programmed with a special WTS Operation Program Version 1.52 that includes the network communication protocol, and running the program is accomplished by connecting any standard RS-232 terminal device to the TT3 serial port. The operating program allows the user to schedule the time between filtering events, as well as the characteristics and limitations of the pumping operation. During the deployment of the IOEB, the ITC transmits event and status information via the MUSSIC network. However, this instrument must be retrieved for a full analysis of the samples to be performed in the laboratory.

The sample interval of the WTS is user programmable in either regular or irregular intervals from $1 \mathrm{hr}$ to 365 days. The conditions of pumping for each filter are controlled by setting the initial flow rate, the maximum pumping volume, the minimum flow rate, or the maximum pumping time. For the IOEB, the WTS was initialized to pump at $60 \mathrm{ml} / \mathrm{min}$ for no more than 150 minutes per filter. Furthermore, pumping will cease for any filter if clogging causes the flow rate to decrease to $20 \mathrm{ml} / \mathrm{min}$, or if the WTS pumps a total of 10 liters. The actual time when the valve moves from one filter to another, and the actual pumping rate and volume information for each filter is recorded on the same ITC to be retrieved when the sampler returns onboard. Under these conditions, the alkaline battery pack will last approximately 1 year, depending upon the total volume and rate of water being processed.

\section{f. Time series sediment trap}

The McLane PARFLUX Mark 7G-21 sediment trap is designed to collect a series of settling particle samples in the deep ocean for the purpose of measuring the seasonal or time-series variability of particle fluxes. Constructed around a wide funnel aperture, it is large enough to collect a sufficient mass of sample for multidisciplinary research studies and biogeochemical, micropaleontological analysis when each fractionated deployment time period is relatively short. Like the water transfer systems, however only event and status information is broadcast by the sediment trap during the IOEB deployment phase since the samples must be recovered for full laboratory processing of their material.

The sediment trap funnels particles from a wide opening $\left(0.5 \mathrm{~m}^{2}\right)$ into narrow-mouthed sample bottles via the long conical funnel. Under the control of a sediment trap ITC, a high-torque electronic stepping motor and rotator collector mechanism sequentially places each sampling bottle under the narrow aperture of the funnel while preserving the integrity, and preventing the contamination of samples previously collected. A microswitch is mechanically activated by a cam on the motor drive shaft to determine the proper displacement of the rotator plate. The diameter of each hole on the rotary disk is greater than the 
stationary hole so that particles can settle into the sample bottles without obstruction. The sampling bottles are $250 \mathrm{ml}$ wide-mouth, thick-walled polyethylene bottles. The circumference of the upper opening of holes on the sampler disk is fitted with a Teflon spring-loaded gasket to positively seal the bottle contents from ambient water, and in air. A baffle of hexagonal cells is inserted into the top of the funnel and protects against large objects or animals from clogging the sediment trap.

The sediment trap ITC is identical to the WTS ITC, except that the pump driver board is omitted and the TT3 is programmed with Sediment Trap Operation Program Version 2.11, which includes the MUSSIC network software. Based on the user input, the ITC controls the dates when the exchange of sampler bottles takes place, sends a specific number of pulses to the bipolar stepping motor which drives the rotator assembly the exact distance to the next bottle, records the actual time of each movement of the stepping motor, and records the microswitch signal as electromechanical verification of correct operation. Each collection period can be set to as little as 2 minutes or as long as 18 months.

The electronics are powered by an alkaline battery pack which will sustain the sediment trap operation for several years. A 9-volt alkaline backup battery retains any previous event data should the main battery pack fail. All WTS and sediment trap ITCs and battery packs are housed in anodized pressure-resistant cylinders made of heat-treated aluminum alloy and are designed to resist static pressure up to $5,500 \mathrm{~m}$ deep.

The frame which contains all components of the sediment trap is a titanium alloy weldment with six vertical tubes welded to a pair of cold-rolled angle rings. It is sufficiently large to completely encage the pieces contained within to protect them from damage due to external bumping. Three $1 \mathrm{~m}$ long wire-rope bridles connect the top of the sediment trap frame to the host mooring array at a depth of $107 \mathrm{~m}$. Three $1 \mathrm{~m}$ chain segments secure the remainder of the mooring system below the frame. On the Beaufort IOEB, the WTS is included inside the sediment trap frame, while on the Transpolar IOEB, the same system is mounted in an electropolished 316 stainless steel welded cage which is deployed in-line with the rest of the mooring system at a depth of $11 \mathrm{~m}$. 


\section{IOEB Transmission Sequence Number}

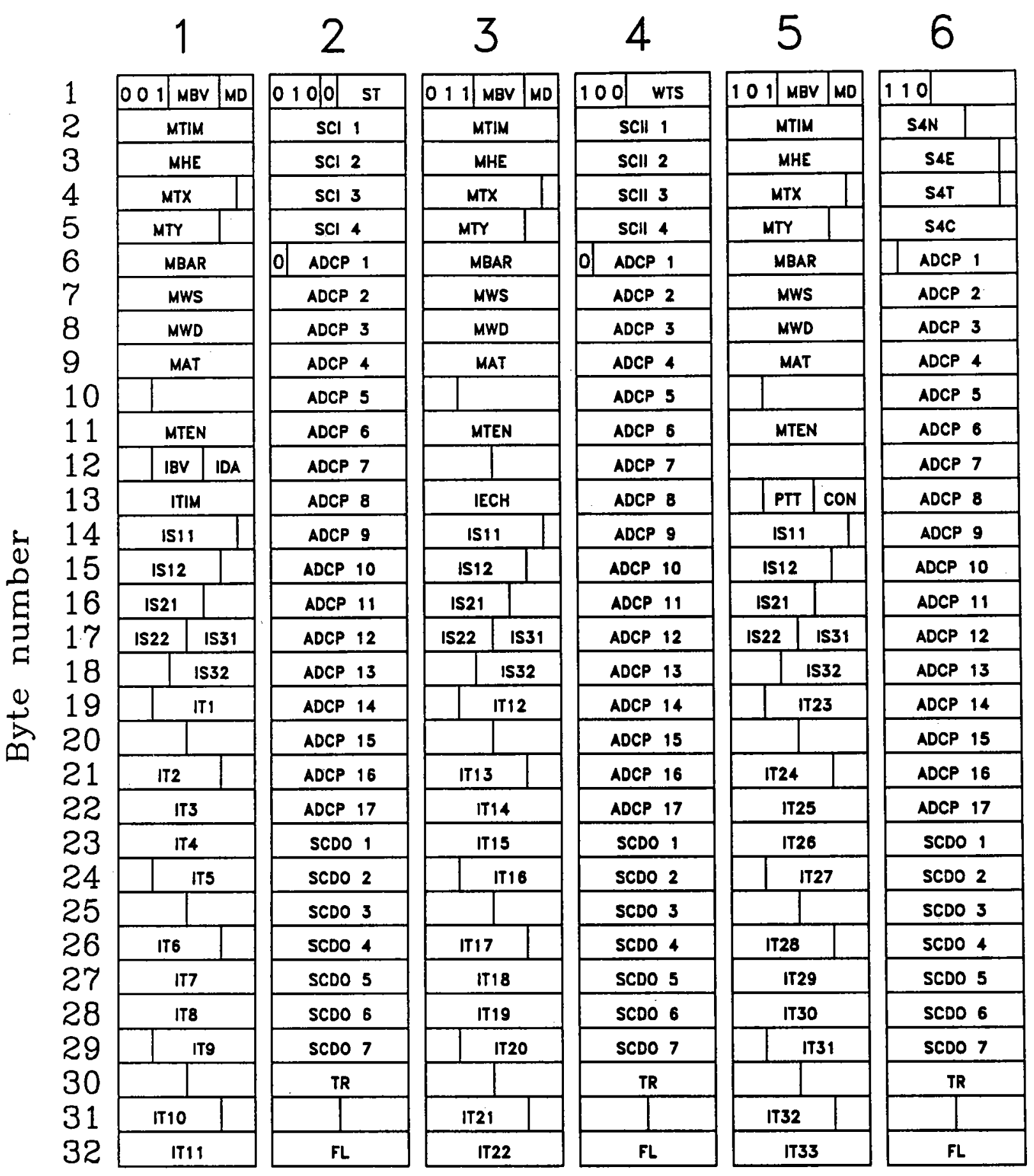

Figure 9: Transmitted Data Format 


\section{Transmitted data format}

Six sequential data formats are used in order to pack the high resolution data from the 104 sensor variables on the IOEB into the 256 bit transmission data stream allowed by ARGOS. Each sequence has its data broadcast by a single PTT for a period of just under one hour. After nearly six hours, all of the sequences have had all of their data transmitted, and this process repeats from the beginning. According to this scheme, instrument data that is acquired infrequently may only be broadcast once during the six sequences, while more frequent data may be updated every other sequence.

The first three bits in every IOEB transmission indicate the sequence number that is being broadcast. Using this sequence number, the format of the remaining bitstream can be determined according to the tables on the following pages. The same sequence formats are transmitted by each MCU/PTT pair, only during operation their timing is offset by 3 and a half hours in order to maximize the data throughput of the combined unit. In effect, when both transmitter pairs are operating properly, the frequency of data transmission is doubled, which allows some of the broadcast sensor variables to be updated nearly every hour. However, the interval between consecutive passes of the ARGOS satellite for receiving the data can be as long as $\mathbf{1 1 0}$ minutes.

The odd sequences are predominantly composed of meteorological and ice sensor data, although sequence five includes the battery voltages of its own MCU/PTT pair. The meteorological data is updated before transmitting a new sequence, along with some of the ice data. However, the 330 bits of ice thermistor data is only acquired every six hours, allowing each of the three odd sequences to contain only one-third of the thermistor data from a single acquisition time. As indicated earlier, this permits all of that data to be broadcast within the ARGOS limitations.

The even sequences contain all of the data from the underwater instruments, and are configured to maximize the transmission of data from the ADCP, the shallow SeaCat, and the TRFL module. The broadcast data from the remaining SeaCats, the S4 current meter, sediment trap, and water transfer system are each updated only once during every six hour period by each MCU/PTT pair.

It is important to note that controller time and checksum data is not being sent during any IOEB transmission sequence. However, since the same data is being repeatedly broadcast for approximately one hour intervals by each PTT, much of the noise can be eliminated when the ARGOS satellites receive several broadcasts during a pass. In fact, atmospheric or other conditions appear to create a substantial amount of satellite induced noise on the IOEB data. By extrapolating backwards to the scheduled acquisition time, time codes can be matched to the transmitted data. Since only the met and ice modules incorporate their times into the data stream, data from all other instruments on the IOEB needs to be time coded in the above manner. 


\section{Table 5: IOEB Sequence Data Formats}

\section{Transmission Sequence 1}

\begin{tabular}{lll} 
Bits & Item & Description \\
\hline $1-3$ & SID=1 & Sequence ID number \\
$4-6$ & MBV & Met module battery voltage \\
$7-8$ & MD & Met module day number \\
$9-16$ & MTIM & Met module time code \\
$17-24$ & MHE & Compass heading \\
$25-31$ & MTX & Tilt X \\
$32-38$ & MTY & Tilt Y \\
$39-48$ & MBAR & Barometric pressure \\
$49-56$ & MWS & Wind speed \\
$57-64$ & MWD & Wind direction \\
$65-74$ & MAT & Air temperature \\
$75-90$ & MTEN & Mooring tension \\
$91-93$ & IBV & Ice module battery voltage \\
$94-96$ & IDA & Ice module day number \\
$97-104$ & ITIM & Ice module time code \\
$105-111$ & IS11 & Ice stress 1: sigma 1 \\
$112-118$ & IS12 & Ice stress 1: sigma 2 \\
$119-125$ & IS21 & Ice stress 2: sigma 1 \\
$126-132$ & IS22 & Ice stress 2: sigma 2 \\
$133-139$ & IS31 & Ice stress 3: sigma 1 \\
$140-146$ & IS32 & Ice stress 3: sigma 2 \\
$147-156$ & IT1 & Ice thermistor 1 \\
$157-166$ & IT2 & Ice thermistor 2 \\
$167-176$ & IT3 & Ice thermistor 3 \\
$177-186$ & IT4 & Ice thermistor 4 \\
$187-196$ & IT5 & Ice thermistor 5 \\
$197-206$ & IT6 & Ice thermistor 6 \\
$207-216$ & IT7 & Ice thermistor 7 \\
$217-226$ & IT8 & Ice thermistor 8 \\
$227-236$ & IT9 & Ice thermistor 9 \\
$237-246$ & IT10 & Ice thermistor 10 \\
$247-256$ & IT11 & Ice thermistor 11 \\
& &
\end{tabular}

Transmisșion Sequence 2

\begin{tabular}{|c|c|c|}
\hline Bits & Item & Description \\
\hline $1-3$ & SID $=2$ & Sequence ID number \\
\hline 4 & & always 0 \\
\hline $5-8$ & ST & Sediment trap status \\
\hline $9-40$ & SCI $1-4$ & SeaCat I: bytes $1-4$ \\
\hline 41 & & always 0 \\
\hline $42-176$ & ADCP 1-17 & ADCP module: bytes $1-17$ \\
\hline $177-232$ & SCDO 1-7 & SeaCat with DO \& FL: bytes $1-7$ \\
\hline 233-244 & TR & Transmissometry at 100 meters \\
\hline $245-256$ & FL & Fluorometry at 100 meters \\
\hline
\end{tabular}




\section{IOEB Sequence Data Formats}

Transmission Sequence 3

\begin{tabular}{lll} 
Bits & Item & Description \\
\hline $1-3$ & SID=3 & Sequence ID number \\
$4-6$ & MBV & Met module battery voltage \\
$7-8$ & MD & Met module day number \\
$9-16$ & MTIM & Met module time code \\
$17-24$ & MHE & Compass heading \\
$25-31$ & MTX & Tilt X \\
$32-38$ & MTY & Tilt Y \\
$39-48$ & MBAR & Barometric pressure \\
$49-56$ & MWS & Wind speed \\
$57-64$ & MWD & Wind direction \\
$65-74$ & MAT & Air temperature \\
$75-92$ & MTEN & Mooring tension \\
$93-104$ & IECH & Echo sounder \\
$105-111$ & IS11 & Ice stress 1: sigma 1 \\
$112-118$ & IS12 & Ice stress 1: sigma 2 \\
$119-125$ & IS21 & Ice stress 2: sigma 1 \\
$126-132$ & IS22 & Ice stress 2: sigma 2 \\
$133-139$ & IS31 & Ice stress 3: sigma 1 \\
$140-146$ & IS32 & Ice stress 3: sigma 2 \\
$147-156$ & IT12 & Ice thermistor 12 \\
$157-166$ & IT13 & Ice thermistor 13 \\
$167-176$ & IT14 & Ice thermistor 14 \\
$177-186$ & IT15 & Ice thermistor 15 \\
$187-196$ & IT16 & Ice thermistor 16 \\
$197-206$ & IT17 & Ice thermistor 17 \\
$207-216$ & IT18 & Ice thermistor 18 \\
$217-226$ & IT19 & Ice thermistor 19 \\
$227-236$ & IT20 & Ice thermistor 20 \\
$237-246$ & IT21 & Ice thermistor 21 \\
$247-256$ & IT22 & Ice thermistor 22 \\
& &
\end{tabular}

\section{Transmission Sequence 4}

\begin{tabular}{lll} 
Bits & Item & Description \\
\hline $1-3$ & SID $=4$ & Sequence ID number \\
$4-8$ & WTS & Water transfer system status \\
$9-40$ & SCII $1-4$ & $\begin{array}{l}\text { SeaCat II: bytes } 1-4 \\
\text { always } 0\end{array}$ \\
41 & & ADCP module: bytes 1-17 \\
$42-176$ & ADCP 1-17 & SeaCat with DO \& FL: bytes 1-7 \\
$177-232$ & SCDO $1-7$ & Transmissometry at 100 meters \\
$233-244$ & TR & Fluorometry at 100 meters
\end{tabular}




\section{IOEB Sequence Data Formats}

\section{Transmission Sequence 5}

\begin{tabular}{lll} 
Bits & Item & Description \\
\hline $1-3$ & SID=5 & Sequence ID number \\
$4-6$ & MBV & Met module battery voltage \\
$7-8$ & MD & Met module day number \\
$9-16$ & MTIM & Met module time code \\
$17-24$ & MHE & Compass heading \\
$25-31$ & MTX & Tilt X \\
$32-38$ & MTY & Tilt Y \\
$39-48$ & MBAR & Barometric pressure \\
$49-56$ & MWS & Wind speed \\
$57-64$ & MWD & Wind direction \\
$65-74$ & MAT & Air temperature \\
$75-98$ & MTEN & Mooring tension \\
$99-101$ & PTT & PTT battery voltage \\
$102-104$ & CON & Controller battery voltage \\
$105-111$ & IS11 & Ice stress 1: sigma 1 \\
$112-118$ & IS12 & Ice stress 1: sigma 2 \\
$119-125$ & IS21 & Ice stress 2: sigma 1 \\
$126-132$ & IS22 & Ice stress 2: sigma 2 \\
$133-139$ & IS31 & Ice stress 3: sigma 1 \\
$140-146$ & IS32 & Ice stress 3: sigma 2 \\
$147-156$ & IT23 & Ice thermistor 23 \\
$157-166$ & IT24 & Ice thermistor 24 \\
$167-176$ & IT25 & Ice thermistor 25 \\
$177-186$ & IT26 & Ice thermistor 26 \\
$187-196$ & IT27 & Ice thermistor 27 \\
$197-206$ & IT28 & Ice thermistor 28 \\
$207-216$ & IT29 & Ice thermistor 29 \\
$217-226$ & IT30 & Ice thermistor 30 \\
$227-236$ & IT31 & Ice thermistor 31 \\
$237-246$ & IT32 & Ice thermistor 32 \\
$247-256$ & IT33 & Ice thermistor 33 \\
& &
\end{tabular}

\section{IOEB Transmission Sequence 6}

\begin{tabular}{lll} 
Bits & Item & Description \\
\hline $1-3$ & SID=6 & Sequence ID number \\
$4-41$ & S4 1-5 & S4 current meter: bytes 1-5 \\
$42-176$ & ADCP 1-17 & ADCP module: bytes 1-17 \\
$177-232$ & SCDO 1-7 & SeaCat with DO \& FL: bytes 1-7 \\
$233-244$ & TR & Transmissometry at 100 meters \\
$245-256$ & FL & Fluorometry at 100 meters
\end{tabular}




\section{Table 6: Data Conversions}

$\mathrm{N}$ = decimal equivalent of binary data word

\begin{tabular}{|c|c|c|}
\hline Item & Conversions & Units \\
\hline ADCP 1-17 & next page & \\
\hline CON & $\mathrm{CON}=\mathrm{N}+9$ & Volts \\
\hline FL & $\mathrm{FL}=5 * \mathrm{~N} / 4095$ & Volts \\
\hline IBV & $\mathrm{IBV}=\mathrm{N}+9$ & Volts \\
\hline IDA & $\mathrm{IDA}=\mathrm{N}$ & days \\
\hline IECH & $\mathrm{IECH}=\mathrm{N} / 409.5$ & meters \\
\hline ISxx & ISxx $=N * 6-270$ & $\mathrm{kPa}$ \\
\hline \multirow[t]{2}{*}{ ITxx } & if $\mathrm{N}<512$, ITxx $=\mathrm{N} * .1-56.1$ & ${ }^{\circ} \mathrm{C}$ \\
\hline & if $\mathrm{N}>511$, ITxx $=(\mathrm{N}-512) * .02-5$ & ${ }^{\circ} \mathrm{C}$ \\
\hline ITIM & $\operatorname{ITIM}=\mathrm{N} / 10$ & hours \\
\hline MAT & $\mathrm{MAT}=\mathrm{N} / 17.05-40$ & ${ }^{\circ} \mathrm{C}$ \\
\hline MBAR & $\mathrm{MBAR}=\mathrm{N} / 7.86923+920$ & $\mathrm{hPa}$ \\
\hline MBV & $\mathrm{MBV}=\mathrm{N} * 0.4+6$ & Volts \\
\hline $\mathrm{MD}$ & $\mathrm{MD}=\mathrm{N}$ & days \\
\hline MHE & $\mathrm{MHE}=\mathrm{N} / .70833333$ & deg \\
\hline \multirow[t]{3}{*}{ MTEN } & byte $1=$ Average tension $=N * 21.6406$ & lbs \\
\hline & byte $2=$ Maximum tension $=N * 21.6406$ & lbs \\
\hline & byte $3=$ STD tension $=N * 10.8203$ & lbs \\
\hline MTIM & MTIM $=$ N / 10 & hours \\
\hline MTX & $\mathrm{MTX}=\mathrm{N} / 1.05833333-60$ & $\operatorname{deg}$ \\
\hline MTY & $\mathrm{MTY}=\mathrm{N} / 1.05833333-60$ & deg \\
\hline MWD & $\mathrm{MWD}=\mathrm{N} / .70833333$ & deg \\
\hline MWS & MWS $=\mathrm{N} / 5.1$ & $\mathrm{~m} / \mathrm{s}$ \\
\hline PTT & $\mathrm{PTT}=\mathrm{N}+9$ & Volts \\
\hline S4N & $\mathrm{S} 4 \mathrm{~N}=\mathrm{N} / 2-256$ & $\mathrm{~cm} / \mathrm{s}$ \\
\hline $\mathrm{S} 4 \mathrm{E}$ & $\mathrm{S} 4 \mathrm{E}=\mathrm{N} / 2-256$ & $\mathrm{~cm} / \mathrm{s}$ \\
\hline S4T & $\mathrm{S} 4 \mathrm{~T}=\mathrm{N} / 10-5$ & ${ }^{\circ} \mathrm{C}$ \\
\hline $\mathrm{S} 4 \mathrm{C}$ & $\mathrm{S} 4 \mathrm{C}=\mathrm{N} / 20+20$ & $\mathrm{mS} / \mathrm{cm}$ \\
\hline \multirow{2}{*}{\multicolumn{3}{|c|}{ SCDO 1-7, SCI 1-4, SCII 1-4: }} \\
\hline & & \\
\hline & Actual Temp freq. $=\mathrm{N} / 19+2100$ & hz \\
\hline & bytes $3 \& 4=$ Conductivity frequency & \\
\hline & Actual Cond freq. $=$ sqrt $(\mathrm{N} * 2100+6250000)$ & $\mathrm{hz}$ \\
\hline & byte $5 \& 4$ MSBits of byte $6=$ Dissolved Oxygen & \\
\hline & Oxygen Current Voltage $=N * 5 / 4095$ & Volts \\
\hline & 4 LSBits of byte $6 \&$ byte 7 = Fluorometer & \\
\hline ST & $\begin{array}{l}\text { Fluorometer }=N * 5 / 4095 \\
\text { if } N=0 \text { then NO EVENTS RUN }\end{array}$ & Volts \\
\hline 51 & $\begin{array}{l}\text { if } N=1 \text { to } 7 \text { then BAD EVENT \# = N } \\
\text { if } N=8 \text { then SHUT DOWN } \\
\text { if } \mathrm{N}=9 \text { to } 15 \text { then GOOD EVENT } \#=(\mathrm{N}-8)\end{array}$ & \\
\hline TR & $\mathrm{TR}=100 * \mathrm{~N} / 4095$ & $\%$ trans. \\
\hline WTS & $\begin{array}{l}\text { for } 2 \text { LSBs, EVENT } \#=N \\
\text { for } 3 \text { MSBs, if } N=0 \text { then TOTAL FLOW REACH } \\
\text { if } N=1 \text { then LOW BATTERY VOLTAGE } \\
\text { if } N=2 \text { then PUMP WON'T START } \\
\text { if } N=3 \text { then MIN. FLOW REACHE } \\
\text { if } N=4 \text { then PUMP SLIPPING } \\
\text { if } N=5 \text { then MAX. TIME REACHED }\end{array}$ & \\
\hline
\end{tabular}




\section{Table 7: IOEB ADCP Data Conversions}

\begin{tabular}{|c|c|c|c|}
\hline Byte & Bit & Variable & Description \\
\hline \multirow[t]{14}{*}{ ADCP 1} & 1 & dummy & no meaning $=$ always 0 \\
\hline & 2 & counter & alternates $0 \& 1$ for each array \\
\hline & \multirow[t]{2}{*}{3} & \multirow[t]{2}{*}{ bin flag } & 0 if EVEN bin data $(0,2,4,6,8)$ \\
\hline & & & 1 if ODD bin data $(1,3,5,7,9)$ \\
\hline & \multirow[t]{2}{*}{4} & \multirow[t]{2}{*}{ status $(1)$} & 0 if data in position 1 is good \\
\hline & & & 1 if low signal-to noise ratio \\
\hline & \multirow[t]{2}{*}{5} & \multirow[t]{2}{*}{ status(2) } & 0 if data in position 2 is good \\
\hline & & & 1 if low signal-to noise ratio \\
\hline & \multirow[t]{2}{*}{6} & \multirow[t]{2}{*}{ status(3) } & 0 if data in position 3 is good \\
\hline & & & 1 if low signal-to noise ratio \\
\hline & \multirow[t]{2}{*}{7} & \multirow[t]{2}{*}{ status $(4)$} & 0 if data in position 4 is good \\
\hline & & & 1 if low signal-to noise ratio \\
\hline & \multirow[t]{2}{*}{8} & \multirow[t]{2}{*}{ status(5) } & 0 if data in position 5 is good \\
\hline & & & 1 if low signal-to noise ratio \\
\hline \multirow[t]{4}{*}{$\mathrm{ADCP} 2$} & 9 & error(4) & $0=$ no error; $1=\mathrm{ADCP}$ receiver error \\
\hline & 10 & error(3) & $0=$ no error; $1=A D C P$ transmit error \\
\hline & 11 & error(2) & $0=$ no error 1 = DPM communication error \\
\hline & 12 & error(1) & $0=$ no error; $1=\mathrm{DPM}$ processing error \\
\hline ADCP 2-3 & $13-20$ & temperature & $\mathrm{N} * 0.098-5.0=\mathrm{T}\left({ }^{\circ} \mathrm{C}\right)$ \\
\hline $\mathrm{ADCP} 3$ & $21-24$ & \#ensembles & averaged by DPM ( 0 to 8 maximum) \\
\hline \multirow[t]{2}{*}{$\mathrm{ADCP} 4$} & \multirow[t]{2}{*}{$25-30$} & \multirow[t]{2}{*}{ tilt var. } & $\left(\right.$ bit $29^{*} 32+$ bit $30^{*} 16+$ bit $25^{*} 8+$ bit $26^{*} 4$ \\
\hline & & & + bit $27^{*} 2+$ bit 28$) / 10=$ std in degrees \\
\hline $\mathrm{ADCP} 4-5$ & $31-36$ & heading var. & $\mathrm{N}=$ std in degrees \\
\hline ADCP 5-6 & $37-44$ & east $(1)$ & $\mathrm{N}-127=$ east velocity $(\mathrm{cm} / \mathrm{s})$ for position 1 \\
\hline ADCP 6-7 & $45-52$ & east(2) & $\mathrm{N}-127=$ east velocity $(\mathrm{cm} / \mathrm{s})$ for position 2 \\
\hline ADCP 7-8 & $53-60$ & east(3) & $\mathrm{N}-127=$ east velocity $(\mathrm{cm} / \mathrm{s})$ for position 3 \\
\hline ADCP 8-9 & $61-68$ & east(4) & $\mathrm{N}-127=$ east velocity $(\mathrm{cm} / \mathrm{s})$ for position 4 \\
\hline ADCP 9-10 & $69-76$ & east(5) & $\mathrm{N}-127=$ east velocity $(\mathrm{cm} / \mathrm{s})$ for position 5 \\
\hline ADCP $10-11$ & $77-84$ & north(1) & $\mathrm{N}-127=$ north velocity $(\mathrm{cm} / \mathrm{s})$ for position 1 \\
\hline ADCP $11-12$ & $85-92$ & north(2) & $\mathrm{N}-127=$ north velocity $(\mathrm{cm} / \mathrm{s})$ for position 2 \\
\hline ADCP 12-13 & $93-100$ & north(3) & $\mathrm{N}-127=$ north velocity $(\mathrm{cm} / \mathrm{s})$ for position 3 \\
\hline ADCP 13-14 & $101-108$ & north $(4)$ & $\mathrm{N}-127=$ north velocity $(\mathrm{cm} / \mathrm{s})$ for position 4 \\
\hline ADCP 14-15 & $109-116$ & north(5) & $\mathrm{N}-127=$ north velocity $(\mathrm{cm} / \mathrm{s})$ for position 5 \\
\hline ADCP 15 & $117-120$ & $\operatorname{vert}(1)$ & $\mathrm{N}-7=$ vertical velocity $(\mathrm{cm} / \mathrm{s})$ for position 1 \\
\hline \multirow[t]{2}{*}{ ADCP 16} & $121-124$ & $\operatorname{vert}(2)$ & $\mathrm{N}-7=$ vertical velocity $(\mathrm{cm} / \mathrm{s})$ for position 2 \\
\hline & $125-128$ & $\operatorname{vert}(3)$ & $\mathrm{N}-7=$ vertical velocity $(\mathrm{cm} / \mathrm{s})$ for position 3 \\
\hline \multirow[t]{2}{*}{$\mathrm{ADCP} 17$} & $129-132$ & vert(4) & $\mathrm{N}-7=$ vertical velocity $(\mathrm{cm} / \mathrm{s})$ for position 4 \\
\hline & $133-136$ & $\operatorname{vert}(5)$ & $\mathrm{N}-7=$ vertical velocity $(\mathrm{cm} / \mathrm{s})$ for position 5 \\
\hline
\end{tabular}


Table 8: IOEB Variable Formats

\begin{tabular}{|c|c|c|c|c|c|}
\hline Variable & Format & Minimum & Maximum & Null & Resolution \\
\hline \multicolumn{6}{|c|}{ ADCP -ctr, bf, status, error } \\
\hline & INT & 0 & 1 & - & 1 \\
\hline -temp & REAL & -5.0 & 20.0 & - & .098 \\
\hline \#ens & INT & 0 & 8 & - & 1 \\
\hline -tilt & REAL & 0 & 6.3 & - & .1 \\
\hline -head & INT & 0 & 63 & - & 1 \\
\hline$-n, e$ & INT & -127 & 127 & - & 1 \\
\hline -vert & INT & -7 & 8 & - & 1 \\
\hline $\mathrm{CON}$ & INT & 9 & 16 & - & 1 \\
\hline FL & REAL & 0 & 5 & - & .001 \\
\hline IBV & INT & 9 & 16 & - & 1 \\
\hline IDA & INT & 0 & 7 & - & 1 \\
\hline $\mathrm{IECH}$ & REAL & 0 & 10 & - & .002 \\
\hline ISxx & INT & -270 & 492 & - & 6 \\
\hline ITxx & REAL & -56.1 & 5.22 & - & .02 \\
\hline ITIM & REAL & 0 & 25.5 & - & .1 \\
\hline MAT & REAL & -40 & 20 & - & .05 \\
\hline MBAR & REAL & 920 & 1050 & - & .1 \\
\hline MBV & REAL & 6 & 8.8 & - & .4 \\
\hline $\mathrm{MD}$ & INT & 0 & 3 & - & 1 \\
\hline MHE & REAL & 0 & 360 & - & 1.4 \\
\hline MTEN-byte1 & REAL & 0 & 5518 & - & 21.6 \\
\hline -byte2 & REAL & 0 & 5518 & - & 21.6 \\
\hline -byte3 & REAL & 0 & 2759 & - & 10.8 \\
\hline MTIM & REAL & 0 & 25.5 & - & .1 \\
\hline MTX & REAL & -60 & 60 & - & .9 \\
\hline MTY & REAL & -60 & 60 & - & .9 \\
\hline MWD & REAL & 0 & 360 & - & 1.4 \\
\hline MWS & REAL & 0 & 50 & - & .19 \\
\hline PTT & INT & 9 & 16 & - & 1 \\
\hline $\mathrm{S} 4 \mathrm{~N}$ & REAL & -256 & 256 & - & .5 \\
\hline $\mathrm{S} 4 \mathrm{E}$ & REAL & -256 & 256 & - & .5 \\
\hline $\mathrm{S} 4 \mathrm{~T}$ & REAL & -5 & 20.5 & - & .1 \\
\hline $\mathrm{S} 4 \mathrm{C}$ & REAL & 20 & 72 & - & .05 \\
\hline \multicolumn{6}{|c|}{ SCDO 1-7, SCI 1-4, SCII 1-4: } \\
\hline$-\mathrm{T}$ & REAL & -5 & 20 & - & .0005 \\
\hline$-C$ & REAL & 20 & 72 & - & .0005 \\
\hline$-\mathrm{O}$ & REAL & 0 & 5 & - & .001 \\
\hline$-F$ & REAL & 0 & 5 & - & .001 \\
\hline $\mathrm{ST}$ & INT & 0 & 15 & - & 1 \\
\hline TR & REAL & 0 & 100 & - & .02 \\
\hline WTS & INT & 0 & 15 & - & 1 \\
\hline
\end{tabular}




\section{TESTING}

During the manufacture of the IOEB, a series of tests were conducted to evaluate the reliability of the whole buoy system under various conditions. However, due to time and budgetary constraints, only a limited number of environmental conditions were simulated. Although these experiments were intended to sufficiently assure that all of the sensors on the buoy would operate properly, unaccountable problems specific to the Arctic environment could not be completely avoided. Regrettably, mechanical shock and vibration tests could not be performed.

\section{A. Preliminary IOEB mechanical package}

Between the recovery of the AEDB and the full-fledged implementation of the IOEB, a Preliminary IOEB (PIOEB) was constructed to test several improvements in the mechanical and electronic design. This test package was deployed in sea-ice in the Northwest Passage from the USCGC Polar Sea during midSeptember 1990 for 20 hours, while the operation was monitored and engineering measurements taken.

One of the major improvements of the PIOEB over the AEDB was the use of surlyn ionomer foam for the outer protective shell of the apex. Consequently, the primary objective of the Northwest Passage experiment was to test the strength of a surface buoy in broken sea ice. Furthermore, electrical conductors were added to the $10 \mathrm{~m}$ strength cable that was to penetrate through the ice and suspend the underwater mooring system. As a result, the reliability of the through-ice $\mathrm{E} / \mathrm{M}$ cable was a secondary objective.

The apex of the PIOEB was similar to that of the subsequent IOEBs which have already been described. Except for the positioning of the watertight bulkhead connectors on the electronic pressure cylinder endcap, only a few other details were different. Inside the electronics tube, two Synergetics PTTs transmitted ARGOS data via patch antennas mounted externally on the surface of the top plate. In this instance, only one TT3 data logger was used feed the datastream to both PTTs via an RS-232 serial port. A QSI 12-bit A/D converter board with added circuitry was controlled by the TT3 to collect data from a tensiometer mounted in the bellmouth flange at the bottom of the surface flotation assembly.

Only one instrument was attached at the bottom of the ice strengthened E/M cable which comprised the whole mooring system. A standard SBE-16 SeaCat was mounted in a stainless steel cage and its data was acquired by the microcontroller in the apex over the conducting wires. Below the SeaCat a $600 \mathrm{lb}$ anchor was fashioned in the field to simulate a heavier mooring system.

On September 13, two Woods Hole Oceanographic Institution (WHOI) scientists were transported by US Coast Guard helicopters from Resolute, Canada to 
the Polar Sea which was offshore. The PIOEB package was deployed from the Polar Sea, between Cornwallis and Griffith Islands where Resolute Channel meets Barrow Strait. The icebreaker was used to induce ice pressure on the float, while observations on the mechanical effects were performed visually, and via ARGOS data transmission. After approximately 24 hours of testing, the buoy was retrieved undamaged from the Canadian waters.

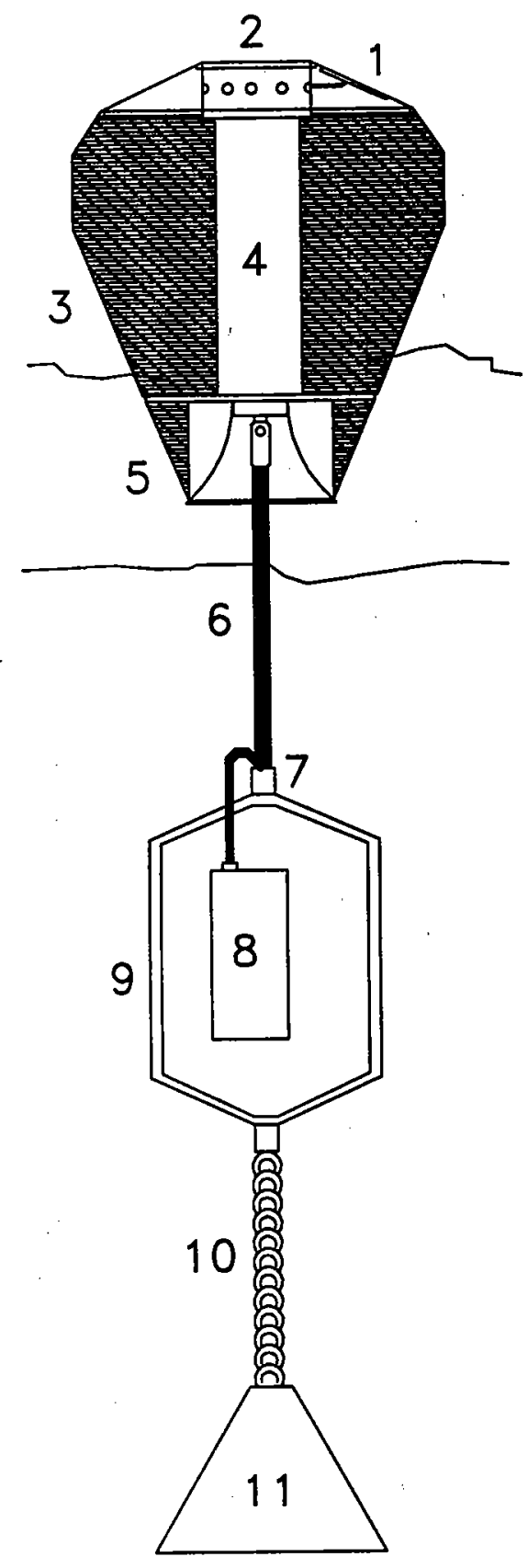

\section{Preliminary Ice-Ocean \\ Environmental Buoy \\ $(P-I O E B)$}

1. Patch antennas

2. Top plate

3. Foam shell

4. Al pressure housing containing:

a. Platform Transmit Terminals

b. Tattletale MCU

c. Battery pack

5. Bell mouth weldment

6. Ice strengthened $E / M$ cable

7. Cable termination

8. SeaCat $C / T$ recorder

9. Protective cage

10. Chain

11. Anchor weight

Figure 10: Preliminary IOEB - 1990 Test 
The visual results from this test confirmed the slipperiness of the outer Surlyn foam shell by escaping vertically between $1 \mathrm{~m}$ icefloes as they came together around the apex. Conductivity, temperature, and depth readings were reliably transmitted at all times by the SeaCat's serial RS-232 port up the ice-penetrator cable to the MCU. Tension readings from the load cell mounted in-line with the mooring system showed remarkable sensitivity to variations as the surface float bobbed, or was pushed up, on the ocean surface surrounded by Summer sea-ice.

Afterwards, the EIA485 standard was adopted for the network drivers. In the mechanical design of the IOEB, accommodations were made for the findings of the PIOEB test. Notably, the ice strengthened E/M link was changed from an assembly based on wire rope to one which incorporated chain.

\section{B. Environmental cold tests}

The most obvious difficulty that needs to be overcome in designing instruments for operation in the Arctic is the extreme cold temperatures (down to below $-60{ }^{\circ} \mathrm{C}$ ) that can persist in the atmosphere over the sea ice in the wintertime. Consequently, environmental cold tests were conducted on the surface electronics to determine their operational durability.

During the design phase of the IOEB, the rated operating temperature of the TT3 data logger $\left(0\right.$ to $\left.70{ }^{\circ} \mathrm{C}\right)$ was a concern. However, since the Tattletale fulfilled all other requirements for use better than any other low-cost, commercially available microcomputer, it was decided to individually test a number of TT3s and choose the best for implementation in the apex electronics. In a tabletop environmental chamber at Woods Hole, all of the Tattletale were cyclically tested between the temperatures of -50 and $100{ }^{\circ} \mathrm{C}$ for varying periods of 1 to 5 days.

In the test chamber, each TT3 was sealed in an airtight bag and exposed to extremely cold and extremely hot temperatures, while monitoring its operation via leads to an apparatus located outside of the chamber. Electrical currents and voltages at different test points were observed while the TT3 was made to perform various functions as programmed. While the cold tests were designed to simulate the Arctic temperatures, the hot temperature tests were performed with the desire to accelerate "infant mortality" defects in any of the integrated circuits on the TT3 before using them on the IOEB. During these experiments, the most difficult test for a Tattletale to pass was reawakening after being in a hibernate mode for an extended period of time at the extreme low temperatures below -40 ${ }^{\circ} \mathrm{C}$. Any TT3 that would not reawaken even once was excluded from use in the IOEB surface flotation package.

The circuit boards that were constructed and added to the TT3s to make the MCUs, met modules, and ice modules, were all outfitted with parts that were 
rated for compliance with military specifications (i.e. tested operation down to $-55{ }^{\circ} \mathrm{C}$ ). In addition, all these assembled units were individually tested in the cold chamber as described above. But in order to verify the operation of entire apex electronics assembly in the cold, a much larger freezer chamber was required. Therefore, the entire surface flotation package was placed inside a cold chamber at CRREL at $-30{ }^{\circ} \mathrm{C}$ for several weeks with all of the electronic units operating. During this time, calibrations of the ice stress sensors were conducted by our colleagues at CRREL. Inside the chamber, the ARGOS signal could not reach the satellite, but the units were still operating properly when removed from the chamber, attesting to their durability at that temperature.

The final test of the entire mooring system was performed outside at Woods Hole during the month of January 1992. While the underwater instrumentation was located inside of laboratory, the surface package was situated outside, subject to the winter elements. Electrically connected through the appropriate mooring cables, all of the units on the mooring system and in the surface package operated properly and transmitted data via ARGOS for one month, until the test battery packs inside the apex were exhausted.

\section{DEPLOYMENT OF IOEBS}

The IOEBs were designed to be deployed from the USCGC Polar Star as part of the International Arctic Ocean Expedition (IAOE) in the summer of 1991. But because of the early turnaround of the icebreaker, the buoys had to be brought back without being installed, and we were forced to initiate ice camp deployments at two separate camps the following Spring of 1992.

The ice camp deployments required modifications made to the surface float package, and a redesign of the deployment operation. Originally to be deployed from ice-breakers where weight and volume were of relatively little concern, the apex had to be reduced in size and divided into two pieces, in order to fit trough the cargo door of the DeHavilland Twin Otter turboprop planes. Though some of the surlyn flotation foam had to be sacrificed, it was not a significant amount compared to the total buoyancy of the buoy and mooring system. Lowering the heavy, highly sophisticated mooring system through the sea-ice without a ship's crane required redesigning an aluminum-alloy, air-portable gantry rig to maneuver a 3-ton object through an icehole in the extremely low Arctic temperatures.

Early in 1992, we sent the modified IOEBs to Nord, Greenland and to Prudhoe Bay, Alaska. The US Air Force transported the Transpolar IOEB from McGuire AFB to Thule by C-141 and then the NY National Guard provided transportation from Thule to Nord by C-130. Cargo for Prudhoe Bay was sent by commercial aircraft. DeHavilland Twin Otter airplanes were used to transport the deployment team, the IOEB components and support material from Nord to 
Camp Crystal and from Prudhoe Bay to LEADEX Camp.

One IOEB was deployed at the center of the Transpolar Driftstream from the northernmost ice camp of the Arctic Region Environmental Activity, 1992 (AREA 1992) of the Space and Naval Warfare Command (SPAWARC), USN, in mid-April, 1992. This camp, Camp Crystal, was located about 800 nautical miles from the Fram Strait. The other IOEB was installed later the same month at the circumference of the Beaufort Gyre from the ONR maintained Lead Experiment (LEADEX) Camp, located in the southern edge of the Beaufort Gyre. In terms of efficiency and flexibility, these ice camp expeditions proved to be better suited for deploying the intricate IOEB stations than conventional icebreakers.

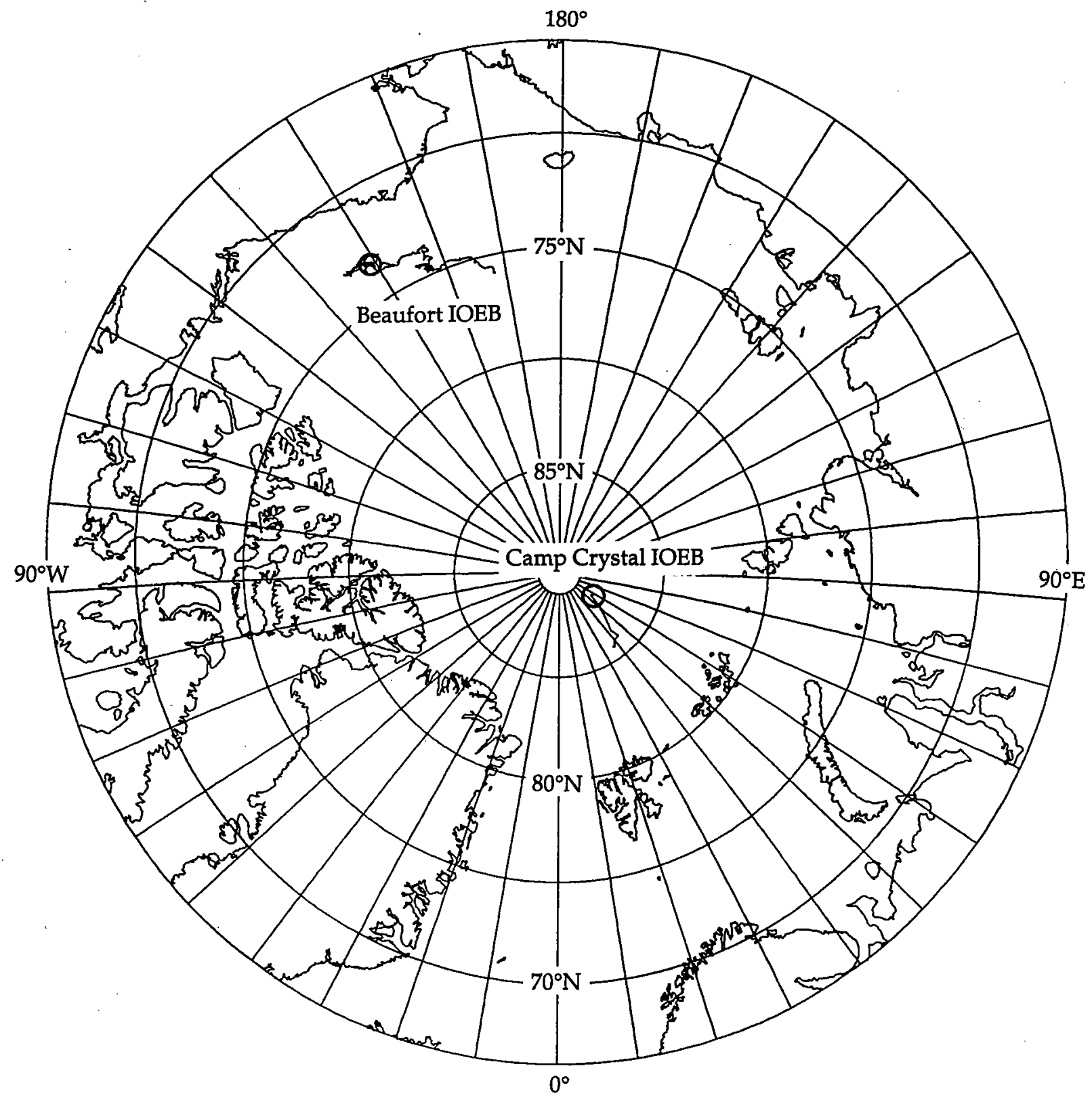

Figure 11: IOEB Deployment Sites 


\section{A. Transpolar Drift IOEB deployment at CRYSTAL}

The operation to deploy the Transpolar IOEB from the Crystal ice camp was delayed due to storms in Greenland which prevented the WHOI/CRREL ice party from being transported to Crystal until the evening of April 12. However, the first IOEB was successfully deployed at $88^{\circ} 01^{\prime} \mathrm{N}, 57^{\circ} 07^{\prime} \mathrm{E}$, about $200 \mathrm{~m}$ from Camp Crystal, 113 nautical miles from the North Pole at the approximate center of Transpolar Drift on April 15, 1992.

Upon arriving at Camp Crystal, the surrounding ice floe was surveyed to select the deployment site for the IOEB, using the same criteria that was used during the AEDB deployment. The ice floe containing the buoy was to be a multi-year and relatively thick $(3$ to $6 \mathrm{~m}$ ) icefloe, surrounded by ice ridges for strength, but otherwise representative of the local ice floe conditions.

On the following day, the surface electronics package was powered, and the ARGOS satellite began receiving transmissions from this buoy. At the same time, the gantry and hand-driven winch were frozen in place for the deployment operation. All of the mooring instrumentation was initialized on April 14, and a 1 meter hole was drilled through the $3.5 \mathrm{~m}$ icefloe below the gantry. After completing these preparations, the actual deployment began at 00:00 on April 15 and finished 4 hours later. On the following day, the ice thermistors, ice stress sensors, and meteorological mast were installed with the buoy. Due to time limitations, the upward pointed echo sounder was not installed.

\section{B. Beaufort Gyre IOEB deployment at LEADEX}

The WHOI team returned home temporarily to re-outfit, then flew to Prudhoe Bay, Alaska to conduct the deployment of the other Arctic IOEB during the backhaul of the LEADEX ice camp in the Beaufort Sea. The second IOEB was successfully deployed on April 24, 1992 at $73^{\circ} 01^{\prime} \mathrm{N}, 148^{\circ} 50^{\prime} \mathrm{W}$, about $70 \mathrm{~m}$ from ONR's LEADEX Camp, 160 nautical miles from the northern coast of Alaska, at the approximate southern end of Beaufort Gyre.

The deployment gantry and winch used at the CRYSTAL deployment were rushed out of Greenland and to Alaska in a matter of days, in order to be used for the deployment of the second IOEB before the camp was abandoned. On April 23, the WHOI ice party arrived at the LEADEX camp with the Beaufort IOEB and began setting up for the deployment. By late that night, the gantry was assembled, the 36" ice hole was drilled, the surface electronics were powered, and the first transmissions were received by the ARGOS satellite (April 24, 06:44 Z). Overnight, one of the controllers failed and in the morning it was replaced and the PTTs restarted.

On April 24, all the instruments at the bottom of the mooring were initialized. The next day, the upper mooring instruments were initialized and the remainder of the buoy was deployed. The surface float was in position by April 26, 03:00 Z. Shortly thereafter, all the ice sensors and the meteorological mast were installed. Later that day, the LEADEX ice camp was abandoned by all. 


\section{THE WEDDELL SEA IOEB}

Between the time of the IAOE Expedition and the ice camp operations, scientists from the Scott Polar Research Institute (SPRI) in Cambridge, England expressed their desire to deploy a similar IOEB in the Weddell Sea, Antarctica from the Nathaniel Palmer. Based upon the work done on the Arctic IOEBs, a less complex version of the IOEB was constructed using parts of the prototype IOEB with new sensors and the new network circuitry. This buoy was deployed on April 26 (coincidental with the Beaufort IOEB deployment) by members of the SPRI at $67^{\circ} 20^{\prime} \mathrm{S}, 49^{\circ} 35^{\prime} \mathrm{W}$.

Like the other IOEBs, the Weddell Sea IOEB contains meteorological, ice, and ocean sensors, and uses dual TT485 microcontrollers and Synergetics PTTs to broadcast the ARGOS datastream via patch antennas. Though there only four instruments on this IOEB mooring system, it extends down to a depth of $331 \mathrm{~m}$, of which only the first $130 \mathrm{~m}$ contains the conductors required for EIA485 data telemetry.

The apex of the buoy is the Preliminary IOEB surface package. Inside the surlyn ionomer foam shell, a watertight pressure cylinder houses the PTTs, MCUs, a TT12AD meteorological module, a TT3 based ice module, and the lithium battery packs. Protruding from the painted steel top plate, an aluminum mast secures the R.M. Young wind monitor and air temperature probe to the buoy. A steel bell mouth flange attaches the mooring system to the bottom.

The met module acquires and telemeters the data from the met mast, as well as from an Aanderaa magnetic compass, Spectron two-axis tilt sensor, and a tensiometer. A barometer was not incorporated on this model. The software to control this TT12AD is different from that of the other IOEBs because of the dissimilarities.

An ice thermistor chain consisting of 16 thermistors is electrically fed to the ice module inside the electronics tube via watertight connectors. There are no other ice sensors on this buoy. Consequently, Campbell instrumentation is not used, but rather a modified QSI 12-bit A/D converter board is added to a TT3 for acquiring and telemetering the ice thermistor data. In addition to the MUSSIC circuitry, analog switches, signal conditioning and power circuitry were added to the QSI board to outfit the module. A unique software program was written to operate the ice module accordingly.

The mooring cables which connect the telemetering instruments underneath the sea-ice are the same as for the other IOEBs, with the exception of the ice strengthened $\mathrm{E} / \mathrm{M}$ link. The first $10 \mathrm{~m}$ segment is the cable developed for the Preliminary IOEB, and consists of potted three conductor stainless steel oceanographic cable. In addition to telemetering to the surface, all of the ocean instruments store their data internally. 


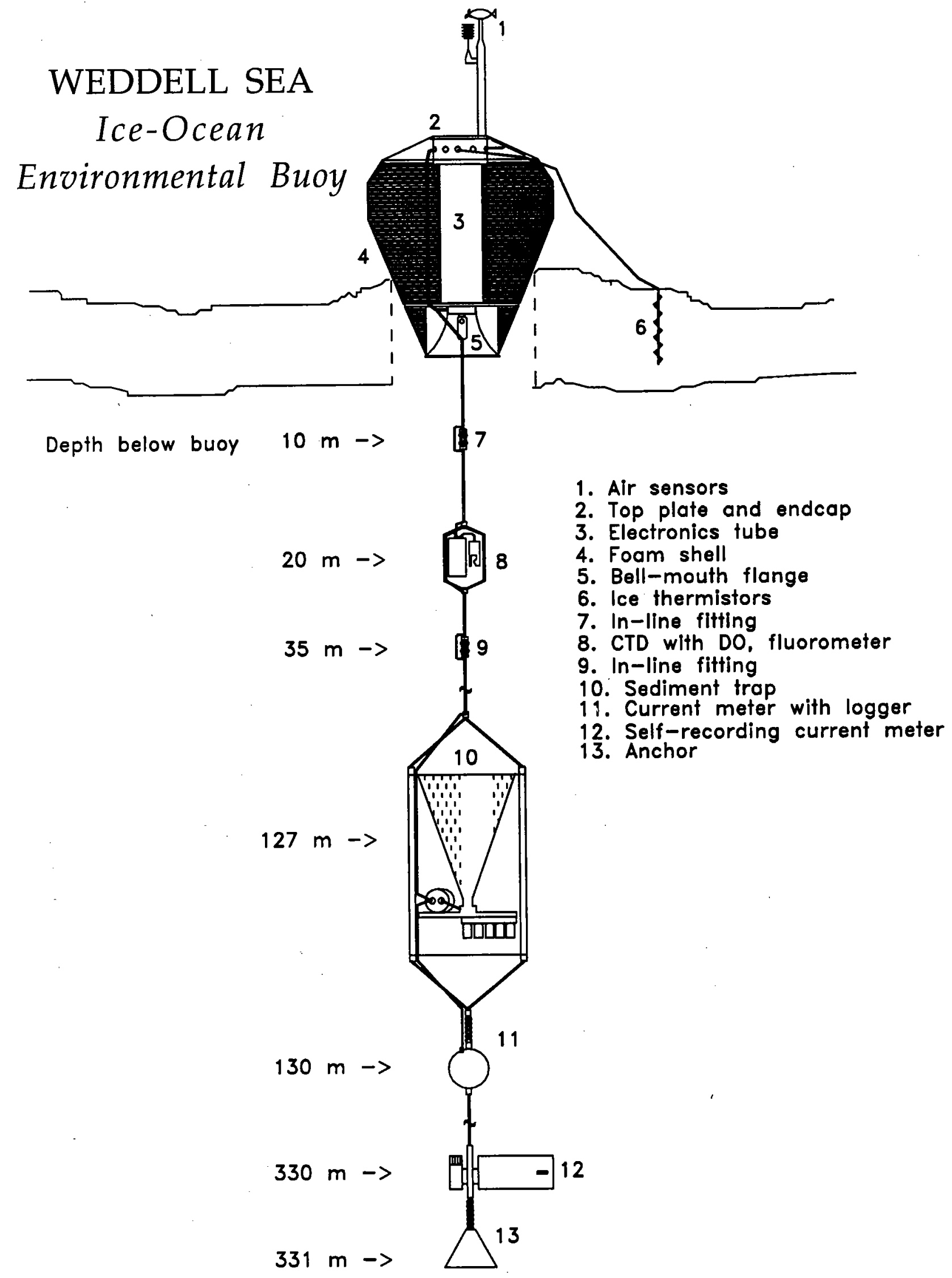

Figure 12: Weddell Sea IOEB - mooring diagram 
The first instrument is located at $20 \mathrm{~m}$, and is a SeaCat C/T recorder with a dissolved oxygen sensor and a Sea Tech Fluorometer. A McLane sediment trap is positioned $127 \mathrm{~m}$ below the apex, and inside its frame is mounted an S4 telemetry module for the S4 current meter which hangs immediately below. At $35 \mathrm{~m}$, a connection was provided for another instrument which was to be incorporated on the Weddell buoy, but never transpired. All of the above devices are networked to the MCUs in the apex and telemeter their data accordingly. However, at $330 \mathrm{~m}$ below the surface package, an Aanderaa current meter is attached to the mooring system by standard oceanographic wire rope cable, and only collects its data internally. A lead anchor hangs immediately below this current meter, and completes the mooring system.

Because this IOEB contains fewer sensors than the other IOEBs, the transmission scheme and data formats are different. This scheme has only two different data sequences which are broadcast alternately every hour. Furthermore, it was desired to transmit four complete ensembles of S4 data in a single sequence, so the appropriate software was modified accordingly. Because of the omission of one of the ocean instruments, 50 bits of the ARGOS datastream are not utilized. Details of the electronic architecture of the Weddell IOEB are included in Appendix $\mathrm{E}$ at the end of this report.

\section{DATA ACQUISITION AND SOFTWARE}

During operation, every IOEB transmits 512 bits of sensor information every 90 minutes via ARGOS. This is equivalent to a data throughput of 24,576 bits/day from all three IOEBs. A comprehensive processing procedure has been devised to accumulate all of the data, and make the filtered processed results accessible worldwide in near-real time. Currently configured to preprocess the data automatically, this software package reduces data acquisition costs by minimizing the use of operational and phone-line time for accessing data from the ARGOS computers. In the future this routine, called SADA (Satellite Automatic Data Acquisition System), will also be able to automatically generate tables and plots of the information.

Every morning before 8:00 EST, the previous 24 hours worth of data from each IOEB is automatically transferred to the WHOI Vax computer from Service ARGOS via the NASA Science Internet - DECnet (NSI-DECnet) network. Hexadecimal data from each buoy is stored in a separate file: BARGOS.DAT for data from the Weddell Sea IOEB, JARGOS.DAT for the Beaufort Gyre IOEB, and WARGOS.DAT for the Transpolar Drift IOEB.

Because of the transmission scheme of the IOEBs, standard ARGOS processing procedures cannot be used to decipher the data. Provisions need to be incorporated to unpack the data according to the first three bits of each transmission, indicating the format of the data that follows. A single $\mathrm{C}$ language program 
developed by Woods Hole, called GARGOYLE, interprets the sequence number and performs all of the data unpacking and processing functions for each of the IOEBs. However, since each buoy may have different instrumentation, and does have unique calibration data, each IOEB has its own configuration file for use with the GARGOYLE program. The operation of the GARGOYLE program is unique in the manner with which it performs all of the various data manipulations across a wide range of configurations. Furthermore, this program was designed to be easily adaptable by making changes in the configuration files to accommodate the differences in the present buoys, or in future buoys.

Shortly after being loaded onto the Vax, the ARGOS data files are processed by GARGOYLE to unpack the ARGOS data, separate the position data from the raw compressed data, prefilter out bad data scans, add the appropriate equations to the raw data to produce the real data, and optionally load the output data into a relational database management system, also on the Vax. The resultant files consist of the reasonably good data from each buoy, as received and time coded by the ARGOS satellite, and in many cases will contain repeated data.

From the position datafiles, hourly drift tracks are determined using the locations of ARGOS quality 2 or better, filtered through a 5-hour Gausian spline, and the drift velocity vectors are recomputed from the hourly drift tracks.

Further processing of the resultant datafiles is required to eliminate the duplicate data, and restore the actual acquisition time to the data. This requires determining the time of the first transmission for each set of scans for each sequence of data, removing the bad scans and determining the good data for each sequence, and recombining the earliest transmission time with the good data. Different instruments collect data at different times, but to determine the actual acquisition time, the sensor data must be interpolated to the measurement time preceding the earliest satellite broadcast of the information.

In the SADA system design for full automatic operation, daily data from any number of IOEBs is acquired, transformed, and loaded onto the WHOI Vax computer every morning before working hours. Once the information from each IOEB is loaded into its particular database, it is then immediately available for use by all eligible users. Since the database is continuously available on the WHOInet network, near real-time accessibility of IOEB data to the worldwide scientific community is possible.

The SYBASE distributed relational database management and development system was selected for this use because it provides scalable high performance, server-enforced integrity and security, high application availability (near continuous availability, even during maintenance activities), and application portability over networks and across a wide variety of terminals and workstations. Because it is on the WHOI Vax, scientists from around the world can access the database 24 hours a day via the WHOInet network which provides local 
links within the Woods Hole community, as well as access to other prominent computer networks, including Internet, NSI-DECnet (formerly SPAN), NCARnet, and NSFNET.

The processed IOEB datafiles will be loaded into multiple raw data tables of the appropriate database. Whenever possible, similar data types will be initially grouped in a single table, but when this is not possible, the database tools allow manipulating data between tables, or even between separate databases from the different buoys. For security, each table can individually be either protected or open to individual users.

Inside the database, the data will be filtered and smoothed, and data tables of the processed, splined results will be created. These tables will form the basis for various plots and printouts which will be generated on a weekly basis in order to monitor the status of results. When completed, this entire operation will run automatically; from the acquisition of the raw ARGOS data to the plotting of the weekly data.

At the same time, Service ARGOS mails us monthly floppy disks with the backup raw data that we use to verify the real-time data.

\section{CONCLUSIONS AND RECOMMENDATIONS}

Since 1990, we planned, supported by a wide network of international colleagues, to deploy IOEBs in the two major ice regions of the Arctic Ocean. The first attempt, using a conventional icebreaker as the platform for deployment, failed due to the malfunctioning of the ship. The second attempt, which relied exclusively on airplane transportation to remote ice camps, not only provided us with total success in deploying both IOEBs at ideal locations in the Arctic, but also gave us a very efficient and safe method to study Polar oceanography and its many ramifications.

Because not all of the instruments on the IOEB are operating as designed, it is apparent that not all of the essential features of an automated Polar research station have been perfected by the development of the IOEB. However, we believe that problems with the current systems are repairable in future systems, and that the data provided by the 1991-92 IOEBs will add significantly toward understanding global warming through the understanding of Arctic processes.

\section{A. Preliminary results}

Unfortunately, after the CRYSTAL deployment operation was completed, it became apparent that the data to the PTTs was not being properly updated every hour. Consequently, the electronics package was removed from the surface float while the mooring system remained deployed. The PTTs and controllers were reinitialized and the electronics reinstalled in the float. However, this did 
not solve the problem, and on April 16, the electronics were removed once again, and a minor hardware modification to the controllers was improvised to enhance the data updating capability. The positive result from this was that the controllers did finally begin to update the data to the PTTs more reliably, only less frequently than expected. On the other hand, since that time, signals from one of the PTTs were not received by the ARGOS satellite for the first 9 weeks, although the local uplink receiver indicated that the PTT was operating properly when the ice party departed from the camp later that day. Afterwards, that same PTT mysteriously was recognized by the ARGOS satellite for the next two weeks.

All of the individual instruments that were to be deployed on this mooring were operating properly indoors at the ice camp before they entered the water. Data from ARGOS indicates that most of the individual instruments were operating properly, though the controllers were updating less frequently than intended, after being deployed. However, the ice stress sensors did not acquire data since the final time that the PTTs were restarted, and the sediment trap and the water transfer system were not communicating with the controllers since being deployed. The S4 current meter has transmitted some questionable data, and the meteorological module has only updated data from its sensors sporadically.

The Beaufort IOEB deployment team noted a significant improvement in their skill after experiencing the deployment of the Transpolar IOEB in the North Pole area. After powering the PTTs and controllers on this buoy, data was being updated by the controllers every hour, as intended. However, immediately after connecting the mooring system to the surface float, the data was not updated for an extended period of time. This fact leads us to believe that noise exists on this mooring network, and probably on the mooring networks of the other IOEBs, as well.

All of the individual instruments on this mooring were operational when deployed, but like the Transpolar IOEB, the sediment trap and water transfer system have not communicated with the controllers. The S4 module has also not communicated, and the meteorological module began by updating sporadically but later became regular. All other instruments are transmitting data, and both MCU/PTT pairs are broadcasting strongly.

By far the most disconcerting result is that no new transmissions from the only operational PTT on the Transpolar IOEB have been received by the ARGOS satellite since July 9, 1992. The unit sent strong signals for over two weeks, halted transmission for 5 weeks, recovered and began transmitting data from the previously non-operational PTT for an additional few weeks. According to the last transmissions received, the batteries supplying either PTT had not deteriorated. Without transmissions from either PTT, the location of this buoy cannot be determined.

Similarly, several of the instruments on the Weddell Sea IOEB experi- 
enced certain problems telemetering their data when deployed. However, as of the publication of this report, the status of this buoy is unknown.

In general, however, a large volume of scientific data is still being transmitted by the Beaufort IOEB sixteen months after being deployed. Since being deployed, the ADCP has been successfully telemetering profiles of the currents via its DPM. In addition, the met and TRFL modules are still broadcasting updated data. On the other hand, after only a month all of the SeaCats failed responding, but even into July 1992, the number of sensor data variables being transmitted from the buoy was about $86 \%$. Since then, the ice sensors apparently were pulled away from the buoy, causing the ice module to transmit only zeros since then. Coincidentally, the apex tilt sensor indicated a lean in excess of $20^{\circ}$ during the period that the sensor strings were removed, one at a time. By now, all the particle collectors have completed their schedules, but the quality of their samples cannot be determined until each system is recovered. Compilations of the full results will be published in later data reports.

\section{B. Estimated causes for sensor failures}

Because none of the IOEBs have been recovered, we are not able to positively diagnose every particular sensor problem. While analyzing the operation remotely, we must always consider possible mechanical breaks or other unknown causes for some sensor failures. However, there are some clues to certain problems which we can detect from the ARGOS data being received here at Woods Hole. Following is our analysis of some of the problems and some recommendations to prevent these errors the future.

All of the underwater instruments were guaranteed to operate down to -5 ${ }^{\circ} \mathrm{C}$, which is sufficient for operation in seawater, but some may have failed during deployment due to the extremely cold Arctic air. This is an operational problem which requires experience in the cold temperatures. The day that the Transpolar IOEB was deployed at the Camp Crystal was particularly cold, and coincidentally, more sensors failed on this buoy than on the Beaufort IOEB. This was the WHOI deployment team's first attempt to deploy an IOEB from an ice camp, and regrettably, we did not work out the details for securing a warmer environment during the critical deployment phase. This situation was corrected during the second deployment of the Beaufort IOEB at the LEADEX Camp where a heated tent was provided adjacent to the site. We believe that much experience was gained during the first IOEB deployments, and more will be gained during further operations, so that we can expect less of these problems in the future.

On the other hand, cold temperatures should not have been a problem for the surface electronics, since all of these units and components were selected for their stated reliable operation down to temperatures of at least $-40{ }^{\circ} \mathrm{C}$. Furthermore, we confirmed their operation at the extreme temperatures in our 
own environmental chamber with cycle testing, as described previously.

All sensors were calibrated by their manufacturers or at Woods Hole. It is possible that some sensors may have drifted from the time they left Woods Hole to the time they were deployed, due to vibrations in shipment, temperature effects, or problems during deployment. To prevent this from occurring again, portable field calibration procedures need to be developed for the most sensitive sensors.

In particular, the most fundamental failure of the IOEB system is the loss of ARGOS transmitting capabilities from both of the Transpolar IOEB PTTs. Without any transmissions, it is extremely difficult to speculate on the actual cause of this failure, but possibly either the PTT or patch antenna have become defective, or the buoy has been environmentally buried under snow or ice, or sunk.

On the other hand, one problem which we have been able to positively detect is the noise on the E/M cable. It has been determined that the EIA485 circuit used by the SeaCat C/T recorders generated instantaneous glitches on the network every time it was powered on or off. Because there are three SeaCats on each mooring system, the noise generated from each unit would wake the other two units, and as a result, an infinite loop of glitching between the units ensued. This effectively kept the SeaCats awake all the time, and prohibited any other communications from occuring on the network. Consequently, the batteries of all the SeaCats were exhausted after only approximately one month, and once the SeaCats stopped functioning, network communications resumed normally. SeaBird Electronics has remedied this situation on new models by incorporating a separate watchdog circuit which powers the EIA485 circuit continuosly but only wakes the SeaCat microprocessor when it recognizes its own address.

Furthermore, an initial problem with the meteorological sensors was a direct result of this noise. The software program being operated by the meteorological module was being continually interrupted by the glitching, and as a result could not acquire all the data from all the sensors as frequently as desired. This problem has been corrected by rewriting the software algorithm used to acquire the data. In addition, this program has also been rewritten to fix bugs that caused corruption in the $y$-tilt and barometer data.

We know that our ice sensors have been ripped from the Beaufort IOEB due to motion of the sea ice, but that was expected. The ice sensors have to be sacrificed in this manner in order to ensure the integrity of the rest of the buoy. We do not know of any way of keeping the ice sensors intact by preventing the icefloes from rafting or breaking apart around the buoy. 


\section{Suggestions for improving future performance}

With regard to its science and engineering components, we are confident that the IOEB concept works. On the other hand, we have also found that not all sensors are responding as they should. Some of the causes of the malfunctioning sensors have already been identified and these relatively minor repairs will certainly be implemented in future versions. On the other hand, the mechanical design of the apex package needs to be reduced in order to ensure mobility and fully realize the IOEB design function. Furthermore, extended dynamic environmental tests need to be conducted on future buoys prior to deployment to definitively eliminate component problems.

Although quite alot of scientific data is being acquired from one IOEB, the inability of the other buoy to transmit after only a few months seriously undermines the entire experiment. Consequently, the choice of PTT, antenna, and MCU needs to be reappraised for implementation in future buoys. Eventhough these units are specified for extreme temperatures, they must be environmentally tested under the most severe conditions. To further protect against intrusion of the environment, the surface electronics package needs to be economically designed to be a sealed air-tight package that can be removed intact from the aluminum pressure housing. This feature would provide extra protection if these units required removal or repowering after deployment of the complete mooring system. The importance of assuring the operation of the transmitters cannot be overstated.

Mechanically, the apex needs to be reduced in size and weight so that it is easily portable in the field. Because the 1991-92 IOEBs were designed for icebreaker deployments, this was previously not presumed to be a major concern. However, since ice camp operations are a more efficient manner to deploy these systems, our structure must conform to the limits of air-supported operations. A portable apex also enhances field initialization and repair of the electronic devices it contains, since all of the surface electronics may be operated on in warm, dry facilities.

In addition, some of the individual scientific instruments indicate that their hardware or firmware needs to be further inspected for possible detrimental effects. Continuing development of the sensor collecting and transmitting devices needs to be a continual priority, not only for the existing instrumentation, but also for the adaptation of other innovative sensor systems onto the IOEB. 


\section{REFERENCES}

Aagaard, K. and Carmack, E. C., 1989. The role of sea ice and other fresh water in the Arctic circulation. J. Geophys. Res., 94: 14,485-14,498.

Busse, D. W., 1987. Quartz Transducers For Precision Under Pressure, Mech. Eng., 109: 5-10.

Colony, R. L., Rigor, I., and Runciman-Moore, K. A., 1990. A Collection of Sea Ice Trajectories in the Arctic Ocean - Preliminary Report. Technical Memorandum APL-UW TM 4-90, University of Washington.

IEEE Computer Society, 1985. IEEE Standard Serial ASCII Instrumentation Loop (SAIL) Shipboard Data Communication, ANSI/IEEE, Std 997-1985, 12 pp.

Electronic Industries Association, 1983. EIA 485 Standard for Electrical Characteristics of Generator and Receivers for use in Balanced Digital Mulitpoint Systems, Electronic Industries Association, Washington, D.C., $22 \mathrm{pp}$.

Hoeber, H. and M. Gube-Lehnhardt, 1987.The Eastern Weddell Sea Drifting Buoy Data Set of the Winter Weddell Sea Project (WWSP) 1986, Alfred Wegener Institute for Polar and Marine Research, Reports on Polar Research 37, 108 pp.

Honjo, S., 1990. Particle Fluxes and Modern Sedimentation in the Polar Oceans, Chapter 12 in Polar Oceanography (W.O. Smith, Jr., ed.), Academic Press, New York.

Honjo, S., R. Krishfield and A. Pleuddemann, 1990.The Arctic Environmental Drifting Buoy (AEDB): Report of Field Operations and Results, Woods Hole Oceanographic Institution, Woods Hole, MA, Technical Report WHOI-90-2, 128 pp.

McPhaden, M.J., H.B. Milburn, A.J. Nakamura and A.J. Shepherd, 1990.

PROTEUS - Profile Telemetry of Upper Ocean Currents, in Proc. MTS '90

Conference, Marine Technology Society, Washington, D.C., pp. 353-357.

Onset Computer, 1988.Tattletale Models II,III, IV \& V, Single-card data loggers 
with TTBASIC coperating system, Onset Computer Corp., N. Falmouth, MA, 264 pp.

Östlund, H. G., Possnert, G., and Swift, J. H., 1987. Ventilation rate of the deep Arctic Ocean from carbon-14 data. J. Geophys. Res., 92: 3769-3777.

Padman, L., A.J. Pleuddemann, R.D. Muench and R. Pinkel, 1992. Diurnal Tides Near the Yermak Plateau, J. Geophys. Res., 97(C8): 12,639-12,652.

Perovich, D.K., W.B. Tucker III and R.A. Krishfield, 1989. Oceanic heat flux in the Fram Strait measured by a drifting buoy, Geophys. Res. Let., 16: 995-998.

Plueddemann, A. J., 1992. Internal Wave Observations From the Arctic Environmental Drifting Buoy, J. Geophys. Res., 97(C8): 12,619-12,638.

Plueddemann, A. J., A. L. Oien, R. C. Singer and S. P. Smith, 1992. A Data Processing Module for Acoustic Doppler Current Meters, Woods Hole Oceanographic Institution, Woods Hole, MA, Technical Report WHOI-9205, $71 \mathrm{pp}$.

RD Instruments, 1991. Self-Contained Acoustic Doppler Current Profiler (SC$A D C P)$ Technical Manual, RD Instruments, San Diego, CA, 320 pp.. 


\section{APPENDIX A: CMOS TO EIA485 CONVERTER CIRCUIT}

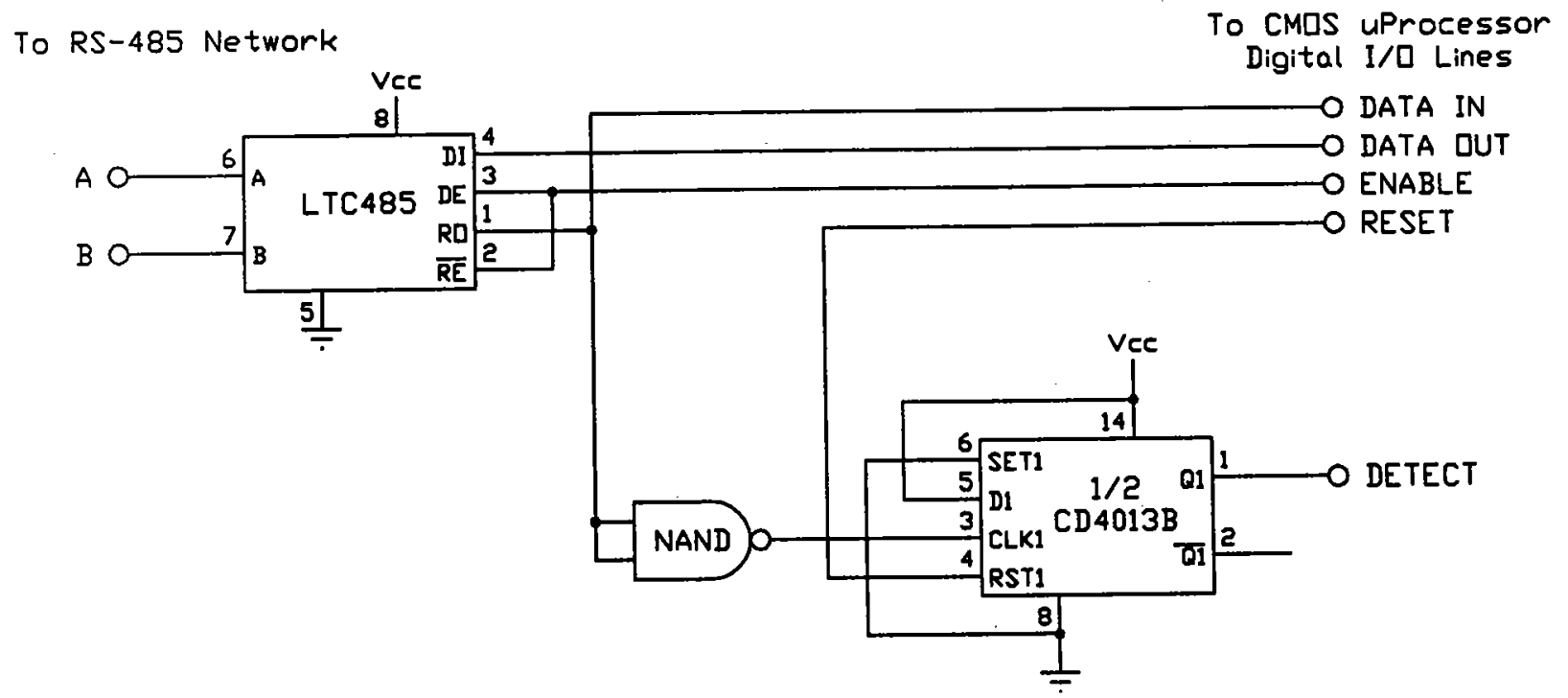

\section{Figure 13: CMOS to EIA485 converter circuit}

The IOEB uses a EIA485 standard network configuration to pass data from individual instruments to two controller units, which in turn transfer data to platform transmit terminals for real-time satellite transmission. The EIA485 standard is a multi-drop serial communication link which uses only two conductors. These conductors are normally identified as A and B. The 3-pin bulkhead connectors on MUSSIC compatible instruments have pin 2 wired to A, and pin 3 wired to B in order to be compatible with the rest of the network. Pin 1 is spare and normally is not connected.

The sample EIA485 circuit draws 300 microamps quiescent current from a 5 Volt supply. It is intended to be operated by digital inputs and outputs from a CMOS based microprocessor. The ENABLE line must be low in order for the circuit to be listening and high for it to be transmitting. No two instruments may communicate over the network at any one time, consequently the ENABLE should usually be low, except when actually transmitting data. The flip-flop is triggered by any character coming into the EIA485 port, and maintains the DETECT line high until RESET by the instrument microprocessor. This allows the device to hibernate in low current mode for most of the time; awaking only at regular intervals to determine if the network is active. Most of the instrument on the IOEB mooring wake up either every 15 or 30 seconds to check for communications. 
Each of the IOEB controllers sequentially interrogates all the instruments on the network once every 59-1/2 minutes. When a controller sends an address code for a specific instrument over the network, it expects only that instrument to reply with its last collected data set in a certain format. Suppose an instrument has been assigned the address number 99 . Consequently, when the controller prompts with \#99R (no carriage return or line feed), it will expect this instrument to respond with $99 R H H H E$, where $H$ represents an ASCII hex digit, and $E$ represents the ASCII value 03 (ETX). About 200 milliseconds needs to be allowed after receiving the address before transmitting data. Each controller will make a maximum number of three attempts at receiving data in the proper format before moving onto the next instrument. In this example, three hex digits allow the transfer of 24 bits of data.

\section{APPENDIX B: MUSSIC SCHEMATICS AND SOFTWARE}

All of the attached schematics include a EIA485 communications circuit connected to a TT3. The TT3 is modified to bring out the main UART input signal UDI (port 23 of the 6303) out to pin E of connector J3. A wire may be tack soldered to the collector of the 2N3904 transistor appearing on the RS-232 driver circuit diagram in the TT3 operating manual (p. 119). When any character is sent to the TT3 via its EIA485 port from an external device (controller), that signal is converted by the LTC485, inverted and fed to the clk of the D flip flop. The sets a digital I/O detect pin.

Every so often, the TT3 wakes up a checks to see if this pin is set. When it is, it then listens for its address in the format \#xxR. Using the ITEXT command the TT3 writes all incoming data into the datafile, looking for an R. When it encounters an $R$, it looks back three characters to see if it is addressing this particular unit with the proper id number (represented by \#xx). When it finds its address, it sets pin another digital I/O pin high which enables EIA485 transmission, and then sends its previous data word out the auxiliary UART pin D8. This signal is converted by the LTC 485 and passed out the EIA485 com port to the external controller. After sending its data, the TT3 then must switch back into listening mode by setting the enable pin low, and must reset the flipflop by setting pin D6 momentarily high. It then may go back into hibernate mode; once again, occasionally checking to set if the detect pin gets set again.

The IOEB MUSIC EIA485 system uses the primary UART input and the auxiliary UART output. The TT3 can still communicate through the primary UART modular connector, as usual. Another RS-232 device can communicate via the auxiliary UART pins D8 and D7 by adding an AND gate and a digital pin to gate the data to the RS-232 drivers.

All the components on this need to be powered by REG5V from the TT3 so that even in hibernate mode they are supplied with $3.5 \mathrm{~V}$. 


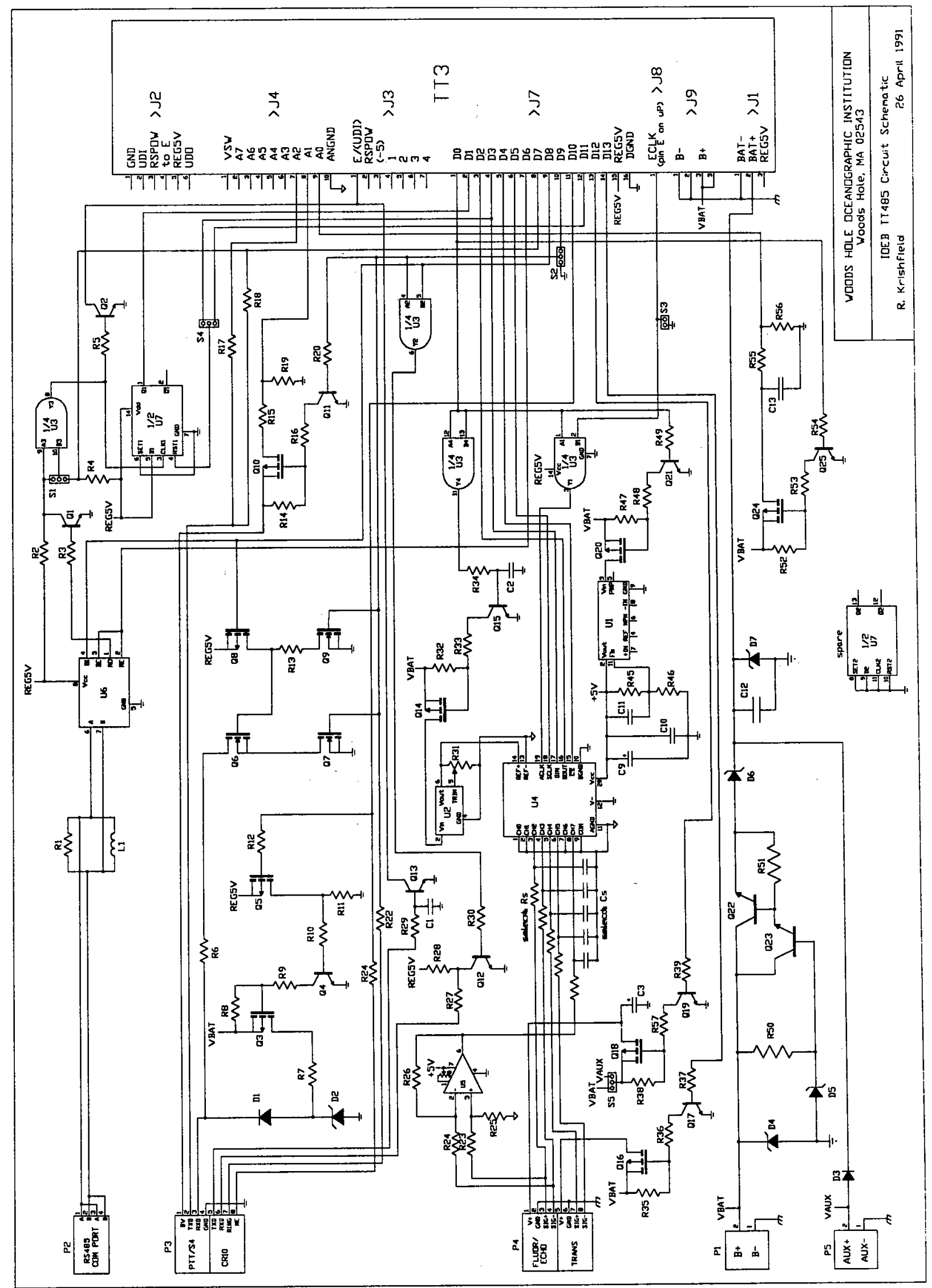

Figure 14: TT485 Schematic Diagram 
TT485 PTT Microcontroller Parts List

TT3 Data Logger and TT485 board with:

C12 1 uF (C)

C13 0.1 uF (C)

D4 $1 \mathrm{~N} 5250(20 \mathrm{~V})$

D5 $1 \mathrm{~N} 5240$

D6 1 N5819

D7 1N5240

P1 AMP 2-Pin Connector

P2 AMP 4-Pin Connector

P3 AMP 4-Pin Connector

Q1 2N3904

Q10 IRFF9131

Q11 2N2222

Q2 2N3904

Q22 2N3725

Q23 2N2484

Q24 IRFF9131

Q25 2N2222

Q6 IRFF131

Q7 IRFF131

Q8 IRFF9131

Q9 IRFF131
R2 470K

R3 100K

R5 10K

R6 1K

R13 4.7K

R14 1M

R15 100K (1\%)

R16 499K

R17 100K

R18 100K

R19 40.2K (1\%)

R20 100K

R50 1M (1\%)

R51 27K

R52 1M

R53 499K

R54 100K

R55 100K (1\%)

R56 40.2K (1\%)

S1 MID-to-BOT

S2 MID-to-RIGHT

S3 SHORT

S4 MID-to-BOT

U3 74HC08

U6 LTC485

U7 CD4013B 
PROGRAM 40CTRL.BAS

FOR IOEB TT3 CONTROLLER

D1, FLIP-FLOP Q1

D3, RESET FLIP-FLOP

D8, AUX UART OUT

D6, EIA485 XMIT ENABLE

100 LET $X=\& H 9 E:$ ASM $X, D B$ 0: ONERR 100

110 LET $B=0, F=0$

120 LET N=1: PSET 3: PCLR 0,2,3,4,5,6,8,9,10,11,12,13: GOTO 210

180 LET N=0: PSET 3: PCLR 0,2,3,4,5,6,8,9,10,11,12,13

190 LET N=N+1: IF N>3 QUIT

200 HYB 0: HYB 3450

210 PSET 0: SLEEP 0: SLEEP 10: LET B=CHAN(0): PCLR 0: IF B<150 GOTO 190

220 IF PIN(1)=1 PSET 3: PCLR 3: PRINT "ON HOLD": HYB 0: HYB 30: GOTO 220

' DETERMINE TRANSMISSION SEQUENCE

300 LET $F=F+1, N=0:$ IF F $>6$ LET $F=1$

305 LET $X=0, Y=0$ : FOR I=0 TO 31: STORE $X$,\#1,Y: NEXT I

310 IF F=1 PRINT: PRINT "Sequence 1 ... ": GOTO 1000

320 IF F=2 PRINT: PRINT "Sequence 2 ... ": GOTO 2000

330 IF F=3 PRINT: PRINT "Sequence 3 ... ": GOTO 3000

340 IF F=4 PRINT: PRINT "Sequence 4 ... ": GOTO 4000

350 IF F=5 PRINT: PRINT "Sequence 5 ... ": GOTO 5000

360 IF F=6 PRINT: PRINT "Sequence 6 ... ": GOTO 6000

370 GOTO 180

- SEND DATA TO PTT

500 PSET 8,6:SLEEP 0:SLEEP 10: USEND 9600,"\#R";:PCLR 6,8

510 PSET 8,6:SLEEP 0:SLEEP 10: USEND 9600,"\#R\#04R";:PCLR 6,8

520 LET $X=50$ : PRINT "CONVERTED PTT DATA"

530 FOR I=0 TO 31: LET $Y=31-I, Z=G E T(Y)$ : STORE $X, \# 1, Z$ : NEXT I

540 FOR I=0 TO 31: LET Z=50+I,Y=GET(Z): PRINT \#3,I,":"\#02H,Y,"=",\#3,Y;:NEXT I

550 IF PIN(7) $=0$ GOTO 550

$560 \mathrm{IF}$ PIN(7) $=1$ GOTO 560

570 PSET 8,9: SLEEP 0: SLEEP 100: USEND 300,"', $\{50,81\} ;:$ PCLR 9,8

575 PRINT: PRINT "DATA SENT TO PTT ..."

580 PSET 3: PCLR 3: GOTO 180

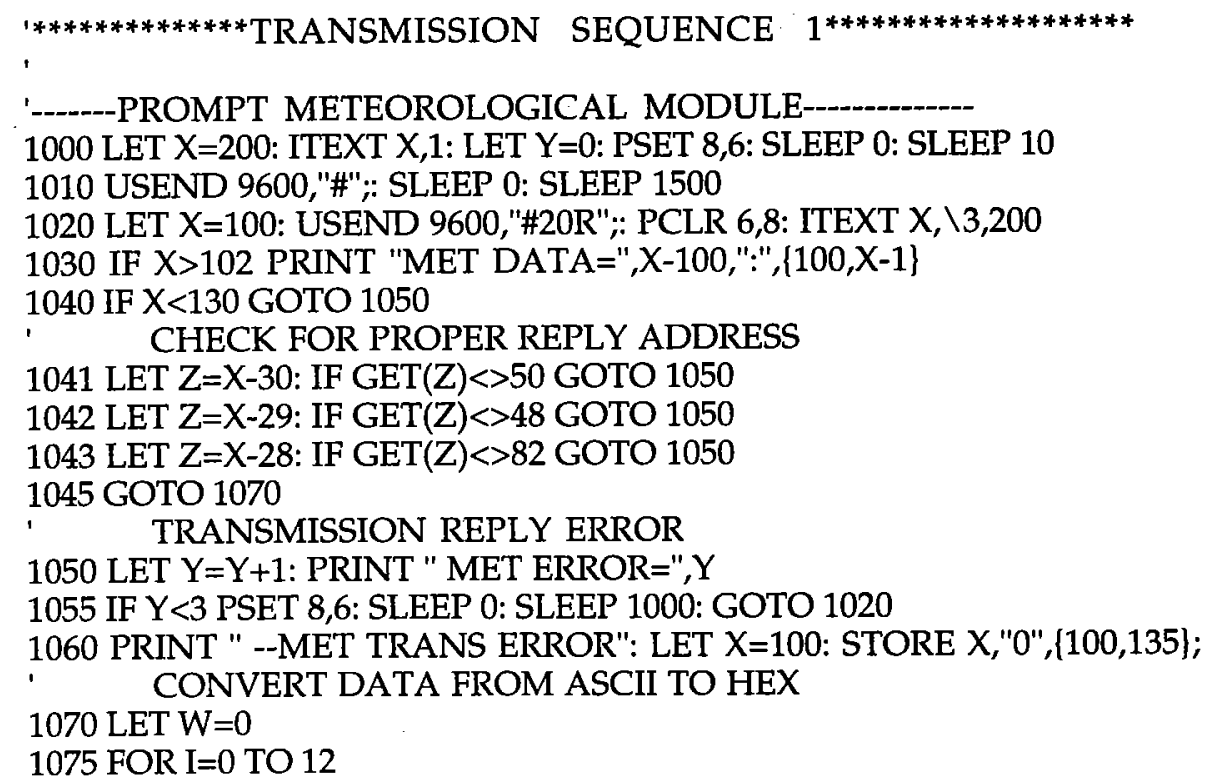


1080 LET $Y=2^{*} \mathrm{I}+\mathrm{X}-27, \mathrm{Z}=2^{*} \mathrm{I}+\mathrm{X}-26:$ LET @(2*I)=GET(Y)-48, @(2*I+1)=GET(Z)-48

1085 IF @(2*I)>9 LET @(2*I)=@(2*I)-7

1090 IF @ $(2 * \mathrm{I}+1)>9$ LET @ $\left(2^{*} \mathrm{I}+1\right)=@\left(2^{*} \mathrm{I}+1\right)-7$

1095 LET @(I)=@(2*I)*16+@(2*I+1)

1096 IF I=0 LET @(I)=@(I)+32

1097 STORE W,\#1,@(I): NEXT I

1098 LET C=@(11)

1099 FOR I=0 TO 31: LET Z=I,Y=GET(Z): PRINT \#3,I,":"\#02H,Y,"=",\#3,Y;: NEXT I

---PROMPT ICE MODULE (I)

1100 SLEEP 0: SLEEP 200: LET X=200: ITEXT X,1

1110 LET $Y=0$ : PSET 8,6: SLEEP 0: SLEEP 10

1120 LET X=100: USEND 9600,"\#21R";: PCLR 6,8: ITEXT X, \3,200

1130 IF $X>102$ PRINT "ICE DATA=",X-100,":",\{100,X-1 $\}$

1140 IF $X<146$ GOTO 1150

$1 \quad$ CHECK FOR PROPER REPLY ADDRESS

$1141 \mathrm{Z}=\mathrm{X}-46:$ IF GET(Z)<>50 GOTO 1150

$1142 \mathrm{Z}=\mathrm{X}-45$ :IF GET(Z)<>49 GOTO 1150

$1143 \mathrm{Z}=\mathrm{X}-44: \mathrm{IF}$ GET(Z)<>82 GOTO 1150

1145 GOTO 1170

. TRANSMISSION REPLY ERROR

1150 LET $Y=Y+1$ : PRINT " ICE ERROR=", $Y$

1155 IF $Y<3$ PSET 8,6: SLEEP 0: SLEEP 1000: GOTO 1120

1160 PRINT " --ICE TRANS ERROR": LET X=100: STORE X,"0",\{100,150\};

1170 LET $W=11$

1175 FOR I $=0$ TO 20

1180 LET $Y=2^{*} \mathrm{I}+\mathrm{X}-43, \mathrm{Z}=2^{*} \mathrm{I}+\mathrm{X}-42:$ LET @(2*I)=GET(Y)-48, @(2*I+1)=GET(Z)-48

1185 IF @(2*I)>9 LET @(2*I)=@(2*I)-7

1190 IF @ $\left(2^{*} \mathrm{I}+1\right)>9$ LET @ $\left(2^{*} \mathrm{I}+1\right)=@\left(2^{*} \mathrm{I}+1\right)-7$

1195 LET @(I)=@(2*I)*16+@(2*I+1)

1196 IF I=0 LET @(I)=C/64+@(I)

1197 STORE W,\#1,@(I): NEXT I

1198 FOR I=0 TO 31: LET Z=I,Y=GET(Z): PRINT \#3,I,":",\#02H,Y,"=",\#3,Y;:NEXT I

1200 GOTO 500

1************* TRANSMISSION SEQUENCE 2********************

'------PROMPT SEDIMENT TRAP

2000 LET $X=200:$ ITEXT X,1: LET Y=0: PSET 8,6: SLEEP 0: SLEEP 10

2010 USEND 9600,"\#";: SLEEP 0: SLEEP 2000

2020 LET X=100: USEND 9600,"\#12R";;: PCLR 6,8: ITEXT X, \3,200

2030 IF $X>102$ PRINT "ST DATA=",X-100,":",\{100,X-1\}

2040 IF $X<105$ GOTO 2050

CHECK FOR PROPER REPLY ADDRESS

2041 LET $Z=X-5$ : IF GET(Z)<>49 GOTO 2050

2042 LET $Z=X-4$ : IF GET(Z)<>50 GOTO 2050

2043 LET Z=X-3: IF GET(Z)<>82 GOTO 2050

2045 GOTO 2070

TRANSMISSION REPLY ERROR

2050 LET $Y=Y+1:$ PRINT " ST ERROR=", $Y$

2055 IF $Y<3$ PSET 8,6: SLEEP 0: SLEEP 1500: GOTO 2020

2060 PRINT " --ST TRANS ERROR": LET X=100: STORE X,"0",\{100,110\};

CONVERT DATA FROM ASCII TO HEX

2070 LET $W=0, Z=X-2:$ LET @ $(0)=G E T(Z)-48$

2080 IF @(0)>9 LET @(0)=@(0)-7

2090 LET @(0)=@(0)+64: STORE W,\#1,@(0)

2095 LET Z=0,Y=GET(Z): PRINT "ST+\#:",\#02H,Y,"=",\#3,Y 


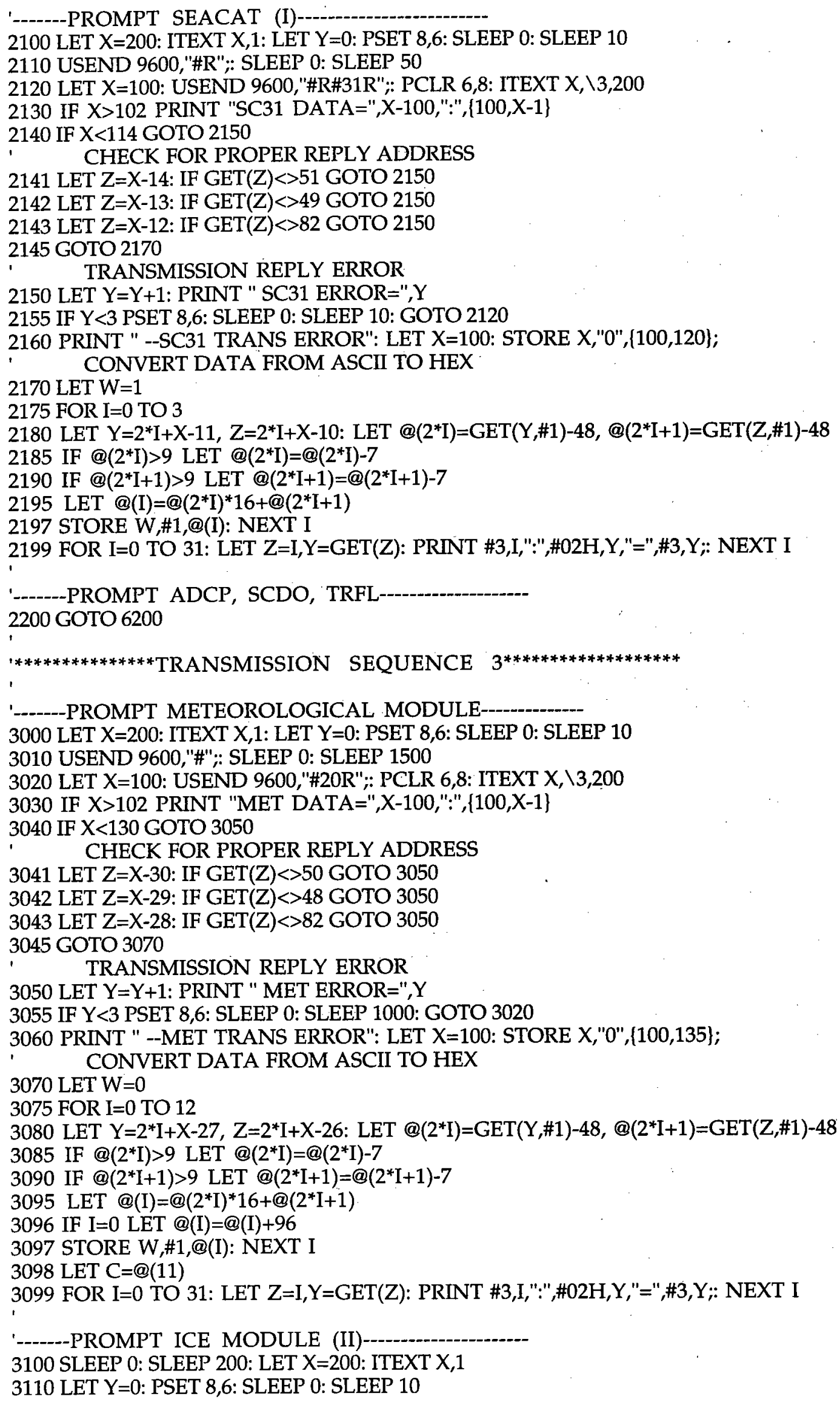


3120 LET X=100: USEND 9600,"\#22R";: PCLR 6,8: ITEXT X,\3,200

3130 IF $X>102$ PRINT "ICE DATA=",X-100,":",\{100,X-1\}

3140 IF $X<146$ GOTO 3150

CHECK FOR PROPER REPLY ADDRESS

$3141 \mathrm{Z}=\mathrm{X}-46: \mathrm{IF}$ GET(Z)<>50 GOTO 3150

$3142 \mathrm{Z}=\mathrm{X}-45$ :IF GET(Z)<>50 GOTO 3150

$3143 \mathrm{Z}=\mathrm{X}-44: \mathrm{IF}$ GET(Z)<>82 GOTO 3150

3145 GOTO 3170

' TRANSMISSION REPLY ERROR

3150 LET $Y=Y+1$ : PRINT " ICE ERROR=", $Y$

3155 IF $Y<3$ PSET 8,6: SLEEP 0: SLEEP 1000: GOTO 3120

3160 PRINT " --ICE TRANS ERROR": LET X=100: STORE X,"0",\{100,150\};

CONVERT DATA FROM ASCII TO HEX

3170 LET $W=11$

3175 FOR I $=0$ TO 20

3180 LET $Y=2^{*} \mathrm{I}+\mathrm{X}-43, \mathrm{Z}=2^{*} \mathrm{I}+\mathrm{X}-42:$ LET $@\left(2^{*} \mathrm{I}\right)=\mathrm{GET}(\mathrm{Y})-48$, @(2*I+1)=GET(Z)-48

3185 IF @(2*I)>9 LET @(2*I)=@(2*I)-7

3190 IF @(2* I+1)>9 LET @ $\left(2^{*} \mathrm{I}+1\right)=@\left(2^{*} \mathrm{I}+1\right)-7$

3195 LET @(I)=@(2*I)*16+@(2*I+1)

3196 IF I=0 LET @(I)=C/16+@(I)

3197 STORE W,\#1,@(I): NEXT I

3198 FOR I=0 TO 31: LET Z=I,Y=GET(Z): PRINT \#3,I,":",\#02H,Y,"=",\#3,Y;:NEXT I

3200 GOTO 500

'*************TRANSMISSION SEQUENCE $4^{* * * * * * * * * * * * * * * * * * *}$

'------PROMPT PUMP

4000 LET $X=200:$ ITEXT $X, 1:$ LET $Y=0$ : PSET 8,6: SLEEP 0: SLEEP 10

4010 USEND 9600,"\#";: SLEEP 0: SLEEP 2000

4020 LET X=100: USEND 9600,"\#13R";: PCLR 6,8: ITEXT X, \3,200

4030 IF $X>102$ PRINT "WTS DATA=",X-100,":",\{100,X-1 $\}$

4040 IF $X<106$ GOTO 4050

- CHECK FOR PROPER REPLY ADDRESS

4041 LET Z=X-6: IF GET(Z)<>49 GOTO 4050

4042 LET $Z=X-5:$ IF GET(Z)<>51 GOTO 4050

4043 LET $Z=X-4$ : IF GET(Z)<>82 GOTO 4050

4045 GOTO 4070

' TRANSMISSION REPLY ERROR

4050 LET $Y=Y+1:$ PRINT " WTS ERROR=", $Y$

4055 IF $Y<3$ PSET 8,6: SLEEP 0: SLEEP 1500: GOTO 4020

4060 PRINT " --WTS TRANS ERROR": LET X=100: STORE X,"0",\{100,135\};

- CONVERT DATA FROM ASCII TO HEX

4070 LET $W=0, Y=X-3, Z=X-2:$ LET @(0)=GET(Y)-48, @(1)=GET(Z)-48

4080 IF @(0)>9 LET @(0)=@(0)-7

4085 IF @(1)>9 LET @(1)=@(1)-7

4090 LET @(0)=@(0)*16+@(1)+128: STORE W,\#1,@(0)

'---.--PROMPT SEACAT (II)

4100 LET X=200: ITEXT X,1: LET Y=0: PSET 8,6: SLEEP 0: SLEEP 10

4110 USEND 9600,"\#R";: SLEEP 0: SLEEP 50

4120 LET X=100: USEND 9600,"\#R\#30R";: PCLR 6,8: ITEXT X, \3,200

4130 IF $X>102$ PRINT "SC30 DATA=",X-100,":", $\{100, X-1\}$

4140 IF $X<114$ GOTO 4150

' . CHECK FOR PROPER REPLY ADDRESS

4141 LET $Z=X-14$ : IF GET(Z)<>51 GOTO 4150

4142 LET $Z=X-13$ : IF GET(Z)<>48 GOTO 4150

4143 LET Z=X-12: IF GET(Z)<>82 GOTO 4150

4145 GOTO 4170

TRANSMISSION REPLY ERROR 
4150 LET Y=Y+1: PRINT " SC30 ERROR=", Y

4155 IF $Y<3$ PSET 8,6: SLEEP 0: SLEEP 1000: GOTO 4120

4160 PRINT " --SC30 TRANS ERROR": LET X=100: STORE X,"0",\{100,135\};

CONV
4170 LET $W=1$

4175 FOR I $=0$ TO 3

4180 LET $Y=2^{*} \mathrm{I}+\mathrm{X}-11, \mathrm{Z}=2^{*} \mathrm{I}+\mathrm{X}-10:$ LET @(2*I)=GET(Y,\#1)-48, @(2*I+1)=GET(Z,\#1)-48

4185 IF @(2*I)>9 LET @(2*I)=@(2*I)-7

4190 IF @ $\left(2^{*} \mathrm{I}+1\right)>9$ LET @ $\left(2^{*} \mathrm{I}+1\right)=@\left(2^{*} \mathrm{I}+1\right)-7$

4195 LET @(I)=@(2*I)*16+@(2*I+1)

4197 STORE W,\#1,@(I): NEXT I

4199 FOR I=0 TO 31: LET Z=I,Y=GET(Z): PRINT \#3,I,":",\#02H,Y,"=",\#3,Y;: NEXT I

'--.-PROMPT ADCP, SCDO, TRFL

4200 GOTO 6200

:*********** TRANSMISSION SEQUENCE $5 * * * * * * * * * * * * * * * * * * * * *$

PROMPT METEOROLOGICAL MODULE

5000 LET X=200: ITEXT X,1: LET Y=0: PSET 8,6: SLEEP 0: SLEEP 10

5010 USEND 9600,"\#";: SLEEP 0: SLEEP 1500

5020 LET X=100: USEND 9600,"\#20R";: PCLR 6,8: ITEXT X,\3,200

5030 IF $X>102$ PRINT "MET DATA=",X-100,":",\{100,X-1\}

5040 IF $X<130$ GOTO 5050

- CHECK FOR PROPER REPLY ADDRESS

5041 LET $Z=X-30$ : IF GET(Z)<>50 GOTO 5050

5042 LET $Z=X-29$ : IF GET(Z)<>48 GOTO 5050

5043 LET Z=X-28: IF GET(Z)<>82 GOTO 5050

5045 GOTO 5070

TRANSMISSION REPLY ERROR

5050 LET $Y=Y+1$ : PRINT " MET ERROR=", $Y$

5055 IF Y<3 PSET 8,6: SLEEP 0: SLEEP 1000: GOTO 5020

5060 PRINT " --MET TRANS ERROR": LET X=100: STORE X,"0",\{100,135\};

5070 LET $W=0$

CONVERT DATA FROM ASCII TO HEX

5075 FOR I=0 TO 12

5080 LET $Y=2^{*} \mathrm{I}+\mathrm{X}-27, \mathrm{Z}=2 * \mathrm{I}+\mathrm{X}-26:$ LET @(2*I)=GET(Y,\#1)-48, @(2*I+1)=GET(Z,\#1)-48

5085 IF @(2*I)>9 LET @ $(2 * \mathrm{I})=@(2 * \mathrm{I})-7$

5090 IF @ $\left(2^{*} \mathrm{I}+1\right)>9$ LET @ $\left(2^{*} \mathrm{I}+1\right)=@\left(2^{*} \mathrm{I}+1\right)-7$

5091 LET @(I)=@(2*I)*16+@(2*I+1)

5092 IF I=0 LET @(I)=@(I)+160

5093 STORE W,\#1,@(I): NEXT I

5094 LET C=@(12)

5095 FOR I=0 TO 31: LET Z=I,Y=GET(Z): PRINT \#3,I,":",\#02H,Y,"=",\#3,Y;: NEXT I

----GET PTT AND CONTROLLER VOLTAGES

5095 LET A=0: PSET 9: SLEEP 0: SLEEP 10

5096 FOR I=1 TO 255: LET @(I)=CHAN(1): LET A=A+@(I): NEXT I

5097 PCLR 9: $L E T A=A / 255$ : LET $A=175^{*} A / 2550-9$

5098 IF $\mathrm{A}>7$ LET $\mathrm{A}=7$

5099 IF $A<0$ LET $A=0$

5100 LET $B=0$ : PSET 0: SLEEP 0: SLEEP 10

5101 FOR I=1 TO 255: LET @(I)=CHAN(0): LET B=B+@(I): NEXT I

5102 PCLR 0: LET $B=B / 255$ : LET $B=175^{*} B / 2550-9$

5103 IF $B>7$ LET $B=7$

5104 IF $B<0$ LET $B=0$

5105 LET $D=8^{*} A+B+C, X=12:$ STORE $X, \# 1, D$

5106 PRINT"PTT=",\#3,A," :CON=", \#3,B,":PTT+CON=",\#O2H,8*A+B," =",\#3,8*A+B

PROMPT ICE MODULE (III) 
5109 SLEEP 0: SLEEP 200: LET $X=200:$ ITEXT $X, 1$

5110 LET $Y=0$ : PSET 8,6: SLEEP 0: SLEEP 10

5120 LET X=100: USEND 9600,"\#23R";: PCLR 6,8: ITEXT X, $\backslash 3,200$

5130 IF $X>102$ PRINT "ICE DATA=",X-100,":",\{100,X-1\}

5140 IF $X<146$ GOTO 5150

' CHECK FOR PROPER REPLY ADDRESS

$5141 \mathrm{Z}=\mathrm{X}-46$ :IF GET(Z)<>50 GOTO 5150

$5142 \mathrm{Z}=\mathrm{X}-45$ :IF GET(Z)<>51 GOTO 5150

$5143 \mathrm{Z}=\mathrm{X}-44$ :IF GET(Z)<>82 GOTO 5150

5145 GOTO 5170

TRANSMISSION REPLY ERROR

5150 LET $Y=Y+1: P R I N T$ " ICE ERROR=", $Y$

5155 IF $Y<3$ PSET 8,6: SLEEP 0: SLEEP 1000: GOTO 5120

5160 PRINT " --ICE TRANS ERROR": LET X=100: STORE X,"0",\{100,150\};

' CONVERT DATA FROM ASCII TO HEX

5170 LET $W=13$

5175 FOR I=2 TO 20

5180 LET $Y=2^{*} \mathrm{I}+\mathrm{X}-43, \mathrm{Z}=2^{*} \mathrm{I}+\mathrm{X}-42:$ LET $@\left(2^{*} \mathrm{I}\right)=\mathrm{GET}(\mathrm{Y})-48$, @(2*I+1)=GET(Z)-48

5185 IF @(2*I)>9 LET @(2*I)=@(2*I)-7

5190 IF @ $\left(2^{*} \mathrm{I}+1\right)>9$ LET @ $\left(2^{*} \mathrm{I}+1\right)=@\left(2^{*} \mathrm{I}+1\right)-7$

5195 LET @(I)=@(2*I)*16+@ $(2 * \mathrm{I}+1)$

5196 STORE W,\#1,@(I): NEXT I

5197 FOR I=0 TO 31: LET Z=I,Y=GET(Z): PRINT \#3,I,":",\#02H,Y,"=",\#3,Y;:NEXT I

5200 GOTO 500

'************TRANSMISSION SEQUENCE $6^{* * * * * * * * * * * * * * * * * * * *}$

'--..-PROMPT S4 MODULE

6000 LET $X=200$ : ITEXT X,1: LET $Y=0$ : PSET 8,6: SLEEP 0: SLEEP 10

6010 USEND 9600,"\#";: SLEEP 0: SLEEP 1500

6020 LET X=100: USEND 9600,"\#50R";: PCLR 6,8: ITEXT X, \3,200

6030 IF $X>102$ PRINT "S4 DATA=",X-100,":",\{100,X-1 $\}$

6040 IF $X<114$ GOTO 6050

' CHECK FOR PROPER REPLY ADDRESS

6041 LET Z=X-14: IF GET(Z)<>53 GOTO 6050

6042 LET Z=X-13: IF GET(Z)<>48 GOTO 6050

6043 LET $Z=X-12$ : IF GET(Z)<>82 GOTO 6050

6045 GOTO 6070

' TRANSMISSION REPLY ERROR

6050 LET $Y=Y+1:$ PRINT " S4 ERROR=", $Y$

6055 IF $Y<3$ PSET 8,6: SLEEP 0: SLEEP 1000: GOTO 6020

6060 PRINT " --S4 TRANS ERROR": LET X=100: STORE $X, " 0 ",\{100,120\}$;

CONVERT DATA FROM ASCII TO HEX

6070 LET $\mathrm{D}=6, \mathrm{~W}=0$

6075 FOR I=0 TO 4

6080 LET $Y=2^{*} I+X-11, Z=2^{*} I+X-10:$ LET @ $\left(2^{*} \mathrm{I}\right)=\mathrm{GET}(\mathrm{Y})-48$, @(2*I+1)=GET(Z)-48

6085 IF @(2*I)>9 LET @ $(2 * I)=@(2 * I)-7$

6090 IF @(2*I+1)>9 LET @(2*I+1)=@(2*I+1)-7

6091 LET C $=@\left(2^{*} \mathrm{I}\right)^{*} 16+@\left(2^{*} \mathrm{I}+1\right)$

6095 LET @(I) $=\mathrm{C} / 8+\mathrm{D} * 32, \mathrm{D}=\mathrm{C} \% 8$

6096 STORE W,\#1,@(I): NEXT I

6097 FOR I=0 TO 31: LET Z=I,Y=GET(Z): PRINT \#3,I,":",\#02H,Y,"=",\#3,Y;: NEXT I

'------PROMPT ADCP

6200 LET $X=200$ : ITEXT $X, 1:$ LET $Y=0$ : PSET 8,6: SLEEP 0: SLEEP 10

6220 LET $X=100$ : USEND 9600,"\#40R";: PCLR 6,8: ITEXT X, \3,200

6230 IF $X>102$ PRINT "ADCP DATA=",X-100,":", $\{100, X-1\}$

6240 IF $X<138$ GOTO 6250

CHECK FOR PROPER REPLY ADDRESS 
6241 LET Z=X-38: IF GET(Z)<>52 GOTO 6250

6242 LET $Z=X-37$ : IF GET(Z)<>48 GOTO 6250

6243 LET $Z=X-36$ : IF GET(Z)<>82 GOTO 6250

6245 GOTO 6270

' TRANSMISSION REPLY ERROR

6250 LET $Y=Y+1$ : PRINT " ADCP ERROR=", $Y$

6255 IF $Y<3$ PSET 8,6: SLEEP 0: SLEEP 10: GOTO 6220

6260 PRINT " --ADCP TRANS ERROR": LET X=100: STORE $X, " 0 ",\{100,145\}$;

- CONVERT DATA FROM ASCII TO HEX

6270 LET $W=5$

6275 FOR I $=0$ TO 16

6280 LET $Y=2^{*} \mathrm{I}+\mathrm{X}-35, \mathrm{Z}=2^{*} \mathrm{I}+\mathrm{X}-34: \mathrm{LET} @\left(2^{*} \mathrm{I}\right)=\mathrm{GET}(\mathrm{Y}, \# 1)-48$, @( $\left(2^{*} \mathrm{I}+1\right)=\mathrm{GET}(\mathrm{Z}, \# 1)-48$

6285 IF @(2*I)>9 LET @(2*I)=@(2*I)-7

6290 IF @(2*I+1)>9 LET @ $\left(2^{*} \mathrm{I}+1\right)=@(2 * \mathrm{I}+1)-7$

6295 LET @(I)=@(2*I)*16+@(2*I+1)

6296 IF I=0 LET @(0)=32*D+@(I)

6297 STORE W,\#1,@(I): NEXT I

6299 FOR I=0 TO 31: LET Z=I,Y=GET(Z): PRINT \#3,I,":",\#02H,Y,"=",\#3,Y;: NEXT I

6300 LET X=200: ITEXT X,1: LET Y=0: PSET 8,6: SLEEP 0: SLEEP 10

6310 USEND 9600,"\#R";: SLEEP 0: SLEEP 50

6320 LET X=100: USEND 9600,"\#R\#32R";: PCLR 6,8: ITEXT X,\3,200

6330 IF $X>102$ PRINT "SCDO DATA=",X-100,":",\{100,X-1 $\}$

6340 IF $X<124$ GOTO 6350

- $\quad$ CHECK FOR PROPER REPLY ADDRESS

6341 LET Z=X-24: IF GET(Z) <>51 GOTO 6350

6342 LET $Z=X-23$ : IF GET(Z)<>50 GOTO 6350

6343 LET $Z=X-22:$ IF GET(Z)<>82 GOTO 6350

6345 GOTO 6370

' TRANSMISSION REPLY ERROR

6350 LET $Y=Y+1:$ PRINT " SCDO ERROR=",Y

6355 IF $Y<3$ PSET 8,6: SLEEP 0: SLEEP 10: GOTO 6320

6360 PRINT " --SCDO TRANS ERROR": LET X=100: STORE $X, " 0 ",\{100,130\}$;

$1 \quad$ CONVERT DATA FROM ASCII TO HEX

6370 LET $Y=X-6, Z=X-10$ : STORE Z,\#1,GET(Y)

6371 LET $Y=X-5, Z=X-9$ : STORE $Z$,\#1,GET(Y)

6372 LET $Y=X-4, Z=X-8$ : STORE $Z$, \#1,GET(Y)

6375 LET $W=22$

6376 FOR I $=0$ TO 6

6380 LET $Y=2^{*} \mathrm{I}+\mathrm{X}-21, \mathrm{Z}=2^{*} \mathrm{I}+\mathrm{X}-20:$ LET @(2*I)=GET(Y,\#1)-48, @(2*I+1)=GET(Z,\#1)-48

6385 IF @(2*I)>9 LET @ $\left(2^{*} \mathrm{I}\right)=@\left(2^{*} \mathrm{I}\right)-7$

6390 IF @ $\left(2^{*} \mathrm{I}+1\right)>9$ LET @ $\left(2^{*} \mathrm{I}+1\right)=@\left(2^{*} \mathrm{I}+1\right)-7$

6395 LET @(I)=@(2*I $)^{*} 16+@(2 * \mathrm{I}+1)$

6397 STORE W,\#1,@(I): NEXT I

6399 FOR I=0 TO 31: LET Z=I,Y=GET(Z): PRINT \#3,I,":",\#02H,Y,"=",\#3,Y;: NEXT I

'-----PROMPT TRANS/FLUOR LOGGER-

6400 LET X=200: ITEXT X,1: LET Y=0: PSET 8,6: SLEEP 0: SLEEP 10

6410 USEND 9600,"\#";: SLEEP 0: SLEEP 1500

6420 LET X=100: USEND 9600,"\#51R";: PCLR 6,8: ITEXT X, \3,200

6430 IF $X>102$ PRINT "TRFL DATA=",X-100,":", $\{100, X-1\}$

6440 IF $X<110$ GOTO 6450

' CHECK FOR PROPER REPLY ADDRESS

6441 LET Z=X-10: IF GET(Z)<>53 GOTO 6450

6442 LET $Z=X-9$ : IF GET(Z)<>49 GOTO 6450

6443 LET Z=X-8: IF GET(Z)<>82 GOTO 6450

6445 GOTO 6470

TRANSMISSION REPLY ERROR

6450 LET $Y=Y+1:$ PRINT " TRFL ERROR=",Y 
6455 IF $Y<3$ PSET 8,6: SLEEP 0: SLEEP 1000: GOTO 6420

6460 PRINT " --TRFL TRANS ERROR": LET $X=100$ : STORE $X, " 0 ",\{100,115\}$;

CONVERT DATA FROM ASCII TO HEX

6470 LET $W=29$

6475 FOR $\mathrm{I}=0$ TO 2

6480 LET Y=2*I+X-7, Z=2*I+X-6: LET @(2*I)=GET(Y)-48, @(2*I+1)=GET(Z)-48

6485 IF @(2*I)>9 LET @(2*I)=@(2*I)-7

6490 IF @ $\left(2^{*} \mathrm{I}+1\right)>9$ LET @ $\left(2^{*} \mathrm{I}+1\right)=@\left(2^{*} \mathrm{I}+1\right)-7$

6495 LET @(I)=@(2*I $)^{*} 16+@\left(2^{*} \mathrm{I}+1\right)$

6496 STORE W,\#1,@(I): NEXT I

6497 FOR I=0 TO 31: LET Z=I,Y=GET(Z): PRINT \#3,I,":",\#02H,Y,"=",\#3,Y;: NEXT I

6500 GOTO 500 
TT485 Ice Module Parts List:

TT3 Data Logger and TT485 board with:

C1 $0.001 \mathrm{uF}(\mathrm{C})$

C2 $1 \mathrm{uF}(\mathrm{C})$

C3 $100 \mathrm{uF}(\mathrm{T})$

C4 select Cs

C5 JUMP

C6 JUMP

C7 JUMP

C8 JUMP

C9 $22 \mathrm{uF}(\mathrm{T})$

C10 0.001 uF (C)

C11 $0.001 \mathrm{uF}(\mathrm{C})$

$\mathrm{C} 121 \mathrm{uF}(\mathrm{C})$

C13 0.1 uF (C)

D4 1N5250 (20V)

D5 1 N5240

D6 1 N5819

D7 $1 \mathrm{~N} 5240$

P1 AMP 2-Pin Connector

P2 AMP 2-Pin Connector

P3 AMP 8-Pin Connector

P4 AMP 4-Pin Connector

P5 AMP 2-Pin Connector

Q1 2N3904

Q2 2N3904

Q12 2N3904

Q13 2N3904

Q14 IRFF9131

Q15 2N2222

Q18 IRFF9131

Q19 2N2222

Q13 2N3904

Q14 IRFF9131

Q15 2N2222

Q20 IRFF9131

Q21 2N2222

Q22 2N3725

Q23 2N2484

Q24 IRFF9131

Q25 2N2222

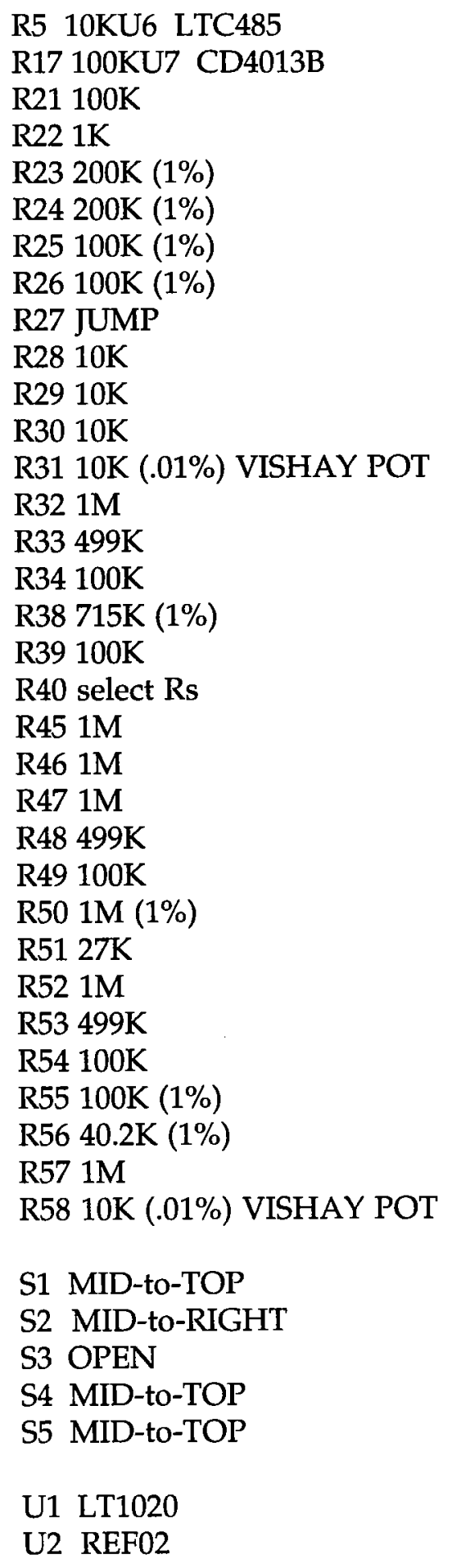

U1 LT1020

U2 REF02

R2 470KU3 74HC08

R3 100KU4 LTC1290

R4 100KU5 LT1077 


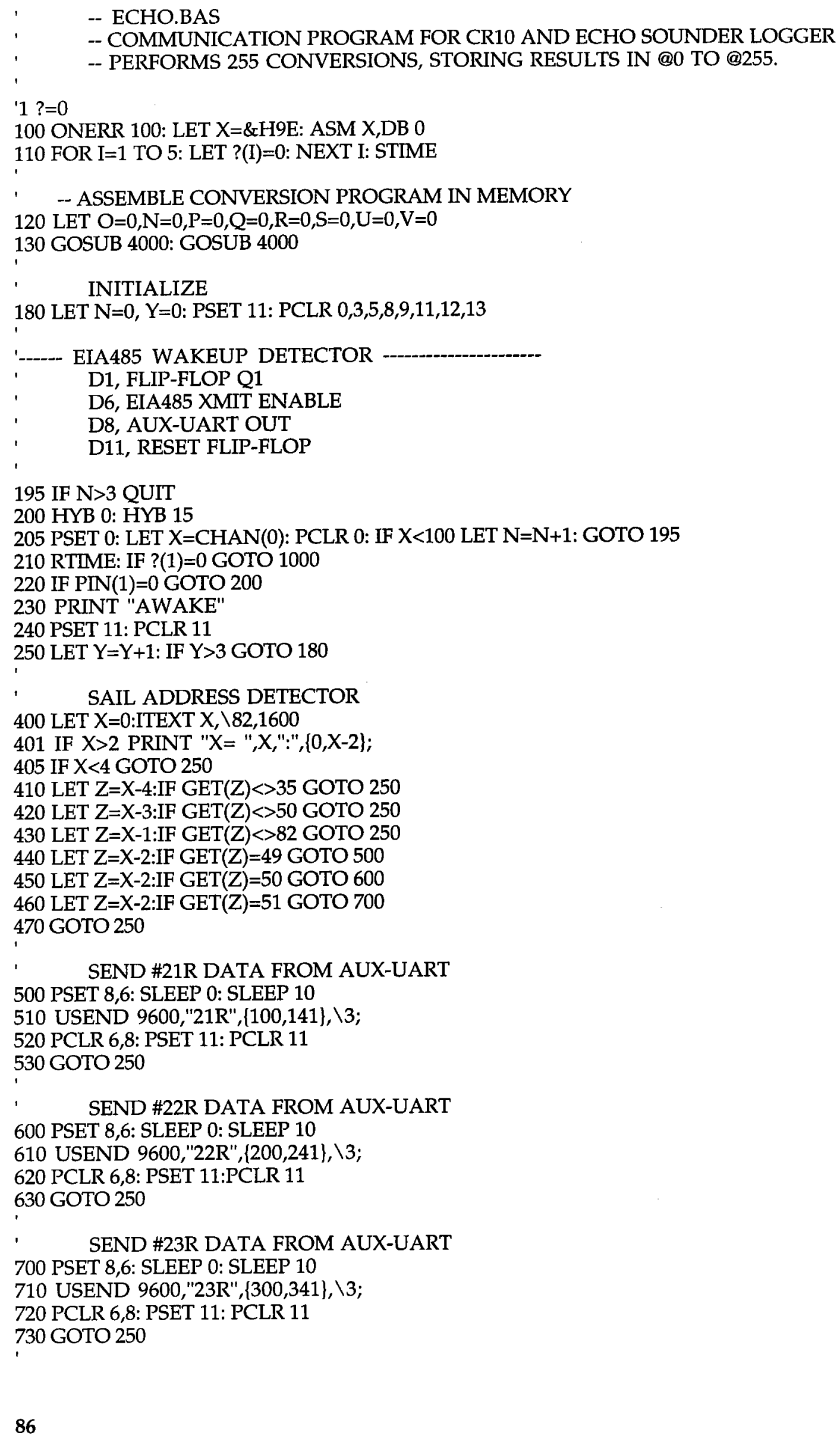

- SEND \#23R DATA FROM AUX-UART

700 PSET 8,6: SLEEP 0: SLEEP 10

710 USEND 9600,"23R",\{300,341\},\3;

720 PCLR 6,8: PSET 11: PCLR 11

730 GOTO 250 


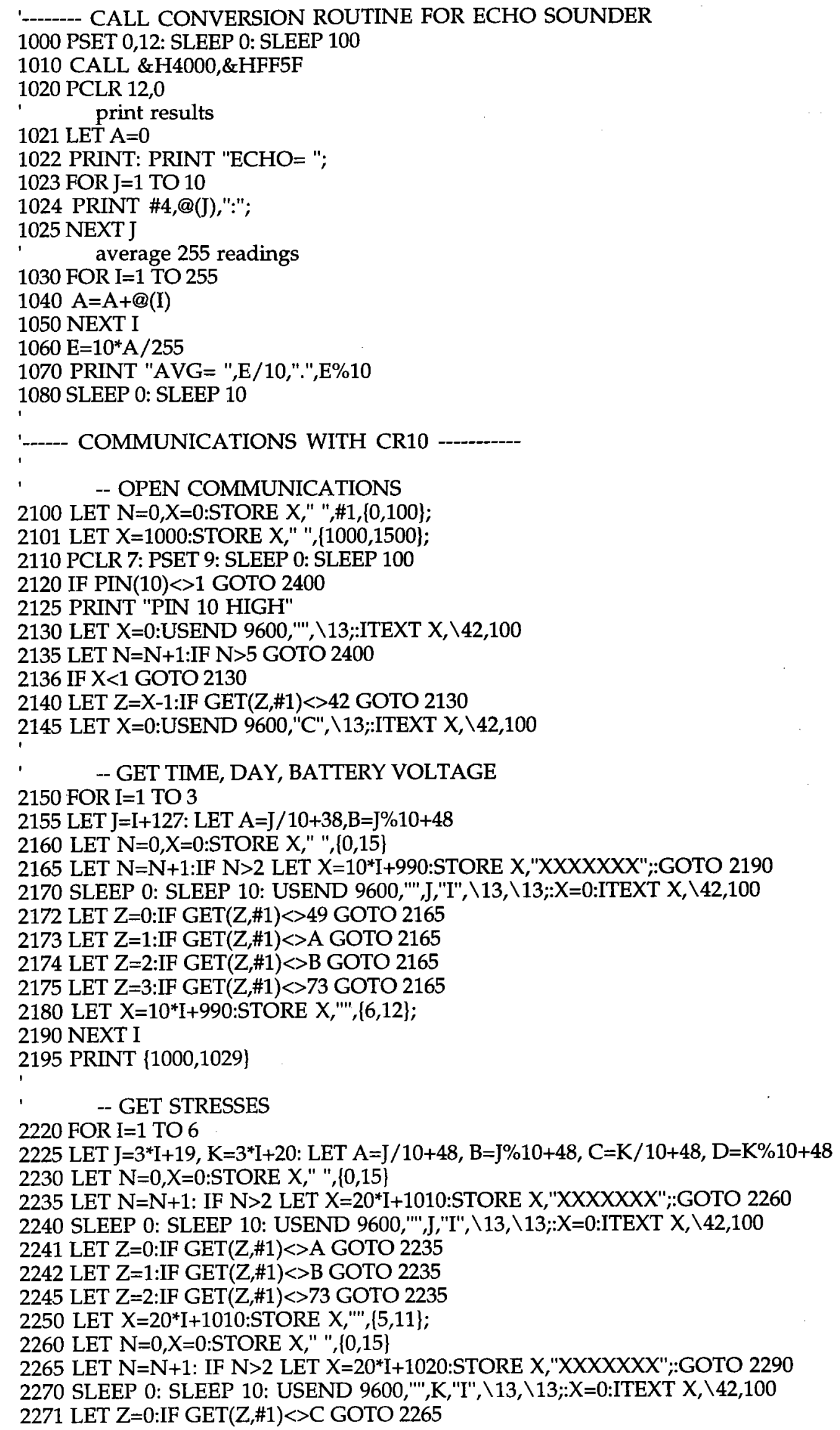


2272 LET $Z=1:$ IF GET(Z,\#1)<>D GOTO 2265

2275 LET $Z=2:$ IF GET $(Z$,\#1)<>73 GOTO 2265

2280 LET $X=20 * I+1020: S T O R E X, '{ }^{\prime \prime},\{5,11\}$;

2290 NEXT I

2295 PRINT $\{1030,1149\}$

2310 FOR I $=1$ TO 33

2315 LET J $=40+\mathrm{I}:$ LET $\mathrm{A}=\mathrm{J} / 10+48, \mathrm{~B}=\mathrm{J} \% 10+48$

2316 LET $N=0, X=0: S T O R E ~ X, " ~ ",\{0,15\}$

2320 LET $\mathrm{N}=\mathrm{N}+1$ : IF $\mathrm{N}>2$ LET $X=10^{*} \mathrm{I}+1140$ : STORE $X, " X X X X X X X " ; ;$ GOTO 2340

2325 SLEEP 0: SLEEP 10: USEND 9600,"',J,"I", \13,\13;:X=0:ITEXT X, $\backslash 42,100$

2330 LET $Z=0:$ IF GET $(Z, \# 1)<>$ A GOTO 2320

2331 LET $Z=1:$ IF GET(Z,\#1)<>B GOTO 2320

2332 LET $Z=2:$ IF GET $(Z, \# 1)<>73$ GOTO 2320

2335 LET $X=10^{*} I+1140:$ STORE $X, " ',\{5,11\}$;

2340 NEXT I

2341 PRINT $\{1150,1479\}$

2400 USEND 9600,"E", \13;:LET X=0:ITEXT X,100

2410 PCLR 9: LET $X=P I N(7)$ : PSET 11: PCLR 11

' -- CONVERT DATA

2500 FOR I $=1$ TO 48

2505 LET $P=0, V=0, X=10 * I+990$

2510 LET $S=G E T(X, \# 1)$

-positive

2515 IF S=43 LET S=1: GOTO 2530

-negative

2520 IF S=45 LET S=0: GOTO 2530

-bad data

2523 LET $Y=I^{*} 5+695:$ LET @ $(100+I)=9999:$ NEXT I

2525 GOTO 2680

2530 FOR J $=1$ TO 5

2540 LET $Z=X+J-1$, $(J)=G E T(Z, \# 1)$

2550 IF @(J)=46 LET $P=6-\mathrm{J}$

2560 IF $P>0$ LET $Z=X+J$, @ $(J)=G E T(Z, \# 1)$

2565 LET @(J)=@(J)-48

2570 NEXT J

- data $=\mathrm{V} / 10^{\wedge} \mathrm{P}$

2580 LET V=@(1)*10000+@(2)*1000+@(3)*100+@(4)*10+@(5)

2590 IF $S=0$ LET $V=0-\mathrm{V}$

2600 IF $P=5$ LET $P=100000$

2601 IF $P=4$ LET $P=10000$

2602 IF $P=3$ LET $P=1000$

2603 IF $P=2$ LET $P=100$

2604 IF $P=1$ LET $P=10$

2605 IF $P=0$ LET $P=1$

2606 LET $X=I^{*} 5+695$

' $\quad$--STORE IN @(101 - 148)

' day code (0-7)

2610 IF I=1 LET V=V/P: LET V=V/24: LET @(100+I)=V\%8: NEXT I tenths of hours

2620 IF I=2 LET V=V/P: LET @(100+I)=V/6: NEXT I

battery voltage -9

2630 IF I=3 LET V=V/P: LET @(100+I)=V-9: NEXT I

(stresses +270$) / 6$ 
2640 IF I $>3$ \& $\mathrm{I}<16$ LET V=V/P: LET V=V+270: LET @(100+I)=V/6: NEXT I thermistors

2650 LET $V=100^{*} \mathrm{~V} / \mathrm{P}$

2660 IF $V>=-500$ LET V=V+500: LET @ $(100+\mathrm{I})=\mathrm{V} / 2+512$ : NEXT I

2670 IF V<-500 LET V=V+5610: LET @ $(100+I)=V / 10:$ NEXT I

print results

2680 FOR I=101 TO 148

2681 PRINT \#10,@(I);

2682 NEXT I

-- CHOOSE GOOD STRESS VALUES

2685 IF @(104)<0 | @(104)>127 LET @(104)=@(106),@(105)=@(107)

2686 IF @(105)<0 | @(105)>127 LET @(104)=@(106),@(105)=@(107)

2687 IF @(108)<0 | @(108)>127 LET @(108)=@(110),@(109)=@(111)

2688 IF @(109)<0 | @(109)>127 LET @(108)=@(110),@(109)=@(111)

-- STORE DATA IN HEX FOR TRANSMISSION

2690 LET $X=100$ : STORE $X, " 0 ",\{100,350\}$;

(IBV+IDA)

2695 IF @(101)>7 LET @(101)=7

2700 IF @(101)<0 LET @(101)=0

2705 IF @(103)>7 LET @(103)=7

$2710 \mathrm{IF} @(103)<0$ LET @(103)=0

2715 LET B=@(103),H=@(103)*8+@(101):LET X=100:STORE X,'"',\#02H,H;

(ITIM)

2720 IF @(102)<0 LET @(102)=0

2725 IF @(102)>255 LET @(102)=255

2730 LET X=102:STORE X,'"',\#02H,@(102);

(IECH)

2734 IF $\mathrm{E}>40950$ । $\mathrm{E}<0$ LET $\mathrm{E}=40950$

2735 LET X=200: STORE X,"',"\#04H,E/10;

(IS11-IS32)

2740 FOR I=104 TO 113

2741 IF @(I)<0 LET @(I)=0

2742 IF @(I) $>127$ LET @(I)=127

2743 NEXT I

2745 LET F=@(104)*2,G=@(105)/64: LET H=F+G

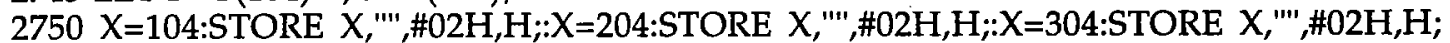
2755 LET $F=@(105) \% 64, G=@(108) / 32:$ LET F=F*4: LET H=F+G

2760 X=106:STORE X,"',"\#02H,H;:X=206:STORE X,"'",\#02H,H;:X=306:STORE X,'"',\#02H,H;

2765 LET $F=@(108) \% 32, G=@(109) / 16:$ LET F=F*8: LET H=F+G

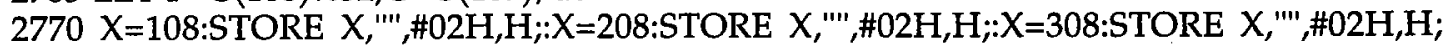
2780 LET $F=@(109) \% 16, G=@(112) / 8:$ LET F=F*16: LET H=F+G

2790 X=110:STORE X,'"',\#02H,H;:X=210:STORE X,"',"\#02H,H;:X=310:STORE X,"', \#02H,H; 2800 LET F=@(112)\%8,G=@(113)/4: LET F=F*32: LET H=F+G

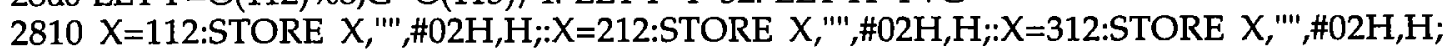
2820 LET F=@(113)\%4: LET L=F*64

(IT1-IT33)

2830 FOR I=116 TO 148

2831 IF @(I)<0 LET @(I)=0

2832 IF @(I)>1023 LET @(I)=1023

2833 NEXT I

2840 FOR I $=1$ TO 3

2850 LET $\mathrm{J}=\mathrm{I} * 100, \mathrm{~K}=\mathrm{I}^{*} 11$

2860 LET G=@(105+K)/16: LET H=L+G, X=J+14: STORE $X, " ', \# 02 H, H$;

2870 LET $\mathrm{F}=@(105+\mathrm{K}) \% 16, \mathrm{G}=@(106+\mathrm{K}) / 64: \mathrm{F}=\mathrm{F}^{*} 16: \mathrm{H}=\mathrm{F}+\mathrm{G}, \mathrm{X}=\mathrm{J}+16: \mathrm{STORE} \mathrm{X},{ }^{\prime \prime \prime}, \# 02 \mathrm{H}, \mathrm{H}$; 2880 LET $\mathrm{F}=@(106+\mathrm{K}) \% 64, \mathrm{G}=@(107+\mathrm{K}) / 256: \mathrm{F}=\mathrm{F}^{*} 4: \mathrm{H}=\mathrm{F}+\mathrm{G}, \mathrm{X}=\mathrm{J}+18:$ STORE $\mathrm{X},{ }^{\prime \prime} ", \# 02 \mathrm{H}, \mathrm{H}$; 2890 LET $\mathrm{H}=@(107+\mathrm{K}) \% 256, \mathrm{X}=\mathrm{J}+20$ : STORE X,"'",\#02H,H; ,

2900 LET $\mathrm{H}=@(108+\mathrm{K}) / 4, \mathrm{X}=\mathrm{J}+22:$ STORE X,"',"\#02H,H;

2910 LET F=@(108+K)\%4,G=@(109+K)/16: F=F*64: H=F+G, X=J+24: STORE X,'",\#02H,H; 
2920 LET $\mathrm{F}=@(109+\mathrm{K}) \% 16, \mathrm{G}=@(110+\mathrm{K}) / 64: \mathrm{F}=\mathrm{F}^{*} 16: \mathrm{H}=\mathrm{F}+\mathrm{G}, \mathrm{X}=\mathrm{J}+26:$ STORE $\mathrm{X},{ }^{\prime \prime \prime}, \# 02 \mathrm{H}, \mathrm{H}$; 2930 LET $\mathrm{F}=@(110+\mathrm{K}) \% 64, \mathrm{G}=@(111+\mathrm{K}) / 256: \mathrm{F}=\mathrm{F}^{*} 4: \mathrm{H}=\mathrm{F}+\mathrm{G}, \mathrm{X}=\mathrm{J}+28:$ STORE $\mathrm{X},{ }^{\prime \prime \prime}, \# 02 \mathrm{H}, \mathrm{H}$; 2940 LET H=@(111+K)\%256,X=J+30: STORE X,'"',\#02H,H;

2950 LET $\mathrm{H}=@(112+\mathrm{K}) / 4, \mathrm{X}=\mathrm{J}+32:$ STORE X,'"',\#02H,H;

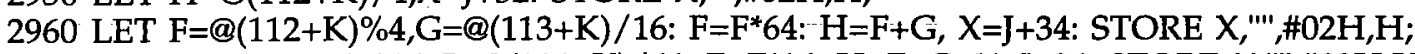

2970 LET $F=@(113+K) \% 16, G=@(114+K) / 64: F=F^{*} 16: H=F+G, X=J+36:$ STORE $X, '{ }^{\prime} ', \# 02 H, H$; 2980 LET $\mathrm{F}=@(114+\mathrm{K}) \% 64, \mathrm{G}=@(115+\mathrm{K}) / 256: \mathrm{F}=\mathrm{F}^{*} 4: \mathrm{H}=\mathrm{F}+\mathrm{G}, \mathrm{X}=\mathrm{J}+38: \mathrm{STORE} \mathrm{X},{ }^{\prime}, ', \# 02 \mathrm{H}, \mathrm{H}$; 2990 LET H=@(115+K)\%256,X=J+40: STORE X,'"',\#02H,H;

3000 NEXT I

3001 LET X=0:STORE $X, " 0 ", \# 1$;

3010 PRINT " $\{100,141\}=",\{100,141\}$

3011 PRINT " $\{200,241\}=",\{200,241\}$

3012 PRINT " $\{300,341\}=",\{300,341\}$

3020 GOTO 220

A/D CONVERSION ROUTINE

' - @0 CONTAINS GARBAGE FROM FIRST "CONVERSION"

' MEMORY MAP:

- $\quad$ RESULTS $=@ 0$ - @N = \&H7218 -

- \&H130 PORT 5 OLD DDR

' \&H131 CONFIGURATION BYTE

' \&H133 TOTAL COUNT

' \&H134 BIT COUNT

, \&H135 4 BIT FLAG

$4000 \mathrm{X}=\& \mathrm{H} 4000: \mathrm{REM}$ load coversion routine at \&H4000

4010 ASM X,STAB \&H131 : REM save config byte in B to memory

4020 ASM X,INCA : REM add 1 to count (1st conversion no good)

4030 ASM X,STAA \&H133 : REM move total count from A to memory

4040 ASM X,CLRA : REM clear A reg -- will hold read value

4050 ASM X,STAA \&H132 : REM store 0 for 1st byte of index

4060 ASM X,STAA \&H135 : REM init 4 bit flag to false

4070 ASM X,LDX \#\&H721B : REM current count index into '@' (4th byte)

4080 ASM X,LDAA \&H8B : REM read current port 5 DDR

4090 ASM X,STAA \&H130 : REM store old DDR

4100 ASM X,OIM \&H1C,\&H20 : REM make port $5.2,3, .4$ output

4110 ASM X,AIM \&HDF,\&H20 : REM make port 5.5 input

4160 ASM X,AIM \&HFB,\&H15 : REM sclk low

4170 ASM $X, O I M ~ \& H 08, \& H 15$ : REM cs high

-- INITIALIZE BIT COUNT TO 8

4180 S=X:ASM X,SLP : REM sleep until $10 \mathrm{~ms}$ interupt

4190 ASM X,AIM \&HF7,\&H15 : REM cs low (they do in example)

4200 ASM $X$, LDAA \#8

4210 ASM X,STAA \&H134 : REM store bit count

4220 ASM X,LDAB \&H131 : REM read config byte from memory

4230 ASM X,CLRA : REM store zero result before stored

4240 ASM $X, S T A A$, $X$

'

-- DO LS 8 BITS OF CONVERSION

$4250 \mathrm{R}=\mathrm{X}$ :ASM X,LDAA 0,X : REM reload current read value

4260 ASM X,LSRA : REM put prior read bits into position

4270 ASM X,TIM \&H20,\&H15: REM see if incoming bit

4280 ASM X,BEQ N : REM don't add if not there

4290 ASM X,ORAA \#128: REM add bit to A

$4300 \mathrm{~N}=\mathrm{X}$ :ASM X,STAA 0,X : REM store result, so can use A register

4310 ASM X,BITB \#1 : REM test config in B, see if 1 st bit is set

4320 ASM X,BEQ $P$ : REM send out a null if nothing there 
4330 ASM $X$,OIM \&H10,\&H15 : REM send out a bit 4340 ASM X,BRA Q : REM goto clock section $4350 \mathrm{P}=\mathrm{X}$ :ASM $X$,AIM \&HEF, \&H15 : REM send out a null $4360 \mathrm{Q}=\mathrm{X}$ :ASM X,ASRB : REM clock section-- shift config bit into position 4370 ASM X,OIM \&H04,\&H15 : REM sclk high (config bit out) 4380 ASM X,AIM \&HFB,\&H15 : REM sclk low -- ready to read bit 4390 ASM X,LDAA \&H134 : REM reload A with current bit count 4400 ASM X,DECA : REM decrement count 4410 ASM X,STAA \&H134 : REM store bit count 4420 ASM X,BNE R : REM branch if not done

-- ALL DONE WITH LS 8 BITS READ/WRITE:

- NOW MUST HANDLE MS 4 BITS

4430 ASM X,LDAA \&H135

4440 ASM X,BNE V : REM branch when 4 bit flag set 4450 ASM X,LDAA \#4

4460 ASM X,STAA \&H135 : REM set 4 bit flag to true 4470 ASM X,STAA \&H134 : REM load bit counter with 4 4480 ASM X,DEX : REM make index point to Byte 3 4490 ASM X,CLRA : REM store zero result before stored 4500 ASM X,STAA $0, X$

4510 ASM X,BRA R : REM do it again $4520 \mathrm{~V}=\mathrm{X}: \mathrm{ASM} X, \mathrm{LDAA} 0, \mathrm{X}: \mathrm{REM}$ reload current read value 4530 ASM X,LSRA : REM shift bits into position 4540 ASM X,LSRA : REM shift bits into position 4550 ASM X,LSRA : REM shift bits into position 4560 ASM X,LSRA : REM shift bits into position 4570 ASM X,STAA 0,X : REM store result

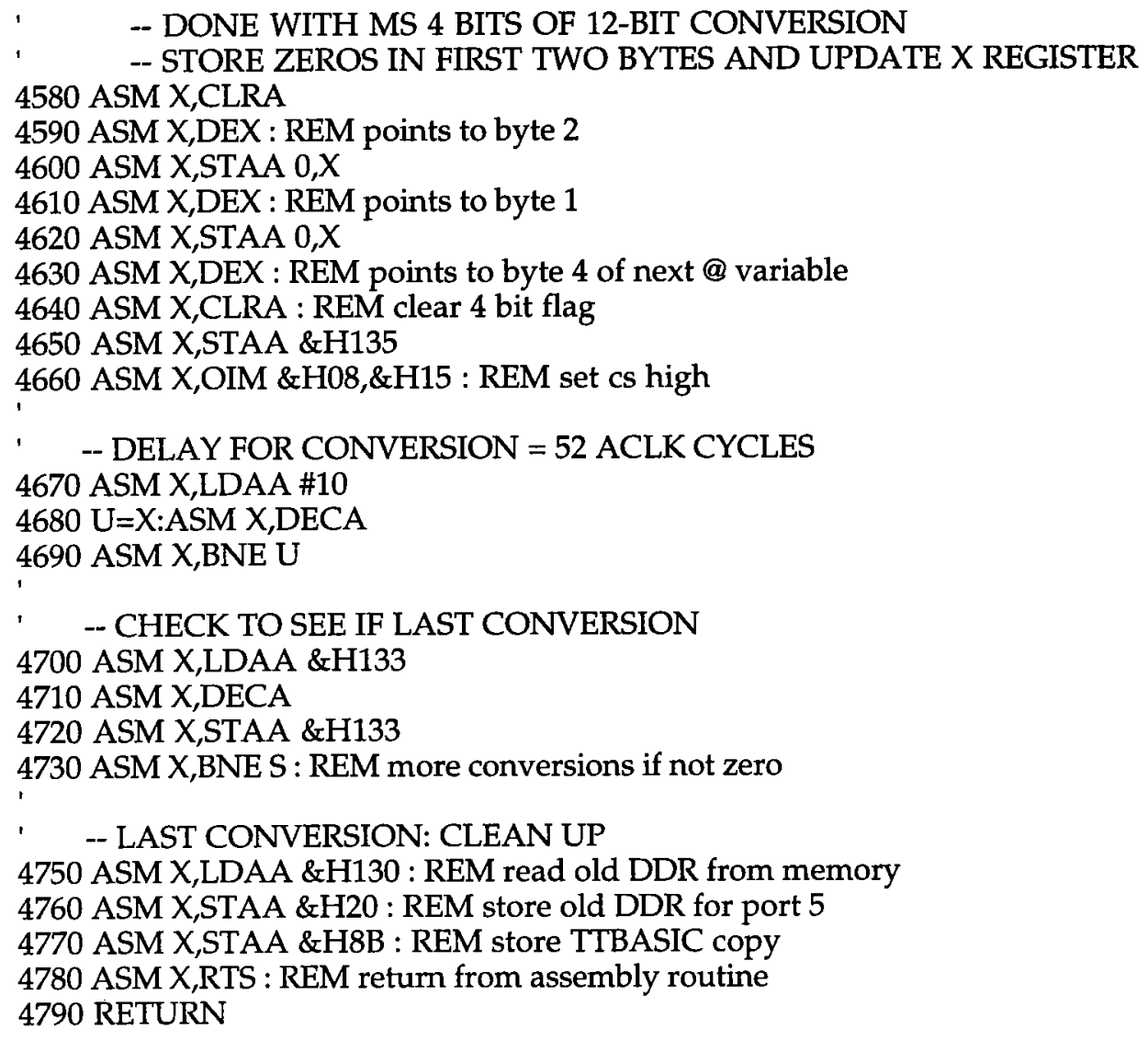


TT485 TRFL Module Parts List:

TT3 Data Logger and TT485 board with:
C2 $1 \mathrm{uF}(\mathrm{C})$
C3 $100 \mathrm{uF}(\mathrm{T})$
C4 JUMP
C5 select $\mathrm{Cs}$
C6 select $\mathrm{Cs}$
$\mathrm{C} 7$ select $\mathrm{Cs}$
$\mathrm{C} 8$ select $\mathrm{Cs}$
C9 $22 \mathrm{uF}(\mathrm{T})$
$\mathrm{C} 100.001 \mathrm{uF}(\mathrm{C})$
$\mathrm{C} 110.001 \mathrm{uF}(\mathrm{C})$
$\mathrm{C} 121 \mathrm{uF}(\mathrm{C})$
$\mathrm{C} 130.1 \mathrm{uF}(\mathrm{C})$
D3 $1 \mathrm{~N} 4002$
D4 $1 \mathrm{~N} 5250(20 \mathrm{~V})$
D5 1 N5240
D6 1 N5819
D7 $1 \mathrm{~N} 5240$

P1 AMP 2-Pin Connector

P2 AMP 2-Pin Connector

P4 AMP 8-Pin Connector

P5 AMP 2-Pin Connector

Q1 2N3904

Q2 2N3904

Q14 IRFF9131

Q15 2N2222

Q16 IRFF9131

Q17 2N2222

Q18 IRFF9131

Q19 2N2222

Q20 IRFF9131

Q21 2N2222

Q22 2N3725

Q23 2N2484

Q24 IRFF9131

Q25 2N2222
R32 1M

R33 499K

R34 100K

R35 1M

R36 499K

R37 100K

R38 1M

R39 100K

R41 select Rs

R42 select Rs

R43 select Rs

R44 select Rs

R45 1M

R46 1M

R47 1M

R48 499K

R49 100K

R50 1M (1\%)

R51 27K

R52 1M

R53 499K

R54 100K

R55 100K (1\%)

R56 40.2K (1\%)

R57 499K

S1 MID-to-BOT

S2 MID-to-LEFT

S3 OPEN

S4 MID-to-TOP

S5 MID-to-BOT

U1 LT1020

U2 REF02

U3 $74 \mathrm{HC} 08$

U4 LTC1290

U6 LTC485

U7 CD4013B

R2 $470 \mathrm{~K}$

R3 100K

R5 $10 \mathrm{~K}$

R31 10K (.01\%) VISHAY POT 


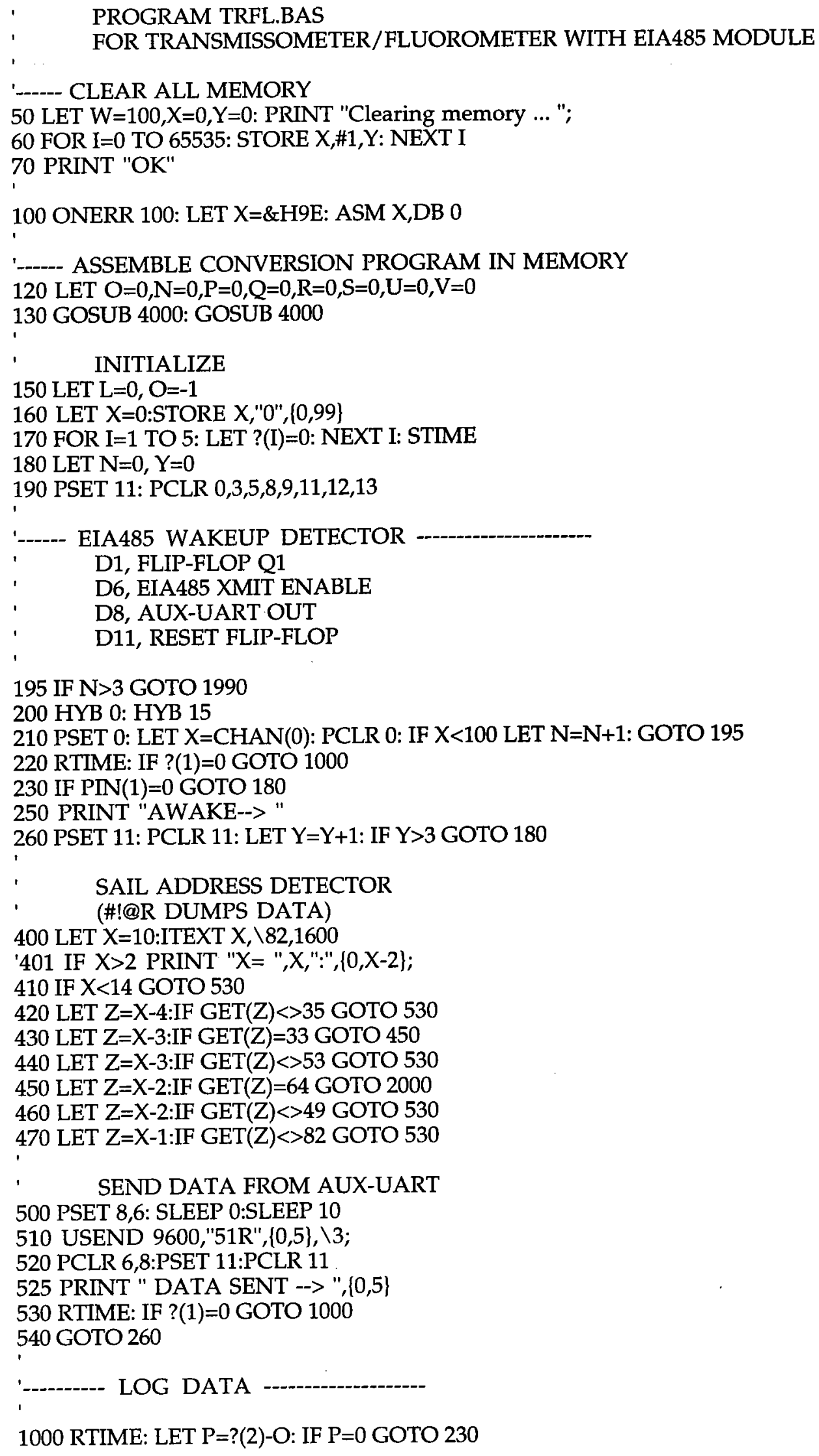


1005 IF W>65530 GOTO 2000

1010 LET O=?(2): PRINT "Start @ ",\#02,?(2),":",?(1),":",?(0);

1015 LET $C=?(4), D=?(3), E=?(5), Q=?(2), R=?(1), S=?(0)$

'1000 RTIME: LET P=?(1)-O: IF P=0 GOTO 230

'1010 LET O=?(1): PRINT "Start @ ",\#02,?(2),":",?(1),":"?(0);

- TRANSMISSOMETER (avg 32 samples after 3 second warmup)

1020 PSET 0,13: SLEEP 0: SLEEP 300

1030 CALL \&H4000,\&HFF54: PCLR 13

1040 LET A=0: FOR I=1 TO 255: LET A=A+@(I): NEXT I

1050 LET T=A/255: STORE W,\#2,T

- FLUOROMETER (avg 32 samples after 15 second warmup)

1100 PSET 12: SLEEP 0: SLEEP 1500

1110 CALL \&H4000,\&HFF58: PCLR 12,0

1120 LET A=0: FOR I=1 TO 255: LET A=A+@(I): NEXT I

1130 LET F=A/255: STORE W,\#2,F

- STORE RESULTS FOR TRANSMISSION

1200 LET $\mathrm{H}=4096^{*} \mathrm{~T}+\mathrm{F}, \mathrm{K}=0$ : STORE $\mathrm{K},{ }^{\prime \prime \prime}, \# 06 \mathrm{H}, \mathrm{H}$;

1210 PRINT " :W= "\#5,W-4," :TR= ",\#4,T," :FL= ",\#4,F," :DATA= "\#06H,H;

1220 RTIME: PRINT " :End @ ",\#02,?(2),":",?(1),":",?(0)

1240 IF PIN(1)=1 GOTO 250

1250 GOTO 180

'

'------ BATTERY LOW

1990 LET L=1: QUIT

1995 PRINT "Battery Low!!!": GOTO 2050

'------ STOP LOGGING -----.--

2000 LET $X=10, Z=10$ : ITEXT $X, 1$ : LET $X=10$ : STORE $X, \# 1, Z$

2005 PRINT "Are you sure you want to stop logging $(Y)$ ?"

2010 LET $X=10, Z=10:$ ITEXT $X, \backslash 13,500:$ LET $X=G E T(Z, \# 1)$

2020 IF $X<>89$ GOTO 220

'----- DUMP RESULTS FROM LOGGER

2030 PRINT "Press ENTER to begin dumping data ...";

2040 LET X=10: ITEXT $X, \backslash 13,6000$

2050 PRINT:PRINT: PRINT " SCAN TRANS FLUOR (4096 MAX)"

2060 LET $Z=W-100$ : FOR I $=0$ TO $Z / 4$ : LET $U=4^{*} I+100, V=4^{*} I+102$

2070 LET $X=G E T(U, \# 2), Y=G E T(V, \# 2)$

2080 PRINT \#5,I+1," ",X," ",Y: SLEEP 0: SLEEP 1: NEXT I

2085 RTIME: PRINT "Last reading @ ",\#02,C,"/",D,"/",E," ",Q,":",R,":",S

2090 IF L=1 PRINT "Low Battery!!!"

2095 PRINT "END OF DATA"

2100 QUIT

'---.-- SELECT DUMP AGAIN, LOG, OR RESTART

2110 LET $X=10, Z=10$ : ITEXT $X, 1$ : LET $X=10$ : STORE $X$,\#1,Z

2120 PRINT: PRINT "ENTER (1) to dump data again"

2130 PRINT "ENTER (2) to continue logging data"

2140 PRINT "ENTER (3) to clear memory and restart"

2150 PRINT: PRINT " $\rightarrow>$ ";

2160 LET X=10: ITEXT X, 13,1500: LET X=GET(Z,\#1): PRINT '"',\#1,X-48

2170 IF $X=49$ GOTO 2030

2180 IF $X=50$ PRINT "Logging again ...": GOTO 220

$2190 \mathrm{IF} X=51$ GOTO 2210

2200 HYB 0: HYB 30: GOTO 2100

2210 LET $X=10, Z=10$ : ITEXT $X, 1$ : LET $X=10$ : STORE $X, \# 1, Z$

2220 PRINT "Are you sure you want to restart $(Y)$ ? "; 
2240 IF $X=89$ GOTO 50

2250 GOTO 2100

$$
\text { - }
$$

' A = AVERAGE VALUE

' $\mathrm{C}=$ MONTH LAST READING

' $\mathrm{D}=$ DAY LAST READING

' $\mathrm{E}=$ YEAR LAST READING

' $\mathrm{F}=$ FLUOROMETER

' $\mathrm{H}=$ HEX VARIABLE

' I = FOR VARIABLE

' $\mathrm{K}$ = TRANS STORE LOCATION

' $\mathrm{L}=$ LOW BATTERY FLAG

' $\mathrm{N}=$ BATTERY VARIABLE

' $\mathrm{O}=$ OLD HOUR

' $\mathrm{P}=$ PREVIOUS HOUR

' $Q=$ HOUR LAST READING

' $\mathrm{R}=$ MINUTE LAST READING

' $\mathrm{S}$ = SECOND LAST READING

' $\mathrm{T}=$ TRANSMISSOMETER

' $U=$ GET VARIABLE

' $\mathrm{V}=$ GET VARIABLE

' $\mathrm{W}=$ STORAGE LOCATION

$' X=$ PTR VARIABLE

' $Y=$ PTR VARIABLE

' $\mathrm{Z}=$ PTR VARIABLE

' @(0)-@(255) = AD VARIABLES

CONVERSION ROUTINE

-- @0 CONTAINS GARBAGE FROM FIRST "CONVERSION"

MEMORY MAP:

RESULTS = @0 - @N = \&H7218 -

\&H130 PORT 5 OLD DDR

\&H131 CONFIGURATION BYTE

\&H133 TOTAL COUNT

$\&$ H134 BIT COUNT

\&H135 4 BIT FLAG

$4000 \mathrm{X}=\& \mathrm{H} 4000$ : REM load coversion routine at \&H4000 4010 ASM X,STAB \&H131: REM save config byte in B to memory 4020 ASM X,INCA : REM add 1 to count (1st conversion no good)

4030 ASM X,STAA \&H133 : REM move total count from A to memory 4040 ASM X,CLRA : REM clear A reg -- will hold read value 4050 ASM X,STAA \&H132 : REM store 0 for 1st byte of index 4060 ASM X,STAA \&H135 : REM init 4 bit flag to false 4070 ASM X,LDX \#\&H721B : REM current count index into '@' (4th byte) 4080 ASM X,LDAA \&H8B : REM read current port 5 DDR 4090 ASM $X$,STAA \&H130 : REM store old DDR 4100 ASM X,OIM \&H1C,\&H20 : REM make port $5.2,3, .4$ output 4110 ASM X,AIM \&HDF,\&H20 : REM make port 5.5 input 4160 ASM X,AIM \&HFB,\&H15 : REM sclk low 4170 ASM X,OIM \&H08,\&H15 : REM cs high

-- INITIALIZE BIT COUNT TO 8

4180 S=X:ASM X,SLP : REM sleep until $10 \mathrm{~ms}$ interupt 4190 ASM X,AIM \&HF7,\&H15 : REM cs low (they do in example) 4200 ASM X,LDAA \#8 4210 ASM X,STAA \&H134 : REM store bit count 
4220 ASM X,LDAB \&H131 : REM read config byte from memory

4230 ASM X,CLRA : REM store zero result before stored

4240 ASM $X, S T A A$ 0,X

- - DO LS 8 BITS OF CONVERSION

$4250 \mathrm{R}=\mathrm{X}$ :ASM X,LDAA 0,X : REM reload current read value

4260 ASM X,LSRA : REM put prior read bits into position

4270 ASM X,TIM \&H20,\&H15 : REM see if incoming bit

4280 ASM X,BEQ N : REM don't add if not there

4290 ASM X,ORAA \#128: REM add bit to A

$4300 \mathrm{~N}=\mathrm{X}$ :ASM X,STAA 0,X : REM store result, so can use A register

4310 ASM X,BITB \#1 : REM test config in B, see if 1st bit is set

4320 ASM X,BEQ $P$ : REM send out a null if nothing there

4330 ASM X,OIM \&H10,\&H15 : REM send out a bit

4340 ASM X,BRA Q : REM goto clock section

$4350 \mathrm{P}=\mathrm{X}: \mathrm{ASM} X, A I M$ \&HEF,\&H15 : REM send out a null

$4360 \mathrm{Q}=\mathrm{X}: \mathrm{ASM}$ X,ASRB : REM clock section-- shift config bit into position

4370 ASM X,OIM \&H04,\&H15 : REM sclk high (config bit out)

4380 ASM X,AIM \&HFB,\&H15 : REM sclk low -- ready to read bit

4390 ASM X,LDAA \&H134 : REM reload A with current bit count

4400 ASM X,DECA : REM decrement count

4410 ASM X,STAA \&H134 : REM store bit count

4420 ASM X,BNE R : REM branch if not done

' -- ALL DONE WITH LS 8 BITS READ/WRITE:

' -- NOW MUST HANDLE MS 4 BITS

4430 ASM X,LDAA \&H135

4440 ASM X,BNE V : REM branch when 4 bit flag set

4450 ASM X,LDAA \#4

4460 ASM X,STAA \&H135 : REM set 4 bit flag to true

4470 ASM X,STAA \&H134: REM load bit counter with 4

4480 ASM X,DEX : REM make index point to Byte 3

4490 ASM X,CLRA : REM store zero result before stored

4500 ASM X,STAA 0,X

4510 ASM X,BRA R : REM do it again

$4520 \mathrm{~V}=\mathrm{X}: \mathrm{ASM} \mathrm{X}, \mathrm{LDAA}$ 0,X : REM reload current read value

4530 ASM X,LSRA : REM shift bits into position

4540 ASM X,LSRA : REM shift bits into position

4550 ASM X,LSRA : REM shift bits into position

4560 ASM X,LSRA : REM shift bits into position

4570 ASM X,STAA 0,X : REM store result

' - DONE WITH MS 4 BITS OF 12-BIT CONVERSION

' -- STORE ZEROS IN FIRST TWO BYTES AND UPDATE X REGISTER

4580 ASM X,CLRA

4590 ASM X,DEX : REM points to byte 2

4600 ASM X,STAA 0,X

4610 ASM X,DEX : REM points to byte 1

4620 ASM X,STAA 0,X

4630 ASM X,DEX : REM points to byte 4 of next @ variable

4640 ASM X,CLRA : REM clear 4 bit flag

4650 ASM X,STAA \&H135

4660 ASM X,OIM \&H08,\&H15 : REM set cs high

-- DELAY FOR CONVERSION $=52$ ACLK CYCLES

4670 ASM X,LDAA \#10

$4680 \mathrm{U}=\mathrm{X}: \mathrm{ASM} \mathrm{X}, \mathrm{DECA}$

4690 ASM $X, B N E U$

' - CHECK TO SEE IF LAST CONVERSION 
4700 ASM $X$, LDAA \&H133

4710 ASM $X, D E C A$

4720 ASM $X, S T A A \& H 133$

4730 ASM X,BNE S : REM more conversions if not zero

' -- LAST CONVERSION: CLEAN UP

4750 ASM X,LDAA \&H130 : REM read old DDR from memory

4760 ASM X,STAA \&H20 : REM store old DDR for port 5

4770 ASM X,STAA \&H8B : REM store TTBASIC copy

4780 ASM X,RTS : REM return from assembly routine

4790 RETURN 
TT485 S4 Module Parts List:

TT3 Data Logger and TT485 board with:
$\mathrm{C} 121 \mathrm{uF}(\mathrm{C})$
$\mathrm{C} 130.1 \mathrm{uF}(\mathrm{C})$
*D1 1N4002
${ }^{*} \mathrm{D} 2$ 1N4743
D3 $1 \mathrm{~N} 4002$
D4 1N4751 (30V)
D5 1 N5240
D6 $1 \mathrm{~N} 5819$
D7 1N5240

P1 AMP 2-Pin Connector

P2 AMP 2-Pin Connector

P3 AMP 4-Pin Connector

P5 AMP 2-Pin Connector

Q1 2N3904

Q2 2N3904

*Q3 IRFF9131

${ }^{*} \mathrm{Q} 4 \quad 2 \mathrm{~N} 2222$

*Q5 IRFF9131

*Q6 IRFF131

*Q7 IRFF131

*Q8 IRFF9131

*Q9 IRFF131

Q22 2N3725

Q23 2N2484

Q24 IRFF9131

Q25 2N2222
R2 $470 \mathrm{~K}$

R3 100K

R5 10K

${ }^{*} \mathrm{R} 6 \quad 1 \mathrm{~K}$

*R7 $1.2 \mathrm{~K}-1 \mathrm{~W}$

*R8 1M

${ }^{*} \mathrm{R} 9 \quad 499 \mathrm{~K}$

*R10 100K

${ }^{*} \mathrm{R} 11$ 10K

*R12 100K

${ }^{*} \mathrm{R} 13 \quad 4.7 \mathrm{~K}$

R17 100K

R18 100K

R50 1M (1\%)

R51 27K

R52 1M

R53 499K

R54 100K

R55 100K (1\%)

R56 20K (1\%)

S1 MID-to-BOT

S2 MID-to-RIGHT

S3 SHORT

S4 MID-to-BOT

U3 $74 \mathrm{HC} 08$

U6 LTC485

U7 CD4013B

* these parts required only for resetting and sending characters to the S4 


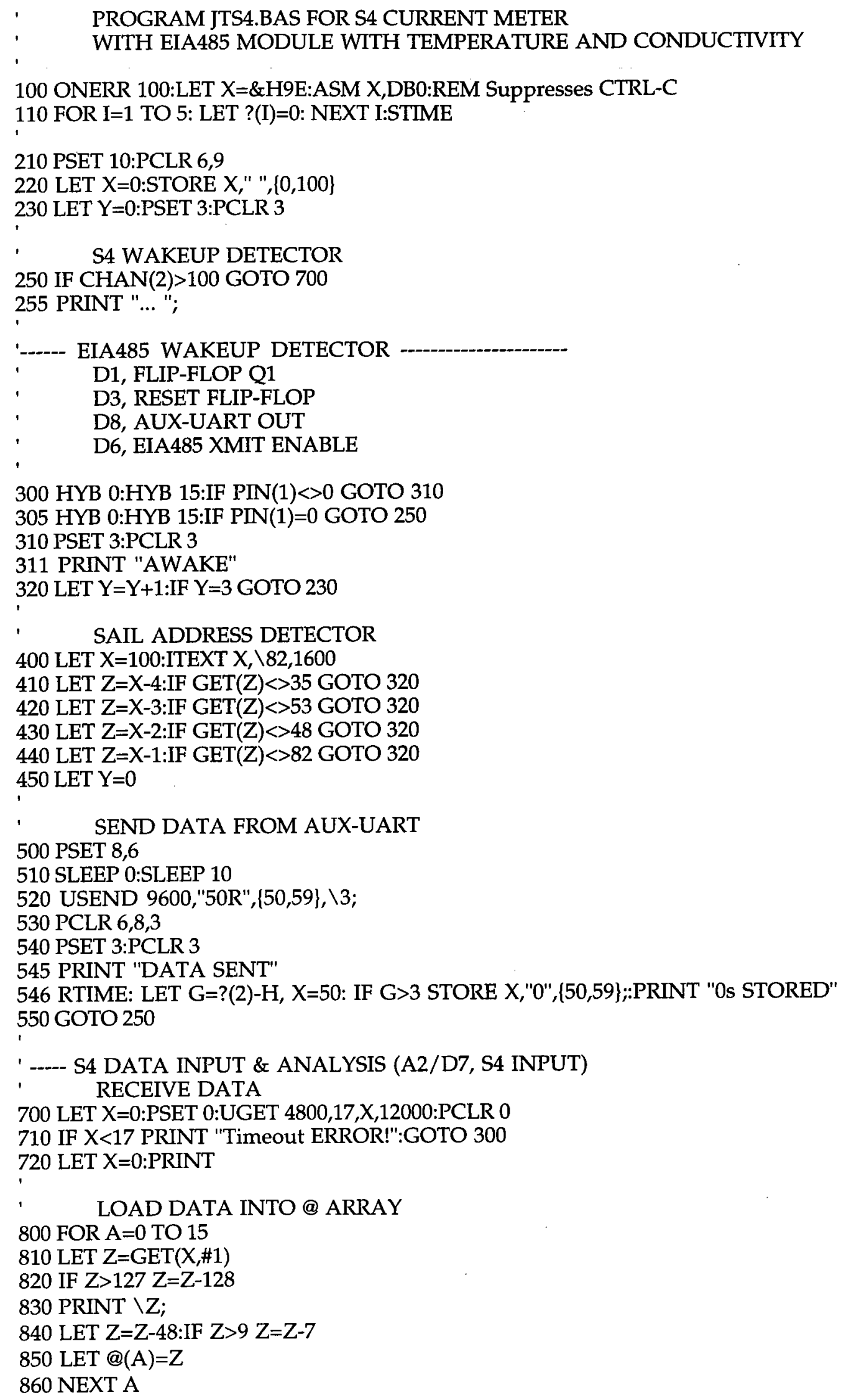




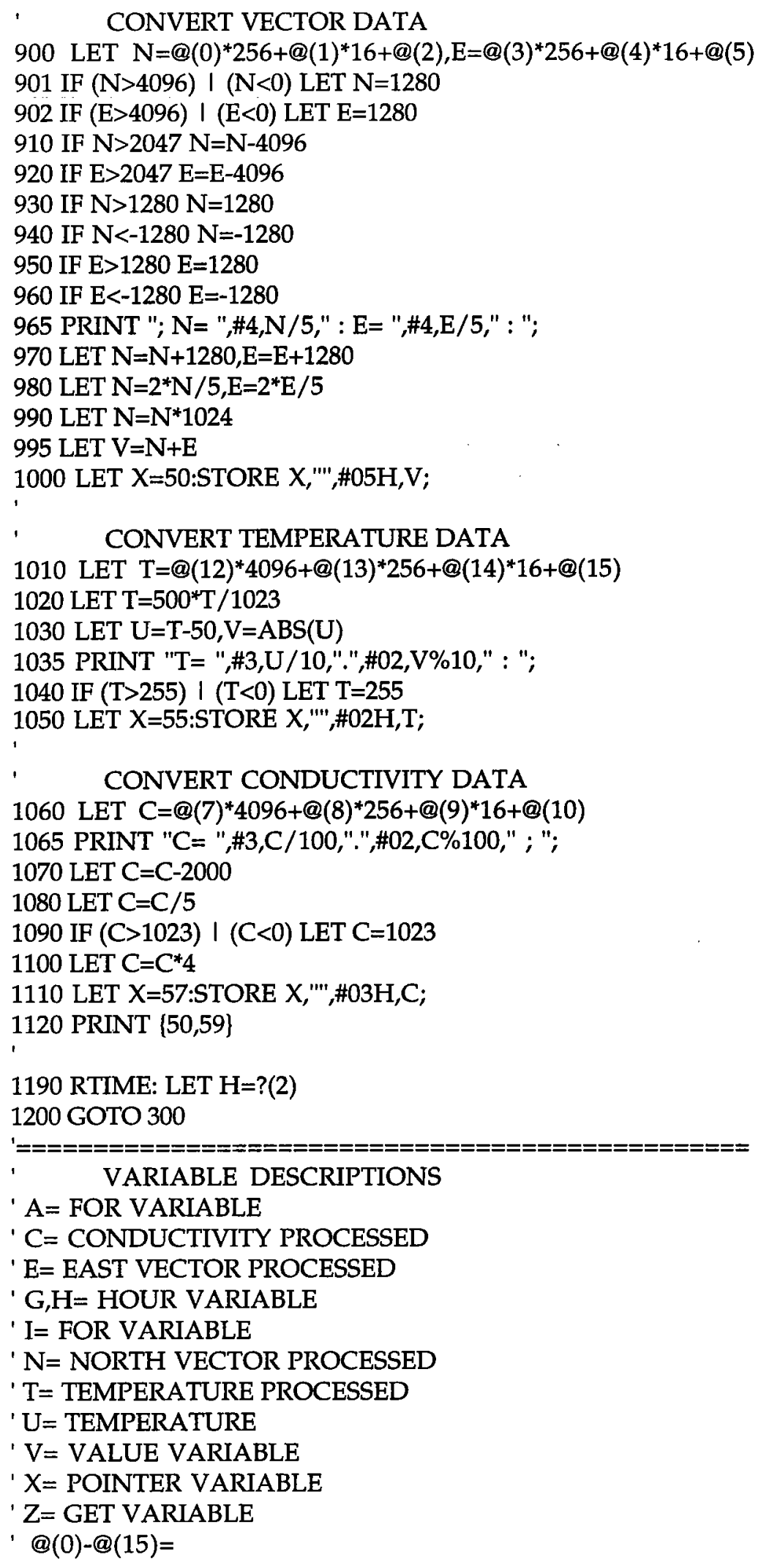




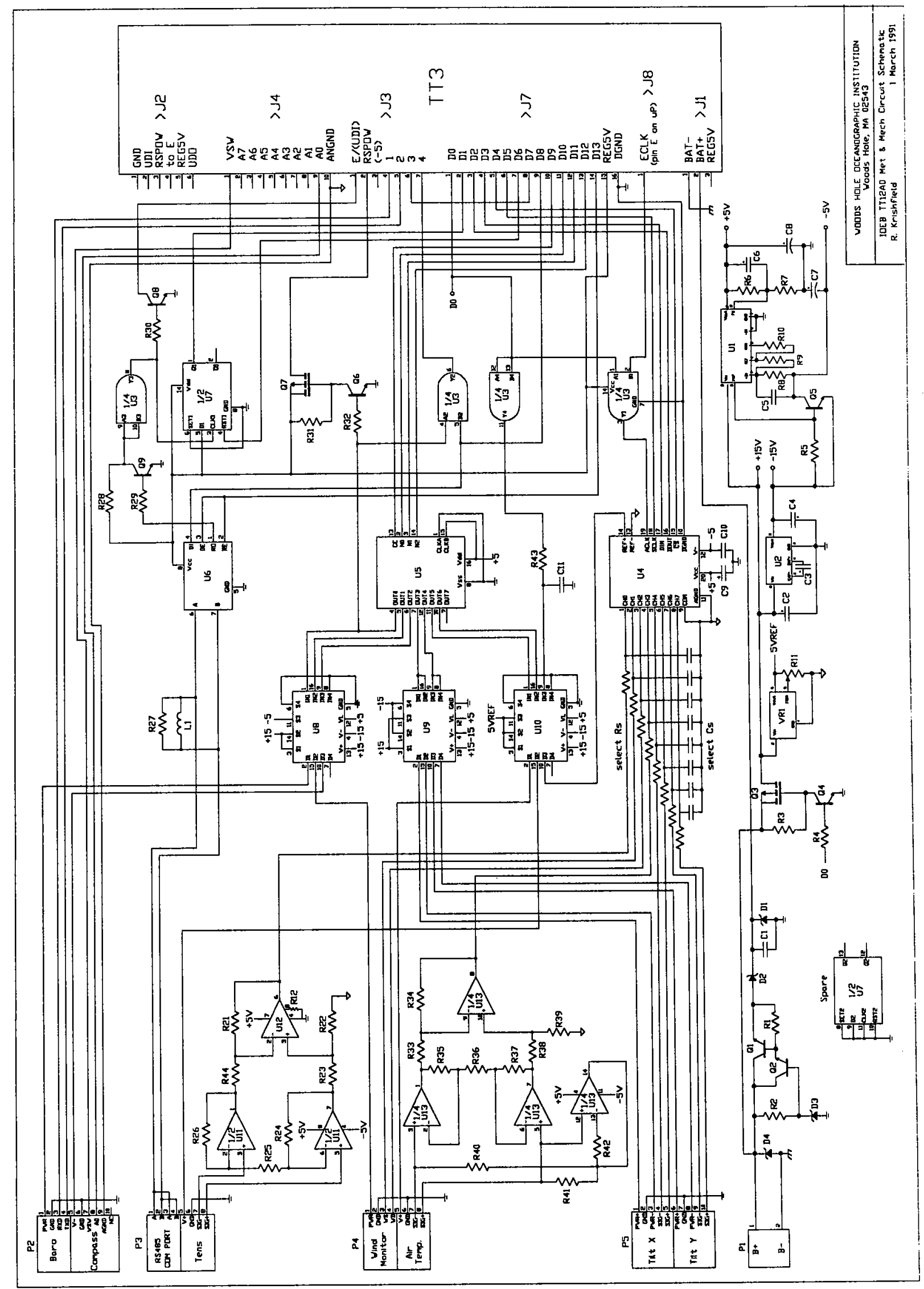

Figure 15: TT12AD Schematic Diagram 
TT12AD Parts List:

TT3 Data Logger and TT12AD board with:

\begin{tabular}{|c|c|c|c|c|c|}
\hline $\mathrm{C} 1$ & luf (CK) & R5 & $51 \mathrm{~K}$ & U6 & LTC485 \\
\hline $\mathrm{C} 2$ & 2.2uf (T) & R6 & $499 \mathrm{~K}(1 \%)$ & U7 & CD4013B \\
\hline C3 & 100 uf $(\mathrm{T})$ & R7 & 499K (1\%) & U8 & DG412AK \\
\hline C4 & $100 \mathrm{uf}(\mathrm{T})$ & R8 & $1 \mathrm{M}(1 \%)$ & U9 & DG412AK \\
\hline C5 & .001 uf (CK) & R9 & $499 \mathrm{~K}(1 \%)$ & U10 & DG412AK \\
\hline C6 & .001 uf (CK) & R10 & $100 \mathrm{~K}(1 \%)$ & U11 & OP220 \\
\hline C7 & 10uf (T) & R11 & $10 \mathrm{~K}$ Pot $(\mathrm{V}$ & U12 & OP22 \\
\hline $\mathrm{C} 8$ & 10uf (T) & R12 & $1.8 \mathrm{M}$ & U13 & LT1079 \\
\hline C9 & $22 \mathrm{uf}(\mathrm{T})$ & R13 & select & & \\
\hline $\mathrm{C} 10$ & $.1 \mathrm{uf}(\mathrm{CK})$ & R14 & select & VR1 & REF02 \\
\hline $\mathrm{C} 11$ & 1uf (CK) & R15 & select & & \\
\hline $\mathrm{C} 12$ & select & R16 & select & & \\
\hline $\mathrm{C} 13$ & select & R17 & select & & \\
\hline C14 & select & R18 & select & & \\
\hline C15 & select & R19 & select & & \\
\hline $\mathrm{C} 16$ & select & R20 & select & & \\
\hline $\mathrm{C} 17$ & select & $\mathrm{R} 21$ & $50 \mathrm{~K}(.01 \%)$ & & \\
\hline $\mathrm{C} 18$ & select & $\mathrm{R} 22$ & $50 \mathrm{~K}(.01 \%)$ & & \\
\hline C19 & select & $\mathrm{R} 23$ & $3 \mathrm{~K}(.01 \%)$ & & \\
\hline \multirow[t]{2}{*}{$\mathrm{C} 20$} & select & R24 & $49.9 \mathrm{~K}(1 \%)$ & & \\
\hline & & R25 & $3.48 \mathrm{~K}(1 \%)$ & & \\
\hline D1 & 1N5240 & $\mathrm{R} 26$ & $49.9 \mathrm{~K}(1 \%)$ & & \\
\hline D2 & 1N5819 & R27 & $100 x$ & & \\
\hline D3 & 1N5240 & R28 & $100 \mathrm{~K}$ & & \\
\hline \multirow[t]{2}{*}{ D4 } & 1N5250 & $\mathrm{R} 29$ & $10 \mathrm{~K}$ & & \\
\hline & & R30 & $10 \mathrm{~K}$ & & \\
\hline P1 & AMP-2 & R31 & $1 \mathrm{M}$ & & \\
\hline P2 & AMP-10 & R32 & $100 \mathrm{~K}$ & & \\
\hline P3 & AMP-8 & R33 & $1 \mathrm{M}(1 \%)$ & & \\
\hline P4 & AMP-8 & R34 & $5.1 \mathrm{M}$ & & \\
\hline \multirow[t]{2}{*}{ P5 } & AMP-10 & R35 & $1 \mathrm{M}(1 \%)$ & & \\
\hline & & R36 & $499 \mathrm{~K}(1 \%)$ & & \\
\hline Q1 & 2N3725 & R37 & $1 \mathrm{M}(1 \%)$ & & \\
\hline Q2 & $2 \mathrm{~N} 2484$ & R38 & $1 \mathrm{M}(1 \%)$ & & \\
\hline $\mathrm{Q} 3$ & IRFF9131 & R39 & $5.1 \mathrm{M}$ & & \\
\hline$\tilde{\mathrm{Q}} 4$ & $2 \mathrm{~N} 2222 \mathrm{~A}$ & R40 & $20 \mathrm{M}$ & & \\
\hline Q5 & 2N3904 & R41 & $10 \mathrm{M}$ & & \\
\hline Q6 & $2 \mathrm{~N} 2222 \mathrm{~A}$ & R42 & $20 \mathrm{M}$ & & \\
\hline Q7 & IRFF9131 & R43 & $100 \mathrm{~K}$ & & \\
\hline $\mathrm{Q} 8$ & 2N3904 & R44 & $3 \mathrm{~K}(.01 \%)$ & & \\
\hline \multirow[t]{2}{*}{ Q9 } & 2N3904 & & & & \\
\hline & & U1 & LT1020 & & \\
\hline R1 & $27 \mathrm{~K}$ & U2 & LT1054 & & \\
\hline R2 & $1 \mathrm{M}(1 \%)$ & U3 & $74 \mathrm{HC} 08$ & & \\
\hline R3 & $1 \mathrm{M}$ & U4 & LTC1290 & & \\
\hline R4 & $100 \mathrm{~K}$ & U5 & CDP1853 & & \\
\hline
\end{tabular}


-- JTMET.BAS

-- FOR IOEB METEOROLOGICAL SENSORS WITH EIA485

100 ONERR 100: LET N=0, X=\&H9E: ASM X,DB0: REM Suppresses CTRL-C

'-----ENTER CURRENT TIME (TIMEOUT AFTER 3 MINUTES)

105 PRINT: LET N=N+1: IF N>3 FOR I=1 TO 5: LET ?(I)=0: NEXT I: GOTO 145

110 PRINT " ENTER yymmddhhmm : ";: LET X=0: ITEXT X,6000: IF X<10 GOTO 105

115 FOR I=1 TO 5

120 LET $X=2^{*} I-2, Y=2^{*} \mathrm{I}-1$ : LET A $=\mathrm{GET}(\mathrm{X}, \# 1), \mathrm{B}=\mathrm{GET}(\mathrm{Y}, \# 1)$

125 LET J=6-I, A=A-48, B=B-48: LET ?(J) $=10^{*} A+B$

130 PRINT \#02,?(J);: NEXT I

135 PRINT: PRINT " ENTER A<CR> to accept ";: LET $X=0, Y=0$ : ITEXT X,3000

140 PRINT: IF GET(Y,\#1)<>65 GOTO 105

145 PRINT: STIME

$$
\text { , }
$$

-- ASSEMBLE PROGRAM IN MEMORY

150 LET $F=0, \mathrm{O}=0, \mathrm{~N}=0, \mathrm{P}=0, \mathrm{Q}=0, \mathrm{R}=0, \mathrm{~S}=0, \mathrm{U}=0, \mathrm{~V}=0, \mathrm{Y}=0$

151 GOSUB 4000: GOSUB 4000

' - INITIALIZE

155 LET $X=0$ : STORE $X, " ',\{0,400\}$;

160 LET $Y=0$ : PSET 6:PCLR 6

170 IF F=1 GOTO 1700

180 LET $N=0, Y=0, X=0$ : STORE $X, "$ ",\{0,150\};

190 PCLR $0,3,4,5,8,9,10,11,12,13$

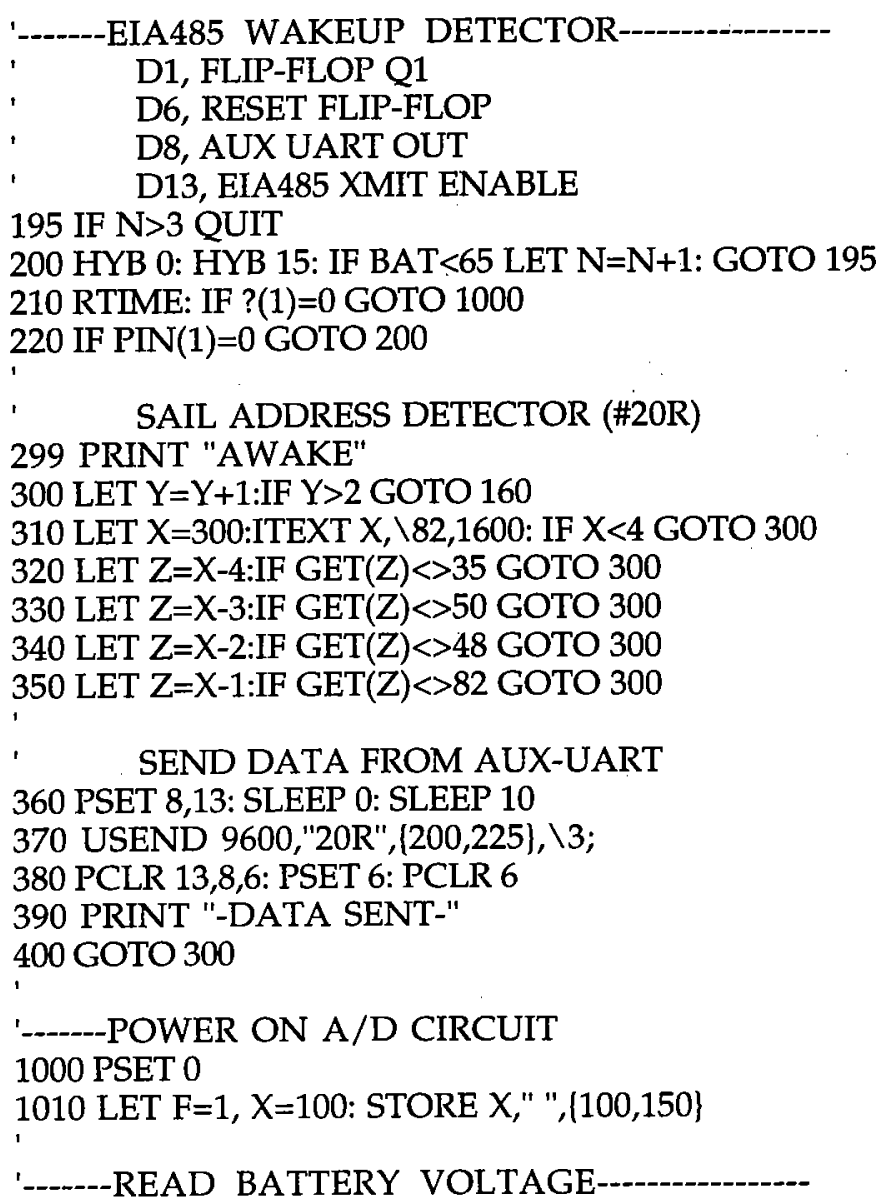




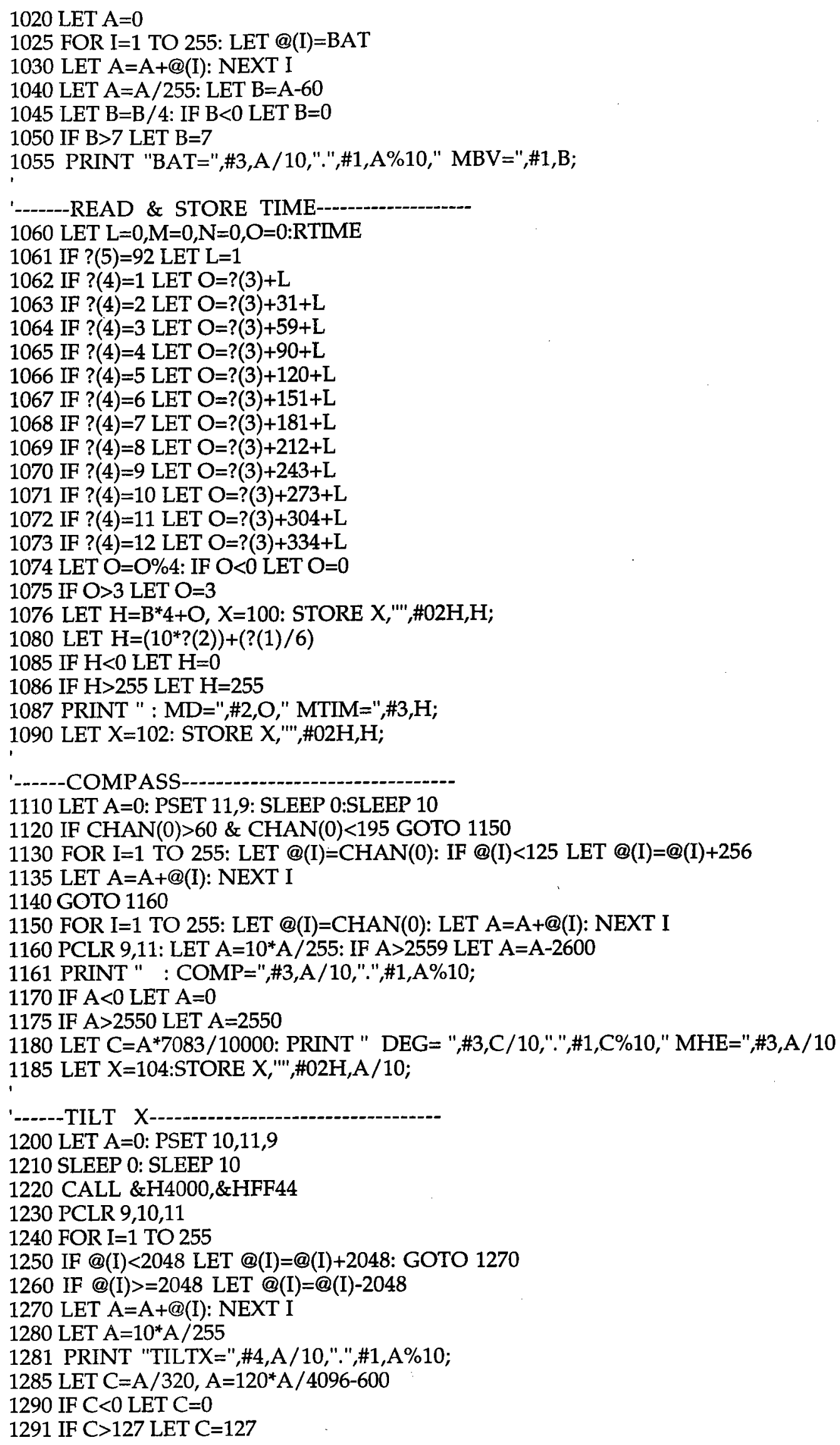


1295 LET E=ABS(A): PRINT " DEG=",\#3,A/10,".",\#1,E\%10," MTX= ",\#3,C;

'-----TILT $Y$

1300 LET A=0: PSET 12,9

1310 SLEEP 0: SLEEP 10

1320 CALL \&H4000,\&HFF4C

1330 PCLR 9,12

1340 FOR I=1 TO 255

1350 IF @(I)<2048 LET @(I)=@(I)+2048: GOTO 1360

1360 IF @(I)>=2048 LET @(I)=@(I)-2048

1370 LET $A=A+@(I):$ NEXT I

1380 LET $A=10^{*} \mathrm{~A} / 255$

1381 PRINT " : TILTY=",\#4,A/10,".",\#1,A\%10;

1385 LET $\mathrm{D}=\mathrm{A} / 320, \mathrm{~A}=120^{*} \mathrm{~A} / 4096-600$

1390 IF $D<0$ LET $D=0$

1391 IF $D>127$ LET $D=127$

1393 LET B=ABS(A): PRINT " DEG=",\#3,A/10,".",\#1,E\%10," MTY= "\#3,D

1395 LET $\mathrm{H}=2^{*} \mathrm{C}+\mathrm{D} / 64, \mathrm{X}=106: \mathrm{STORE} \mathrm{X},{ }^{\prime \prime \prime}, \# 02 \mathrm{H}, \mathrm{H}$;

'

'------BAROMETRIC PRESSURE

1400 LET $A=0, L=0, N=0:$ PSET 9,8

1410 SLEEP 0: SLEEP 10

1420 LET $X=0$ : STORE $X, "$ ",\{0,50\}

1430 LET $N=N+1$ : IF $N>3$ LET L=129921: GOTO 1530

1440 LET $X=0$ : USEND 4800,"*0100P1": UGET 4800,14,X,500

1450 LET $X=0$ : USEND 4800,"*0100Q1": UGET 4800,14,X,500

1460 LET $X=0$ : USEND 4800,"*0100P3": UGET 4800,14,X,500

1465 IF $X>7$ PRINT "BARO= ", $\{5, X-2\}$;

1470 IF $X<13$ GOTO 1430

1480 PCLR 9

- -convert

1490 FOR $\mathrm{I}=1$ TO 8

1500 LET $X=\mathrm{I}+4$, @(I)=GET $(\mathrm{X}, \# 1)-48$

1510 IF @(I)>9 LET @(I)=@(I)-7

1515 NEXT I

1520 LET L=1000000*@(1)+100000*@(2)+10000*@(3)+1000*@(4)+100*@(6)+10*@(7)+@(8)

1530 IF @(4)=-2 LET L=100000*@(1)+10000*@(2)+1000*@(3)+100*@(5)+10*@(6)+@(7)

1540 LET L=L-920000

1550 IF $\mathrm{L}<0$ LET $\mathrm{L}=0$

1560 IF L/ $127>1023$ LET L=129921

1565 PRINT " MBAR=",\#6,L/127;

1570 LET D=D\%64: LET D=D*4: LET $\mathrm{H}=\mathrm{L} / 127+\mathrm{D}, \mathrm{X}=108$ : STORE $\mathrm{X}$,'"',\#04H,H;

$$
\text { . }
$$

'----AIR TEMPERATURE

1600 LET A=0: PSET 10,12,9

1610 SLEEP 0:SLEEP 10

1620 CALL \&H4000,\&HFF4B

1630 PCLR 9,10,12

1640 FOR I=1 TO 255

1650 IF @(I)<2048 LET @(I)=@(I)+2048: GOTO 1670

1660 IF @(I)>=2048 LET @(I)=@(I)-2048

1670 LET $A=A+@(I):$ NEXT I

1680 LET $A=10^{*} \mathrm{~A} / 255$

1681 PRINT " : AIR=",\#5,A/10,".",\#1,A\%10;

1685 LET $A=A^{*} 17603 / 100000+587$ : LET $D=1705^{*} A / 10000$

1686 IF $D<0$ LET $D=0$

1687 IF $D>1023$ LET $D=1023$

1688 PRINT " DEG= ",\#3,A/100-40,".",\#02,A\%100," MAT=",\#4,D

1690 LET $X=116: S T O R E ~ X, " ', \# 02 H, D / 4$;

1691 LET $B=D \% 4$ : LET $B=B^{*} 64, X=118$ : STORE $X,{ }^{\prime \prime \prime}, \# 02 H, B$; 
1692 LET $X=112$ : STORE $X, " 0 ",\{112,114\} ;:$ LET $X=120$ : STORE $X, " 0 ",\{120,124\}$;

1693 LET $X=200$ : STORE $X,{ }^{\prime \prime \prime},\{100,125\}$;

'----WIND SPEED AND DIRECTION

1700 LET N=0: FOR I=297 TO 311: LET @(I)=0: NEXT I

1705 PSET 0: SLEEP 0: SLEEP 10

1710 LET A=0: PSET 10,9: SLEEP 0: SLEEP 10

1720 CALL \&H4000,\&HFF53

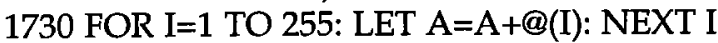

1740 LET S $=10^{*} \mathrm{~A} / 255$

1750 IF $S<0$ LET $S=0$

1760 IF $S>40959$ LET $S=40959$

1761 PRINT "N=",\#2,N+1," : WSPD=",\#3,S/10,".",\#1,S\%10;

1770 LET C=50*S/4096: PRINT " M/S=",\#3,C/10,".",\#1,C\%10;

1800 LET $A=0$

1810 CALL \&H4000,\&HFF59

1820 IF @(1)>1024 \& @(1)<3072 GOTO 1860

1830 FOR I=1 TO 255: IF @(I)<2048 LET @(I)=@(I)+4096

1840 LET $A=A+@(I):$ NEXT I

1850 GOTO 1870

1860 FOR I=1 TO 255: LET A=A+@(I): NEXT I

1870 PCLR 9,10

1880 LET $R=10^{*} A / 255:$ IF $R>40959$ LET R=R-40960

1885 IF $R<0$ LET R=0

1890 IF $R>40959$ LET $R=40959$

1891 PRINT " : WDIR=",\#4,R/10,".",\#1,R\%10;

1892 LET C=360*R/4096: PRINT " DEG=",\#4,C/10,".",\#1,C\%10; ,

'-----TENSIOMETER

1900 LET A=0: PSET 11,12,9

1910 SLEEP 0: SLEEP 10

1920 CALL \&H4000,\&HFF41

1930 PCLR 9,11,12

1940 FOR I=1 TO 255

1941 IF @(I)<2048 LET @(I)=@(I)+2048: GOTO 1945

1942 IF @(I)>=2048 LET @(I)=@(I)-2048

1945 LET $\mathrm{A}=\mathrm{A}+\mathrm{Q}(\mathrm{I}): \mathrm{NEXT} \mathrm{I}$

1950 LET T $=10^{*} \mathrm{~A} / 255$

1960 IF T $<0$ LET T $=0$

1970 IF $\mathrm{T}>40959$ LET $\mathrm{T}=40959$

1971 PRINT " : TENS=",\#4,T/10,".",\#1,T\%10;

1972 LET C=T-20480: LET C $=5540^{\circ} \mathrm{C} / 2048:$ LET $E=A B S(C)$

1973 PRINT " LBS=",\#4,C/10,".",\#1,E\%10

'-----DO 10 MINUTE AVERAGES OF WS/WD \& TENSION

2100 PCLR 0: IF N=0 LET @(297)=R

2110 LET @(298)=@(298)+S, @(300)=@(300)+T, @(N+301)=T

2115 IF @(297)>10240 \& @(297)<30720 GOTO 2117

2116 IF $R<20480$ LET R=R+40960

2117 LET @(299)=@(299)+R

2120 LET $N=\mathrm{N}+1$ : IF $\mathrm{N}>9$ GOTO 2160

2125 IF PIN(1)=1 LET Y=0: GOTO 300

2126 HYB 0: HYB 15

2130 IF PIN(1)=1 LET $Y=0$ : GOTO 300

2131 HYB 0: HYB 15

2135 IF PIN(1)=1 LET $Y=0:$ GOTO 300

2136 HYB 0: HYB 15

2140 IF PIN(1)=1 LET $Y=0$ : GOTO 300

2141 HYB 0: HYB 15

2145 IF PIN(1)=1 LET Y=0: GOTO 300 
2150 GOTO 1705

2160 LET $S=@(298) / 1600, R=@(299) / 1600, T=@(300)-204800:$ LET T=T $/ 800$

2161 PRINT "AVG WSPD=",\#4,@(298)/100,".",\#1,@(298)\%100;

2162 LET C=5*@(298)/4096: PRINT " M/S=",\#4,C/10,".",\#1,C\%10," S=",\#3,S

2163 PRINT "AVG WDIR=",\#4,@(299)/100,".",\#1,@(299)\%100;

2164 LET C=36*@(299)/4096: PRINT " DEG=",\#4,C/10,".",\#1,C\%10," R=",\#3,R

2165 IF R>255 LET R=R-256: IF R $>255$ LET $R=255$

2166 IF $R<0$ LET R=0

2167 IF $S<0$ LET $S=0$

2168 IF $S>255$ LET $S=255$

2169 IF $\mathrm{T}<0$ LET $\mathrm{T}=0$

2170 IF $\mathrm{T}>255$ LET $\mathrm{T}=255$

2175 LET X=112: STORE X,"',"\#02H,S;: LET X=114: STORE $X,{ }^{\prime \prime \prime, " \# 02 H, R ; ~}$

2180 LET D=D\%4: LET D=D*64: LET H=T/4+D, X=118: STORE X,"', \#02H,H;

'-----CALCULATE MAX \& MEAN DEV OF TENSION------

2200 LET $U=0, V=0$

2210 FOR I=301 TO 310: IF @(I)>U LET U=@(I)

2220 LET V=V+ABS(@(I)-@(300)/10): NEXT I

2230 LET C $=@(300)-204800$

2231 PRINT "AVG TENS=",\#4,@(300)/100,".",\#1,@(300)\%100;

2235 LET $C=5540^{*} \mathrm{C} / 20480$ : LET $\mathrm{E}=\mathrm{ABS}(\mathrm{C})$ : LET $\mathrm{D}=\mathrm{ABS}(\mathrm{U})$

2236 PRINT " LBS=",\#4,C/10,".",\#1,E\%10," T=",\#3,T

2237 PRINT "MAX TENS=",\#4,U/10,".",\#1,D\%10;

2240 LET U=U-20480: LET C=5540*U/2048: LET E=ABS(C)

2241 PRINT " LBS=",\#4,C/10,".",\#1,E\%10," U=",\#3,U/80

2242 PRINT "DEV TENS=",\#4,V/100,".",\#1,V\%100;

2245 LET C $=5540^{*} \mathrm{~V} / 20480$ : LET $\mathrm{E}=\mathrm{ABS}(\mathrm{C})$

2246 PRINT " LBS=",\#4,C/10,".",\#1,C\%10," V=",\#3,V/400

2250 LET U=U $/ 80, V=V / 400, T=T \% 4$

2255 IF $U<0$ LET $U=0$

2260 IF $U>255$ LET $U=255$

2265 IF $V<0$ LET $V=0$

2270 IF $V>255$ LET $V=255$

2275 LET $\mathrm{H}=\mathrm{T}^{*} 64+\mathrm{U} / 4, \mathrm{X}=120$ : STORE $\mathrm{X}$,"'", \#02H,H;

2280 LET U=U\%4: LET $\mathrm{H}=\mathrm{U}^{*} 64+\mathrm{V} / 4, \mathrm{X}=122$ : STORE $X,{ }^{\prime}, ", \# 02 \mathrm{H}, \mathrm{H}$;

2285 LET V=V\%4: LET $\mathrm{H}=\mathrm{V}^{*} 64, \mathrm{X}=124$ : STORE $\mathrm{X}^{\prime \prime}, ", \# 02 \mathrm{H}, \mathrm{H}$;

'----STORE DATA AND LOOP

2300 LET $X=200$ : STORE $\left.X, '{ }^{\prime}, ', 100,125\right\}$;

2310 PRINT "\{200,225\}=",(200,225\}: PRINT: LET F=0: GOTO 180

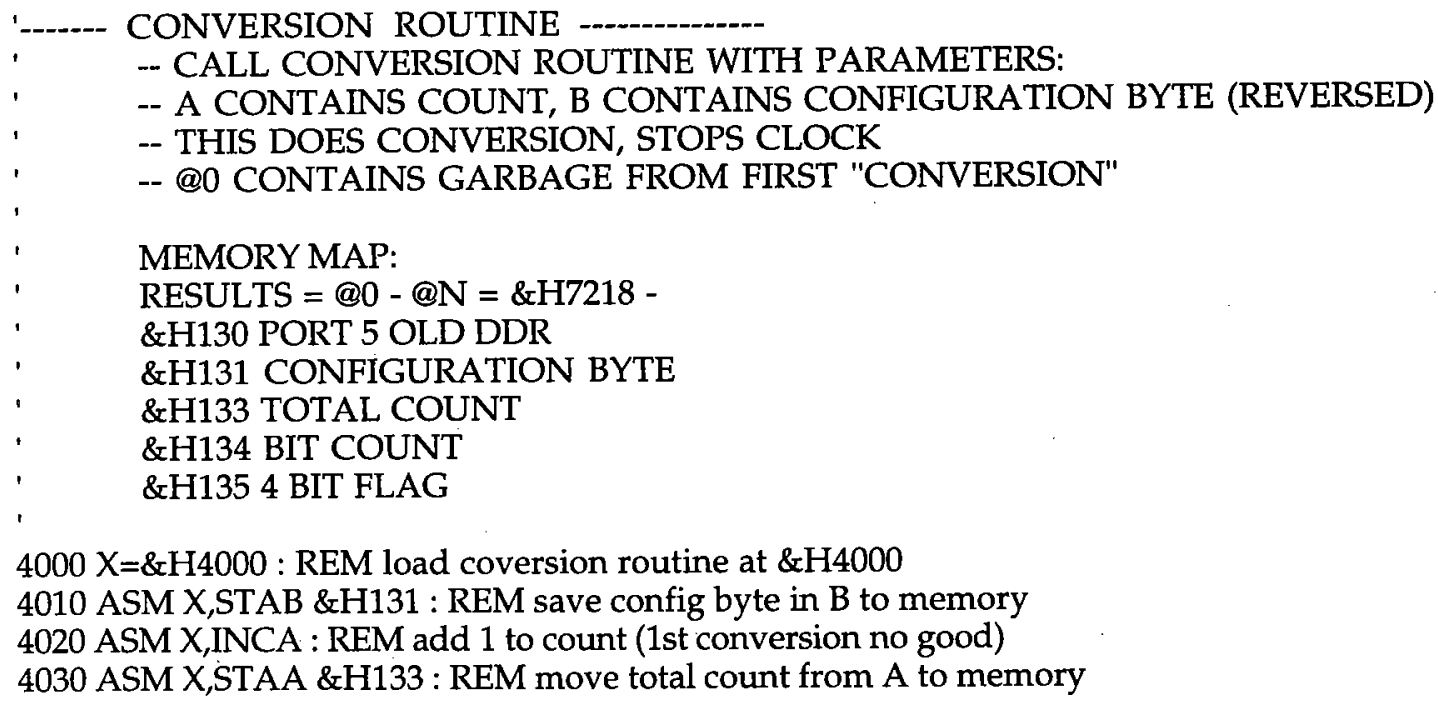

$4000 \mathrm{X}=\& \mathrm{H} 4000$ : REM load coversion routine at \&H4000 4010 ASM X,STAB \&H131 : REM save config byte in B to memory 4020 ASM X,INCA : REM add 1 to count (1st conversion no good) 4030 ASM X,STAA \&H133 : REM move total count from A to memory 
4040 ASM X,CLRA : REM clear A reg -- will hold read value 4050 ASM X,STAA \&H132 : REM store 0 for 1st byte of index 4060 ASM X,STAA \&H135 : REM init 4 bit flag to false 4070 ASM X,LDX \#\&H721B : REM current count index into '@' (4th byte) 4080 ASM X,LDAA \&H8B : REM read current port 5 DDR 4090 ASM X,STAA \&H130 : REM store old DDR 4100 ASM X,OIM \&H1C,\&H20 : REM make port 5 .2,.3,.4 output 4110 ASM X,AIM \&HDF,\&H20 : REM make port 5.5 input 4160 ASM X,AIM \&HFB,\&H15 : REM sclk low 4170 ASM X,OIM \&H08,\&H15 : REM cs high

-- INITIALIZE BIT COUNT TO 8

$4180 \mathrm{~S}=\mathrm{X}$ :ASM X,SLP : REM sleep until $10 \mathrm{~ms}$ interupt 4190 ASM X,AIM \&HF7,\&H15 : REM cs low (they do in example) 4200 ASM X,LDAA \#8

4210 ASM X,STAA \&H134 : REM store bit count 4220 ASM X,LDAB \&H131 : REM read config byte from memory 4230 ASM X,CLRA : REM store zero result before stored 4240 ASM $X$,STAA $0, X$

' $\quad$-- DO LS 8 BITS OF CONVERSION $4250 \mathrm{R}=\mathrm{X}$ :ASM X,LDAA 0,X : REM reload current read value 4260 ASM X,LSRA : REM put prior read bits into position 4270 ASM X,TIM \&H20,\&H15: REM see if incoming bit 4280 ASM X,BEQ $N$ : REM don't add if not there 4290 ASM X,ORAA \#128: REM add bit to A $4300 \mathrm{~N}=\mathrm{X}: \mathrm{ASM} \mathrm{X}, \mathrm{STAA} 0, \mathrm{X}: \mathrm{REM}$ store result, so can use A register 4310 ASM X,BITB \#1 : REM test config in B, see if 1st bit is set 4320 ASM X,BEQ P : REM send out a null if nothing there 4330 ASM X,OIM \&H10,\&H15 : REM send out a bit 4340 ASM X,BRA Q : REM goto clock section $4350 \mathrm{P}=\mathrm{X}$ :ASM X,AIM \&HEF,\&H15 : REM send out a null $4360 \mathrm{Q}=\mathrm{X}$ :ASM X,ASRB : REM clock section-- shift config bit into position 4370 ASM X,OIM \&H04,\&H15 : REM sclk high (config bit out) 4380 ASM X,AIM \&HFB,\&H15 : REM sclk low -- ready to read bit 4390 ASM X,LDAA \&H134 : REM reload A with current bit count 4400 ASM X,DECA : REM decrement count 4410 ASM X,STAA \&H134 : REM store bit count 4420 ASM X,BNE R : REM branch if not done

' -- ALL DONE WITH LS 8 BITS READ/WRITE:

' -- NOW MUST HANDLE MS 4 BITS

4430 ASM X,LDAA \&H135

4440 ASM X,BNE V : REM branch when 4 bit flag set

4450 ASM X,LDAA \#4

4460 ASM X,STAA \&H135 : REM set 4 bit flag to true

4470 ASM X,STAA \&H134 : REM load bit counter with 4

4480 ASM X,DEX : REM make index point to Byte 3

4490 ASM X,CLRA : REM store zero result before stored

4500 ASM X,STAA 0,X

4510 ASM X,BRA R : REM do it again

$4520 \mathrm{~V}=\mathrm{X}: \mathrm{ASM} X, \mathrm{LDAA} 0, \mathrm{X}: \mathrm{REM}$ reload current read value

4530 ASM X,LSRA : REM shift bits into position

4540 ASM X,LSRA : REM shift bits into position

4550 ASM X,LSRA : REM shift bits into position

4560 ASM X,LSRA : REM shift bits into position

4570 ASM X,STAA 0,X : REM store result

-- DONE WITH MS 4 BITS OF 12-BIT CONVERSION

-- STORE ZEROS IN FIRST TWO BYTES AND UPDATE X REGISTER 


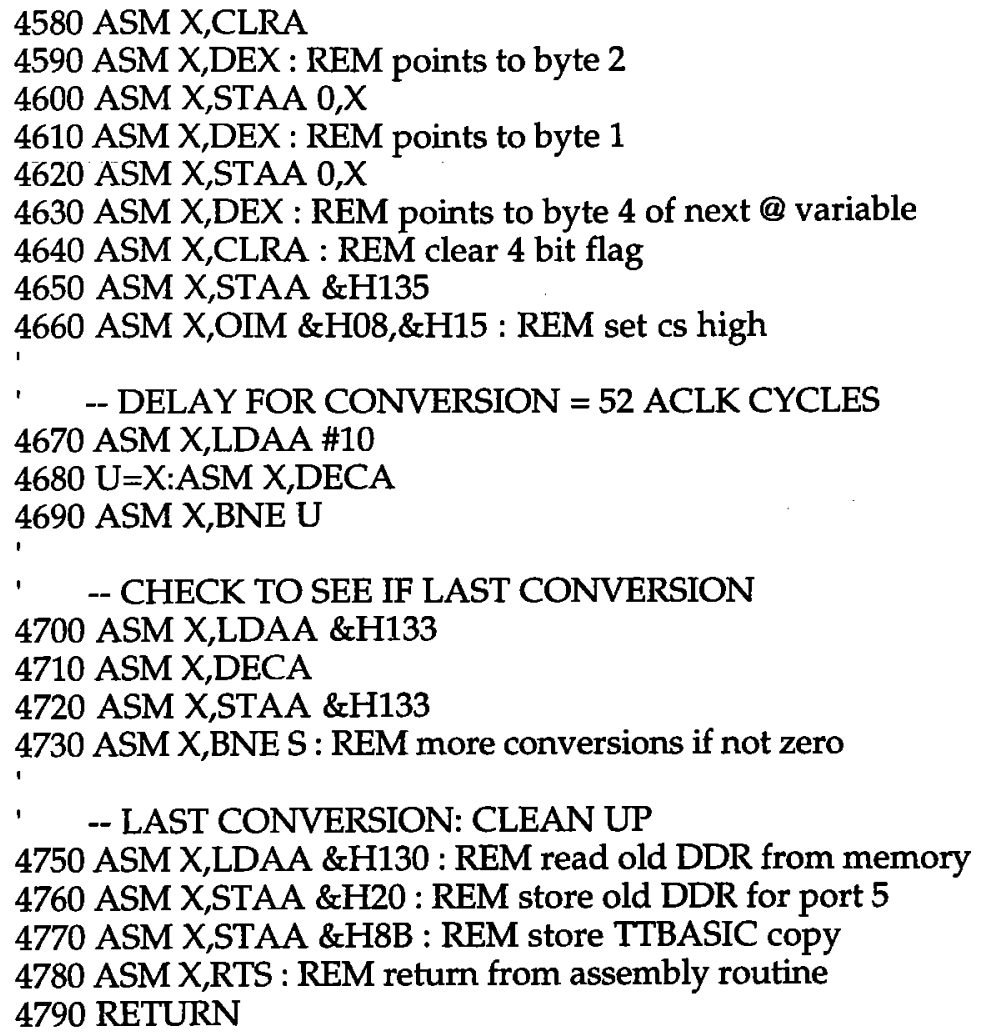


Appendix C: Ice sensor wiring and software

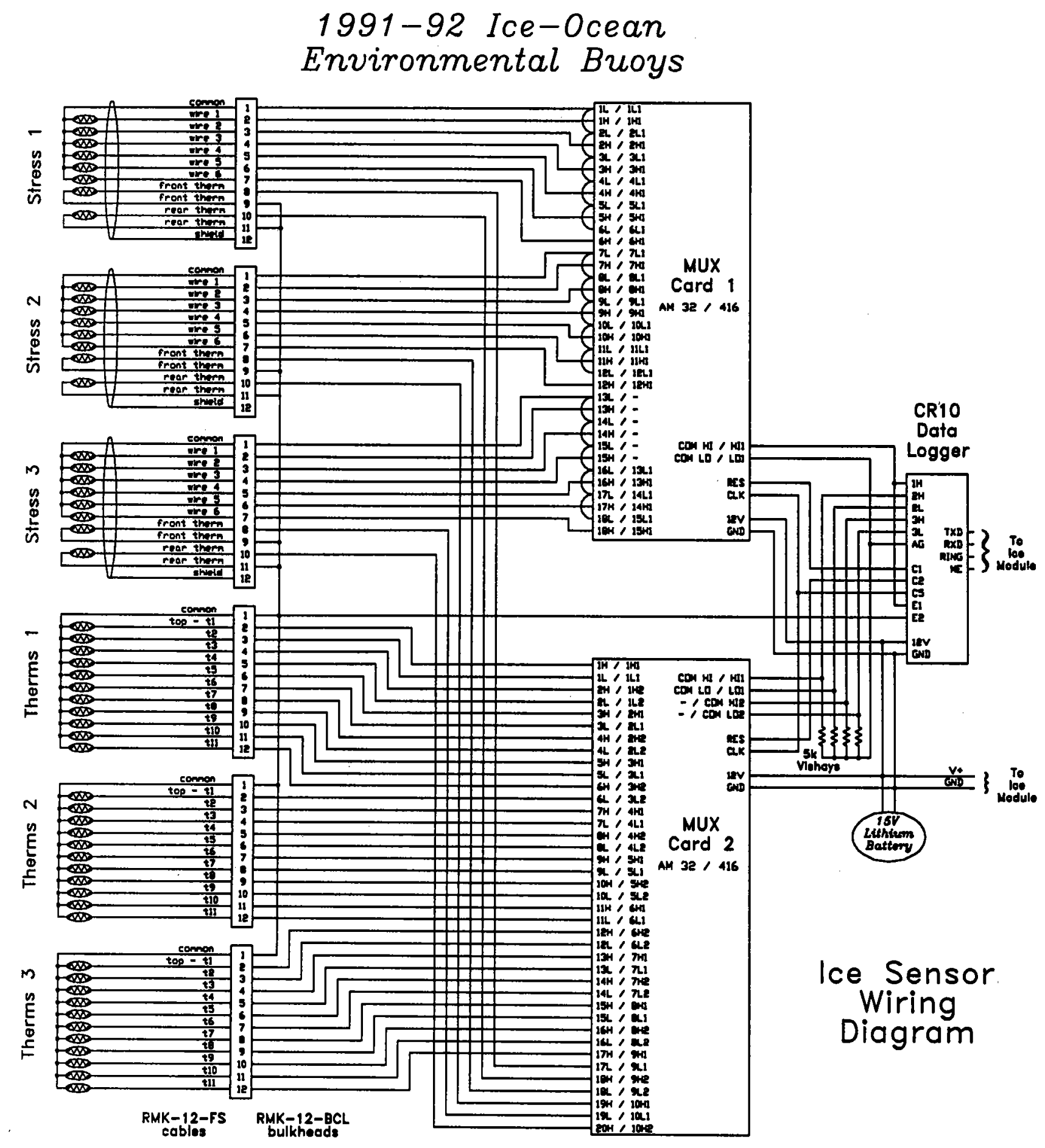

Figure 16: Ice Sensor Wiring Diagram 
Program: JAMSIOEB for Beaufort Gyre IOEB ice sensors

Flag Usage: 5 for thermistor interval

Input Channel Usage: $1 \mathrm{H}, 2 \mathrm{H}, 2 \mathrm{~L}, 3 \mathrm{H}, 3 \mathrm{~L}$

Excitation Channel Usage: E1, E2

Control Port Usage: 1, C2, C5

* 1 Table 1 Programs (sets timing for stress sens in sec)

01: 3600 Sec. Execution Interval <=stress interval goes here

Set flag for thermistors

01: P10 Battery Voltage

01: 130 Loc:

02: $\mathrm{P} 89$ If $\mathrm{X}<=>\mathrm{F}$

01: $130 \times$ Loc

$02: 4<$

03: $10.5 \quad \mathrm{~F}$

04: 0 Go to end of Program Table

03: P92 If time is (sets time interval for thermistors)

01: 0 minutes into a

02: 360 minute interval (<=interval in minutes goes here)

03: 15 Set high Flag 5

04: P20 Set Port(s)

01: $4 \quad$ C8..C5=low $/$ low $/$ low $/ 10 \mathrm{~ms}$ (enable $c 5$ to pulse mplexer)

02: $7777 \quad$ C4..C1=output/output/output/output

05: P86 Do

01: 41 Set high Port 1 (wake up multiplexer 1)

Read stress sensors

06: P87 Beginning of Loop

01:0 Delay

02: 15 Loop Count

07: P86 Do

01: 75 Pulse Port 5

08: P28 Vibrating Wire (SE) (excite wires)

01: 1 Rep

02: 1 IN Chan

03: 1 Excite all reps $w /$ EXchan 1

04: 10 Starting Freq. (units $=100 \mathrm{~Hz}$ )

05: 18 End Freq. (units $=100 \mathrm{~Hz}$ )

06: 500 No. of Cycles

07: 0 Rep delay (units $=.01 \mathrm{sec}$ )

08: 1-- Loc : (store result in indexed location 1-15)

09: 1 Mult

10: 0 Offset

09: P95 End

10: P86 Do

01: 51 Set low Port 1 (turn off multiplexer 1)

Convert to $\mathrm{Wi}$ in memory locations 1 to 15

11: $\mathrm{P} 30 \quad \mathrm{Z}=\mathrm{F}$

01:2 F

02: 0 Exponent of 10

03: 39 Z Loc:

12: $\mathrm{P} 30 \quad \mathrm{Z}=\mathrm{F}$

01: 1 F

02: 6 Exponent of 10

03: 80 Z Loc:

13: P87 Beginning of Loop

01:0 Delay

02: 15 Loop Count (repeat for 15 stress channels) 
14: $P 42 \quad Z=1 / X(W i+650)^{\wedge} 2 / 1000000$

01: 1- X LoC

02:1-- Z Loc:

15: $P 36 \quad Z=X^{*} Y(W i+650)^{\wedge} 2$

01: 1- 'X LoC

02: 80 Y Loc

03: 1-- Z Loc:

16: P39 Z=SQRT $(X)(\mathrm{Wi}+650)$

01: 1- X LoC

02: 1- Z Loc:

17: $\mathrm{P} 34 \quad \mathrm{Z}=\mathrm{X}+\mathrm{F}$ Wi

01: 1- X LOC

02: $-650 \quad F$

03: 1- Z LoC:

18: P95 End

19: P87 Beginning of Loop

01: 00 Delay

02: 15 Loop Count

20: $\mathrm{P} 34 \quad \mathrm{Z}=\mathrm{X}+\mathrm{F}(\mathrm{Wi}+650)$

01: 1- X LoC

02: $650 \quad \mathrm{~F}$

03: 1- Z LoC:

21: $\mathrm{P} 47 \quad \mathrm{Z}=\mathrm{X}^{\wedge} \mathrm{Y}(\mathrm{Wi}+650)^{\wedge} 2$

01:1- XLoc

02: 39 Y Loc

03: 1- Z Loc:

22: $\mathrm{P} 42 \mathrm{Z}=1 / \mathrm{X} 1 /(\mathrm{Wi}+650)^{\wedge} 2$

01: 1- X Loc

02: 1- Z Loc:

23: $P 95$ End

Initialize $\mathrm{Ci}$ (negative)

24: P30 Z=F -Ci $(1972-1)$

01: -.050 F

02: 00 Exponent of 10

03: 21 Z Loc:

25: P30 Z=F-Ci (1972 - 2)

01: $-.032 \mathrm{~F}$

02: 00 Exponent of 10

03: 22 Z Loc:

26: P30 Z=F-Ci (1972 - 3)

01: $-.040 \mathrm{~F}$

02: 00 Exponent of 10

03: 23 Z Loc:

27: P30 Z=F-Ci (1972 - 4)

01: $-.070 \mathrm{~F}$

02:00 Exponent of 10

03: 24 Z Loc:

28: $\mathrm{P} 30 \quad \mathrm{Z}=\mathrm{F}-\mathrm{Ci}(1972-5)$

01:-.054 F

02: 00 Exponent of 10

03: 25 Z Loc:

29: $P 30 \quad Z=F-C i(1972-6)$

01: $-.079 \mathrm{~F}$

02:00 Exponent of 10

03: 26 Z Loc:

30: P30 Z=F -Ci (1971 - 1)

01: -.019 F

02:00 Exponent of 10

03: 27 Z Loc: 


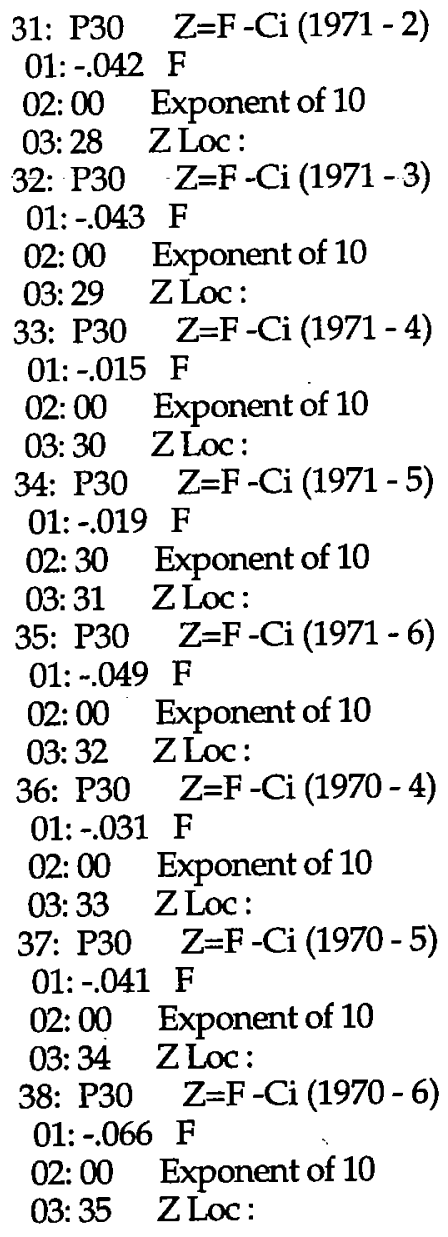

Check for good temperature 39: P87 Beginning of Loop 01:00 Delay 02: 3 Loop Count 40: P90 Step Loop Index 01: 2 Step

41: P89 If $X<=>F$

01: 74- X LOC

02: 3 >=

03: $-100 \quad F$

04: 30 Then Do

42: $\mathrm{P} 89$ If $\mathrm{X}<=>\mathrm{F}$

01:74- X LoC

$02: 4<$

03: $20 \quad \mathrm{~F}$

04: 30 Then Do

43: P31 Z=X

01:74- X Loc

02: 81- Z Loc:

44: P94 Else

45: P89 If $\mathrm{X}<=>\mathrm{F}$

01:75- X LoC

$02: 3>=$

03: 100 F

04: 30 Then Do

46: P89 If $\mathrm{X}<=>\mathrm{F}$

01:75- X Loc 


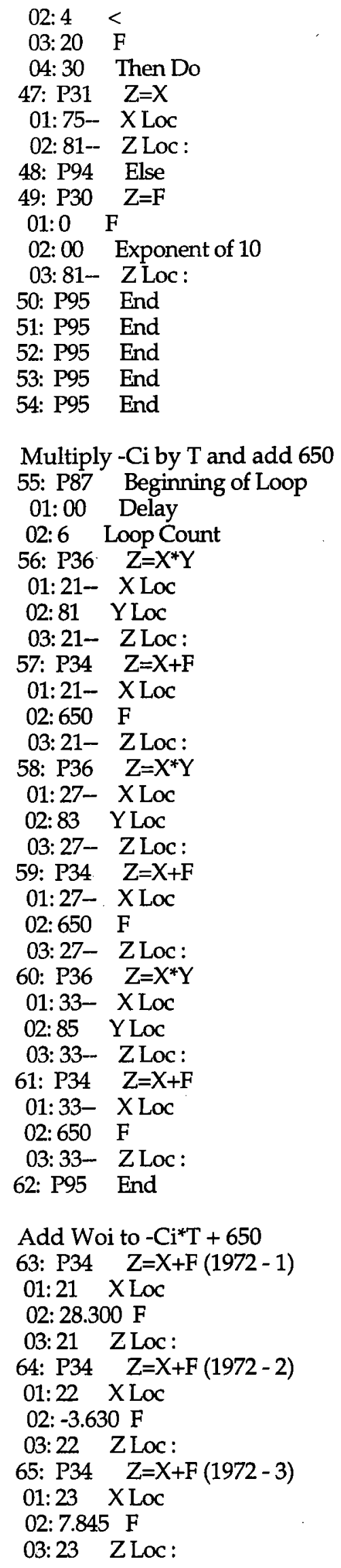




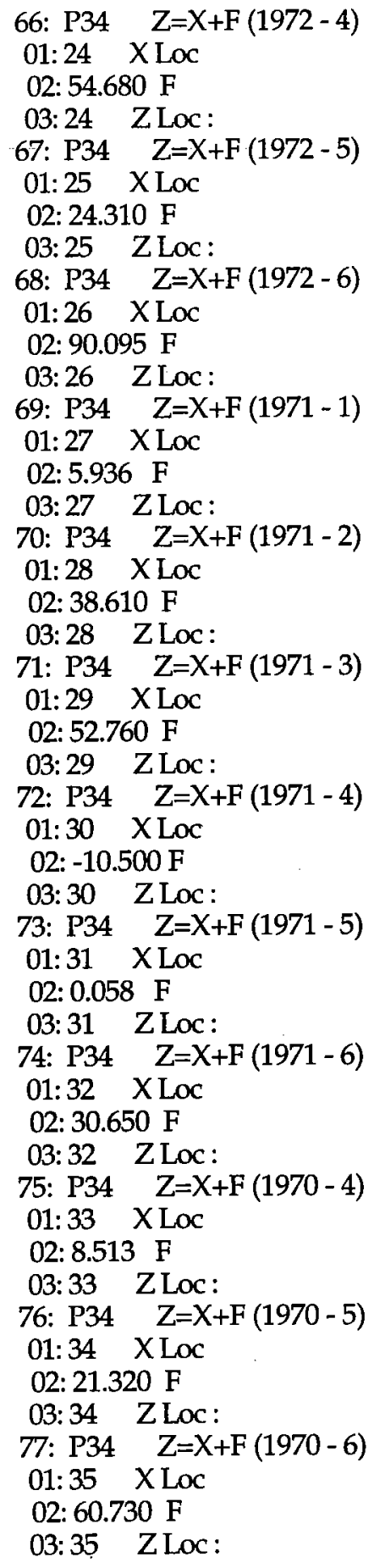

Square result, invert and make negative Add result to previous calculation

78: P87 Beginning of Loop 01:00 Delay

02: 15 Loop Count

79: $\mathrm{P} 47 \mathrm{Z}=\mathrm{X}^{\wedge} \mathrm{Y}\left(\mathrm{Woi}-\mathrm{Ci}^{*} \mathrm{~T}+650\right)^{\wedge} 2$

01:21- X LoC

02: 39 Y Loc

03: 21- Z Loc:

80: P42 $\mathrm{Z}=1 / \mathrm{X} 1 /\left(\mathrm{Woi}-\mathrm{Ci}^{*} \mathrm{~T}+650\right)^{\wedge} 2$

01:21- X LoC 
02: 21- Z Loc:

81: P37 $Z=X^{*} F-1 /\left(\text { Woi }-\mathrm{Ci}^{*} \mathrm{~T}+650\right)^{\wedge} 2$

01: 21- X Loc

02: $-1 \quad F$

03: 21-- Z Loc:

82: $\mathrm{P} 33 \quad \mathrm{Z}=\mathrm{X}+\mathrm{Y} \mathrm{Vi} / \mathrm{Ki}$

01: 1- X LOC

02: 21- Y LoC

03:1- Z Loc:

83: P95 End

Initialize A, B, and $\mathrm{Ki}$ for stress calculations

84: $\mathrm{P} 30 \quad \mathrm{Z}=\mathrm{F}\left(\mathrm{A}^{\prime}\right)$

01: $5.3146 \mathrm{~F}$

02: 6 Exponent of 10

03: 19 Z Loc:

85: $\mathrm{P} 30 \quad \mathrm{Z}=\mathrm{F}\left(\mathrm{B}^{\prime}\right)$

01: $1.2950 \mathrm{~F}$

02: 6 Exponent of 10

03: 20 Z Loc:

86: $\mathrm{P} 30 \quad \mathrm{Z}=\mathrm{F} \mathrm{Ki}(1972-1)$

01: $-3.1394 \mathrm{~F}$

02: 2 Exponent of 10

03: 21 ZLoc:

87: P30 Z $=$ F Ki $(1972-2)$

01: $-3.5285 \mathrm{~F}$

02: 2 Exponent of 10

03: 22 Z Loc:

88: P30 Z=F Ki $(1972-3)$

01:-3.2546 F

02: 2 Exponent of 10

03: 23 ZLoc:

89: P30 Z=F Ki $(1972-4)$

01: $-3.1558 \mathrm{~F}$

02: 2 Exponent of 10

03: 24 Z Loc:

90: P30 Z=F Ki (1972 - 5)

01: $-3.0169 \mathrm{~F}$

02: 2 Exponent of 10

03: 25 Z Loc:

91: P30 Z=F Ki (1972 - 6)

01: $-3.1877 \mathrm{~F}$

02: 2 Exponent of 10

03: 26 . Z Loc:

92: P30 Z=F Ki $(1971$ - 1)

01: $-3.2625 \mathrm{~F}$

02: 2 Exponent of 10

03: 27 Z Loc:

93: $\mathrm{P} 30 \quad \mathrm{Z}=\mathrm{F}$ Ki $(1971$ - 2)

01: $-3.2175 \mathrm{~F}$

02: 2 Exponent of 10

03: 28 Z Loc:

94: P30 Z=F Ki (1971 - 3)

01: $-3.2742 \mathrm{~F}$

02: 2 Exponent of 10

03: 29 Z Loc:

95: P30 Z=F Ki (1971 - 4)

01: $-3.3286 \mathrm{~F}$

02: 2 Exponent of 10

03: 30 Z Loc: 


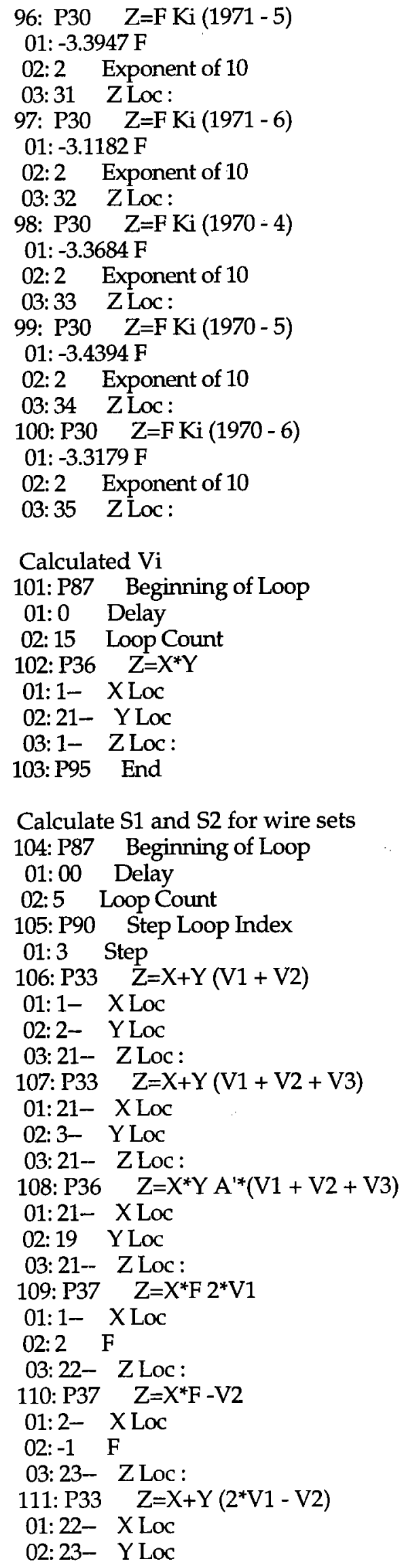




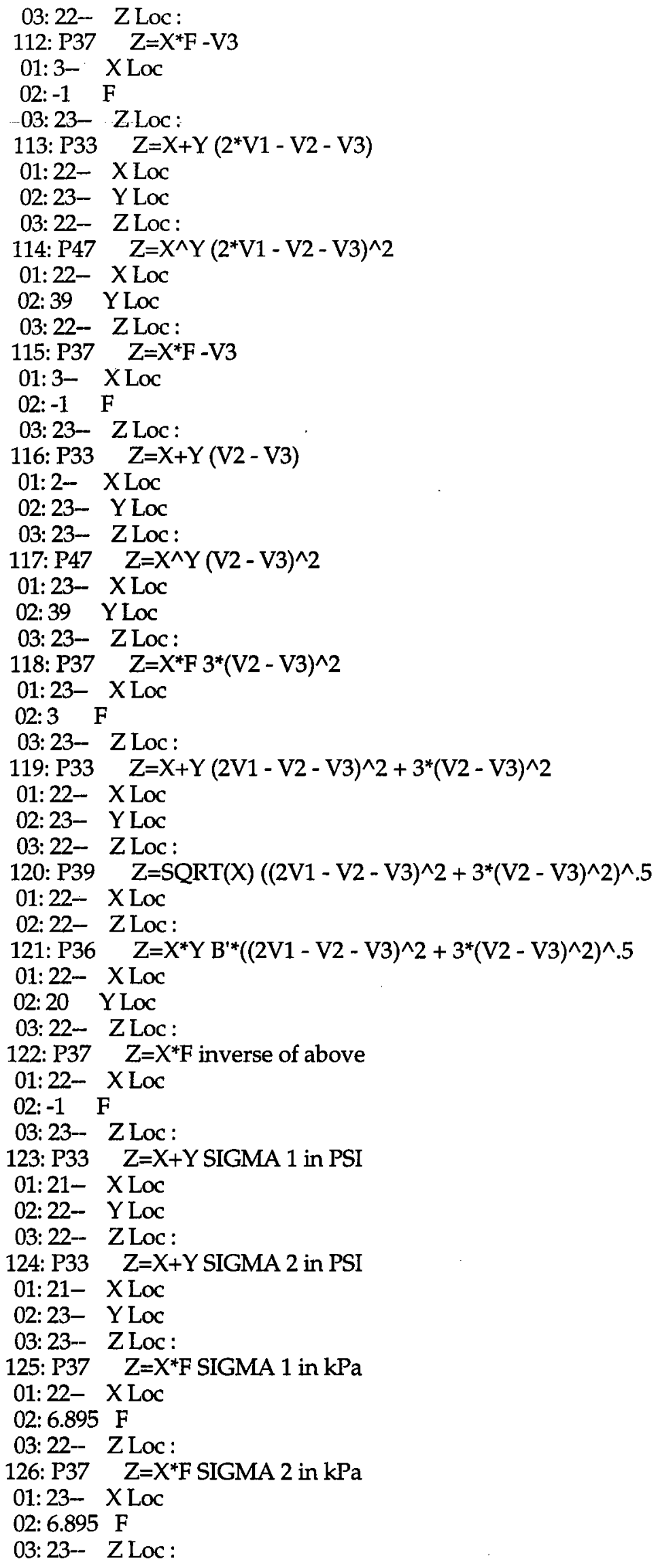


127: P95 End

Decide whether to call thermistor subroutine

128: P91 If Flag/Port

01: 15 Do if flag 5 is high

02: 1 Call Subroutine 1 (performs therms read/write)

129: P86 Do (turn thermistor flag off)

01: 25 Set low Flag 5

130: $P \quad$ End Table 1

* 3 Table 3 Subroutines

Subroutine 1 does thermistor read/write

01: P85 Beginning of Subroutine

01: 1 Subroutine Number

Set constants for thermistor calculations

02: $\mathrm{P} 30 \quad \mathrm{Z}=\mathrm{F}$ (store cubic value)

01: $3 \quad \mathrm{~F}$

02: 0 Exponent of 10

03: 40 Z Loc:

03: $\mathrm{P} 30 \quad \mathrm{Z}=\mathrm{F}$ (store excition voltage 2500 )

01: $2.5 \quad F$

02: 3 Exponent of 10

03: 120 ZLoc:

04: P30 $Z=F$ (store $R F$ value)

01:5 F

02: 3 Exponent of 10

03: 121 ZLoc:

05: P30 Z=F (store aT)

01: $1.4681 \mathrm{~F}$

02: 3- Exponent of 10

03: 122 Z Loc:

06: P30 $Z=F$ (store $b T$ )

01: $2.3828 \mathrm{~F}$

02: 4-- Exponent of 10

03: 123 Z Loc:

07: $\mathrm{P} 30 \quad \mathrm{Z}=\mathrm{F}$ (store $\mathrm{CT}$ )

01: $1.0125 \mathrm{~F}$

02: 7- Exponent of 10

03: 124 Z Loc:

08: $\mathrm{P} 30 \quad \mathrm{Z}=\mathrm{F}$ (store aS)

01: $1.4020 \mathrm{~F}$

02: 3- Exponent of 10

03: 125 Z Loc:

09: P30 Z $\mathrm{Z}=\mathrm{F}$ (store $\mathrm{bS}$ )

01: $2.3753 \mathrm{~F}$

02: 4- Exponent of 10

03: 126 Z Loc:

10: $\mathrm{P} 30 \quad \mathrm{Z}=\mathrm{F}$ (store $\mathrm{CS}$ )

01: $9.8110 \mathrm{~F}$

02: 8-- Exponent of 10

03: 127 Z Loc :

11: P18 Time

01: 2 Hours into current year (maximum 8784)

02:0 Mod/by

03: 128 Loc:

12: P18 Time 
01: 1 Minutes into current day (maximum 1440)

02: 0 Mod/by

03: 129 Loc:

13: P86 Do

01: 42 Set high Port 2 (switch to 2nd multiplexer)

Begin loop to read therms

14: P87 Beginning of Loop

01: 0 Delay

02: 10 Loop Count (total of 39 therms 20 on $\mathrm{H}, 19$ on L)

15: P90 Step Loop Index

01: 4 Step (augments loop index by 4 )

16: P86 Do

01: 75 Pulse Port 5

17: P4 Excite,Delay,Volt(SE) (scan $1 \mathrm{H}$ thermistor)

01: 1 Rep

02: $15 \quad 2500 \mathrm{mV}$ fast Range

03: 3 INChan

04: 2 Excite all reps w/EXchan 2

05: 0000 Delay (units .01sec)

06: 2500-- mV Excitation

07: 41- Loc:

08: $-1 \quad$ Mult

09: 0.0000 Offset

18: P4 Excite,Delay,Volt(SE) (scan $1 \mathrm{~L}$ thermistor)

01:1 Rep

02: $15 \quad 2500 \mathrm{mV}$ fast Range

03: 4 INChan

04: 2 Excite all reps w/EXchan 2

05: 0000 Delay (units .01sec)

06: 2500-- mV Excitation

07: 42-- Loc:

08: -1 Mult

09: 0 Offset

19: P4 Excite,Delay,Volt(SE) (scan 2H thermistor)

01: 1 Rep

02: $15 \quad 2500 \mathrm{mV}$ fast Range

03: 5 INChan

04: 2 Excite all reps w/EXchan 2

05: 0000 Delay (units .01sec)

06: 2500-- mV Excitation

07:43- Loc:

08: $-1 \quad$ Mult

09: 0 Offset

20: P4 Excite,Delay,Volt(SE) (scan 2L thermistor)

01: $1 \quad \operatorname{Rep}$

02: $15 \quad 2500 \mathrm{mV}$ fast Range

03: 6 IN Chan

04: 2 Excite all reps w/EXchan 2

05: 0000 Delay (units .01sec)

06: 2500-- mV Excitation

07: 44- Loc:

08: $-1 \quad$ Mult

09: 0 Offset

21: P95 End

22: P86 Do

01: 52 Set low Port 2 (turn off multiplexer 2)

Convert voltages to resistances

23: $\mathrm{P} 30 \quad \mathrm{Z}=\mathrm{F}$ (store $\mathrm{K}-\mathrm{C}$ constant) 


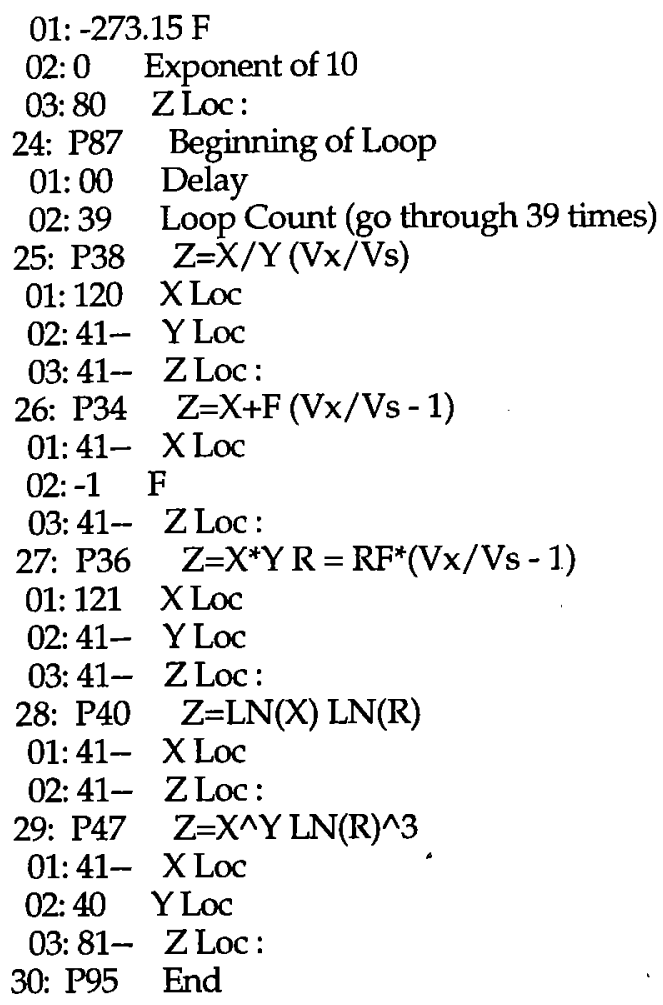

Convert Ice thermistor resistances to temperatures

31: P87 Beginning of Loop

01:00 Delay

02: 33 Loop Count (go through 33 times)

32: $\mathrm{P} 36 \quad \mathrm{Z}=\mathrm{X}^{*} \mathrm{Y}$ bT ${ }^{*} \mathrm{LN}(\mathrm{R})$

01:41- X LoC

02: 123 Y Loc

03: 41- Z Loc:

33: P36 $Z=X^{*} Y c T^{*} L N(R)^{\wedge} 3$

01: 81- X LoC

02: 124 YLoC

03: 81- Z Loc:

34: P33 $\mathrm{Z}=\mathrm{X}+\mathrm{Y} b \mathrm{bT}^{*} \mathrm{LN}(\mathrm{R})+\mathrm{cT}^{*} \mathrm{LN}(\mathrm{R})^{\wedge} 3$

01: 41- X Loc

02: 81- Y LoC

03: 41- Z Loc:

35: P33 $\mathrm{Z}=\mathrm{X}+\mathrm{Y} a \mathrm{a}+\mathrm{bT} \mathrm{T}^{*} \mathrm{LN}(\mathrm{R})+\mathrm{cT}^{*} \mathrm{LN}(\mathrm{R})^{\wedge} 3$

01:41- X LoC

02: 122 Y Loc

03: 41-- Z Loc:

36: $\mathrm{P} 42 \mathrm{Z}=1 / \mathrm{XT}=1 /$ above

01:41- X LoC

02: 41-- Z Loc:

37: P33 $Z=X+Y$ convert from Kelvin to $C$

01:41- X LoC

02: 80 Y Loc

03: 41- Z Loc:

38: P95 End

Convert Stress thermistors resistances to temperature
39: P87 Beginning of Loop
01: 00 Delay
02: 6 Loop Count 


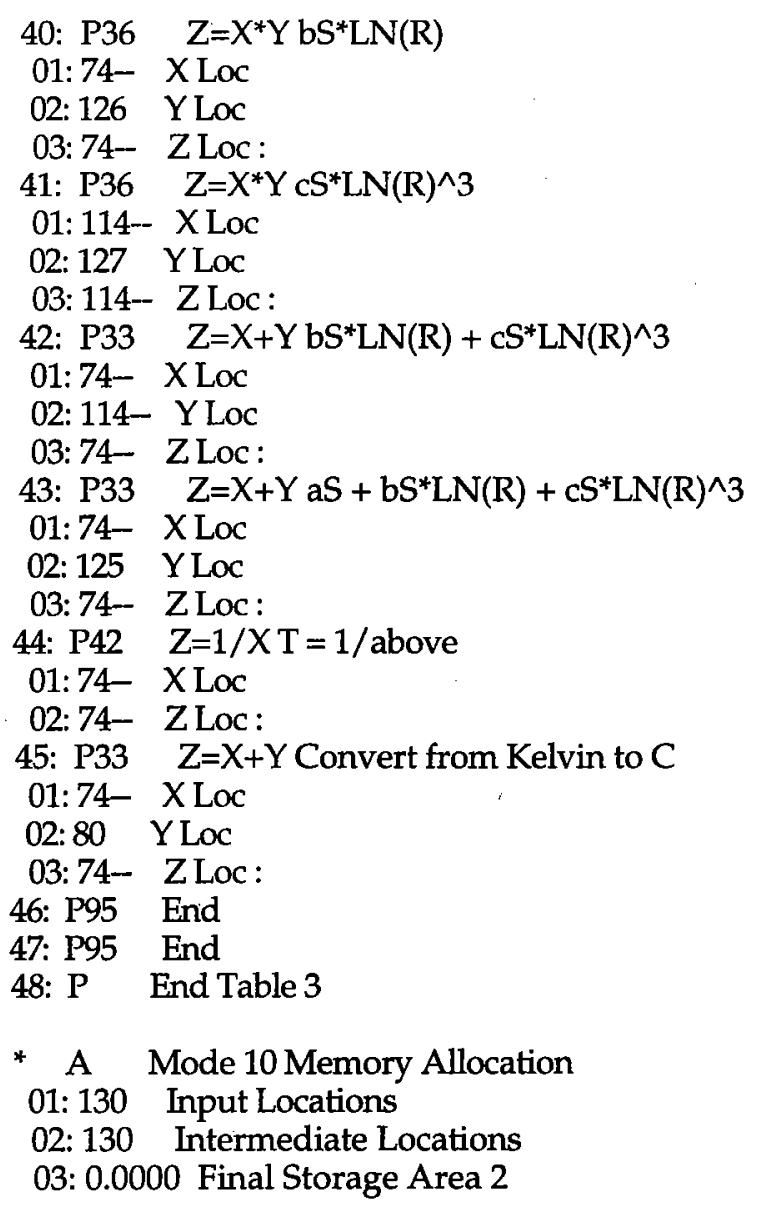


Appendix D: Sediment trap and WTS schedules

(all times in UTC)

Transpolar Drift IOEB Sediment Trap:

Event 01 of $22=04 / 15 / 92 \quad 12: 00: 00$

Event 02 of $22=04 / 25 / 92 \quad 12: 00: 00$

Event 03 of $22=05 / 05 / 92 \quad 12: 00: 00$

Event 04 of $22=05 / 15 / 92 \quad 12: 00: 00$

Event 05 of $22=05 / 25 / 92$ 12:00:00

Event 06 of $22=06 / 04 / 92$ 12:00:00

Event 07 of $22=06 / 14 / 92 \quad 12: 00: 00$

Event 08 of $22=06 / 24 / 92$ 12:00:00

Event 09 of $22=07 / 04 / 92$ 12:00:00

Event 10 of $22=07 / 14 / 92 \quad 12: 00: 00$

Event 11 of $22=07 / 24 / 92 \quad 12: 00: 00$

Event 12 of $22=08 / 03 / 92 \quad 12: 00: 00$

Event 13 of $22=08 / 13 / 92 \quad 12: 00: 00$

Event 14 of $22=08 / 23 / 92$ 12:00:00

Event 15 of $22=09 / 02 / 92 \quad 12: 00: 00$

Event 16 of $22=09 / 12 / 92$ 12:00:00

Event 17 of $22=09 / 22 / 92$ 12:00:00

Event 18 of $22=10 / 02 / 92$ 12:00:00

Event 19 of $22=10 / 12 / 92$ 12:00:00

Event 20 of $22=10 / 22 / 9212: 00: 00$

Event 21 of $22=11 / 01 / 92$ 12:00:00

Event 22 of $22=11 / 11 / 92$ 12:00:00
Transpolar Drift IOEB Water Transfer System:

Event 1 of $18=04 / 15 / 92$ 12:00:00

Event 2 of $18=04 / 25 / 92 \quad 12: 00: 00$

Event 3 of $18=05 / 05 / 92$ 12:00:00

Event 4 of $18=05 / 15 / 92 \quad 12: 00: 00$

Event 5 of $18=05 / 25 / 92 \quad 12: 00: 00$

Event 6 of $18=06 / 04 / 92$ 12:00:00

Event 7 of $18=06 / 14 / 92$ 12:00:00

Event 8 of $18=06 / 24 / 9212: 00: 00$

Event 9 of $18=07 / 04 / 9212: 00: 00$

Event 10 of $18=07 / 14 / 92 \quad 12: 00: 00$

Event 11 of $18=07 / 24 / 9212: 00: 00$

Event 12 of $18=08 / 03 / 92$ 12:00:00

Event 13 of $18=08 / 13 / 92$ 12:00:00

Event 14 of $18=08 / 23 / 9212: 00: 00$

Event 15 of $18=09 / 02 / 92$ 12:00:00

Event 16 of $18=09 / 12 / 92$ 12:00:00

Event 17 of $18=09 / 22 / 92$ 12:00:00

Event 18 of $18=10 / 02 / 9212: 00: 00$

Initial pump flow rate $60 \mathrm{~mL} / \mathrm{minute}$ Total flow $\quad 10000 \mathrm{~mL}$

Minimum pump flow rate $20 \mathrm{~mL} /$ minute

Maximum pumping time 150 minutes 
Beaufort Gyre IOEB Sediment Trap:

Event 01 of $22=04 / 26 / 92 \quad 12: 00: 00$

Event 02 of $22=05 / 16 / 92$ 12:00:00

Event 03 of $22=06 / 05 / 92 \quad 12: 00: 00$

Event 04 of $22=06 / 25 / 92 \quad 12: 00: 00$

Event 05 of $22=07 / 15 / 92 \quad 12: 00: 00$

Event 06 of $22=08 / 04 / 92 \quad 12: 00: 00$

Event 07 of $22=08 / 24 / 92 \quad 12: 00: 00$

Event 08 of $22=09 / 13 / 92 \quad 12: 00: 00$

Event 09 of $22=10 / 03 / 92 \quad 12: 00: 00$

Event 10 of $22=10 / 23 / 92$ 12:00:00

Event 11 of $22=11 / 12 / 92$ 12:00:00

Event 12 of $22=12 / 02 / 92 \quad 12: 00: 00$

Event 13 of $22=12 / 22 / 92 \quad 12: 00: 00$

Event 14 of $22=01 / 11 / 93 \quad 12: 00: 00$

Event 15 of $22=01 / 31 / 93 \quad 12: 00: 00$

Event 16 of $22=02 / 20 / 93 \quad 12: 00: 00$

Event 17 of $22=03 / 12 / 93 \quad 12: 00: 00$

Event 18 of $22=04 / 01 / 93 \quad 12: 00: 00$

Event 19 of $22=04 / 21 / 93$ 12:00:00

Event 20 of $22=05 / 11 / 93 \quad 12: 00: 00$

Event 21 of $22=05 / 31 / 93 \quad 12: 00: 00$

Event 22 of $22=06 / 20 / 93$ 12:00:00
Beaufort Gyre IOEB Water Transfer System:

Event 1 of $17=04 / 26 / 92$ 12:00:00

Event 2 of $17=05 / 16 / 92$ 12:00:00

Event 3 of $17=06 / 05 / 92 \quad 12: 00: 00$

Event 4 of $17=06 / 25 / 92$ 12:00:00

Event 5 of $17=07 / 15 / 92 \quad 12: 00: 00$

Event 6 of $17=08 / 04 / 92$ 12:00:00

Event 7 of $17=08 / 24 / 92$ 12:00:00

Event 8 of $17=09 / 13 / 92$ 12:00:00

Event 9 of $17=10 / 03 / 92$ 12:00:00

Event 10 of $17=10 / 23 / 92$ 12:00:00

Event 11 of $17=11 / 12 / 92$ 12:00:00

Event 12 of $17=12 / 02 / 92$ 12:00:00

Event 13 of $17=12 / 22 / 92$ 12:00:00

Event 14 of $17=01 / 11 / 93 \quad 12: 00: 00$

Event 15 of $17=01 / 31 / 93 \quad 12: 00: 00$

Event 16 of $17=02 / 20 / 93 \quad 12: 00: 00$

Event 17 of $17=03 / 12 / 9312: 00: 00$

Initial pump flow rate $60 \mathrm{~mL} /$ minute

Total flow $\quad 10000 \mathrm{~mL}$

Minimum pump flow rate $20 \mathrm{~mL} /$ minute

Maximum pumping time 150 minutes 
Appendix E: Weddell Sea IOEB architecture

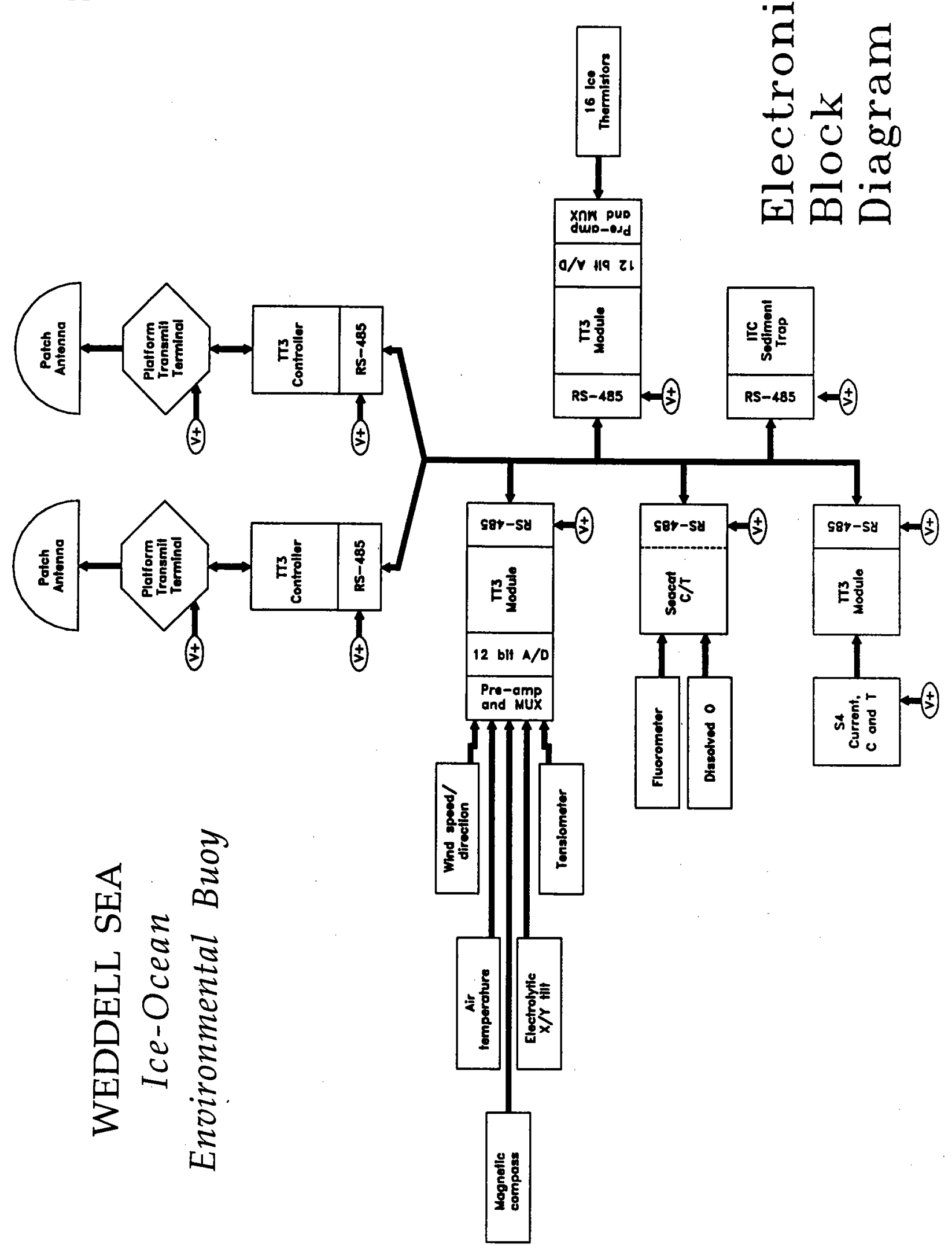

Figure 17: Weddell Sea IOEB - Electronic Block Diagram 


\section{Weddell Sea Ice-Ocean Environmental Buoy}

Transmission Scheme
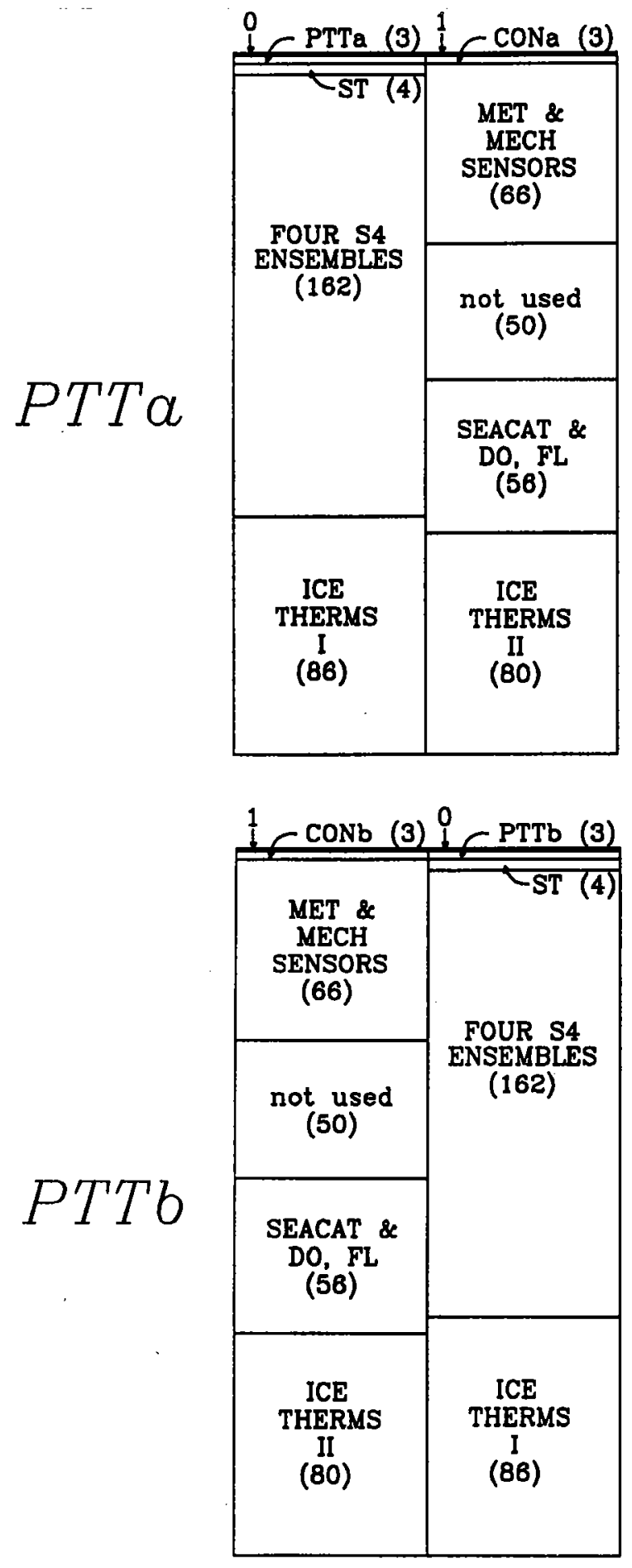

Hour 1 Hour 2
Data Format

Sequence Number

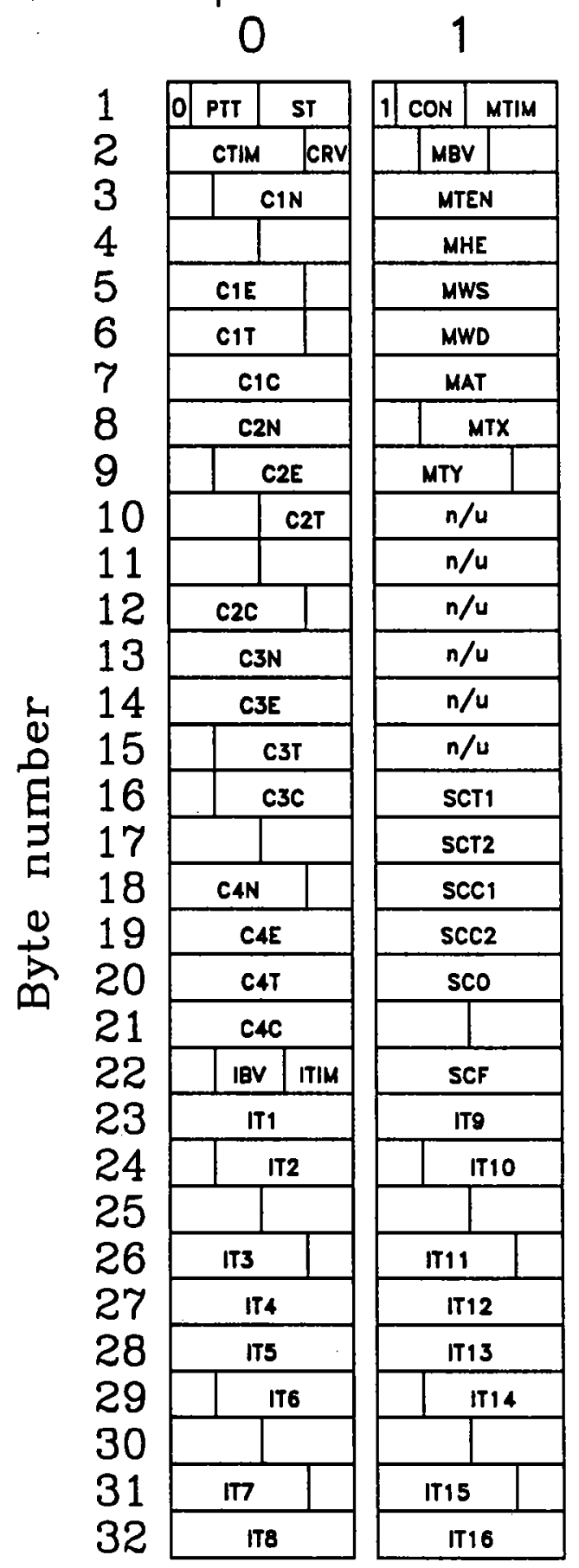

Figure 18: Weddell Sea IOEB - Transmitted Data Format 
Table 9: Weddell Sea IOEB - Sequence Data Formats

Transmission Sequence 0

\begin{tabular}{|c|c|c|}
\hline Bits & Item & Description \\
\hline 1 & $\mathrm{SID}=1$ & Sequence ID number \\
\hline $2-4$ & PTT & PTT battery voltage \\
\hline $5-8$ & $\mathrm{ST}$ & Sediment trap status \\
\hline $9-14$ & CTIM & S4 time code of 4 th ensemble \\
\hline $15-18$ & CRV & S4 reference voltage from last SRB \\
\hline $19-28$ & $\mathrm{C} 1 \mathrm{~N}$ & S4 ensemble 1 - north velocity \\
\hline $29-38$ & $\mathrm{C} 1 \mathrm{E}$ & S4 ensemble 1 - east velocity \\
\hline $39-46$ & $\mathrm{C} 1 \mathrm{~T}$ & S4 ensemble 1 - temperature \\
\hline $47-56$ & $\mathrm{C} 1 \mathrm{C}$ & S4 ensemble 1 - conductivity \\
\hline $57-66$ & $\mathrm{C} 2 \mathrm{~N}$ & S4 ensemble 2 - north velocity \\
\hline $67-76$ & $\mathrm{C} 2 \mathrm{E}$ & S4 ensemble 2 - east velocity \\
\hline $77-84$ & $\mathrm{C} 2 \mathrm{~T}$ & S4 ensemble 2 - temperature \\
\hline $85-94$ & $\mathrm{C} 2 \mathrm{C}$ & S4 ensemble 2 - conductivity \\
\hline $95-104$ & $\mathrm{C} 3 \mathrm{~N}$ & S4 ensemble 3 - north velocity \\
\hline $105-114$ & $\mathrm{C} 3 \mathrm{E}$ & S4 ensemble 3 - east velocity \\
\hline $115-122$ & $\mathrm{C} 3 \mathrm{~T}$ & S4 ensemble 3 - temperature \\
\hline $123-132$ & $\mathrm{C} 3 \mathrm{C}$ & S4 ensemble 3 - conductivity \\
\hline $133-142$ & $\mathrm{C} 4 \mathrm{~N}$ & S4 ensemble 4 - north velocity \\
\hline $143-152$ & $\mathrm{C} 4 \mathrm{E}$ & S4 ensemble 4 - east velocity \\
\hline $153-160$ & $\mathrm{C} 4 \mathrm{~T}$ & S4 ensemble 4 - temperature \\
\hline $161-170$ & $\mathrm{C} 4 \mathrm{C}$ & S4 ensemble 4 - conductivity \\
\hline $171-173$ & IBV & Ice module battery voltage \\
\hline $174-176$ & ITIM & Ice module time code \\
\hline $177-186$ & IT1 & Ice thermistor 1 \\
\hline $187-196$ & IT2 & Ice thermistor 2 \\
\hline 197-206 & IT3 & Ice thermistor 3 \\
\hline $207-216$ & IT4 & Ice thermistor 4 \\
\hline $217-226$ & IT5 & Ice thermistor 5 \\
\hline $227-236$ & IT6 & Ice thermistor 6 \\
\hline $237-246$ & IT7 & Ice thermistor 7 \\
\hline $247-256$ & IT8 & Ice thermistor 8 \\
\hline
\end{tabular}


Weddell Sea IOEB - Sequence Data Formats

Transmission Sequence 1

\begin{tabular}{cll} 
Bits & Item & Description \\
\hline 1 & SID $=1$ & Sequence ID number \\
$2-4$ & CON & Controller battery voltage \\
$5-10$ & MTIM & Met module time code \\
$11-13$ & MBV & Met module battery voltage \\
$14-24$ & MTEN & Mooring tension \\
$25-32$ & MHE & Compass heading \\
$33-40$ & MWS & Wind speed \\
$41-48$ & MWD & Wind direction \\
$49-58$ & MAT & Air temperature \\
$59-64$ & MTX & Tilt X \\
$65-70$ & MTY & Tilt Y \\
$71-120$ & not used & \\
$121-136$ & SCT 1-2 & Seacat temperature: bytes 1-2 \\
$137-152$ & SCC 1-2 & Seacat conductivity: bytes 1-2 \\
$153-164$ & SCO & Seacat dissolved oxygen \\
$165-176$ & SCF & Seacat fluorometry \\
$177-186$ & IT9 & Ice thermistor 9 \\
$187-196$ & IT10 & Ice thermistor 10 \\
$197-206$ & IT11 & Ice thermistor 11 \\
$207-216$ & IT12 & Ice thermistor 12 \\
$217-226$ & IT13 & Ice thermistor 13 \\
$227-236$ & IT14 & Ice thermistor 14 \\
$237-246$ & IT15 & Ice thermistor 15 \\
$247-256$ & IT16 & Ice thermistor 16
\end{tabular}




\section{Table 10: Weddell Sea IOEB - Data Conversions}

$$
\mathrm{N}=\text { decimal equivalent of binary data word }
$$

\begin{tabular}{|c|c|c|}
\hline Item & Conversion & Units \\
\hline $\mathrm{CON}$ & $\mathrm{CON}=\mathrm{N}+9$ & Volts \\
\hline IBV & $\mathrm{IBV}=\mathrm{N} * 0.4+6$ & Volts \\
\hline ITxx & $\begin{array}{l}\text { if } \mathrm{N}<512, \text { ITxx }=\mathrm{N}^{*}-93457 \mathrm{e}-02+42.9{ }^{\circ} \mathrm{C} \\
\text { if } \mathrm{N}>511, \text { ITxx }=\mathrm{N}^{*}-71783 \mathrm{e}-04+8.14{ }^{\circ} \mathrm{C}\end{array}$ & \\
\hline ITIM & $\mathrm{ITIM}=\mathrm{N}$ & hours \\
\hline MAT & $\mathrm{MAT}=\mathrm{N} / 17.05-40$ & ${ }^{\circ} \mathrm{C}$ \\
\hline MBV & $\mathrm{MBV}=\mathrm{N} * 0.4+6$ & Volts \\
\hline MHE & $\mathrm{MHE}=\mathrm{N} / 0.70833333$ & $\operatorname{deg}$ \\
\hline \multirow[t]{4}{*}{ MTEN } & 6 MSBits = Average tension & \\
\hline & $A V G=N * 84.7+775$ & lbs \\
\hline & 5 LSBits = Maximum tension & \\
\hline & $\mathrm{MAX}=\mathrm{N} * 21.2+775$ & lbs \\
\hline MTIM & $\mathrm{MTIM}=\mathrm{N} / 2$ & hours \\
\hline MTX & $\mathrm{MTX}=\mathrm{N} / 0.525-60$ & deg \\
\hline MTY & $\mathrm{MTY}=\mathrm{N} / 0.525-60$ & deg \\
\hline MWD & MWD $=\mathrm{N} / 0.70833333$ & deg \\
\hline MWS & MWS = N / 5.1 & $\mathrm{~m} / \mathrm{s}$ \\
\hline PTT & $\mathrm{PTT}=\mathrm{N}+9$ & Volts \\
\hline $\mathrm{CxN}$ & $\mathrm{S} 4 \mathrm{~N}=\mathrm{N} / 2-256$ & $\mathrm{~cm} / \mathrm{s}$ \\
\hline $\mathrm{CXE}$ & $\mathrm{S} 4 \mathrm{E}=\mathrm{N} / 2-256$ & $\mathrm{~cm} / \mathrm{s}$ \\
\hline $\mathrm{CxT}$ & $\mathrm{S} 4 \mathrm{~T}=\mathrm{N} / 10-5$ & ${ }^{\circ} \mathrm{C}$ \\
\hline $\mathrm{CxC}$ & $\mathrm{S} 4 \mathrm{C}=\mathrm{N} / 20+20$ & $\mathrm{mS} / \mathrm{cm}$ \\
\hline CRV & $C R V=N * 0.02+1.09$ & Volts \\
\hline CTIM & $\mathrm{CTIM}=\mathrm{N} / 2$ & hours \\
\hline SCT 1-2 & $\mathrm{SCT}=\mathrm{N} / 19+2100$ & hz \\
\hline SCC 1-2 & $\mathrm{SCC}=\operatorname{sqrt}(\mathrm{N} * 2100+6250000)$ & $\mathrm{hz}$ \\
\hline $\mathrm{SCO}$ & $\mathrm{SCO}=\mathrm{N}^{*} 5 / 4095$ & Volts \\
\hline SCF & $\mathrm{SCF}=\mathrm{N} * 5 / 4095$ & $\mathrm{~V}$ \\
\hline $\mathrm{ST}$ & $\begin{array}{l}\text { if } \mathrm{N}=0 \text { then NO EVENTS RUN } \\
\text { if } \mathrm{N}=1 \text { to } 7 \text { then BAD EVENT \#=N } \\
\text { if } \mathrm{N}=8 \text { then SHUT DOWN } \\
\text { if } \mathrm{N}=9 \text { to } 15 \text { then GOOD EVENT } \#=(\mathrm{N}-8)\end{array}$ & \\
\hline
\end{tabular}




\section{DOCUMENT LIBRARY}

Distribution List for Technical Report Exchange - July I, 1993

University of California, San Diego

SIO Library 0175C (TRC)

9500 Gilman Drive

La Jolla, CA 92093-0175

Hancock Library of Biology \& Oceanography

Alan Hancock Laboratory

University of Southern California

University Park

Los Angeles, CA 90089-0371

Gifts \& Exchanges

Library

Bedford Institute of Oceanography

P.O. Box 1006

Dartmouth, NS, B2Y 4A2, CANADA

Office of the International Ice Patrol

c/o Coast Guard R \& D Center

Avery Point

Groton, CT 06340

NOAA/EDIS Miami Library Center

4301 Rickenbacker Causeway

Miami, FL 33149

Library

Skidaway Institute of Oceanography

P.O. Box 13687

Savannah, GA 31416

Institute of Geophysics

University of Hawaii

Library Room 252

2525 Correa Road

Honolulu, HI 96822

Marine Resources Information Center

Building E38-320

MIT

Cambridge, MA 02139

Library

Lamont-Doherty Geological Observatory

Columbia University

Palisades, NY 10964

Library

Serials Department

Oregon State University

Corvallis, OR 97331

Pell Marine Science Library

University of Rhode Island

Narragansett Bay Campus

Narragansett, RI 02882
Working Collection

Texas A\&M University

Dept. of Oceanography

College Station, TX 77843

Fisheries-Oceanography Library

151 Oceanography Teaching Bldg.

University of Washington

Seattle, WA 98195

Library

R.S.M.A.S.

University of Miami

4600 Rickenbacker Causeway

Miami, FL 33149

Maury Oceanographic Library

Naval Oceanographic Office

Stennis Space Center

NSTL, MS 39522-50()1

Library

Institute of Ocean Sciences

P.O. Box 6000

Sidney, B.C. V8L 4B2

CANADA

Library

Institute of Oceanographic Sciences

Deacon Laboratory

Wormley, Godalming

Surrey GU8 5UB

UNITED KINGDOM

The Librarian

CSIRO Marine Laboratories

G.P.O. Box 1538

Hobart, Tasmania

AUSTRALIA 7001

Library

Proudman Oceanographic Laboratory

Bidston Observatory

Birkenhead

Merseyside L43 7 RA

UNITED KINGDOM

IFREMER

Centre de Brest

Service Documentation - Publications

BP 70) 29280 PLOUZANE

FRANCE 



\begin{tabular}{|c|c|c|}
\hline $\begin{array}{l}\text { REPORT DOCUMENTATION } \\
\text { PAGE }\end{array}$ & $\begin{array}{l}\text { 1. REPORT NO. } \\
\text { WHOI-93-45 }\end{array}$ & 3. Recipient's Accession No. \\
\hline \multirow{2}{*}{\multicolumn{2}{|c|}{$\begin{array}{l}\text { 4. Title and Subtitle } \\
\text { Ice-Ocean Environmental Buoys (IOEB); Technology and Deployment in } \\
\text { 1991-1992 }\end{array}$}} & $\begin{array}{l}\text { 5. Report Date } \\
\text { October } 1993 \\
\end{array}$ \\
\hline & & 6. \\
\hline \multicolumn{2}{|c|}{ 7. Author(s) Richard Krishfield, Kenneth Doherty, Susumu Honjo } & $\begin{array}{l}\text { 8. Performing Organization Rept. No. } \\
\text { WHOI-93-45 }\end{array}$ \\
\hline \multirow{2}{*}{\multicolumn{2}{|c|}{$\begin{array}{l}\text { 9. Performing Organization Name and Address } \\
\text { Woods Hole Oceanographic Institution } \\
\text { Woods Hole, Massachusetts } 02543\end{array}$}} & 10. Project/Task/Work Unit No. \\
\hline & & $\begin{array}{l}\text { 11. Contract(C) or Grant(G) No. } \\
\text { (C) No0014-89-J-1288 } \\
\text { (G) }\end{array}$ \\
\hline \multicolumn{2}{|c|}{ 12. Sponsoring Organization Name and Address } & $\begin{array}{l}\text { 13. Type of Report \& Period Covered } \\
\text { Technical Report }\end{array}$ \\
\hline \multicolumn{2}{|l|}{ Gilce un lyaval Researla } & 14. \\
\hline
\end{tabular}

\section{Supplementary Notes}

This report should be cited as: Woods Hole Oceanog. Inst. Tech. Rept., WHOI-93-45.

\section{Abstract (Limit: 200 words)}

Based upon the 1987-88 Arctic Environmental Drifting Buoy (AEDB), the Ice-Ocean Environmental Buoy (IOEB) was developed to acquire and telemeter in near real-time inter-relatable time-series data on atmospheric, oceanographic and ice physics in ice-covered oceans during all seasons. Two IOEBs were successfully deployed in two Arctic Sea Basin Stations in April, 1992. Since then, although some sensors malfunctioned, for 18 continuous months, they have been sending massive amounts of information. In this report we describe the technology which was developed for the 1991 IOEB. Mechanically, the IOEB consists of an extremely durable surface flotation package and an underwater mooring line of instruments and sensors. The apex contains data loggers for air, ice and engineering measurements, microcontroller modules for accumulating the data from all the instruments, and ARGOS platform transmit terminals (PTTs) for broadcasting the data. Extending above the surface float, a mast supports a wind monitor and air temperature probe, which along with a barometer provides meteorological data. Thermistor strings, vibrating wire stress sensors, and a thickness gauge are installed in the ice surrounding the buoy, and are interrogated by the modules inside the apex. In the ocean, $110 \mathrm{~m}$ of conducting strength cable passes the data from conductivity/temperature recorders, an Acoustic Doppler Current Profiler and data compression module, a dissolved oxygen sensor, a transmissometer and fluorometers to the PTT microcontrollers. Furthermore, a suspended particle collector and sediment trap transmit status information along the two-wire multidrop network cable. Because the IOEB differs from the AEDB by telemetering the majority of the scientific data, a complicated compression scheme is incorporated to broadcast the data from the 103 variables within the allowable 256-bit ARGOS data stream. Via Service ARGOS, this data currently becomes available to scientists in several countries within eight hours of transmission.

In April 1992, two IOEBs were deployed at separate ice camps in the Arctic Ocean with battery power adequate to sustain the systems for over two years. One was deployed 115 miles from the North Pole in the center of the Transpolar Drift sea-ice current, and the other off of the coast of Alaska along the edge of the Beaufort Gyre. Airplanes capable of landing on ice were used for the transportation of the systems to their final destination. Simultaneously, a third, reduced version of the IOEB was deployed in the Weddell Sea by the Scott Polar Research Institute.

\section{Document Analysis a. Descriptors}

Arctic

telemetry

underwater mooring

b. Identifiers/Open-Ended Terms

c. COSATI Field/Group

18. Availability Statement

Approved for public release; distribution unlimited.

\begin{tabular}{|l|l|}
\hline $\begin{array}{c}\text { 19. Security Class (This Report) } \\
\text { UNCLASSIFIED }\end{array}$ & $\begin{array}{c}\text { 21. No. of Pages } \\
138\end{array}$ \\
\hline 20. Security Class (This Page) & 22. Price \\
\hline
\end{tabular}


